\title{
1992-1993 \\ Bonneville Appliance Efficiency \\ Program: Showerhead Evaluation Volume II - Appendices
}

W. M. Warwick

January 1995

Prepared for the Bonneville Power Administration under a Related Services Agreement with the U.S. Department of Energy Contract DE-AC06-76RLO 1830

Pacific Northwest Laboratory Richland, Washington 99352 


\section{DISCLAIMER}

This report was prepared as an account of work sponsored by an agency of the United States Government. Neither the United States Government nor any agency thereof, nor Battelle Memorial Institute, nor any of their employees, makes any warranty, oxprossed or implied, or assumes any legal labitity or responsibitity for the accuracy, completeness, or usofulness of any information, apparatus, product, or process disclosed, or represents that its use would not infringe privately owned rights. Reference herein to any specific commercial product, process, or service by trade name, trademark, manufacturer, or otherwise does not necessarily constitute or imply its endorsement, recommendation, or favoring by the United Stetes Government or any agency thereof, or Bettelle Memorial Institute. The views and opinions of authors expressed herein do not necessarily state or reflect those of the United States Government or any agency thereof.

\section{PACIFIC NORTHWEST LABORATORY operated by BATTELLE MEMORIAL INSTITUTE for the UNITED STATES DEPARTMENT OF ENERGY under Contract DE-AC06-76RLO 1830}

Printed in the United States of America

Available to DOE and DOE contractore from the

Office of Sciontific and Technical Informntion, P.O. Box 62, Oak Ridge, TN 37831; prices available from (615) 576-8401. FTs 626-8401.

Available to the public from the Netional Technical Information Service, U.S. Department of Commerce, 5285 Port Royal Rd., Springfield, VA 22161.

\section{DISCLAIMER}

This report was prepared as an account of work sponsored by an agency of the United States Government. Neither the United States Government nor any agency thereof, nor any of their employees, makes any warranty, express or implied, or assumes any legal liability or responsibility for the accuracy, completeness, or usefulness of any information, apparatus, product, or process disclosed, or represents that its use would not infringe privately owned rights. Reference herein to any specific commercial product, process, or service by trade name, trademark, manufacturer, or otherwise does not necessarily constitute or imply its endorsement, recommendation, or favoring by the United States Government or any agency thereof. The views and opinions of authors expressed herein do not necessarily state or reflect those of the United States Government or any agency thereof. 


\section{2-1993}

Bonneville Appliance Efficiency

Program: Showerhead Evaluation

Volume II - Appendices

W. M. Warwick

January 1995

Prepared for

the Bonneville Power Administration under a Related Services Agreement with the U.S. Department of Energy Contract DE-AC06-76RLO 1830

Pacific Northwest Laboratory

Richland, Washington 99352 
: 


\section{DISCLAIMER}

Portions of this document may be illegible in electronic image products. Images are produced from the best available original document. 


\section{Contents}

Appendix A Bonneville Documents $\ldots \ldots \ldots \ldots \ldots \ldots \ldots \ldots \ldots \ldots$ A.2

Appendix B Overview of Research Projects $\ldots \ldots \ldots \ldots \ldots \ldots \ldots \ldots \ldots$ B.2

Appendix C Puget Power and Light Persistence Study . . . . . . . . . . C.2

Appendix D Hot-Water Flow Analyses and Assumptions Documentation $\ldots \ldots \ldots$ D.2

Appendix E Regional End-Use Metering Program $\ldots \ldots \ldots \ldots \ldots \ldots \ldots \ldots$ E.2

Appendix F Showerhead and Faucet Aerator Performance Assessment ......... F.2

Appendix G Bonneville Showerhead Program Distribution Methods

by Participating Utility $\ldots \ldots \ldots \ldots \ldots \ldots \ldots \ldots \ldots \ldots$ G.2

Appendix H Water- and Energy-Saving Measure Distribution

Methods Literature Review . . . . . . . . . . . . . . H.2

Appendix I REMP Study Load Shape Results $\ldots \ldots \ldots \ldots \ldots \ldots \ldots \ldots$ I.2 


\section{Appendix A}

\section{Bonneville Documents}




\section{Department of Energy}

Bonneville Power Administration

P.O. Box 3621

Portland, Oregon 97208-3621

Juty 20 1981

In reply refer to: RPEB

Mr. Michael Harwick

Battelle, Pacific Northwest Laboratories

500 NE. Multnomah, Suite 650

Portland, OR 97232

Dear Mike:

Energy efficient showerheads result in water heating savings. However, the amount of savings obtained with the latest technologies is uncertain.

The Bonneville Power Administration (BPA) is in the process of developing an Efficient Showerhead Program. This program will promote the installation of energy efficient showerheads throughout the region. IOU's and public utilities throughout the region are also sponsoring programs.

Under normal circumstances, to determine the amount of savings a program like this would generate, BPA would perform an impact evaluation using pre/post billing history analysis on weather normalized billing histories and utilizing a comparison group.

However, in this program, efficient showerheads will be the only measure installed. Measuring the buildings' pre-program and post-program energy use would, in all probability, not reflect a change in energy use that could be easily attributed to the program, especially in electrically heated homes.

Our proposal is to install, free, efficient showerheads in 120 End-Use Load and Consumer Assessment Project (ELCAP) homes. He will also offer to pay the owner/tenant a $\$ 40.00$ bounty for their old showerheads.

We propose to market directly to all residences with adequate historical water heating data that have not expressed concerns about being contacted. We expect about half of the contacted households to accept the offer.

There are several advantages to using ELCAP buildings. The buildings already have their water heater use sub-metered and they are participating in a research program. It will save us at least 1 year. Any "contamination" to the ELCAP buildings will be easily measurable, as we know specifically what was done. The installers could also provide a handle on what the current equipment is. 
Please find enclosed a proposal for conducting the showerhead research. He would like you to submit an estimate for performing this task.

\section{Sincerely,}

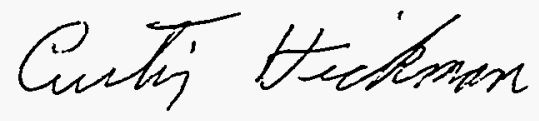

Curtis Hickman

Public Utilities Specialist

Enclosure 
DATE : KAY $2 \& 2991$

ғном : Ken Keating KK Chief, Program Evaluation Section - RPEB

sUвJect: Values for Deemed Savings in the Residential Sector
L. Marsh - LCB
D. Anderson - PMCE
R. Freeman - RMB
M. Newsham - RMRC
L. Lee - RMRD
R. Reinhart - RMRD
J. Holmstrom - RPE
P. Brandis - RPEB
B. Cody - RPEB .
S. Riewer - RPEB
J. Cade - RPED
H. Herman - RPED
R. A. James - RPED
Y. Coleman - RPED
M. Ebberts - RPPB
J. Clune - RPPC
P. Norman - RPP
B. Hickey - TBB
In response to some inconsistencies between values published for Competitive Acquisition and those being.prepared for contract offerings under Billing Credits, Ruth Bennett and I (acting for John Holmstrom) agreed to ask the RPE and RMR staff to work together to come. up with consistent annual savings and measure lives for several technologies that are likely to be "deemed," i.e. accepted for payment purposes as the amount of savings being achieved simply on the basis of the physical presence of the measure.
The attached annual savings estimates should be used consistently in both Billing Credits and Competitive Acquisition programs. The documentation of the assumptions used and the sources considered is attached for your reference if you receive, or have, questions about the numbers. This will entail reworking some alternative costs for Billing Credits. Please be sure that everyone you know,. who has a need to know these numbers, has received a copy of these attachments.

Attachments (2)

KKeating:csd:5857:5/.28/91 (VS5-RPE-3329b/1)

cc:
R. Bennett - RMR
D. Byers - RMRC
F. Pratt - RMRC
C. Hickman - RPEB
A. Vinnard - RPED
M. Taylor - RPEE
official File - RPE (RP-25)
R. Gillman - RPEE 


\section{ATTAChMENT- I.}

\section{VERIFICATION OF SAVINGS}

VIII.1. Q. Please provide the deemed savings in $\mathrm{kth}$ per measure of residential water heating and lighting savings and the expected life of the measure (we recognize that life expectancy is not deemed).

Please provide the deemed savings in annual $\mathrm{kHh}$ and the expected life for the following:

a. Hater heater wrap

b. Showerhead(s)

c. Pipe wrap (per foot or otherwise)

d. Faucet aerators (also maximum number expected per house)

e. Compact fluorescent bulb (for this, please provide average annual expected hours use per bulb, the wattage differential and the expected bulb life)

What other measures in residential programs are eligible for "deeming?"

A. The deemed savings in annual $\mathrm{kWh}$ and the expected iffe for following are:

\begin{tabular}{|c|c|c|}
\hline & Annual kWh & Life (years) \\
\hline $\begin{array}{l}\text { Water heater wrap } \\
\text { (existing) }\end{array}$ & 200 & 6 \\
\hline $\begin{array}{l}\text { Showerheads ( } 2.5 \mathrm{gpm} \\
\text { or less at } 65 \mathrm{psi})\end{array}$ & $\begin{array}{l}400 \text { per house if } \\
\text { all SH are replaced }\end{array}$ & 12 \\
\hline Pipe wrap & $\begin{array}{l}70 \mathrm{kWh} \text { (if ist } \\
5 \mathrm{ft} \text { of the hot \& } \\
\text { cold pipes from the } \\
\text { water heater are } \\
\text { wrapped) }\end{array}$ & 10 \\
\hline Faucet aerators & None & -- \\
\hline Compact Fluorescent & $\begin{array}{l}40 \mathrm{kWh} / \mathrm{yr} / \mathrm{bulb} \\
\text { assuming } 1000 \mathrm{hrs} / \mathrm{yr} \\
\text { operation and with an } \\
18 \text { watt compact } \\
\text { replacing an average } \\
\text { wattage of } 70\end{array}$ & 7 \\
\hline $\begin{array}{l}\text { Energy Efficient } \\
\text { Water Heater }\end{array}$ & $\begin{array}{l}250 \mathrm{kWh} \text { (Energy } \\
\text { factor of .95) }\end{array}$ & 12 \\
\hline
\end{tabular}




\section{WATER HEATER WRAP (EXISTTING)}

Savings can be deemed only for pre-1993 (existing) water heaters, because Cal Ek tested three water heaters with .94 efficiency factor (EF), .95 EF and .97 EF both before and after being wrapped with $R-11$ insulation. The savings were negligible, so are not included in either the supply curve or the competitive bidding contract (Cal Ek's laboratory report dated May 1, 1991).

The water heater wrap savings for existing water heaters are $\mathbf{2 0 0} \mathrm{kWh}$ per year. This estimate assumes a $\mathbf{5 2}$ gallon electric water heater (the common size in the Northwest, WSEO studies), $17 \%$ space heating interaction for $48 \%$ of the water heaters which are contained in a heated area of the house (1990 Draft Conservation Supply Curve Document and PNWRES83, respectively). In addition, the Central Hudson's Easy \$avers program evaluation had water heater wraps' savings ranging from $193 \mathrm{kWh} / \mathrm{yr}$ to 231. Using $230 \mathrm{kWh} / \mathrm{yr}$ savings to determine the savings per house given the Northwest market, the data resulted in $0.52(230 \mathrm{kWh} / \mathrm{yr})+0.48(230 * 0.83$ space heating interaction excluded) $=211 \mathrm{kWh} / \mathrm{yr}$. These savings were rounded down to $200 \mathrm{kWh} / \mathrm{yr}$ to be conservative.

Note: this deemed savings estimate is also the number the the Council uses, which Margie Gardner based on a Seattle City Light study.

The expected life for the R-11 wrap is 6 years. This estimate is based on wraps being placed on existing water. heaters which already have some of their expected life elapsed. Since it is unknown. how old the water heater to be wrapped is and the expected life of water heaters is 12 years, 6 years--half the water heater life--seemed reasonable, based on the Central Hudson evaluation's findings that about half of the water heaters in the program were older than five years. 


\section{SHOWERHEADS}

To deem savings, the showerheads are required to be 2.5 gallons per minute $(\mathrm{gpm})$ or less at 65 pounds per square inch (psi). In addition, all showerheads, in the home are required to be replaced, in order to receive the $400 \mathrm{kWh} / \mathrm{yr}$ deemed savings. This last requirement avoids showerheads being placed in the bathroom rarely used, which can result in no savings being acquired.

The $400 \mathrm{kWh} / \mathrm{yr}$ savings is based on the following:

The length of a shower used is $\mathbf{6 . 5}$ minutes. This number is based on two evaluations, (1) the Evaluation of the Easy \$avers Program, March 1990, by Techplan Associates, Inc. for the Central Hudson Gas and Electric Corporation, Poughkeepsie, New York. and (2) Residential Hot Water: A Behaviorally-Driven System, July 15, 1984, by Willett Kempton of Michigan State University.

$1.0 \mathrm{gpm}$ savings for replacing existing households' showerheads. The newer the showerhead, the lower the flow rate--8.0 gpm maximum in the 1983 HUD study down to less than $3.0 \mathrm{gpm}$ in ODOE's August 1989 draft. In addition, the July 1990 issue of Consumer Reports found people to use a lower flow rate than the maximum flow rate of the showerhead. Based on the data from these sources, $1.0 \mathrm{gpm}$ savings was used for replacing existing households' showerheads.

The HUD study found the households in the sample with showerheads that had flow rates of greater than $3.0 \mathrm{gpm}$ to use $103^{\circ} \mathrm{F}$ water (PG \& E's FAX to Yvonne Coleman, p. 4). Since no known studies have metered the set point for water heaters, the $\mathbf{5 0} \%$ cold and $\mathbf{5 0} \%$ hot water mix used to take a shower in the analysis is a guesstimate.

0.77 showers per person per day is used in the analysis. This number is based on the Central Hudson survey data. Table III-8 of the Hudson evaluation showed the number and length of showers--baths were not included--by family composition types. 
2.3 persons per household represents family size in the outyears of the load forecast (May 16, 1991, Ottie Nabors).

$80^{\circ} \mathrm{F}$ is the temperature difference used from the water heater temperature to the inlet water temperature.

The calculations below are based on the previous data.

(6.5 mins)(1 gpm savings)(0.5 hot $\mathrm{H} 20$ use)(0.77 showers/person day) $\mathrm{x}$

. (365 days/year)(2.3 person/house)(8.25 Btu/ $\left.{ }^{\circ} \mathrm{F} \mathrm{gal}\right) \mathrm{x}$

$\left(80^{\circ} \mathrm{F}\right)(1 \mathrm{kWh} / 3413 \mathrm{Btu})=406 \mathrm{kWh} /$ year

For calculation ease; the existing showerhead savings were rounded down to $400 \mathrm{kWh} / \mathrm{yr}$ for the program.

\section{PIPE WRAP}

The deemed savings for wrapping the first 5 feet of the hot and cold water pipes from the water heater are 70 kWh. These savings are based on Jon Biemer and Cal Ek's analyses cited on p. 5 of the CON-238, Hood River report. Previous studies have used a 10 year measure life and no other data have shown otherwise, so 10 years is the expected life.

\section{FAUCET AERATORS}

No savings will be deemed for faucet aerators. In the Central Hudson evaluation the savings for faucet aerators ranged from 36 to $46 \mathrm{kWh} / \mathrm{yr}$. Given the range, we selected $40 \mathrm{kWh} / \mathrm{yr}$. However, these: savings needed to be reduced to incorporate inappropriately placed faucet aerators. 
Savings can be acquired only where the amount of water used is significant, such as in a main bathroom or in the kitchen, and where the amount of water needed is inconsequential. For instance, if you are using the faucet to fill a tea kettle, the flow rate of the faucet will only determine how long you wait for the tea kettle to fill. You' still will use the same amount of water; thus, no savings. However, if you are using the water to rinse dishes, then you can save kilowatts by using less water, since you can use less water to complete this . task.

When the $40 . \mathrm{kWh} / \mathrm{yr}$ savings from faucet aerators are reduced by inappropriate placement of aerators and the overall persistence of aerators remaining installed, the savings per house are negligible. Only $50 \%$ of the houses still wash dishes by hand (1990 Draft Conservation Supply Curve Document). Since most houses have 4 faucets--the utility sink, the kitchen and two bathrooms--and two accrue savings in $50 \%$ of the homes and only 1 accrues savings in the other $50 \%$ of the homes, the savings need to be reduced by $62 \%$, i.e., $(1-[(0.50 * 2 / 4)+(0.50 * 1 / 4)]=0.62)$. Just reducing the savings by inappropriately placed aerators, changes the savings from $40 \mathrm{kWh} / \mathrm{yr}$ to 15 . After including the persistency rate of $88.5 \%$ (do-it-yourself installation in the Central Hudson program), we decided the savings would be negligible.

\section{COMPACT FLUORESCENTS}

Burn time will be 1000 hours per year or about 2.75 hours per day. This takes into account the expectation of multiple applications involving higher and lower use (PP \& $L$ report on reported hours of use).

The expected displaced wattage in the average installation is 52 watts. This is based on a mix of existing bulbs, mainly in the 60-75 watt range, being replaced with an 18 watt compact fluorescent. We chose the average wattage to be 70 watts both to be a little liberal (given the Central Maine Power study, 
p. 44 , indicating that 60 watt bulbs were $50 \%$ more frequently replaced than 75 watt bulbs) and to reflect the judgment that lower wattage bulbs are more frequently found in multiple bulb fixtures, which are less capable of accommodating the compact fluorescents.

There is an assumption that $50 \%$ of the bulbs will go into the $50 \%$ of the regional homes with electric space heat, where electric heating energy will have to make up for the reduced internal gains due to the lighting retrofit. This interaction was calculated at $47 \%$ (Cost-Effectiveness of Compact Fluorescent Lighting Retrofits for Residential Consumers in the Pacific Northwest, WSEO) on an annual basis. Therefore; the annual savings are $52 \mathrm{kWh} * 11-$ $[0.47 * .5])=39.8 \mathrm{kWh} / \mathrm{bulb}$. Therefore, we will use 40 $\mathrm{kWh} / \mathrm{bulb}$.

The life of the measure is estimated at 10,000 hours, but this represents the median measure life, not the average which can be expected to be less, and the life of the bulb is greatly reduced by the number of times it is turned on. Switching is likely to be relatively frequent in residential settings, and there may be,some bulbs placed in inappropriate operating temperatures, thus, further reducing the measure life. We believe that 7,000 hours or 7 years of 1,000 hours/year operation is , a reasonable basis for deeming if the bulbs are actually installed and stay installed.

\section{ENERGY EFFICIENT WATER HEATERS}

$250 \mathrm{kWh} /$ year savings is to be deemed for water heaters. This estimate assumes a $\mathbf{5 2}$ gallon electric water heater (the common size in the Northwest, WSEO studies), $17 \%$ space heating interaction for $48 \%$ of the water heaters which are contained in a heated area of the house 1990 Draft Conservation Supply Curve Document and PNWRES83, respectively). 
The deemed savings are less than the savings from the national standard to the program level, i.e., $0.88 \mathrm{EF}$ to $0.95 \mathrm{EF}$, because even without the program, consumers would purchase water heaters above the $0.88 \mathrm{EF}$. So, based on evaluations of other programs (e.g., New England Electric) and WSEO's findings of water heaters available in the 1-5 corridor where water heater programs are present, an average of $0.91 \mathrm{EF}$ is used instead of $0.88 \mathrm{EF}$ as the base.

The deemed savings are calculated below.

Fifty-four percent of electric water heaters are located in electrically space heated homes. About half of these electric water heaters are located in heated and half in unheated spaces, and $46 \%$ are located in fossil fuel heated homes (so there would be no electric space heating interactions). The calculations follow:

$.54((.52 * 290 \mathrm{kWh})+(.48 * 290 * .83))+.46(290)=277$ $\mathrm{kWh} / \mathrm{yr}$

The $\mathrm{kWh} / \mathrm{yr}$ use per single family, multifamily and manufactured housing for both public and private range from 2,800 to $4,300 \mathrm{kWh} / \mathrm{yr}$. To adjust for this range, the housing stock was weighted according to the load. forecast. This weighting is a proxy for displacing water heating measures' interactions amongst themselves if more than one measure is installed in a household. With this $10 \%$ adjustment, the deemed savings for new efficient water heaters are $250 \mathrm{kWh} / \mathrm{yr}$.

12 years expected life was used for the program since this is the measure life used in the load forecast and supply curves. 
Appendix B

\section{Overview of Research Projects}




\section{Appendix B Overview of Research Projects}

This evaluation uses results from several Bonneville Power Administration (Bonneville)-sponsored studies in contrast to previous evaluations, which tended to be self-contained. This research was conducted sequentially, guided by questions that arose during program design and implementation and based on the results of previous research. The evaluation drew on the following Bonneville-supported studies:

- the Puget Persistence Study (Bailey and Warwick 1993)

- the Residential End-Use Metering Project (REMP) field study (Warwick and Bailey 1993)

- REMP energy savings analysis study (Warwick 1993)

- Puget water-metering study (SBW Consulting, Inc. 1994).

The report and appendices refer to these studies by these names, although the REMP energy saving analysis is often included in the context of the reference to the REMP field study.

In addition, this evaluation benefited from similar research and program evaluations conducted by others and from supplementary research undertaken by the Pacific Northwest Laboratory (PNL). The major studies are described in sections B.1 through B.4.

\section{B.1 Puget Persistence Study}

Section B.1.1 describes the Puget persistence study. Participants were selected from a sample drawn from over 26 cities, as discussed in section B.1.2. Data management and quality control are discussed in section B.1.3.

\section{B.1.1 Overview of the Puget Persistence Study}

Puget Power and Bonneville collaborated on a study of the persistence of energy-efficient showerheads distributed to Puget Power customers as part of Puget Power's energy-efficient showerhead program. This persistence study included a field study that was performed by PNL in the spring of 1992. In this study, program persistence is defined as finding at least one installed Puget Power showerhead in a home whereas measure persistence refers to the total number of energyefficient showerheads in a home visited during the site visits.

Bonneville's three main objectives for the PNL field study were 1) to see if the showerheads remained in operation, 2) to compare the number of showerheads that were actually installed with the number reported in an earlier telephone survey conducted by Puget Power, and 3) to measure water 
- persistence rate

- customer satisfaction with showerhead performance

- reliability of the telephone survey responses to questions about program persistence

- customer satisfaction with Puget Power's showerhead program.

\section{B.1.2 Sample Design and Selection}

Puget Power began distributing energy-efficient showerheads to households in its service area in July of 1990. Initially a pilot program that began in the last 6 months of 1990, it became a full-scale program in 1991. In early 1992, Puget Power conducted a telephone survey of 402 randomly selected homes that participated in the pilot program in 1990. The purpose of this survey was to determine how many energy-efficient showerheads had actually been installed and how many were still in use, as well as to answer several other questions about the showerhead program.

From March to June of 1992, PNL conducted a field study to visit a sample of 100 of the homes in Puget Power's showerhead program to verify that the showerheads were installed and still in use. The 100 homes visited were a subset of 402 respondents to the Puget Power telephone survey. Only telephone survey responses for these 100 households, not the full 402 telephone survey respondents, were used in this study.

The sample was drawn from over 26 cities, with the sample distribution as shown in Table B.1. The 101-home sample contained 43 one-shower homes, 52 two-shower homes, 5 three-shower homes, and 1 four-shower home, for a total of 166 showers. However, two were not used as showers, they were used for storage only and were not accessible to the field technician. 
Table B.1 Sample Distribution by City

\begin{tabular}{|l|c|}
\hline \multicolumn{1}{|c|}{ City } & Number of Homes \\
\hline \hline Auburn & 13 \\
\hline Bellevue & 2 \\
\hline Bellingham & 11 \\
\hline Bow & 4 \\
\hline Kent & 10 \\
\hline Kirkland & 2 \\
\hline LaConner & 2 \\
\hline Mt. Vernon & 7 \\
\hline Oak Harbor & 7 \\
\hline Olympia & 6 \\
\hline Port Orchard & 6 \\
\hline Puyallup & 2 \\
\hline Renton & 5 \\
\hline Rochester & 2 \\
\hline Seattle & 3 \\
\hline Sedro Wooley & 5 \\
\hline Sumner & 5 \\
\hline $\begin{array}{l}\text { One home each: Algona, Bainbridge Island, Bremerton, } \\
\text { Coupeville, Federal Way, Pacific, Port Ludlow, } \\
\text { Suquamish, and Vashon. }\end{array}$ \\
\hline
\end{tabular}

The sample distribution was selected to reflect geographic variety among water suppliers; however, the specific cities and sites were also selected to reduce travel time and costs. As a result, the findings described in this report are not expected to be statistically representative of Puget Power's customers or program participants and should not be directly applied to Puget Power's showerhead program.

Instead, the findings are relevant to the accuracy and reliability of telephone survey data and add to the body of knowledge regarding the measurement of conservation persistence and the conservation potential of energy-efficient showerheads. 


\section{B.1.3 Data Management and Quality Control}

Data for this study came from the following sources:

- Puget Power program records and other documents

- PNL observations in the field

- Participant responses to surveys.

Puget Power's program records were designed for use in administering its programs, not necessarily for research purposes. Puget Power had operated at least two programs that distributed efficient showerheads by the time of this field study. Unfortunately, Puget Power's records were not adequate to distinguish which showerhead program may have been used to install specific showerheads at participant sites. Consequently, there was some uncertainty about the number of Puget Powerprovided showerheads installed at study sites, because the same models of showerheads could be purchased by consumers locally.

The following characteristics information was gathered by PNL, either by direct questioning of customers or by measurements and observations completed by the field technician.

- brand name of each showerhead in the home, where available

- an estimate of how long the showerhead had been in place

- location of the bathroom

- shower activation methods

- use of full force when showering

- flow rate through showerhead

- water-heater brand, model, size, age, fuel source, location

- conditioned or unconditioned location of water heater

- additional insulation present around water heater

- hot-water temperature at showerhead

- hot-water temperature at tap nearest the water heater and location of tap

- water pressure

- water source (well or city) 
- tub diverter effectiveness

- comments.

The location of each shower, the source of each showerhead, and showerhead installation dates were determined during the site visits. These questions did not constitute a survey and no survey script was used.

\section{B.2 REMP Field Study and Energy Savings Analysis}

Section B.2.1 describes the REMP field study. Energy-use data from field study sites were used for the REMP energy savings analysis. Sample design and selection of participants is described in section B.2.2, and section B.2.3 discusses data management.

\section{B.2.1 Overview of the REMP Field Study}

In 1983, Bonneville conducted a regional residential survey of over 4,000 residences in the Northwest called the Pacific Northwest Residential Energy Consumption Survey (PNWRES). A sample of these residences was recruited for inclusion in the End-Use Load and Conservation Assessment Project (ELCAP), a multi-year study Bonneville initiated in 1985. Under ELCAP, energyuse monitoring equipment was installed to meter a variety of electrical circuits individually in over 400 selected residential buildings. ELCAP's successor is REMP, which continues data collection from a subset of the original ELCAP sites.

Bonneville initiated the Energy-Efficient Showerhead Field Data Collection Project in August 1991. The goal of the project was to collect site-specific field data regarding the installation of energyefficient showerheads. The REMP sites were used for this study because they were already being monitored and a hot-water energy-use history was already available to establish a pre-existing baseline. Each REMP site is equipped with a data logger that records energy use, individually, for all major appliance circuits, including space and water heating. Data is recorded hourly and archived on a daily basis. Several years of data are available for each site. The availability of electric water-heater energy-use data for the pre-retrofit period meant that retrofit savings data could be collected as soon as showerheads were installed. Consequently, the study was able to proceed without having to collect pre-retrofit period data at significant savings in both time and money.

PNL implemented the field data-collection effort to collect information about site and occupant characteristics that may affect participation in energy-efficient showerhead programs and performance of energy-efficient showerheads in use. The following procedures were used to recruit sites and install the energy-efficient showerheads: customers were solicited to participate, arrangements were made to install showerheads, and payments were made after installation. 
In the course of the field study, data was collected on the following:

- installation of showerheads

- site and occupant characteristics

- post-installation retention and satisfaction.

As a result, PNL was able to identify program-implementation barriers, installation problems, and measure penetration rates.

\section{B.2.2 Sample Design and Selection}

The focus of the showerhead field study was single-family homes with at least one electric water heater. A total of 154 single-family homes were still participating in the REMP metering study at the time of the showerhead retrofit program. Of these 154 sites, 150 were eligible for the showerhead installation field study. (Some were ineligible because they had gas water heaters.) Although the field study sites are not directly representative of the region, they were drawn from PNWRES in a way that permits extrapolations to the region using engineering data from the study sites and socioeconomic data from the census, surveys, or forecasts.

PNL attempted to recruit each of these homes to participate in the field study by promising to replace current showerheads at no charge, return original showerheads upon request, repair minor plumbing problems, and pay each participant forty dollars in cash. Participating homes were subjected to a field inspection and multiple surveys. The disposition of the original REMP sample is shown in Table B.2. 
Table B.2 REMP Field Study Participation History

\begin{tabular}{|c|c|c|}
\hline $\begin{array}{l}\text { REMP showerhead study original } \\
\text { sample }\end{array}$ & 150 & $\begin{array}{l}\text { Four of the } 154 \text { REMP sites were not } \\
\text { eligible for program participation because } \\
\text { they were manufactured homes or were } \\
\text { known to have a gas water heater. (a) }\end{array}$ \\
\hline \multirow[t]{2}{*}{ REMP showerhead sites recruited } & 111 & $\begin{array}{l}\text { Initially, } 111 \text { of the } 150 \text { sites agreed to } \\
\text { participate. }\end{array}$ \\
\hline & -6 & $\begin{array}{l}\text { Six of the } 111 \text { sites were dropped from the } \\
\text { study before the site visits - either the } \\
\text { owners changed their minds or we learned } \\
\text { the home had a gas water heater. }\end{array}$ \\
\hline \multirow{2}{*}{$\begin{array}{l}\text { REMP initial retrofit participants } \\
\text { (homes visited) }\end{array}$} & 105 & PNL visited 105 sites. \\
\hline & -7 & $\begin{array}{l}\text { At } 7 \text { sites the owners changed their minds } \\
\text { about participating, or we decided not to } \\
\text { install a new showerhead because we found } \\
\text { nonstandard plumbing or a gas water } \\
\text { heater. (a) }\end{array}$ \\
\hline \multirow[t]{2}{*}{ REMP final participants } & $98^{(b)}$ & $\begin{array}{l}\text { New showerheads were actually installed in } \\
98 \text { sites. }\end{array}$ \\
\hline & -7 & $\begin{array}{l}\text { Three had missing data and } 4 \text { had gas water } \\
\text { heaters. (a) }\end{array}$ \\
\hline REMP potential-savings sites & $91^{\text {(c) }}$ & Ninety sites had complete sets of data. \\
\hline REMP energy-savings sites & $85^{(d)}$ & $\begin{array}{l}\text { Eighty-five sites had energy use data that } \\
\text { was complete after appropriate outlier sites } \\
\text { were removed. }\end{array}$ \\
\hline \multicolumn{3}{|c|}{$\begin{array}{l}\text { (a) The original ELCAP study included a case study of homes with gas space and water } \\
\text { heating. These were excluded from the showerhead field study. However, some of the } \\
\text { eligible sites had multiple water heaters, including both gas and electric models. In } \\
\text { addition, some of the electric water heaters in the original sample may have been } \\
\text { converted to gas. } \\
\text { (b) Participation, penetration, and persistence calculations are based on the } 98 \text {-site sample. } \\
\text { (c) All flow-rate calculations are based on the sample size of } 91 \text {. } \\
\text { (d) All energy-savings calculations are based on an 85-site sample, unless noted. }\end{array}$} \\
\hline
\end{tabular}

Water-heater energy-use data was monitored from all sites, participant and nonparticipant, for one year after the participant sites were retrofit with showerheads. This data was used to estimate energy savings from the showerhead retrofits by comparing energy use for the year after the retrofit to energy 
use in the previous year. Data from the nonparticipant sites was also analyzed to compare changes in hot-water energy use at these sites to the savings estimated for the participant sites.

\section{B.2.3 Data Management and Quality Control}

ELCAP/REMP data is collected from sensors (potential and current transformers, or PTs and CTs) on the circuit wiring between the circuit breaker box and the end-use load(s). A single CT is required for each phase of a circuit. Typically, residential buildings have two separate 120-volt power circuits into the main breaker box. Each of these is a different "phase" so that both phases can be used together to provide a total of 240 volts of power to energy-intensive end uses. Household voltage is monitored by a PT placed on each phase of the incoming power circuit. These individual measurements are called "channel-level" data in ELCAP/REMP. Energy use, in watts, is derived by multiplying the individual current measurements by the voltage for that circuit. This is done in the data logger, and the result is "end-use" data. End uses that require 240 volts are measured by adding together the separate channel-level data. Electric hot-water heaters are a 240-volt end use. These data are stored locally and retrieved via by PNL telephone lines routinely, generally daily. The channel data is also retained.

The incoming data stream is subjected to a variety of "data-quality" flags. Data-quality flags are set as part of the data-retrieval process. For example, a "no data" flag could indicate tampering with or failure of a sensor, which would need remedial action. However, there is a lag before the datamanagement staff review the data-quality flags. As a result, some errors that may have a systematic cause such as a modem failure, may not be addressed for a few weeks. This could result in missing data for a month or more. Generally, the flags are not systematically reviewed except as part of an analysis project. They provide analysts with a quick indication of any problems both with the data and the logger. They would also provide the analyst with an indication of which data are not valid observations, but "missing" data.

For the REMP Showerhead energy savings analysis study, standard ELCAP/REMP data quality checks for the hot water end use included looking at the total site data quality as well as the individual hot-water end use. Data for specific time periods or sites was only removed from the analysis if there was a data quality problem specifically associated with the hot-water end use. In some sites, other end uses may have had data-quality problems (contributing to poor "total" use-data quality) but the hot water end use was not affected. The two most common reasons for dropping data or sites for dataquality reasons were for "zero" readings and "sum-check" failures (see below).

Selected data or a whole site would be removed from the analysis if the hot-water end use had low or no consumption. Zero readings are rare in the ELCAP/REMP study due to minor calibration errors. These errors show up as a constant, or "offset," which can be corrected by adjusting the data by the magnitude of the offset. The REMP energy savings analysis study primarily used two data sets: hot-water heating and "billing" data. Billing data is constructed by summing together all end uses except for temperature-sensitive heating and air-conditioning end uses. In terms of data-quality checks, 
the billing analysis data set can be different from the hot-water data set due to dropping different sites for data quality reasons.

Data was also removed if the "sumcheck" error was associated with the billing data end uses (all end uses in the home but space heating). The basis for a sumcheck is that the power into the building is equal to the sum of the power from each of the circuits (end uses). For example: total = hot water + heating + range + dryer + washer + lights + other. When this equation is not balanced (within a specified equipment-limited accuracy range) this indicates a sumcheck or metering error. Data with sumcheck or metering errors were not included in the analyses.

\section{B.3 REMP Energy Savings Analysis Study}

Collection of longitudinal data from time-of-use meters presents unique problems for data analysts. Time-of-use metering generates a tremendous volume of time series data. This data is subject to a variety of errors, as discussed in the previous section. Errors are flagged so that observations that may not meet specific quality standards can be omitted. The sheer number of data points provides sufficient "degrees of freedom" that some data losses will not significantly affect resulting analyses. Further, the ELCAP/REMP analysis protocols developed by PNL include methods to "fill" missing data using a variety of smoothing techniques. Nevertheless, there is always the possibility that the processes used to exclude data or to fill missing data may introduce unintended errors.

The data series for the REMP energy savings analysis study included data for 12 months prior to retrofit of efficient showerheads and 12 months after retrofit. When the time lags for retrofit are included, the monitoring period covered nearly three years. Each data monitoring point and data logger was subject to numerous events that could corrupt data during this period. The most damaging errors were those associated with data retrieval or sensor problems that required a site visit to repair. Typically, these types of errors are clustered during the winter months when cold, wet conditions impair the operation of rural electric and telephone services and electronic equipment (the data loggers) located in unheated spaces. Generally, these types of problems resulted in lost data for a month or more. The first data-quality screening for the REMP data involved looking for whole months' worth of useable data. In other words, the data for each site was reviewed to determine if any whole months of data were missing. Attempts were made to ensure that the months could be matched during the pre and post periods. For example, the data series included data for January in both periods.

The initial data screening resulted in only 6 months of annual data available for analysis using the most stringent standards for data quality, namely, no missing data for each month used in the analysis. Unfortunately, these 6-month periods were in the warmest months of the year, which was expected to introduce a bias in the results. As a result, the data-quality standards were relaxed to permit filling of missing data series to increase the number of months of data available for analysis in each of the oneyear periods pre- and post- retrofit. This resulted in two more analytic data sets, one with 11 months of data for analysis and one with 12 . The 11-month data set recovered data by minor data filling and cleaning. The 12-month data set required significant data filling, filling two or more weeks of missing 
observations. Tests were conducted on all three of the analytic data sets $(6,11$, and 12 months) to determine if the selection of analysis period would affect results. As expected, the 6-month data series significantly affected results. Measured changes in energy use were much less for the 6 month data set than for the 11- and 12-month sets, due to the shorter period. Extrapolation of results from the 6month data series would require information about the "missing" 6 months, which obviously was not available unless the data-quality standards were relaxed. Accordingly, the focus shifted to the 11- and 12-month data series. Estimates from each of these data sets were not significantly different. The 11month series was a larger sample than the 12-month series (more sites had at least 11 months of data than had 12, which was expected) thus the 11-month data series and respective sample was used for the energy use and savings analysis. Results were extrapolated for an entire year.

\section{B.4 Puget Water-Metering Study}

Sections B.4.1 and B.4.2 describe the Puget water-flow study and the sample design and customerselection process. Section B.3.3 discusses data management.

\section{B.4.1 Overview of the Puget Water-Metering Study}

Bonneville's Appliance Efficiency Program included low-flow faucet aerators as well as efficient showerheads. Bonneville did not attribute any savings to these measures in its program design because other evaluations failed to provide concrete evidence that they produced significant savings. Nevertheless, they were included to have a comprehensive approach to energy and water efficiency. The REMP field study looked only at efficient showerheads; faucet aerators were not replaced. Continuing interest in faucet aerator savings potential by Bonneville and utility program staff resulted in a collaborative study between Bonneville and Puget Power to directly monitor hot water use in bathroom and kitchen faucets and showerhead water flows.

The Puget water-metering study was designed to directly monitor water flows in the bathrooms and kitchens in a sample of homes prior to and after water-conservation measures were installed. The research design also included monitoring the number of minutes the hot-water heater was in use (direct measurement of energy use and/or time of use metering was considered to be too expensive). The water-heater run-time measurement was expected to provide a means to verify the REMP energysavings estimates.

\section{B.4.2 Sample Design and Selection}

Puget Power had been offering water-conserving measures for several years by the time this study was conducted. A sample of customers who had not yet participated in Puget Power's water and energy conservation program were used for the water-flow study. This sample was drawn from utility records for owner-occupied, single-family homes in Puget Power's King County service area. The sample was screened to obtain a variety of household sizes, occupant ages, and structure ages, and to verify the structure and water heating fuel type. Recruitment of study participants included sending out 
an introductory letter describing the study and follow-up telephone calls to obtain a sample of 95. Participants were offered a one hundred and fifty-dollar "nuisance" payment as well as professional installation of efficiency measures. Ultimately, a total of 75 sites were used for the study (the other sites were rejected for a variety of reasons). The total size of the sample was dictated, in part, by budgets and the limited number of water-flow meters available for the study (300).

\section{B.4.3 Data Management}

Bonneville provided Puget Power with Water Tracker and Badger brand water-flow meters for the study. These were selected after comparing alternative brands available. All of the water meters purchased for the study were tested by Bonneville to ensure accuracy. Flow meters were installed on one water heater (the Badger meters), one showerhead, one kitchen hot-water supply line, and up to two bathroom sinks at each site. If a site had more than one water heater or shower, the additional devices were not monitored. All of the water-flow meters measured water flow on a cumulative register that required readings at the beginning of the study, after the "pre-retrofit" monitoring period, after the measure retrofits, and finally, at the end of the study.

Puget Power supplied the motor loggers to measure water-heater run time. These were installed on the water heater. During installation, the electricity required by the water heater was measured. Multiplying this one-time measurement by the motor-logger meter reading provided the approximate amount of energy used by the water heater during the period covered by the run-time metering.

Occupant and structural data were collected during the initial site visit and updated on subsequent . visits to install measures and retrieve data. A variety of other data were collected during each site visit including water pressure and cold- and hot-water temperature.

The total monitoring period was approximately 60 days, with roughly 28 days in the pre- and postretrofit periods. Cumulative readings from the various data recorders were converted to daily values by dividing the readings by the number of days in the recording period. Annual estimates were extrapolated from this data and results adjusted for seasonal and year-to-year variations in weather.

\section{B.5 Other Studies}

Several other studies were used for this evaluation. The most important of these is the Bonneville Showerhead and Aerator Performance Test described in Appendix F. Bonneville and Seattle City Light also cooperated on a water metering study similar to the Puget water-metering study (Section B.4) among multi-family units. Initially, it was assumed that multi-family savings potential was lower due to smaller household size. However, analysis of regional demographic data did not support this assumption. Then, early shower flow measurements led to assertions that savings may be higher in multi-family units due to much older and inefficient fixtures. Properly designed water-flow tests failed to confirm this assertion. Consequently, the evaluation did not distinguish between savings for singleand multi-family units, and these studies were not used directly in the evaluation. 


\section{B.6 References}

Bailey, S. A., and W. M. Warwick. 1993. Persistence of Energy-Efficient Showerheads: Field Study Results. PNL-8432, prepared for the Bonneville Power Administration under a Related Services Agreement with the U.S. Department of Energy by Pacific Northwest Laboratory, Richland, Washington.

SBW Consulting, Inc., and NCAT-Development Corporation. 1994. Energy Efficient Showerhead and Faucet Aerator Metering Study. 9414, prepared by SBW Consulting, Inc. with NCAT- . Development Corporation for Puget Sound Power and Light, Bellevue, Washington.

Warwick, W. M. 1993. Energy Savings from Energy-Efficient Showerheads: REMP Study Results, Proposed Evaluation Algorithm, and Program Design Implications. PNL 8763 Prepared for the Bonneville Power Administration under a Related Services Agreement with the U.S. Department of Energy by Pacific Northwest Laboratory, Richland, Washington.

Warwick, W. M., and S. A. Bailey. 1993. Results from an Energy-Efficient Showerhead Field Study. PNL-8715, prepared for the Bonneville Power Administration under a Related Services Agreement with the U.S. Department of Energy by Pacific Northwest Laboratory, Richland, Washington. 


\section{Appendix C}

Puget Power and Light Persistence Study 


\section{Appendix C Puget Power and Light Persistence Study}

The results presented in this Appendix are drawn from a field study conducted by the Pacific Northwest Laboratory (PNL) and sponsored collaboratively by Puget Power Sound Power and Light (Puget Power) and Bonneville Power Administration (Bonneville). The study is known as the Puget persistence study (Bailey and Warwick 1993).

\section{C.1 Measure Installation and Participation Results}

The study yielded results in terms of participation, penetration, and persistence based on observations after measure installation. These results can be viewed in terms of program (per household) or measure (per shower) success. Each perspective provides different results. From a program perspective, participation is based on the number of eligible households that participated in the Puget Power program. Puget Power actually distributed showerheads to 97 of the 100 sites PNL visited, for a participation rate of 97 percent. Program penetration is defined as the fraction of participants that actually installed a Puget Power showerhead. According to Puget Power's telephone survey, 86 of the site-visit households indicated they had installed at least one of the showerheads Puget Power distributed, for an $89 \%$ participation rate. Program persistence is based on the fraction of the households who installed measures where at least one measure remained in service. Eighty-two of the 97 homes that received showerheads from Puget Power still had them in place during the site visit, for an $85 \%$ persistence rate.

Because energy savings are achieved from the performance of measures rather than households, a more accurate portrayal of program accomplishments may result from viewing them on a per-measure basis rather than a per-household basis. The measure participation rate is based on the number of measures distributed compared to the total number that could be installed. In this study, 166 showers were identified, but Puget Power only distributed 150 of these showerheads, for an $89 \%$ participation rate. Measure penetration is based on the number of measures distributed compared to the number installed. Puget Power's telephone survey indicated that 121 of the 150 showerheads distributed were installed, for an $81 \%$ measure penetration rate. Measure penetration can also be viewed from the broader perspective of total potential. From this perspective, a total of 166 showerheads could have been replaced, and 121 actually were replaced, for a $72 \%$ penetration or retrofit rate.

\section{C.2 Results}

Field study results indicate an $85 \%$ program persistence rate. The persistence rate is the fraction of measures installed remaining in service at a subsequent time. This value is of interest for two reasons. First, the PNL observations were done after installation, and therefore, we were unable to verify Puget Power or customer claims of initial installation. Second, one objective of this study was to verify the 
accuracy of telephone responses compared to actual site inspections. The telephone survey yielded a persistence rate similar to the site visits (80\%, corrected for reporting errors). However, this rate includes the customers who did not receive showerheads (3\%), and those who installed the showerheads prior to the Puget Power distribution program (7\%). If adjustments are made to reflect nonreceipt or prior installation, program persistence is $91 \%$. The total showerhead installation or measure penetration rate was $89 \%$ for this adjusted sample, and the total measure persistence rate was $66 \%$.

In terms of estimating the showerhead installation rate, the telephone survey appears to be correct approximately $95 \%$ of the time. However, the site visits showed several discrepancies in the information provided by the customers during the telephone survey, which amount to compensating errors. When these are counted, the precision of the telephone survey drops to approximately $80 \%$.

\section{C.2.1 Water-Flow Results}

Flow-rate measurements were taken with a Micro Weir water measuring device, which is reported to have an accuracy of 0.25 gallons per minute (gpm) (Manclark 1991). The flow measurement was taken at full force, with a mix of hot and cold water to approximate bathing temperature.

Of the 164 working showerheads found at the sample sites, 106 were determined to be the energyefficient heads distributed by Puget Power. The Puget Power energy-efficient showerheads have lower flow rates than the rest of the sample. The average flow rate for the Puget Power showerheads is $1.8 \mathrm{gpm}$, with a standard deviation of 0.2 , compared to $2.7 \mathrm{gpm}$ (standard deviation of 1.1) for the non-Puget Power showerheads. Of the energy-efficient showerheads, the lowest average flow rate was with the Conserve brand (1.4 gpm with a standard deviation of 0.4). Overall, the sample average flow rate was $2.1 \mathrm{gpm}$ with a standard deviation of 0.8 . Table C.1 shows the flow rates by showerhead brand. 
Table C.1 Average Flow Rate by Showerhead Brand

\begin{tabular}{|c|c|c|}
\hline Brand & \multicolumn{2}{|c|}{ Standard Deviation } \\
\hline Puget Power Showerheads: & \multicolumn{2}{|c|}{$\begin{array}{l}\text { Avg. for Puget Power Hds }=1.8 \mathrm{gpm} \\
\text { Standard Deviation }=0.2\end{array}$} \\
\hline Conserve & 1.4 & 0.4 \\
\hline Ultra & 1.9 & 0.5 \\
\hline Niagara & 1.8 & 0.2 \\
\hline Ondine & 1.9 & 0.4 \\
\hline Other Showerheads: & \multicolumn{2}{|c|}{$\begin{array}{l}\text { Avg. for All Others }=2.7 \mathrm{gpm} \\
\text { Standard Deviation }=1.1\end{array}$} \\
\hline Teledyne & 2.5 & 1.0 \\
\hline Unk/Not Spec. & 2.7 & 1.1 \\
\hline Water Pic & 3.0 & 1.0 \\
\hline Alsons & 1.0 & NA \\
\hline Crane & 4.3 & NA \\
\hline Lasco & 1.5 & NA \\
\hline Polinex & 2.0 & NA \\
\hline Price Phister & 2.5 & NA \\
\hline Stanadyne & 2.5 & NA \\
\hline Synergy Int. & 3.8 & NA \\
\hline Windmere & 2.8 & NA \\
\hline Average for all Heads: & 2.1 & 0.8 \\
\hline
\end{tabular}

Showerhead flow rates can be affected by the method used to activate the shower. Leakage past diverter valves in showers installed in tub/shower combinations was one unknown this study hoped to address. Shower activation methods were categorized in the following four ways: a single-handled bath control with a spout diverter, hot and cold (two-handled) bath control with a spout diverter, a single-handled shower valve, and a two-handled shower valve. Table C.2 shows the distribution of the sample. 
Table C.2 Shower Activation Methods

\begin{tabular}{|l|c|c|}
\hline Show Activation Method & \multicolumn{2}{|c|}{ Number Percentage of Sample } \\
\hline Single-Handled Bath w/Diverter & 71 & 43 \\
\hline Two-Handled Bath w/Diverter & 36 & 22 \\
\hline Single-Handled Shower Valve & 42 & 25 \\
\hline Two-Handled Shower Valve & 7 & 4 \\
\hline Unknown/Not Specified & 10 & 6 \\
\hline
\end{tabular}

Only one out of the 100 customers indicated any significant leakage problems; study designers had expected that there would be quite a few leakage problems in the sample. It was also anticipated that leakage problems might be a reason why occupants would not install the energy-efficient heads, but this was not reported as the case in the telephone survey.

Another factor expected to affect flow rates was water pressure. Use of domestic wells for water supplies emerged in this study as a potentially significant predictor of water pressure. Of the 101 customers in the sample, $29 \%$ reported that their homes were supplied by a well. One-time water pressure measurements were taken at each home from an outside tap. The average for the full sample was 66.7 pounds per square inch (psi), with a standard deviation of 22.0 , a high of $148 \mathrm{psi}$, and a low of 30 psi. The average water pressure for homes on a well was $49.5 \mathrm{psi}$, with a standard deviation of 14.7. The average for city-supplied homes was $72.5 \mathrm{psi}$, with a standard deviation of 21.1. Low water pressures may affect (reduce) water-flow rates and therefore, savings rates.

One final factor that was unknown prior to this study was the range of water-heater temperatures and errors. These errors may be associated with measurements of water-heater temperatures taken at the shower, which is easy to do, versus at the water heater itself, which is often awkward. One-time hot-water temperature measurements were taken at the showerhead and at a tap location nearest to the hot-water heater. (Water withdrawals directly from the water heater are complicated by the lack of taps on the tank and drains for the water.) The average temperature at the showerhead was $132.2^{\circ} \mathrm{F}$, with a standard deviation of $11.6^{\circ} \mathrm{F}$. The average temperature at the tap closest to the hot-water heater was $132.8^{\circ} \mathrm{F}$, with a standard deviation of $11.5^{\circ} \mathrm{F}$. In 74 homes, there was no difference between the two temperatures. The average difference (excluding one $28^{\circ} \mathrm{F}$ difference home) was $0.4^{\circ} \mathrm{F}$ with a standard deviation of $1.2^{\circ} \mathrm{F}$. If all of the zero difference homes are excluded, the average difference is $1.5^{\circ} \mathrm{F}$, with a standard deviation of $2.0^{\circ} \mathrm{F}$. 


\section{C.3 Conclusions}

The key conclùsions from this study for the evaluation were that measure installation rates, or the fraction of showerheads retrofit in a home, is a critical variable for estimating household, and thus, program savings. The Regional End-Use Monitoring Project (REMP) field study (Warwick and Bailey 1993) replaced all possible showerheads due to the use of professional installers charged with "wholehouse" treatment. Puget Power's professional installers were not charged with whole house treatment responsibility and did not always replace all showerheads. The Puget Power program also used selfinstallation field results, which indicated that self-installation methods only achieve a 50\% retrofit rate when compared to professional installation rates. These results confirmed that the installation method needed to be included explicitly in the program evaluation.

The Puget persistence study also confirmed earlier REMP results that pre-installation flow rates were not as high as assumed, and that manufacturers' flow ratings were not necessarily reliable indicators of field-monitored flow rates. The study also identified critical limits to the usefulness of consumer surveys for evaluating measure retrofit rates, showerhead models, and installation dates. 


\section{C.4 References}

Bailey, S. A., and W. M. Warwick. 1993. Persistence of Energy-Efficient Showerheads: Field Study Results. PNL-8432, prepared for the Bonneville Power Administration under a Related Services Agreement with the U.S. Department of Energy by Pacific Northwest Laboratory, Richland, Washington.

Manclark, S. 1991. "Does Low Flow Still Mean Low Satisfaction?" Home Energy, July/August.

Warwick, W. M., and S. A. Bailey. 1993. Results from an Energy-Efficient Showerhead Field Study. PNL-8715, prepared for the Bonneville Power Administration under a Related Services Agreement with the U.S. Department of Energy by Pacific Northwest Laboratory, Richland, Washington. 


\section{Appendix D}

Hot-Water Flow Analyses and Assumptions Documentation 


\section{Appendix D Hot-Water Flow Analyses and Assumptions Documentation}

\section{D.1 Introduction}

This Appendix provides a summary of results from the Puget Sound Power and Light (Puget Power) water-metering study (SBW Consulting 1994) and compares them to two other studies. The latter studies, the Regional End-Use Metering Program (REMP) field study and the Puget persistence study were conducted for Bonneville Power Administration (Bonneville) by Pacific Northwest Laboratory (PNL) (Warwick 1993; Bailey and Warwick 1993). We refer to these studies in this report as the Puget water-metering study, the REMP field study, and the Puget persistence study, respectively. Results from the Puget persistence study are presented in Appendix C, and the REMP field study results are presented in Appendix $\mathrm{E}$. ${ }^{\text {(a) }}$

The REMP and both Puget studies measured water pressure and on-site showerhead in Appendix $\mathrm{C}$, and flow rates. The REMP field study also monitored water-heater energy use and savings. The Puget water-metering study alone, monitored water use in showers. Although this data includes both hot- and cold-water use, the relative differences in water use in that study were also used to confirm the REMP energy savings. Water flow-rate measurements (in contrast to cumulative water-flow measurements as in the Puget water-metering study) are one-time measurements. The Puget persistence study and the REMP field study both provided evidence that water flow rates in efficient showerheads vary, sometimes significantly, from manufacturers' ratings (Appendix F). Although estimates of showerhead savings potential can be derived by comparing existing flow-rate measurements with the flow rates claimed by manufacturers, this estimate will not be reliable. Similarly, estimates based on pre- and post-retrofit flow rates will be misleading because they will not capture dynamic behavior, such as longer or hotter showers, which can be inferred from the REMP savings data or changes in user settings of shower force as observed in the Puget water-metering study.

Savings estimates presented here are based on measurements of water and energy use pre- and postretrofit of efficiency measures. Analyses done after the fact are only accurate for a specific sample and period of time. Nevertheless, reliable extrapolations can be made from these results if the underlying conditions that produce the results are understood and reflected in subsequent projections. These conditions include the number of occupants, vacancy rates, cold water temperature, and so on. In general, these factors have a greater influence on estimates when the monitoring periods are short, because small variations can lead to big differences in estimates. The REMP study spanned over two

(a) PNL was aided in the Puget persistence and REMP studies by the field work of Pacific Science and Technology. The Puget water-metering study was conducted by SBW Consulting, Inc. for Puget. 
years; whereas, the Puget water-metering study covered less than three months. Consequently, the variance in savings estimates is greater for the Puget water-metering study.

The primary focus of the Puget persistence study for Puget Power, was to verify the reliability of telephone survey responses regarding persistence of water-efficiency measures. However, it also included a collection of information on water-flow rates and other characteristics that could affect the performance of efficient showerhead programs.

The primary focus of the Puget water-metering study was to measure specific estimates of water and energy savings from faucet aerators on kitchen sinks, bathroom vanities, and from efficient showerheads. The primary data collected in the Puget water-metering study was water-flow data, both one-time measurements (flow rates) and cumulative flows (water use). Water-heater "on" time was also monitored to capture energy-use data. Energy savings estimates were derived from this primary data as described in Appendix B and Section D.3 below. Water flow measurements were taken from up to four water-using devices in $\mathbf{7 5}$ homes, as well as from the water heater. In addition to the water heater, each home had a water monitor installed on at least one shower (at the arm) and one kitchen sink and up to two vanity sinks (on the hot-water supply lines). The water-heater meter measured the total amount of hot water that was used by the household. The water meters on each of the sink supply lines measured the amount of hot water used at each of those sinks. Unfortunately, it was not possible to separately meter the hot water used by the shower, so that meter measures total both hot and cold mixed water flow through the shower. The fraction of shower water that was drawn from the hotwater tank was estimated using the temperature settings occupants claimed to have used during showers to establish a ratio for the mix of hot and cold water (the mixing ratio). Water used by unmetered devices, obviously, was not measured. The distribution of sinks and showers and of the water meters in the sample is summarized in Table D.1.

Table D.1 Distribution of Water Meters in the Puget Sample

\begin{tabular}{|l|c|c|c|c|}
\hline \multicolumn{1}{|c|}{ Device } & $\begin{array}{c}\text { Total } \\
\text { Devices }\end{array}$ & $\begin{array}{l}\text { Number Retrofit/ } \\
\text { Monitored }\end{array}$ & $\begin{array}{l}\text { Number Not } \\
\text { Retrofit/Monitored }\end{array}$ & Retrofit Rate (\%) \\
\hline Hot water heater & 75 & 75 & 0 & 100 \\
\hline Showers & 127 & 86 & 41 & 66 \\
\hline Kitchen sinks & 75 & 75 & 0 & 100 \\
\hline Bathroom sinks & 199 & 83 & 116 & 42 \\
\hline
\end{tabular}

\section{D.2 Water-Flow Rate Results}

Each of the three studies collected field data on shower flow rates, and household water temperature, pressure, and source. The samples used in each of the studies were similar in many 
respects, such as the number of showers per home, but differed in others, such as number of persons per household (Table D.2).

Table D.2 Sample Characteristics

\begin{tabular}{||l|c|c|c|}
\hline & REMP & Persistence & Water-metering \\
\hline Showers/home & 1.7 & 1.7 & 1.7 \\
\hline Person/home & 2.8 & 3.4 & 3.5 \\
\hline \% on wells & 20 & 20 & 24 \\
\hline Well pressure (avg. psi) & 39 & 49.5 & 44 \\
\hline City Pressure (avg. psi) & 66 & 72.7 & 67.5 \\
\hline Average Pressure (avg. psi) & 60.5 & 66.7 & 62.9 \\
\hline
\end{tabular}

The REMP, and Puget water-metering studies included measurements of water-flow rates before and after existing showerheads were replaced with energy-efficient models. The Puget persistence study did not include retrofit of showerheads, since the sample was selected based on prior participation in a retrofit program. However, not all of the showerheads in each home appeared to have been replaced prior to the site visit, and flow-rate data was collected on the non-retrofit showerheads. This data may not be representative of the pre-retrofit flow rates for the showers that were retrofit; however, it is included in Table D.3.

Table D.3 Existing Shower Flow Rates

\begin{tabular}{|l|c|c|c|c|}
\hline & REMP & Persistence & $\begin{array}{c}\text { Water- } \\
\text { metering } \\
\text { (full force) }\end{array}$ & $\begin{array}{c}\text { Water- } \\
\text { metering } \\
\text { (user force) }\end{array}$ \\
\hline Pre-Flow (avg. gpm) & 3.2 & 2.7 & 3.0 & 2.6 \\
\hline
\end{tabular}

Flow-rate measurements for the REMP and Puget persistence studies were taken with a Micro Weir water measuring device, which is reported to have an accuracy of 0.25 gallons per minute (gpm) (Manclark 1991). The flow measurement was taken at full force, with a mix of hot and cold water to approximate bathing temperature. The Puget water-metering study used a Water Tracker in-line flow meter for a one-minute interval. Two measurements were taken, one at full force and one at the setting a resident said they normally use.

Efficient showerheads were installed at the sites in each of the studies. The manufactures' ratings for the retrofit showerheads were known. Actual flow rates were also measured using the same methods as described above. The weighted average manufacturers' flow rates and actual flow rates are presented in Table D.4. 
Table D.4 Field Measurements of Efficient Showerheads

\begin{tabular}{||l|c|c|}
\hline & Rated Flow (gpm) & Measured Flow (gpm) \\
\hline REMP & 2.3 & 1.8 \\
\hline Persistence & 2.1 & 1.8 \\
\hline Water-metering (full force) & 2.3 & 1.9 \\
\hline Water-metering (user force) & 2.3 & 1.8 \\
\hline
\end{tabular}

The gross changes in flow rates for the three studies are summarized in Table D.5.

Table D.5 Showerhead Flow Rate Changes

\begin{tabular}{||l|c|c|c|c||}
\hline & REMP & Persistence & $\begin{array}{c}\text { Water- } \\
\text { metering } \\
\text { (Full force) }\end{array}$ & $\begin{array}{c}\text { Water- } \\
\text { metering } \\
\text { (User force) }\end{array}$ \\
\hline Pre-flow (avg. gpm) & 3.2 & 2.7 & 3.0 & 2.5 \\
\hline Post-flow (avg. gpm) & 1.8 & 1.8 & 1.9 & 1.8 \\
\hline Flow Change(avg. gpm) & 1.4 & .9 & 1.1 & .7 \\
\hline Percent Change & $44 \%$ & $33 \%$ & $37 \%$ & $28 \%$ \\
\hline
\end{tabular}

The samples of Puget Power customers (persistence and water-metering studies) were taken a few years apart, from participants early and late in the program. It would be natural to assume that the so-called "innovators" and "laggards" would have different characteristics; however, these are not obvious in terms of their ability to save water or energy from showerhead retrofits. Innovators do not appear to have a greater propensity to save water or energy than laggards do, based on the number of occupants and pre-retrofit flow rates, which are similar.

The relative change in flow rates should be indicative of the magnitude of water and energy savings. However, the comparison of full force and user flow rates results from water-metering in Tables D.4 and D.5 provides evidence that consumers attempt to return to the same flow rates as they had before the efficient showerhead has been installed. This observation is also supported by analyses of the number of minutes showers were used in Puget water-metering study and a similar study by Proctor Engineering (1994). Both studies indicated that the length of showers remains constant before and after retrofit of efficient showerheads. 


\section{D.3 Puget Water-metering Study Savings Results}

The Puget water-metering study provides the best data on actual water use available. It is also the only source for information on the effectiveness of faucet aerators that was available to support Bonneville's showerhead program evaluation. Monitored flow rates for the pre- and post-retrofit periods for all water-efficiency measures are summarized in Tables D.6 and D.7.

Table D.6 Water-Metering Study Daily Water Use Estimates, Pre-Retrofit

\begin{tabular}{|l|c|c|}
\hline & Avg. Gallons/Day & $\begin{array}{c}\text { Standard } \\
\text { Deviation }\end{array}$ \\
\hline Hot water use & 61.6 & 36.23 \\
\hline Shower use (1 shower) & 25.1 & 20.41 \\
\hline Shower use (hot only) & 19.3 & 17.80 \\
\hline Kitchen sink use (1 only) & 10.4 & 5.94 \\
\hline Vanity sink use & 3.1 & 2.91 \\
\hline
\end{tabular}

Table D.7 Water-Metering Study Daily

Water Use Estimates, Post-Retrofit

\begin{tabular}{||l|c|c||}
\hline & Avg. Gallons/Day & $\begin{array}{c}\text { Standard } \\
\text { Deviation }\end{array}$ \\
\hline Hot-water use & 57.1 & 32.99 \\
\hline Shower use (1 shower) & 18.8 & 12.18 \\
\hline Shower use (hot only) & 14.6 & 10.94 \\
\hline Kitchen sink use & 10.5 & 5.82 \\
\hline Vanity sink use & 3.5 & 2.82 \\
\hline
\end{tabular}

The estimated differences in daily water use between the pre- and post-retrofit periods are summarized in Table D.8. 
Table D.8 Water-metering Study Mean Differences, Pre- and Post-Retrofit (gallons and percent)

\begin{tabular}{|l|c|c|}
\hline & Mean Difference (gallons) & Relative Difference (\%) \\
\hline Hot-water use & -4.65 & -7.55 \\
\hline Shower use (1) & -6.33 & -24.97 \\
\hline Shower use (hot only) & -4.76 & -24.64 \\
\hline Kitchen sink use (1) & +0.22 & +2.12 \\
\hline Vanity sink use & +0.18 & +5.75 \\
\hline
\end{tabular}

Relative errors for the initial use estimates range between $11 \%$ and $16 \%$ at a $90 \%$ confidence level. As a result, the gross changes in sink and total hot-water use are not significant.

The Puget water-metering study did not directly measure electricity use. Instead, it used a timer to monitor the amount of time the water heater was on and multiplied this value by the one-time measurement of water-heater current and voltage. This assumes current and voltage are constant, which may not be correct. Nevertheless, estimates of energy use and savings can be derived from both this run-time data and from gross-water use.changes.

The short monitoring period used to collect this data also requires adjustments to the data to correct for differences in cold-water temperature. The monitoring period was in the fall, and the coldwater temperature was warmer during the pre-period than the post. As a result, it took more energy in the post-period to heat the cold water. Although the Puget water-metering study collected data on household cold-water temperature during the study, there is no time-series data on household coldwater temperature for the year or for the region for the Puget water-metering study or Bonneville's evaluation. As an alternative, the Puget water-metering study used average temperatures for a reservoir to provide a benchmark for temperature correction. This data provided an annual average temperature of $48.7^{\circ} \mathrm{F}$, an average temperature during the pre-period of $59.4^{\circ}$, and during the postperiod of $55.1^{\circ}$.

The variety of data available from the different meters permitted four alternative approaches to savings estimation. Each of these approaches can be used with different assumptions to produce estimates from a variety of perspectives. The results from the perspective of household-level savings are presented in Table D.9. 
Table D.9 Alternative Estimates of Household Savings (unadjusted for outliers)

\begin{tabular}{|l|c|c|c|c||}
\hline \multicolumn{1}{|c|}{ Method } & $\begin{array}{c}\text { Mean } \\
(\mathbf{k W h} / \mathbf{y r} .)\end{array}$ & $\mathbf{N}$ & $\begin{array}{c}\text { Standard } \\
\text { Deviation } \\
(\mathbf{k W h} / \mathbf{y r} .)\end{array}$ & $\begin{array}{c}\text { Standard } \\
\text { Error } \\
(\mathbf{k W h} / \mathbf{y r} .)\end{array}$ \\
\hline Water-heater energy & 380 & 65 & 847 & 105 \\
\hline Hot-water use & 312 & 74 & 871 & 101 \\
\hline Sum of savings & 299 & 67 & 845 & 103 \\
\hline Adjusted sum of savings & 391 & 75 & 611 & 71 \\
\hline
\end{tabular}

The data and methods used to produce these results include:

Water-heater energy. Savings were estimated based on water-heater on-time readings that were converted into energy use in kilowatt hours $(\mathrm{kWh})$. Savings were estimated by subtracting preand post-retrofit use and normalizing for variations in cold-water temperature.

Hot-water use. Hot-water savings were estimated based on the hot-water heater flow meter readings. Savings were estimated by subtracting pre- and post-retrofit use, calculating the electricity needed to raise the temperature in each of the periods from the temperature of cold water to that of hot water, and normalizing for variations in cold-water temperature.

Sum of Savings.The study monitored water use at each point of use (Table D.1). The sum of savings approach involved adding up the savings observed at that level over the study period, calculating the electricity needed to raise the temperature in each of the periods from the temperature of cold water to that of hot water, and normalizing for variations in cold-water temperature. This should produce the same result as the hot water use estimate, if all of the savings are the result of the retrofit measures. However, the shower flow meter recorded both hot- and cold-water flows, so it was necessary to apportion the change in shower-water use between hot and cold. This adjustment was imperfect and may have accounted for the resulting difference in estimates between the hot-water use and sum of savings methods.

Adjusted sum of savings. Savings were not observed at all sites and for all hot water uses; hence, the smaller sample $(n=67)$ for the sum of savings estimate. Efforts were taken to adjust the pre-and post-retrofit data using occupant data to correct for differences in occupancy and use practices to increase the sample for analysis. This involved projecting savings based on preperiod data using the change in user water-flow settings observed in the pre- and post-periods. These projected savings were then summed to produce the adjusted sum of savings. 


\section{D.4 Comparison of Puget Water-Metering and REMP Field Study Results}

The results from the Puget water-metering study need to be placed in context with the REMP savings estimates for purposes of this evaluation. This requires a choice among the four competing savings estimates and reconciliation of the differences in the research design and field conditions of the two studies. The characteristics of the two study results are summarized in Table D.10.

Table D.10 Comparison of Puget Water-metering and REMP Field Studies

\begin{tabular}{||l|c|c||}
\hline & REMP & PUGET \\
\hline Household Savings & Yes & Yes \\
\hline Individual Measure Savings & No & Yes \\
\hline Retrofit Rate & Whole House & 1 or 2 showerheads only \\
\hline Retrofit Faucets & No & Yes \\
\hline Retrofit Showerheads & Yes & Yes \\
\hline No. of Persons & 2.8 & 3.4 \\
\hline $\begin{array}{l}\text { Showerhead Flow Rates } \\
\text { (user settings) }\end{array}$ & Not measured & Reduced by 1.7 gpm \\
\hline $\begin{array}{l}\text { Showerhead Flow Rates } \\
\text { (full force) }\end{array}$ & Reduced by 1.4 gpm & Reduced by 1.1 gpm \\
\hline \begin{tabular}{l} 
Domestic Wells \\
\hline
\end{tabular} & $20 \%$ & $24 \%$ \\
\hline
\end{tabular}

The Puget water-metering study estimates range from $299 \mathrm{kWh}$ to $391 \mathrm{kWh}$, per house, annually. In order to compare these results to those of the REMP field study it is necessary to select savings estimates that are most directly comparable to those of the REMP field study. The waterheater energy savings results include assumptions about current and voltage that the hot-water use estimates do not. As a result, the hot-water use estimates may be favored because of their simplicity. However, both estimates are based on changes in total hot-water use and may attribute savings to changes in hot-water use that are independent of the retrofit measures, (tub baths and clothes and dish washing). The Puget sum-of-savings estimates are based only on changes in retrofit showerhead and faucet use, and hence, avoid this source of error. However, showering-water use has to be apportioned between hot and cold water, introducing a different adjustment.

The Puget water-metering results presented in Table D.9, except for the adjusted sum of savings, are for the household as a whole. As such, increases that were observed for some measures (e.g., aerators) offset savings for others. These estimates should be the most directly comparable to the REMP energy savings of $515 \mathrm{kWh}$ annually, except they include savings from aerators that were not 
included in the REMP field study. These are estimated to be about $65 \mathrm{kWh}$ annually. If aerator savings are subtracted from the water-heater energy estimate, the net savings are $326 \mathrm{kWh}$ annually. The hot-water use (312 kWh) and sum of savings ( $299 \mathrm{kWh})$ results are quite close to each other and similar to the net, or showerhead only, savings from the water-heater energy method. For ease of comparisons with REMP results, we will assume $325 \mathrm{kWh}$ annual savings from showerhead savings only for the Puget households.

The REMP field study retrofit $90 \%$ of the showerheads with efficient models. The Puget water-metering study retrofit $67 \%$. Accordingly, it would be reasonable to assume that the savings achieved would be proportionately (35\%) greater with whole-house retrofit. If the Puget watermetering study results are extrapolated to reflect whole-house retrofit, the savings increase to $439 \mathrm{kWh}$.

The Puget efficient showerheads reduced full-force water flows $1.1 \mathrm{gpm}$, compared to the 1.4 gpm reduction measured in the REMP field study. Again, it is reasonable to assume savings in the Puget water-metering study would be increased proportionately if they achieved flow-rate reductions comparable to the REMP sites. Adjusting for the difference in flow rates increases the Puget showerhead-only savings from $439 \mathrm{kWh}$ to $558 \mathrm{kWh}$, which is similar to the $515 \mathrm{kWh}$ savings found in the REMP study.

The remaining two differences in the studies are the fraction of homes on wells $(24 \%$ versus $20 \%$ ) and the number of persons per household (3.4 versus 2.8). For purposes of comparison with the REMP results, these can be ignored. The slightly greater fraction of wells among the Puget sites would be expected to decrease savings compared to the REMP sites, however, the somewhat higher average water pressure for the Puget sample (62.9 pounds per square inch [psi] versus 60.5 psi for the REMP sample) may offset this effect. Moreover, the use of the Puget pre-flow rate data in this comparison already includes the effect of differences in local water pressure, so further adjustments may lead to double counting.

The higher number of occupants in the Puget sample could be expected to increase hot-water use. However, there does not appear to be a strong correlation between persons per household and water-heating savings in either the Puget water-metering or the REMP field study. We are forced to speculate about the reasons for this in the absence of better data or further research on this topic. People tend to follow a similar bathing routine, typically before or after returning from work or school. Mornings are favored (Appendix I). In large households this may result in a peak-load problem, both in terms of access to a bathroom and available hot-water reserves. The larger the household, the greater the potential problem. At some point, the limited amount of hot water stored in the water heater effectively may limit the amount of hot water that can be used, and hence, the amount of waterheating energy that can be saved.

The hot-water storage capacity limit is determined by how much hot water is used and by how long it takes for the water heater to heat the cold water that replaces it. A typical 52-gallon electric water heater can store enough hot water for 3.7 showers of 10 minutes in length at 1.4 gallons of hot water per minute at a 2.0 gpm rate of flow. This is a typical shower in terms of length and ratio of hot to cold water. However, as the hot water is withdrawn from the tank, the incoming cold water reduces 
the temperature of the hot water remaining in the tank. To maintain a shower at the same temperature the proportion of hot water must increase, and this depletes the hot-water supply at an increasing rate. A typical electric water heater can heat roughly 20 gallons of cold water an hour. As a result, the number of showers that can be taken in a one-hour period is likely to be far less than the 3.7 that are theoretically possible. It is likely that two showers could be taken with comfort, but three is probably a stretch. Consequently, the increase in number of occupants may not affect showering hot-water use or savings unless bathing hours are spread throughout the day or unless water-heater capacity is larger than average.

The age composition of the household may also influence savings. Larger households may include younger children who are not regular shower users. This influence was not examined in the Puget water-metering study and results from the REMP field study.

\section{D.5 Summary and Conclusions}

The Puget water-metering study results provide valuable data on water use and savings potential. Because of the short study period, some adjustments need to be made to study data to produce annual estimates of use and savings. The range of the resulting estimates, from $299 \mathrm{kWh}$ annually to 391 $\mathrm{kWh}$ annually, reflects different methods and underlying dynamics in the data. After reviewing the data we selected an estimate of $325 \mathrm{kWh}$ annual savings for efficient showerheads only.

Comparing the Puget water-metering results with savings from the REMP study is complicated due to differences in the research design and samples. Nevertheless, comparable results are obtained when reasonable adjustments are made to the Puget water-metering savings to facilitate direct comparison of estimates from the two studies ( $558 \mathrm{kWh}$ annual savings for the Puget water-metering study versus $515 \mathrm{kWh}$ savings for the REMP field study). 


\section{D.6 References}

Bailey, S.A., and W. M. Warwick. 1993. Persistence of Energy-Efficient Showerheads: Field Study Results. PNL-8432, prepared for the Bonneville Power Administration under a Related Services Agreement with the U. S. Department of Energy by Pacific Northwest Laboratory, Richland, Washington.

Manclark, S. 1991. "Does 'Low-Flow' Still Mean Low Satisfaction?" Home Energy, July/August.

Proctor, J., S. Gavelis, and S. Miller. 1994. "Savings and Showers: It's All in the Head." Home Energy, July/August.

SBW Consulting, Inc., and NCAT-Development Corporation. 1994. Energy Efficient Showerhead and Faucet Aerator Metering Study. 9414, prepared by SBW Consulting, Inc. with WCATDevelopment Corporation for Puget Sound Power and Light, Bellevue, Washington.

Warwick, W. M. 1993. Energy Savings from Energy-Efficient Showerheads: REMP Study Results, Proposed Evaluation Algorithm, and Program Design Implications. PNL 8763, prepared for the Bonneville Power Administration under a Related Services Agreement with the U. S. Department of Energy by Pacific Northwest Laboratory, Richland, Washington. 


\section{Appendix E}

\section{Regional End-Use Metering Program}




\section{Appendix E Regional End-Use Metering Program}

\section{E.1 Introduction}

The results presented in this Appendix are drawn from analysis of Bonneville Power Administration (Bonneville)'s Regional End-Use Metering Program (REMP) field study conducted by the Pacific Northwest Laboratory (PNL) as described in Appendix B (Warwick and Bailey 1993; Warwick 1993).

\section{E.2 Participation and Measure Installation Results}

The savings from retrofit programs depend on participation in the program and installation and performance of measures. The success of a program is usually based on the number of sites that are involved at various stages of a program. Field study results from each of these perspectives are presented in the following sections and summarized in Table E.1.

Table E.1 Site (Program) and Measure Results

\begin{tabular}{|c|c|c|c|c|}
\hline & \multicolumn{2}{|c|}{$\begin{array}{l}\text { Number of Actual vs. Potential } \\
\text { Sites }\end{array}$} & \multicolumn{2}{|c|}{$\begin{array}{c}\text { Number of Actual vs. Potential } \\
\text { Measures }\end{array}$} \\
\hline & Number & Fraction & Number & Fraction \\
\hline Participation Penetration & $111 / 150$ & 74 & $158 / 240$ & 66 \\
\hline All Sites & $98 / 150$ & 65 & $158 / 240$ & 66 \\
\hline Participants onlya & $98 / 111$ & 88 & $158 / 161$ & 98 \\
\hline \multicolumn{5}{|l|}{ Persistence in First Year ${ }^{b}$} \\
\hline Actual Returns & 6, or $92 / 98$ & 94 & 9, or $149 / 158$ & 94 \\
\hline Survey Results ${ }^{c}$ & 6, or $30 / 36$ & 83 & c & c \\
\hline \multicolumn{5}{|c|}{$\begin{array}{l}\text { Participants are defined here on the basis of willingness to participate in the program. } \\
\text { Some of these were later unwilling or unable to adopt measures. } \\
\text { b Persistence is based on actual participants (those who had measures installed). } \\
\text { c Not all subjects responded to the survey (only } 36 \text { of the } 98 \text { responded). Further, the survey } \\
\text { responses did not specify how many measures were replaced, so no measure-based estimate is } \\
\text { available. }\end{array}$} \\
\hline
\end{tabular}




\section{E.2.1 Site-or Program-Level Results}

Program participation is the number of households who initially agreed to have showerheads installed. Recruitment letters and follow-up telephone calls were made to 150 REMP sites, and 111 elected to participate, for a $74 \%$ participation rate.

Program penetration is the fraction of households that had showerheads installed compared to the number who could have participated. Ninety-eight of the 150 REMP homes had at least one showerhead replaced, for a $65 \%$ penetration rate among all households. Alternatively, 98 of the 111 participants installed one or more showerheads for an $88 \%$ penetration rate among interested households.

Program persistence is the fraction of initial participants who had showerheads installed who still have at least one in place. Persistence was measured two ways. First, a survey was administered after showerheads had been in place about 8 months. Thirty out of 36 responses indicated no showerheads had been replaced, for a persistence rate of $83 \%$. If the six sites who claim to have removed showerheads are the only sites who did so, persistence in the entire sample increases to $93 \%$ at eight months. Persistence was also calculated based on the actual rate of return of original showerheads by PNL staff, because survey responses are not always reliable. At the end of the REMP study, 15 months after retrofit, 92 of the 98 homes had not asked PNL for their showerheads back, for a 94\% program persistence rate.

\section{E.2.2 Measure Results}

Homes can have multiple showers. As a result, participation, penetration, and persistence need to be reported based on the number of showers or measures, as well as the number of homes or participants.

A total of 173 showers were identified at the 105 homes PNL visited. Although attempts were made to retrofit all showerheads in each home, this was not possible in all cases. The distribution of showers per home and the number of showerheads retrofit are summarized in Table E.2.

Table E.2. Installations (105 sites)

\begin{tabular}{|c|c|c|c|c|c|c||}
\hline \multirow{2}{*}{$\begin{array}{c}\text { Number of } \\
\text { Showers }\end{array}$} & \multirow{2}{*}{$\begin{array}{c}\text { Number of } \\
\text { Sites }\end{array}$} & \multicolumn{4}{|c|}{$\begin{array}{c}\text { Number of Sites with This Number of } \\
\text { Showerheads Replaced }\end{array}$} & $\begin{array}{c}\text { Total Number of } \\
\text { Showerheads } \\
\text { Replaced }\end{array}$ \\
\cline { 3 - 6 } & & 1 & 2 & 3 & 0 & \\
\hline 1 & 47 & 44 & NA & NA & 3 & 44 \\
\hline 2 & 48 & 3 & 43 & NA & 2 & 89 \\
\hline 3 & 10 & 1 & 0 & 8 & 1 & 25 \\
\hline Total: & 105 sites & & & & & 158 \\
\hline
\end{tabular}


Achievement of conservation potential is based on the number of measures that are installed at various stages of a program.

Measure participation is based on the actual number of showerheads distributed compared to the total number that could be installed. The original 150 potential REMP participants had an estimated 240 showerheads. Of the 240,158 were replaced for an approximate measure participation rate of $66 \%$.

Measure penetration is based on the number of efficient showerheads installed in homes compared to the number that could have been installed. The 98 homes that received showerheads contained 161 showers; 158 showerheads were replaced for a measure penetration of $98 \%$ for the 98 participating homes, and $66 \%$ for the 150 original eligible homes.

Measure persistence is based on the fraction of measures that remain in service compared to the number installed. Survey responses did not identify the number of showerheads that were replaced, so. the only source of data on measure persistence is requested returns. Of the 158 showerheads that were installed in the 98 homes, 149 remained in service after 15 months for a $94 \%$ measure persistence rate.

\section{E.3 Site, Pressure, and Water Flow Results}

The REMP field study examined water pressure and reductions in water-flow rates in two different brands of retrofit showerheads. These rates were compared to flow rates of existing showerheads. Results are described in Sections E.3.1 and E.3.2.

\section{E.3.1 Effects of Site Conditions on Research Design}

The initial field study design specified a single brand and model of showerhead to eliminate the possibility of differences in estimated energy use because of variations from one brand to another. However, water-flow rate analyses early in the research showed water flow rates for existing showerheads that were far below what had been expected. Ultimately, two brands of showerheads were used as replacements. Both were chosen on the basis of previous program experience and customer studies (Katzev 1991). The models selected are used extensively in the Pacific Northwest in utility showerhead retrofit programs.

The first choice was an Ondine brand showerhead. The Ondine model selected had a 2.5 gallon per minute (gpm) design flow rate. Bonneville staff indicated that this flow rate was approximately one-half of the average showerheads' flow rate of 4 to $5 \mathrm{gpm}$ assumed for non-low-flow. However, after completing measurements and installations in 13 homes (22 showerheads), field personnel noted lower-than-expected flow rates before replacement. "Before" flow rates averaged $3.9 \mathrm{gpm}$ instead of between 4 and $5 \mathrm{gpm}$. A flow reduction from $3.9 \mathrm{gpm}$ to $2.5 \mathrm{gpm}(1.4 \mathrm{gpm})$ based on installation of the Ondine showerheads was thought to be too small a change to measure using total water-heating energy data for a sample of roughly 100 homes. 
A second retrofit showerhead, the ETL Spa 2001 brand (rated at $2.0 \mathrm{gpm}$ ), was purchased for use in the study, rather than discontinuing the study and leaving the question of showerhead savings unanswered. The remainder of the retrofits were completed with this model showerhead to decrease flow rates by about $2 \mathrm{gpm}$, which was expected, based on pre-flow data at that point. In total, 22 of the Ondine showerheads were installed in 13 homes; 136 Spa 2001 showerheads were installed in the remaining 85 homes. Flow rate results are presented below for each showerhead model where appropriate.

\section{E.3.2. Water Pressure and Flow Rates}

Water pressure and water flow rates are assumed to be primary determinants of showerhead flow rates. This study found a moderate correlation between water pressure and flow rates (see Figures E.1 and E.2). However, the difference in pre- and post-flow rate was highly correlated to the pre-flow rate. In other words, higher pre-flows resulted in a greater reduction after the efficient showerheads were installed, as expected. Again, water pressure was only moderately correlated with decrease in flow. As can be seen in Tables E.4 and E.5, the variability of the flows was noticeably reduced by the retrofit installations. Tables E.6 and E.7 show Pearson and Spearman correlation coefficients for pressure, flows, and change in flow.

There was no change in flow rate or an increase in flow rate for 23\% (5 of 22) of the Ondine showerheads installed and 13\% (18 of 136) of the Spa showerheads installed. This unexpected increase in flow rate may be due to removal of old showerheads that had been clogged with corrosion or particles that had severely impeded water flow.

A bar graph and table illustrate the distribution of pre-flow rates for the 170 showers where preflow rates were measured (Figure E.1). The table at the bottom of the bar chart provides a basis for estimating potential savings from showerhead retrofits with different flow rates. For example, 81 showerheads had rates of flow of greater than 3.0 gpm; reduced flows would be realized if these showerheads were replaced by showerheads rated at $3.0 \mathrm{gpm}$. A showerhead that is rated at $2 \mathrm{gpm}$ would result in reduced flows for a total of 121 showerheads, or $29 \%$. In other words the potential for savings varies as a function of the flow rate of the retrofit showerhead; the lower the flow rate, the greater the savings potential (see Table E.7). 
Pre-Flow Rate Vs. Pressure

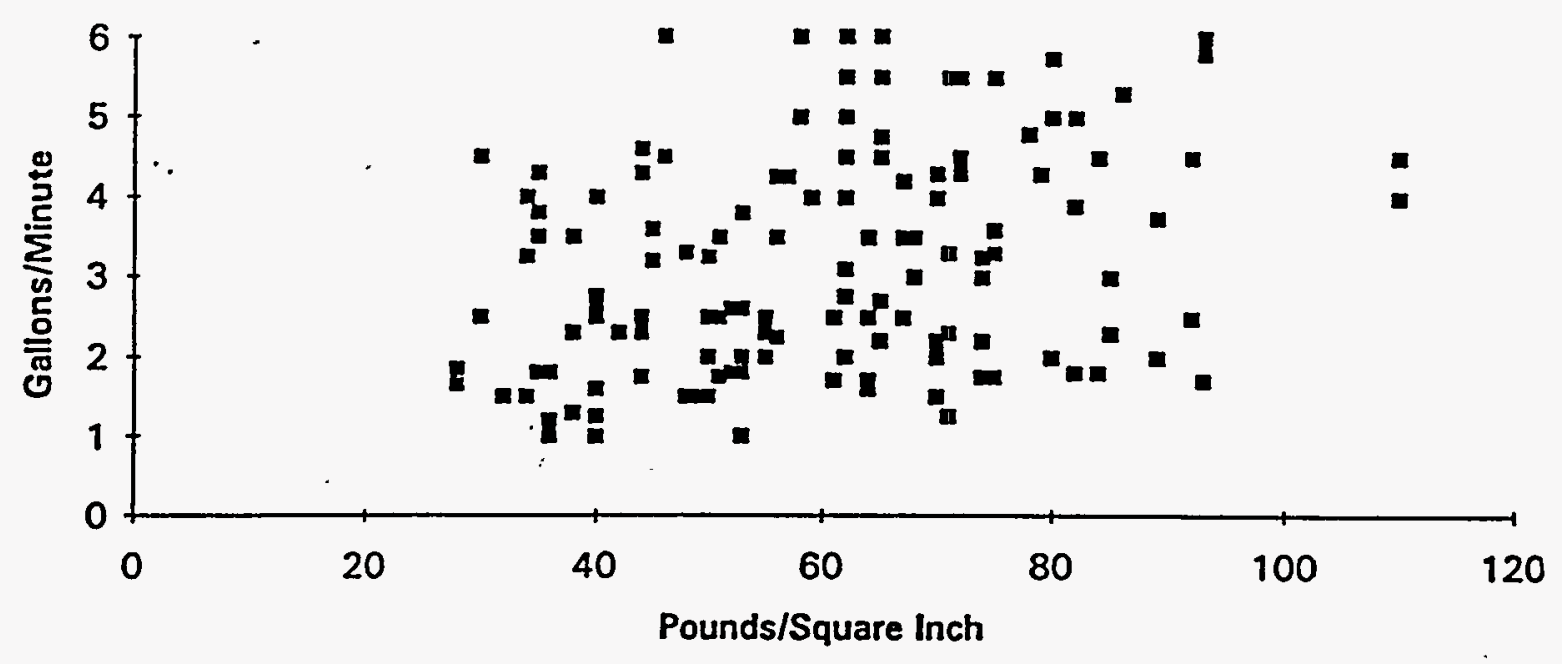

Figure E.1 Pre-Flow Rate versus Pressure

Post-Flow Rate Vs. Pressure

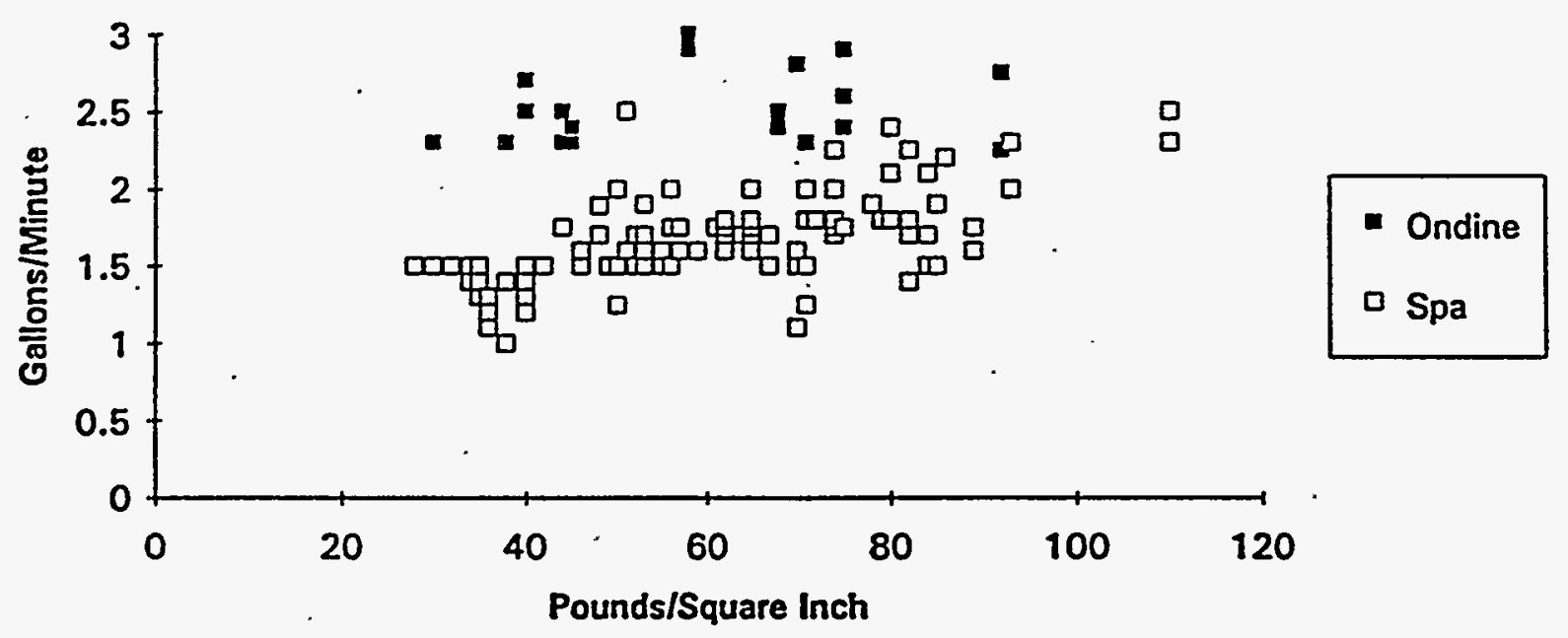

Figure E.2 Post-Flow Rate versus Pressure 
Table E.3 Water Pressure and Pre-and Post-Installation Flow Rate Descriptive Statistics for ETL Spa 2001 Showerhead Installations $(\mathbf{n = 8 0})$

\begin{tabular}{|l|c|c|c|}
\hline & Water Pressure & Pre-Flow & Post-Flow \\
\hline Mean & 60.7 & 3.09 & 1.67 \\
\hline Standard Deviation & 17.9 & 1.34 & 0.26 \\
\hline
\end{tabular}

Table E.4 Water Pressure and Pre-and Post-Installation Flow Rate Descriptive Statistics for Ondine Showerhead Installations $(n=13)$

\begin{tabular}{||c|c|c|c|}
\hline & $\begin{array}{c}\text { Water Pressure } \\
\text { (pounds/square inch) }\end{array}$ & $\begin{array}{c}\text { Pre-flow } \\
\text { (gallons/minute) }\end{array}$ & $\begin{array}{c}\text { Post-Flow } \\
\text { (gallons/minute) }\end{array}$ \\
\hline Mean & 57.7 & 3.89 & 2.55 \\
\hline Standard Deviation & 18.7 & 1.21 & 0.24 \\
\hline
\end{tabular}

Table E.5 Pearson and Spearman Correlation Coefficients for Pressure, Flows, and Change in Flow for ETL Spa 2001 Showerhead Installations $(n=80)$

\begin{tabular}{|l|c|c|c|c||}
\hline & Pressure & Pre-Flow & Post-Flow & Change (pre-post) \\
\hline Pearson Coefficients & 1.00 & & & \\
\hline Pressure & 0.41 & 1.00 & & \\
\hline Pre-Flow & 0.58 & 0.39 & 1.00 & \\
\hline Post-Flow & 0.31 & 0.98 & .20 & 1.00 \\
\hline Change (Post-Pre) & & & & \\
\hline Spearman Coefficients & 1.00 & & & \\
\hline Pressure & 0.42 & 1.00 & & \\
\hline Pre-Flow & 0.59 & 0.38 & 1.00 & .00 \\
\hline Post-Flow & 0.37 & 0.97 & .20 & \\
\hline Change (Post-Pre) &
\end{tabular}


Table E.6 Pearson and Spearman Correlation Coefficients for Pressure, Flows, and Change in Flow for Ondine Showerhead Installations $(n=13)$

\begin{tabular}{|l|c|c|c|c||}
\hline & Pressure & Pre-Flow & Post-Flow & Change (pre-post) \\
\hline Pearson Coefficients & \multicolumn{5}{|l||}{} \\
\hline Pressure & 1.00 & & & \\
\hline Pre-Flow & 0.47 & 1.00 & & \\
\hline Post-Flow & 0.55 & 0.43 & 1.00 & \\
\hline Change (Post-Pre) & 0.38 & 0.98 & .25 & 1.00 \\
\hline Spearman Coefficients & & & & \\
\hline Pressure & 1.00 & & & \\
\hline Pre-Flow & 0.46 & 1.00 & & 1.00 \\
\hline Post-Flow & 0.53 & 0.42 & 1.00 & \\
\hline Change (Post-Pre) & 0.33 & 0.96 & .24 & \\
\hline
\end{tabular}

Another conclusion that can be drawn from Tables E.4 through E. 6 is that existing showerheads have a greater variation in flow rates than retrofit showerheads. The causes for the greater variation in pre-flow rates are unknown, but could be attributed to one or a combination of the following: first, the existing showerheads reflect a variety of showerhead types and flow rates. This heterogeneity by itself would lead to greater variation in flow rates when compared to a single model of showerhead. Second, a relatively large fraction of the existing showerheads had measured flows that would place them in the category of "low-flow" showerheads, although they were not "low-flow" models. It is possible that these showerheads had lower flow rates because they had become fouled by scale, rust, and other debris carried in the water line over time. Finally, 26 of the 173 pre-retrofit showerheads were characterized as "energy efficient" by participants. Seventy of the 173 showerheads were not classified and the participants were "unsure" about the efficiency of 36. Both of these categories could include additional energy-efficient showerheads (see Figure E.3). If this is the case, the low-flow observations may include a large fraction of existing showerheads that are already low-flow models.

After this analysis was conducted, Bonneville tested the flow rates of REMP showerheads in the laboratory. These results are provided in Appendix F. When laboratory flow rates are compared to insite flow rates, at identical water pressure, it appears that showerheads with high flow rates (i.e., over $5.5 \mathrm{gpm}$ ) routinely exceed their field flow rates in laboratory tests. This supports the conclusion that the household plumbing system itself restricts water flows above $3.5 \mathrm{gpm}$ due to seating, rot, and so on. 


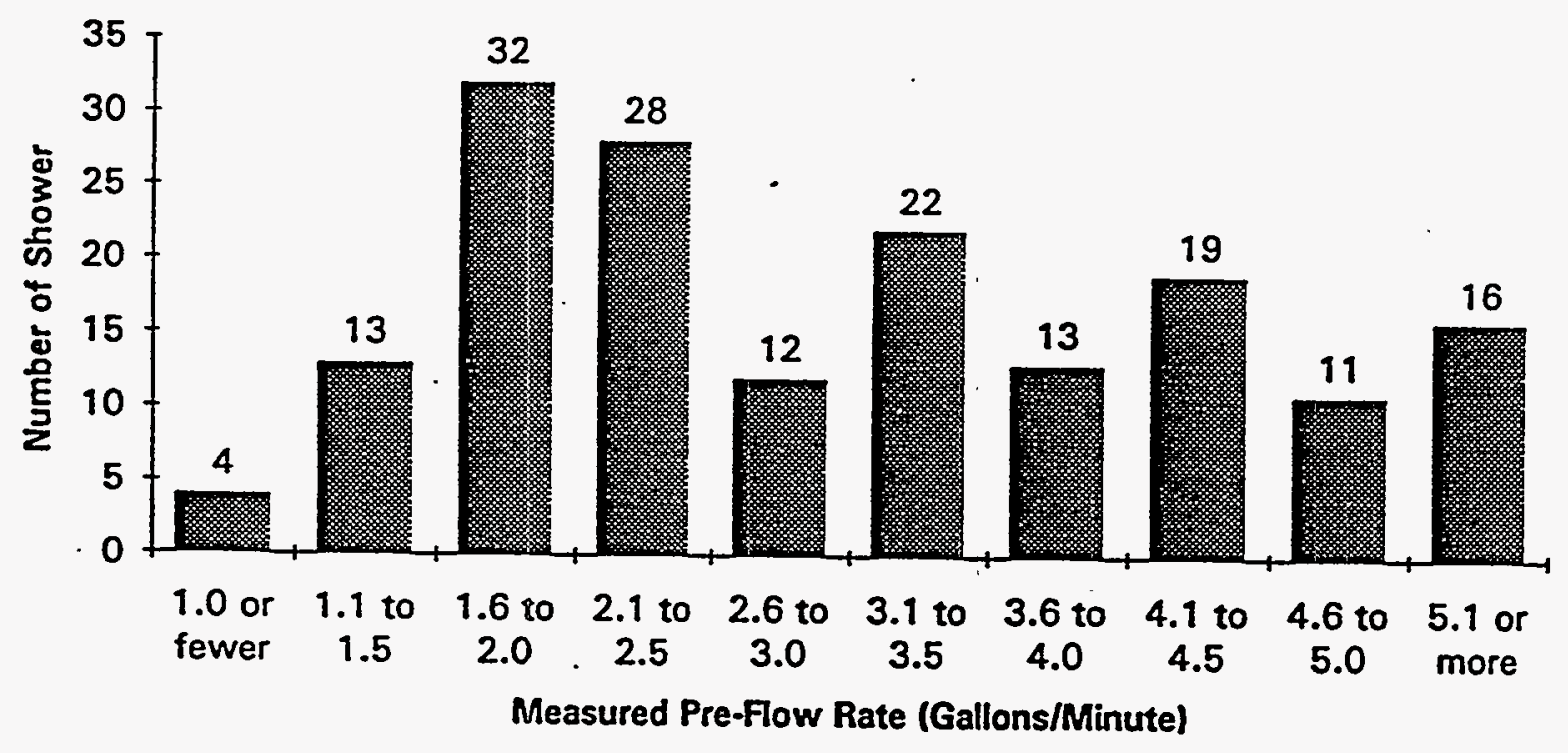

\begin{tabular}{|l|l|l|l|l|l|l|l|l|l|}
\hline \multicolumn{10}{|c|}{ Cumulative Frequency of Showerheads } \\
\hline 170 & 166 & 153 & 121 & 93 & 81 & 59 & 46 & 27 & 16 \\
\hline
\end{tabular}

Figure E.3 Distribution of Measured Pre-Flow Rates

Table E.7 Showerhead Savings Estimates at Various Retrofit Flow Rates

\begin{tabular}{||c|c|c|}
\hline $\begin{array}{c}\text { Design Flow Rate of Retrofit } \\
\text { Showerhead (gpm) }\end{array}$ & $\begin{array}{c}\text { Number of Showerheads with } \\
\text { Savings (base 173) }\end{array}$ & $\begin{array}{c}\text { Fraction of Showerheads } \\
\text { with Savings (173=100\%) }\end{array}$ \\
\hline 3.0 & 81 & $48 \%$ \\
\hline 2.5 & 93 & 55 \\
\hline 2.0 & 121 & 71 \\
\hline 1.5 & 153 & 90 \\
\hline 1.0 & 166 & 98 \\
\hline
\end{tabular}

Whatever the reason, existing showerhead flow rates in this sample vary significantly from the expected rate of 4 to 5 gallons per minute, with a large fraction substantially below that level. This raises questions about energy savings estimates based on assumed average flow rates of between 4 and 
5 gpm. Nevertheless, similar savings could be achieved with showerheads that provide the same flow rate reduction. For example, flow-rate reductions of $1.5 \mathrm{gpm}$ could be achieved from a $2.5 \mathrm{gpm}$ showerhead with average flows of $4 \mathrm{gpm}$. If average flows are actually $3.1 \mathrm{gpm}$, as verified in this study, this $1.5-\mathrm{gpm}$ reduction would require a showerhead that performed at a 1.6-gpm rate.

The mean water pressure for sites in the showerhead installation study was 60.3 psi. The variety of showerheads and consequent range in flow rates confounds correlations of pre-flow rates with water pressure. At least two factors are present. The first is the variation of flow rates for the same model of showerhead across a range of water pressures. The second is the variation of flow rates across various showerhead models. When only one model of showerhead is used, the deviations in flow rate associated with pressure are significantly reduced. This probably indicates that modern showerheads are designed to function satisfactorily across a broad range of water pressures. This conclusion is reinforced when the sample is grouped by low, medium, and high water pressures (Table E.8). (It is also supported by subsequent flow tests concluded by Bonneville and presented in Appendix F). Table E.8 also illustrates that low water pressures are associated with noticeable reductions in both pre- and post-installation flow rates and subsequent water savings. Low water pressures were often associated with households using wells for the water supply (Table E.9).

Table E.8 Water Pressure and Flow Rates for the Total Sample and by Low, Medium, and High Water Pressure Groupings (ETL Spa 2001 sites only)

\begin{tabular}{|c|c|c|c|c|}
\hline Total $(n=80)$ & Water Pressure (psi) & Pre-Flow (gpm) & Post-Flow (gpm) & Difference (gpm) \\
\hline Mean & 60.7 & 3.09 & 1.67 & 1.42 \\
\hline Standard Deviation & 17.9 & 1.34 & 0.26 & 1.26 \\
\hline $\begin{array}{c}\text { Low Pressure } \\
(\mathbf{n}=18)\end{array}$ & Water Pressure (psi) & Pre-Flow (gpm) & Post-Flow (gpm) & Difference (gpm) \\
\hline Mean & 36.6 & 2.33 & 1.41 & 0.92 \\
\hline Standard Deviation & 4.2 & 1.06 & 0.17 & 0.99 \\
\hline $\begin{array}{l}\text { Medium Pressure } \\
(\mathrm{n}=28)\end{array}$ & Water Pressure (psi) & Pre-Flow (gpm) & Post-Flow (gpm) & Difference (gpm) \\
\hline Mean & 57.5 & 3.10 & 1.70 & 1.40 \\
\hline Standard Deviaton & 6.4 & 1.34 & 0.20 & 1.35 \\
\hline $\begin{array}{l}\text { High Pressure } \\
\qquad(n=28)\end{array}$ & Water Pressure (psi) & Pre-Flow (gpm) & Post-Flow (gpm) & Difference (gpm) \\
\hline Mean & 80.0 & 3.56 & 1.80 & 1.76 \\
\hline Standard Deviation & 9.4 & 1.32 & 0.28 & 1.24 \\
\hline
\end{tabular}


Table E.9 Water Pressure for Sites. With and Without a Well

\begin{tabular}{||l|c|c|c|}
\hline & Number of Sites & Average Water Pressure (psi) & Standard Deviation \\
\hline All Sites $^{(a)}$ & 96 & 60.50 & 17.72 \\
\hline No Well & 77 & 66.08 & 14.98 \\
\hline With Well & 19 & 37.89 & 6.08 \\
\hline
\end{tabular}

(a) Water source was not asked of all participants. These figures were constructed from other sources (Table B.2 in Appendix B) for a total of 96 sites.

\section{E.3.3 Projecting Savings from Flow Rates}

Using the results from this study as a basis for projecting savings potential provides a range of results depending on the assumptions made regarding the flow rate of the retrofit showerhead and the source of domestic water (well or no well). Savings potential varies directly with water pressure, because lower pressures result in lower initial flow rates and thus less savings potential (Table E.10). Although, this range of estimates reflects the dynamics of household hydraulics, it does not include behavioral dynamics and is thus a "best case" estimate. The most reliable estimates of savings are derived from longitudinal studies of water and/or energy use before and after showerhead retrofits, so that household plumbing and behavioral effects are included.

Table E.10 Projected Savings for Representative Showerheads and Water Pressures

\begin{tabular}{||l|c|c|c|c|c||}
\hline Assumed Flow Rate & $\begin{array}{c}\text { Water Pressure } \\
\text { (psi) }\end{array}$ & $\begin{array}{c}\text { Pre-flow } \\
(\mathrm{gpm})\end{array}$ & $\begin{array}{c}\text { Post-flow } \\
(\mathrm{gpm})\end{array}$ & $\begin{array}{c}\text { Delta } \\
\text { (gpm) }\end{array}$ & $\begin{array}{c}\text { Delta } \\
(\%)\end{array}$ \\
\hline 2.5 gpm showerhead & 36.6 & 2.3 & 2.1 & .2 & 9 \\
\hline 2.5 gpm showerhead & 67.7 & 3.3 & 2.5 & .7 & 21 \\
\hline 2.0 gpm showerhead & 36.6 & 2.3 & 2.0 & .3 & 13 \\
\hline 2.0 gpm showerhead & 67.7 & 3.3 & 2.0 & 1.3 & 39 \\
\hline
\end{tabular}

\section{E.4 Energy Savings Estimates}

Hot-water energy savings were analyzed in both the test group (sites where showerheads were replaced) and the comparison group (non-participating sites). Sections E.4.2.1 through E.4.2.4 describe the assumptions and tests involved in these analyses and summarize the savings for each group. Pre-retrofit and post-retrofit differences were compared between the two populations taking into account behavioral factors due to a drought-induced crisis. 


\section{E.4.1 Data Analysis Overview}

A variety of approaches were used to estimate energy savings from the REMP sites. Of the 105 sites recruited in the study, only 91 could be used for all of the energy savings analyses because some of the 105 sites had non-electric water heaters or critical missing data. At the 91 sites, 139 showerheads were replaced. These sites are called test sites in this report. Initially, 150 homes were contacted to participate in this study (Appendix B). The occupants of some of the homes refused to participate, although energy use data continued to be collected at these sites as part of the ongoing REMP field study. Eventually, this data was used in this study to compare with the energy savings among study participants. These non-participants are referred to as the "comparison." or "control" group in this report.

The principal approach used for this study treated the data from each site in matched pairs. This contrasts with the more common comparison of means for two populations. Statistics that make use of the matched pair approach account for some of the underlying variability in the data and produce more efficient results, which is important in this study where the sample size is restricted. This approach was applied to various data aggregations (test or control) as well as to data specific to the hot water heater and to data for the total household (called "billing" data in this report). Billing data includes hot water energy use as well as all other electricity uses (except temperature-sensitive heating and cooling uses).

End-use-metered data for hot-water heating is specific to the hot-water-saving measures being studied. Nonetheless, it includes all hot-water use, not just use for showering. As a result, our estimates of differences in use include all changes in hot-water use. Some of these may not be directly attributable to conservation devices, leading to an inaccurate estimation of showerhead savings. Two alternative analysis approaches were taken in an effort to address shower energy use and savings more specifically. These were exploratory analyses, but provided useful confirmation of our primary results. Further exploratory analyses were undertaken to determine the effects of other factors on hot water use and savings. These analyses are discussed in Section E.4.2.

\section{E.4.2 Water-Heater Energy Savings Analysis}

This section addresses questions concerning the comparisons of the pre- and post-retrofit data obtained for the houses in the control and test sites. Statistical tests are used to determine possible changes regarding the mean response for each population to detect any savings in the mean usage when comparing the post-retrofit period data. 


\section{E.4.2.1 Test Site Summary Results}

This section provides summary statistics for the sub-population of homes in the test group. These homes are characterized in terms of savings in kilowatt hours (kWh) as shown in Table E.11.

Table E.11 Summary Statistics for Test Site Homes

\begin{tabular}{|c|r|r|r|}
\hline \multirow{2}{*}{ Statistic } & \multicolumn{3}{|c|}{ Energy Use (kWh) } \\
\cline { 2 - 4 } & \multicolumn{1}{|c|}{ Pre } & \multicolumn{1}{c|}{ Post } & Post-Pre \\
\hline \hline Mean & 4402.80 & 3887.59 & -515.48 \\
\hline Standard Deviation & 1832.49 & 1790.49 & 588.89 \\
\hline Count & 87.00 & 85.00 & 85.00 \\
\hline Minimum & 1018.84 & 362.45 & -2116.58 \\
\hline $25 \%$ & 2912.47 & 2508.90 & -880.80 \\
\hline $50 \%$ & 4206.88 & 3665.40 & -448.97 \\
\hline $75 \%$ & 5485.95 & 5128.46 & -85.84 \\
\hline Maximum & 9253.54 & 8791.32 & 710.08 \\
\hline Range & 8234.70 & 8428.87 & 2826.67 \\
\hline Skewness & 0.38 & 0.45 & -0.68 \\
\hline Kurtosis & -0.28 & -0.39 & -0.09 \\
\hline
\end{tabular}

To determine if there is a savings in energy, the post-retrofit period data were compared to the preretrofit period data. Since the data from the pre- and post-retrofit periods come from the same population of homes, we say that the data are paired and use this to account for some of the variability when designing our test statistic. Graphically, we may view the two populations A and B (where A is the pre-retrofit period data from the control homes and B is the post-retrofit period data from the same homes) in side-by-side box and whisker plots as in Figure E.4. Another graphical representation of the differences appears in Figure E.5 where a grid has been added to the plot along with the line depicting $100 \%$ agreement with pre-retrofit period and post-retrofit period data. The results fluctuate around this line. Note that if most of the observations are below the line, that means most homes had a decrease in energy consumption while if most observations are above the reference line then most homes had an increase in energy consumption. 


\section{E.4.2.2 Assumptions and Tests}

In the sample population of test sites, hot-water usage data were collected from a population of homes for each hour of each day for a period of one year prior to the installation of the new showerhead and one year after the new showerhead was installed.

An initial investigation should focus on the test site group alone before comparing this group to the control population. We want to look at the estimation of $m_{D}$ (the mean difference for pre- and postretrofit periods) where we have matched pairs. The assumptions that go into the test for detecting a difference in the means between the pre-retrofit data and the post-retrofit data are as follows:

- The sample paired observations are randomly selected from the target population of paired values.

- The population of paired differences is normally distributed.

The first assumption has been met according to the criteria used to set up the data collection scheme. The second assumption may be verified by looking at a QQ-plot of the data. If the differences come from a normal distribution, then the plot should appear as a straight line along the diagonal. Figures E.6 and E.7, show the QQ-plots of the pre-retrofit period and post-retrofit period data from the test group. These figures show a tight fit; thus, we have no reason to reject the assumptions of normality.

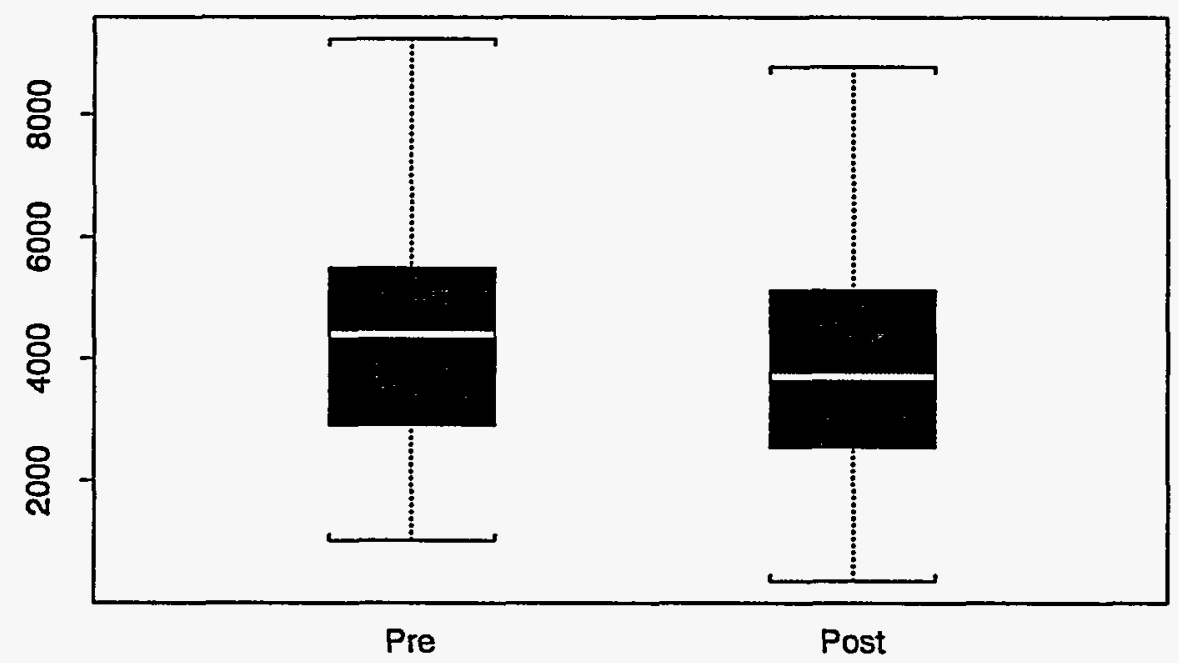

Figure E.4 Side-by-Side Box and Whisker Plots for the Pre-Retrofit Period and Post-Retrofit Period Data for Homes in the Test Population 


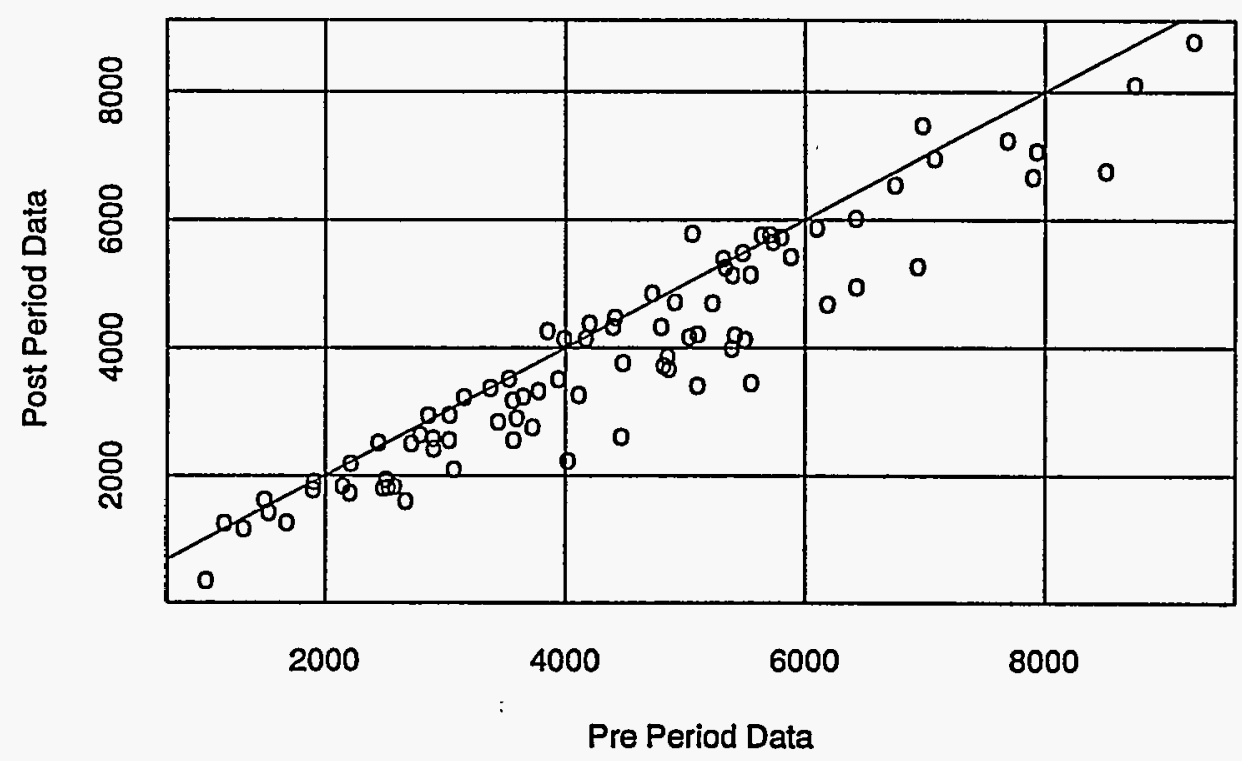

Figure E.5 Pre-Retrofit Period and Post-Retrofit Period Data for Homes in the Test Population (solid line indicates positions at which there is no difference between the two time periods)

Since our data satisfies the assumptions of the test, we can proceed under the hypotheses:

$$
H_{0}: m_{D}=0
$$

(There is no difference between the pre-retrofit and post-retrofit means).

$$
H_{1}: m_{D}>0
$$

(The post-retrofit mean usage is less than the pre-retrofit mean usage).

The associated test statistic to be computed is given by

$$
T=\frac{\mu_{\Delta}}{s_{d} / \sqrt{n}}=\frac{515.48}{588.89 / \sqrt{85}}=8.07
$$


where this implies a p-value less than 0.0001 (less than any level of significance commonly used in practice). Numeric values for this equation came from Table E.11.

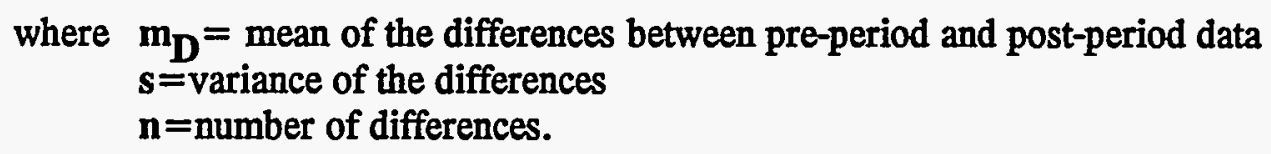

This test statistic will be compared to a value obtained from the Student's $t$ - distribution at the upper $\alpha$ percentile. The value of $\alpha$ determines the level of significance of the test. A typical value for $\alpha$ is .05 , though others are sometimes used. We may also calculate the associated p-value of our test statistic $\mathrm{T}$ and compare that to $\alpha$. If the $\mathrm{p}$-value of $\mathrm{T}$ is less than $\alpha$, then we reject $\mathrm{H}_{0}$ and conclude that the post-retrofit mean usage is less than the pre-retrofit mean usage. Note that the numbers presented here are for the data in terms of $\mathrm{kWh}$. (This approach also applies to the test and control billing and end-use data.)

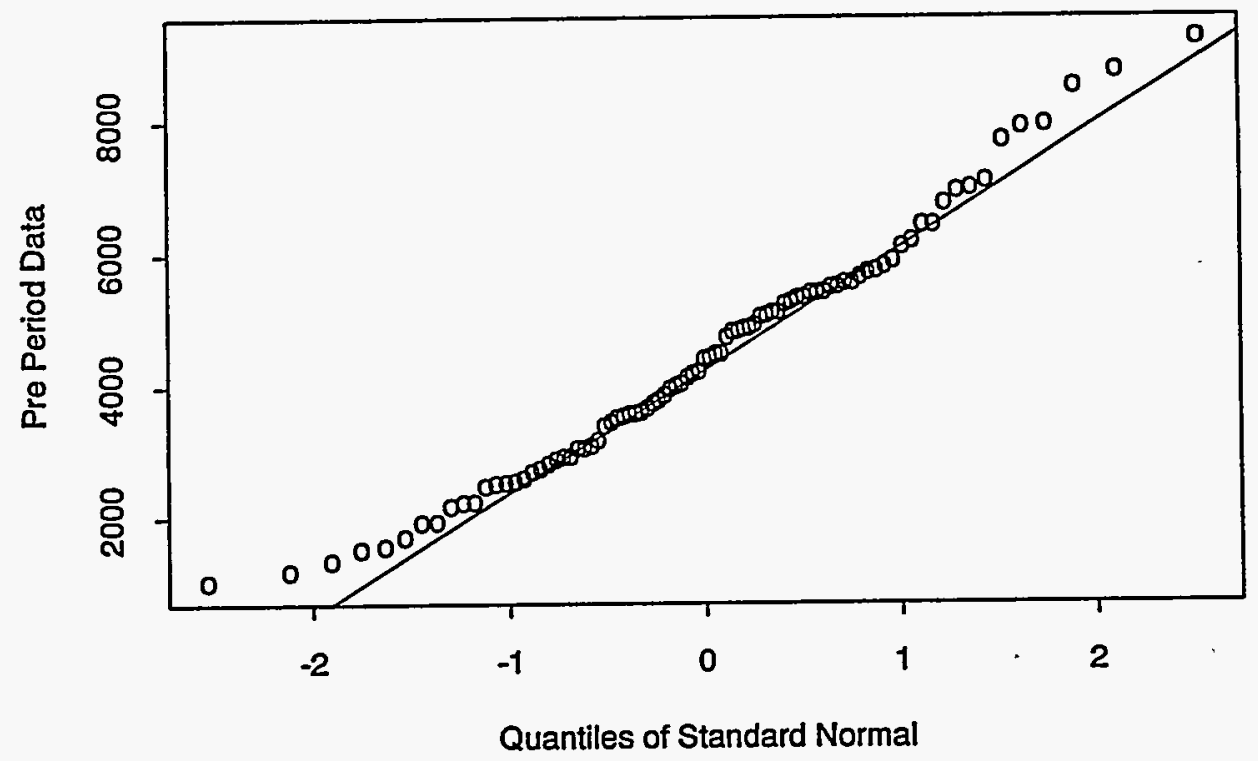

Figure E.6 QQ-Plot for the Pre-Retrofit Period Data for the Test Population 


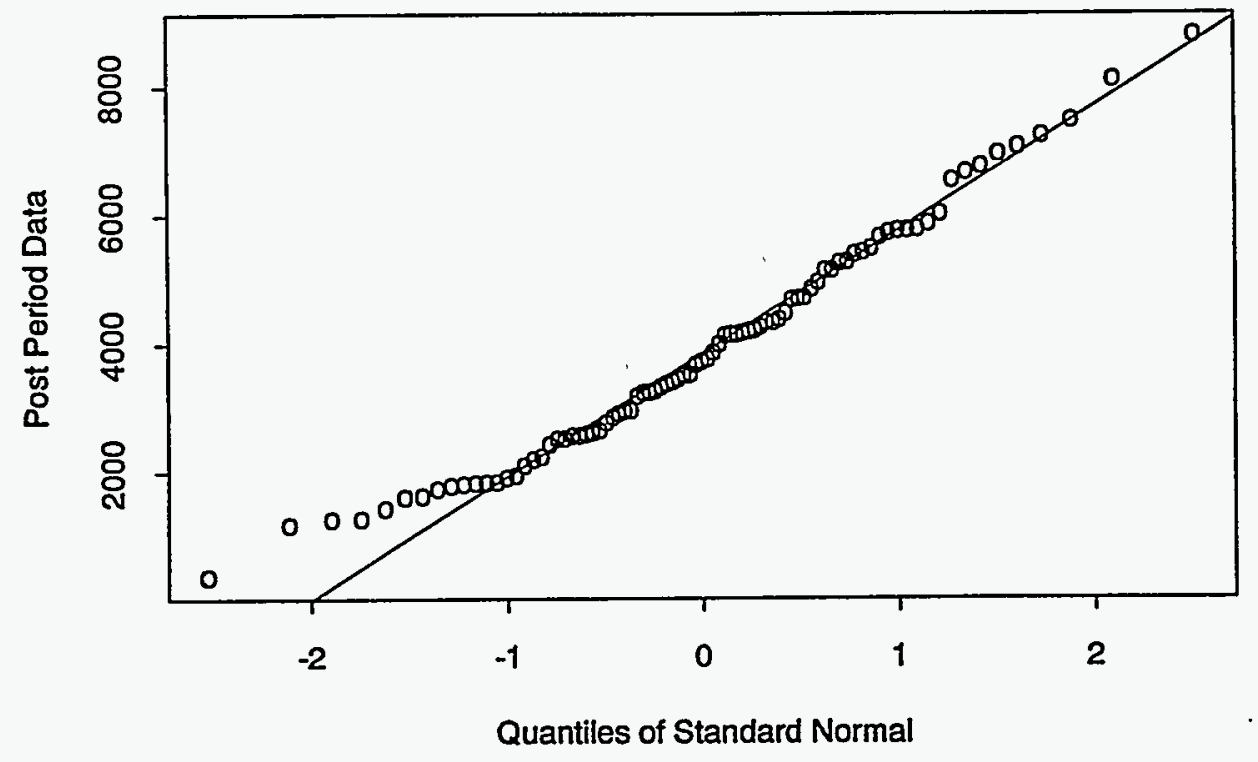

Figure E.7 QQ-Plot for the Post-Retrofit Period Data for the Test Population

Now, the $t$ distribution yields 1.66 for a level of significance of .05 . Equivalently, we observe that the p-value of the test statistic is less than a. Hence our conclusion is to reject the null hypothesis and conclude that the post-retrofit mean usage is less than the pre-retrofit mean usage for the population that installed the energy-saving showerheads. In the preceding paragraph we may compare $\mathrm{T}$ to our test statistic (8.07) calculated earlier to see if it is bigger than the Student's t-value of 1.66; or, we may see if the p-value of our test statistic $(<.0001)$ is less than .06 .

Another way to examine this difference is with (one-sided) confidence intervals. Table E.12 presents two confidence intervals derived for the paired differences and Figure E.8 also shows that the confidence intervals are different from zero.

The results from this analysis provide an estimated savings of $515.48 \mathrm{kWh}$ for the first year. These savings represent total, or "gross," impacts associated with participation in the study and presumably resulting from the measures installed. Ideally, the measurement of gross impacts can specifically exclude effects that are not directly attributable to the specific measures. However, these non-measure effects are often unknown in advance; hence, this is rarely the case. 
Table E.12 Confidence Limits for Savings from the Test Population

\begin{tabular}{|c|c|}
\hline Confidence Level & One-Sided Lower Limit \\
\hline 0.80 & 461.4559 \\
\hline 0.81 & 459.1164 \\
\hline 0.82 & 456.6986 \\
\hline 0.83 & 454.1933 \\
\hline 0.84 & 451.5898 \\
\hline 0.85 & 448.8757 \\
\hline 0.86 & 446.0357 \\
\hline 0.87 & 443.0517 \\
\hline 0.88 & 439.9012 \\
\hline 0.89 & 436.5562 \\
\hline 0.90 & 432.9810 \\
\hline 0.91 & 429.1291 \\
\hline 0.92 & 424.9384 \\
\hline 0.93 & 420.3226 \\
\hline 0.94 & 415.1573 \\
\hline 0.95 & 409.2523 \\
\hline 0.96 & 402.2945 \\
\hline 0.97 & 393.7090 \\
\hline 0.98 & 382.2373 \\
\hline 0.99 & 364.0052 \\
\hline
\end{tabular}




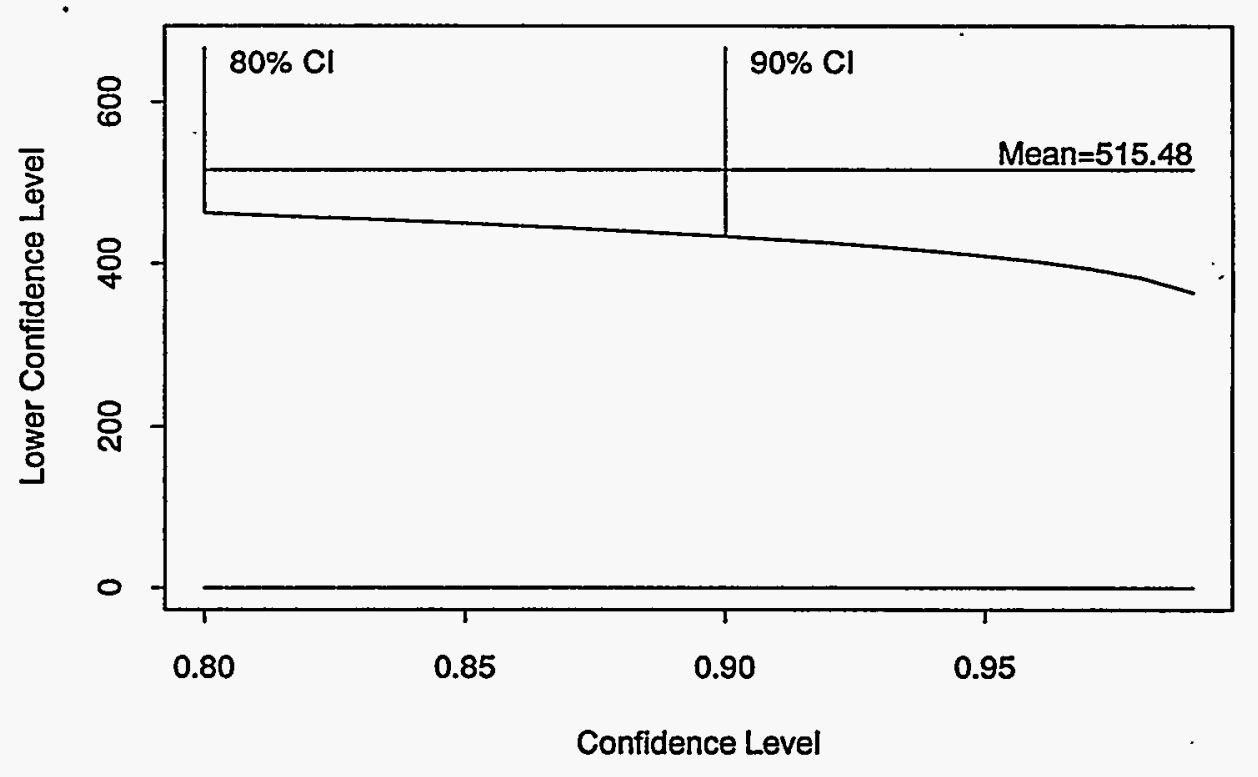

Figure E.8 Confidence Intervals for Paired Differences for the Test Population (comparing pre-retrofit and post-retrofit)

\section{E.4.2.3 Comparison Group Savings}

The inclusion of a comparison group in the research design is typically considered "good" evaluation practice as it provides a basis to estimate "normal" changes in energy use that should not be attributed to efficiency measures. The research design for the REMP savings analysis was restricted to the size of the REMP sample, which did not support a comparison group. This was not deemed to be a significant shortcoming because it was assumed that showerheads are not normally replaced with energy-efficient models, therefore "normal" changes in hot water energy use from this effect would be slight. However, this assumption was challenged shortly after the study began by two factors. The first, and most significant was a drought that was occurring in the region at the time of the study and required water rationing and other limits on water use. The second factor was the adoption of maximum water flow standards for showerheads and other water fixtures by the states of Oregon and Washington and eventually, the federal government. When this became apparent in the spring of 1992 , few options were available to estimate these effects. Because of the drought, aggressive water-conserving actions were adopted by most of the region's major cities and were widely reported via regional newspapers, and television and radio news broadcasts. As a result, few areas were unaware of the issue, which was being treated as a crisis in the media. Consequently, it was decided to assess these impacts by examining the change in hot-water energy use among the roughly 50 REMP sites that did not participate in the showerhead retrofit study. 
A true comparison group is one in which the participants could be expected to have participated in the program that was delivered to the "test" group. This situation does not describe the REMP non-test cases, which specifically rejected solicitations to participate in a test of water-conserving devices. Consequently, they did not constitute a true comparison group. Their bias against participation could be assumed to translate into an aversion toward the voluntary retrofit of water-saving devices. As a result, it was assumed that they would still provide insights into actions people may take in the face of a drought that stop short of the adoption of water-saving devices, in other words, purely behavioral changes. Behavioral actions are likely to have both less impact than the installation of water-savings devices and limited persistence once the crisis passes. All of these issues call into question the usefulness of our assessment of "comparison" group impacts. Nevertheless, we found it worthwhile to pursue the results for their suggestive, if not definitive, value.

\section{E.4.2.4 Summary Results}

This section provides summary statistics for the subpopulation of homes in the control group. These homes are characterized in terms of savings in kilowatt hours as shown in Table E.13.

Table E.13 Summary Statistics for Control Site Homes

\begin{tabular}{|c|c|c|c|}
\hline \multirow{2}{*}{ Statistic } & \multicolumn{3}{|c|}{ Energy Savings (kWh) } \\
\hline & Pre & Post & Post-Pre \\
\hline Mean & 4619.72 & 4468.11 & -152.57 \\
\hline Standard Deviation & 2204.85 & 2187.21 & 1087.61 \\
\hline Count & 57.00 & 56.00 & 56.00 \\
\hline Minimum & 1003.37 & 1273.51 & -4492.69 \\
\hline $25 \%$ & 2720.38 & 2835.38 & -589.50 \\
\hline $50 \%$ & 4211.58 & 4204.16 & -115.56 \\
\hline $75 \%$ & 5702.07 & 5104.45 & 294.02 \\
\hline Maximum & 11497.76 & 11388.35 & 2513.52 \\
\hline Range & 10494.38 & 10114.83 & 7006.22 \\
\hline Skewness & 0.76 & 1.10 & -0.90 \\
\hline Kurtosis & 0.45 & 1.20 & 4.03 \\
\hline
\end{tabular}


We treat the data from this population of homes the same as the data from the test group. Specifically, we are interested in determining if there is a savings in energy when the post-retrofit period data is compared to the pre-retrofit period data. Since the data from the pre- and post-retrofit periods come from the same population of homes, we say that the data are paired and use this to account for some of the variability when designing our test statistic. (That is why the post-pre mean value in Table E.13 is not simply the pre-mean less the post-mean.) Graphically, we may view the two populations $A$ and $B$ (where $A$ is the pre-retrofit period data from the control homes and $B$ is the post-retrofit period data from the same homes) in side-by-side box and whisker plots as in Figure E.9. For the control group, since there is no treatment, we expect that the pre-retrofit period and post-retrofit period data should be very similar. This is depicted in Figure E.10 where a grid has been added to the plot along with the line depicting $100 \%$ agreement with pre-retrofit period and post-retrofit period data. The results we have fluctuate around this line, which indicates no systematic changes over the two periods. In other words, there is no apparent savings in the comparison group.

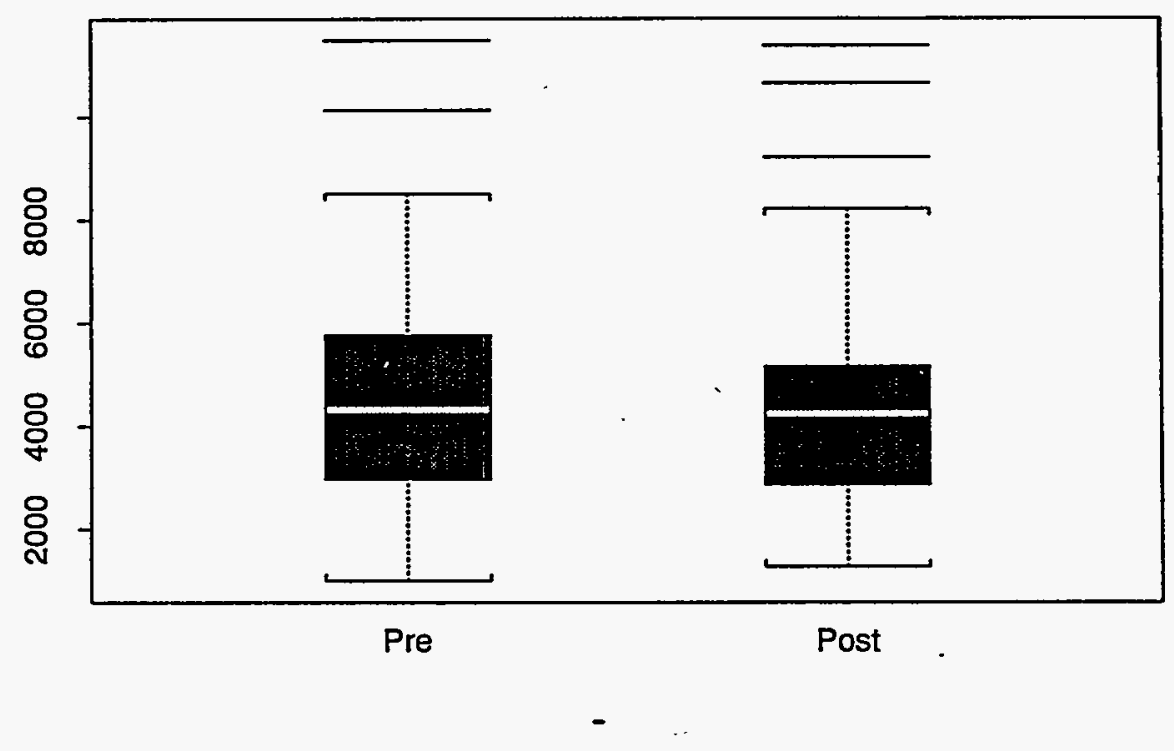

Figure E.9 Side-by-Side Box and Whisker Plots for the Pre-Retrofit Period and Post-Retrofit Period Data for Homes in the Control Population 


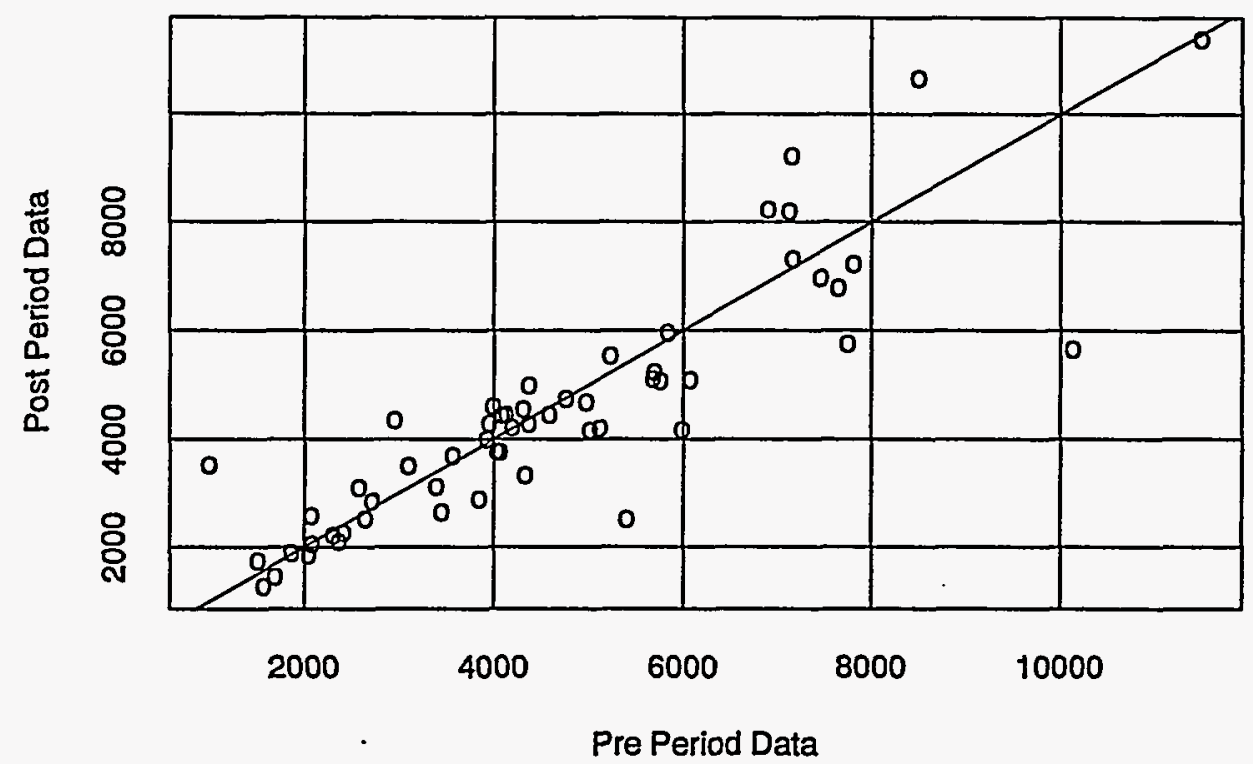

Figure E.10 Pre-Retrofit Period and Post-Retrofit Period Data for Homes in the Control Population (Solid line indicates positions at which there is no difference between the two time periods)

\section{E.4.2.5 Assumptions and Tests}

To compare the pre-retrofit period and post-retrofit period data, we may perform a paired $t$-test. We will want to look at the estimation of $m_{1}-m_{2}$ where we have matched pairs. Within the control group, we have data for pre- and post-retrofit periods. The assumptions that go into the test for detecting a difference in the means between the pre-retrofit data and the post-retrofit data are as follows:

- The sample paired observations are randomly selected from the target population of paired values.

- The population of paired differences is normally distributed.

The first assumption has been met according to the criteria used to set up the data collection scheme. The second assumption may be verified by looking at a QQ-plot of the data. If the differences come from a normal distribution, then the plot should appear as a straight line along the diagonal. Figures E.11 and E.12, show QQ-plots of the pre-retrofit period and post-retrofit period data. Again, these show a tight fit, which leads us to assume a normal distribution. 


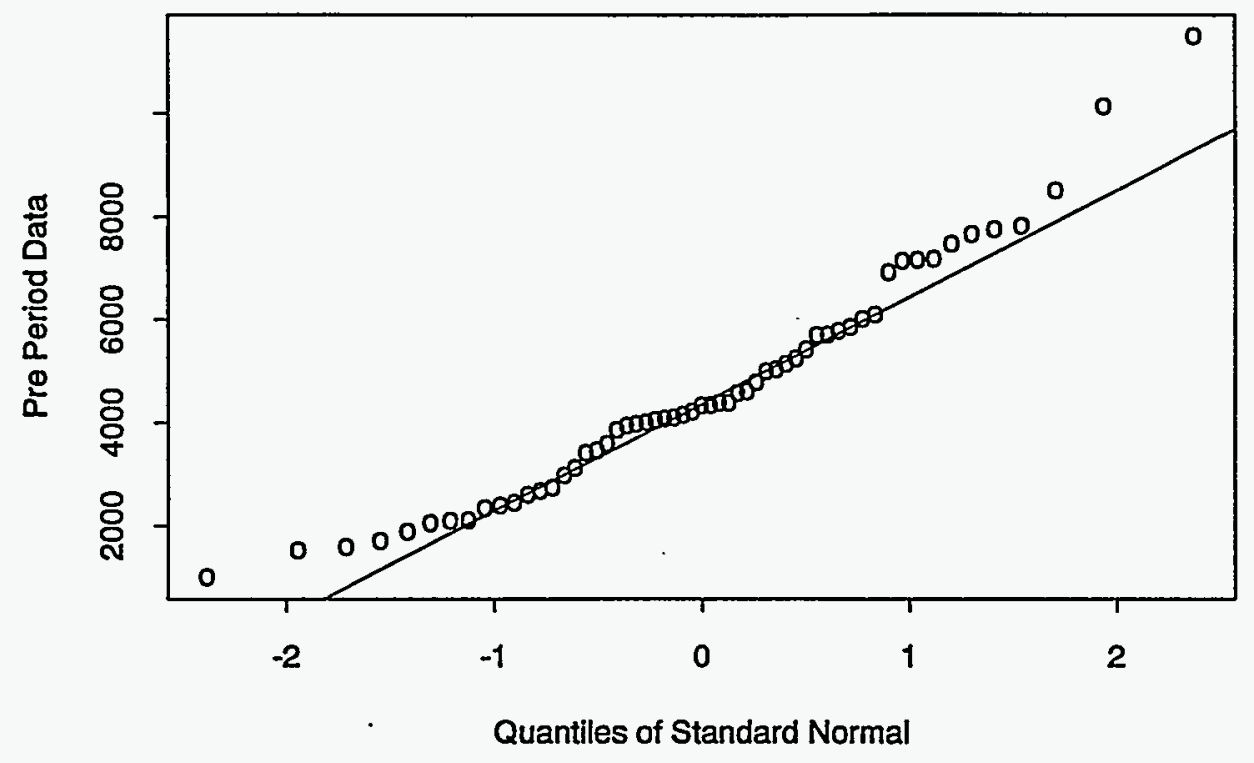

Figure E.11 QQ-Plot for the Pre-Retrofit Period Data for the Control Population

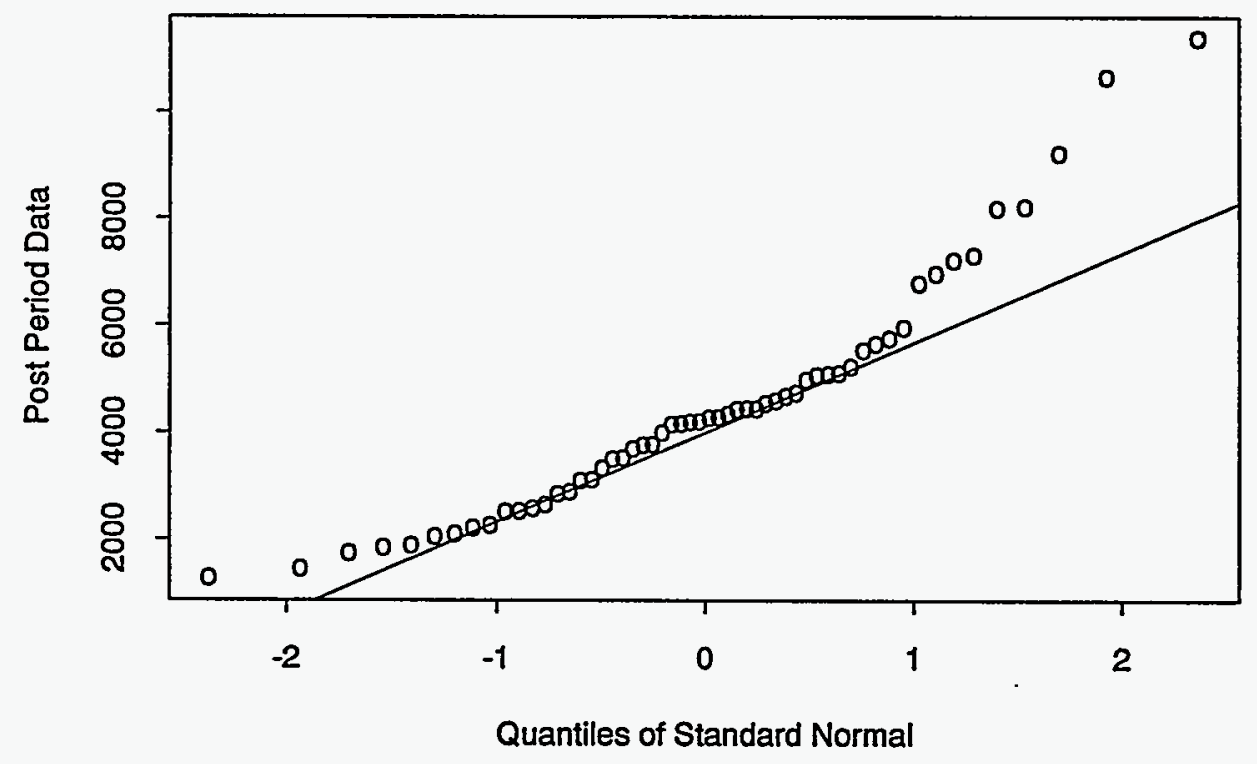

Figure E.12 QQ-Plot for the Post-Retrofit Period Data for the Control Population

\section{E.23}


Since our data satisfies the assumptions of the test, we can proceed under the hypotheses:

$$
H_{0}: m_{D}=0
$$

(There is no difference between the pre-retrofit and post-retrofit means).

$$
H_{1}: m_{D}>0
$$

(The post-retrofit mean usage is less than the pre-retrofit mean usage).

The associated test statistic to be computed is given by

where $\mathbf{m}_{\mathbf{D}}=$ mean of the differences between pre-period and post-period data

$$
T=\frac{\mu_{\Delta}}{\sqrt{s_{d}^{2} / n}}=\frac{152.57}{1087.61 / \sqrt{56}}=8.07
$$

$s=$ variance of the differences

$n=$ number of differences.

Numeric values for this equation come from Table E.13.

The associated p-value for our test statistic is 0.1398 , which is not less than the 0.5 value for a. The Student's t-distribution yields 1.67 at a level of significance of .05 . Equivalently, we observe that the p-value of the test statistic is greater than a. Hence our conclusion is to fail to reject the null hypothesis and conclude that there is not enough evidence to support the hypothesis that the post-retrofit mean energy consumption is less than the pre-retrofit mean energy consumption for the control sites.

Another way to look at this difference is with the aid of (one-sided) confidence intervals. Table E.14 presents two confidence intervals derived for the paired differences. Figure E.13 also shows that the confidence intervals on the average difference are not different from zero. 
Table E.14 Confidence Limits for Savings from the Control Population

\begin{tabular}{|c|c|}
\hline Confidence Level & One-Sided Lower Limit \\
\hline 0.80 & 29.2953 \\
\hline 0.81 & 23.9450 \\
\hline 0.82 & 18.413 \\
\hline 0.83 & 12.6805 \\
\hline 0.84 & 6.7205 \\
\hline 0.85 & 0.5046 \\
\hline 0.86 & -6.0021 \\
\hline 0.87 & -12.8420 \\
\hline 0.88 & -20.0672 \\
\hline 0.89 & -27.742 \\
\hline 0.90 & -35.9517 \\
\hline 0.91 & -44.8019 \\
\hline 0.92 & -54.4384 \\
\hline 0.93 & -65.0618 \\
\hline 0.94 & -76.9626 \\
\hline 0.95 & -90.5846 \\
\hline 0.96 & -106.6598 \\
\hline 0.97 & -126.5348 \\
\hline 0.98 & -153.1637 \\
\hline 0.99 & -195.6717 \\
\hline
\end{tabular}




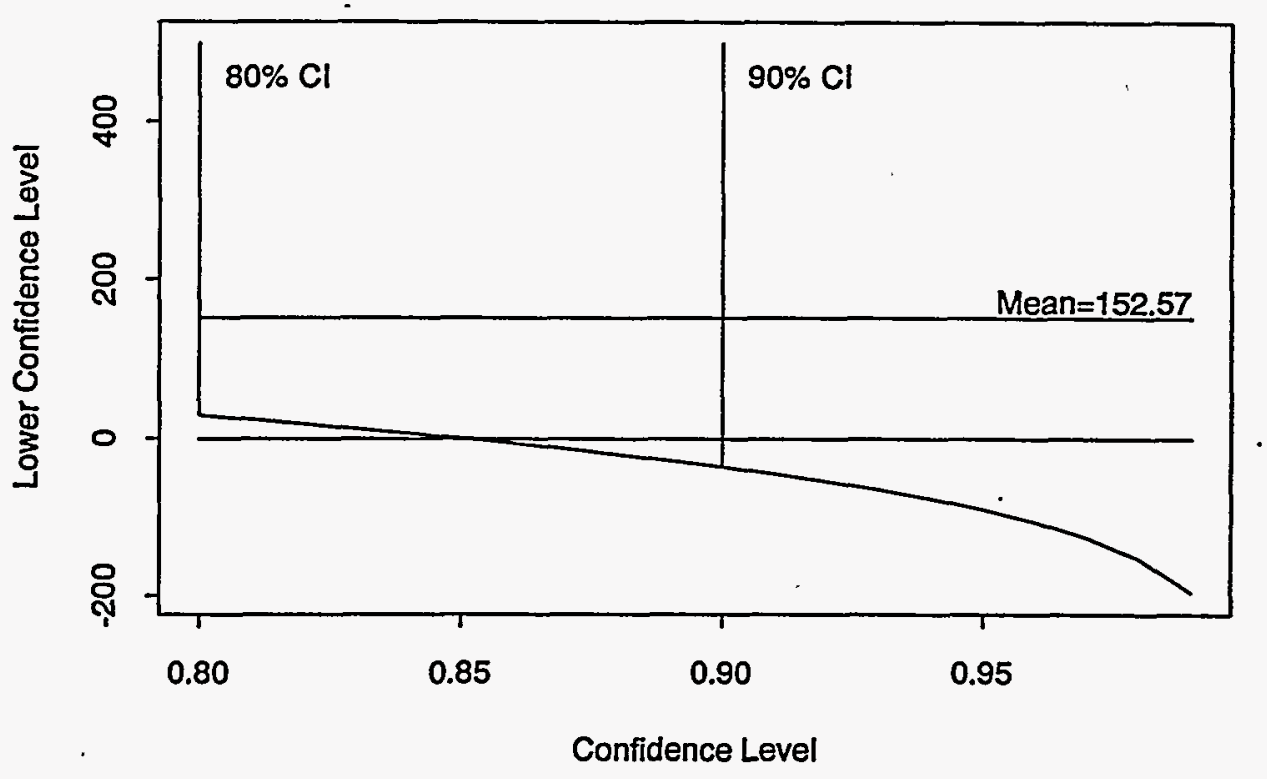

Figure E.13 Confidence Intervals for Paired Differences for the Control Population (comparing pre-retrofit and post-retrofit)

\section{E.4.2.6 Comparing The Test and Comparison Group Populations}

In this final section we compare the populations of differences for the test and control groups. In other words, we wish to consider the differences between the pre-retrofit and post-retrofit data for homes that used the new showerhead to be considered as one group and we wish to consider the differences between pre-retrofit and post-retrofit for homes that did not use the new showerhead as the other group. Our hypotheses of interest are then

$$
H_{0}: m_{1}-m_{2}=0
$$

(The mean hot-water savings for the two populations are identical.)

$$
H_{1}: m_{1}-m_{2}>0
$$

(The mean hot-water savings for the test population is larger than the mean hot water savings for the control group.) 


\section{E.4.2.7 Assumptions and Tests}

To use the standard parametric t-test that is usually employed in this situation, we must first stop and check to see that the assumptions underlying the $t$-test are met by our data. If these assumptions are not met, then performing the t-test is invalid and we must use another approach to investigate the hypotheses. There are the assumptions to be checked:

- The sample sizes are sufficiently large ( $n_{1}$ and $n_{2}$ both larger than about 30$)$.

- The two samples are selected randomly and independently from the target populations.

In this case, we have sample sizes that are larger than $\mathbf{3 0}$ for both of the groups under consideration and the second assumption is a result of the original sampling plan. Therefore, we may apply the standard parametric test. The results for this test are presented in Section E.4.2.8.

\section{E.4.2.8 REMP Showerhead Savings}

$$
\frac{\mu_{1}-\mu_{2}}{\sigma_{\delta}}=\frac{515.48-152.57}{142.88}=2.54
$$

which leads to a p-value equal to 0.0061 (recall that most comparison levels of significance are much greater than this value). So, we see that at a level .05 test, the mean savings in hot-water usage for the test population is larger than the mean savings in hot water usage for the control population. The homes that received the energy-saving showerheads exhibited, on average, a greater overall savings in hot water usage.

Once again, the result may be verified by looking at the confidence intervals in Table E.15 and noting Figure E.14, which graphically depicts these intervals. 
Table E.15 Confidence Limits for Differences in Savings Between the Test and Control Population

\begin{tabular}{|c|c|}
\hline Confidence Level & One-Sided Lower Limit \\
\hline 0.80 & 242.7437 \\
\hline 0.81 & 237.5282 \\
\hline 0.82 & 232.1363 \\
\hline 0.83 & 226.5474 \\
\hline 0.84 & 220.7375 \\
\hline 0.85 & 214.6782 \\
\hline 0.86 & 208.3353 \\
\hline 0.87 & 201.6676 \\
\hline 0.88 & 194.6244 \\
\hline 0.89 & 187.1421 \\
\hline 0.90 & 179.1400 \\
\hline 0.91 & 170.5127 \\
\hline 0.92 & 161.1189 \\
\hline 0.93 & 150.7630 \\
\hline 0.94 & 139.1619 \\
\hline 0.95 & 125.8829 \\
\hline 0.96 & 110.2126 \\
\hline 0.97 & 90.8382 \\
\hline 0.98 & 64.8794 \\
\hline 0.99 & 23.4424 \\
\hline
\end{tabular}




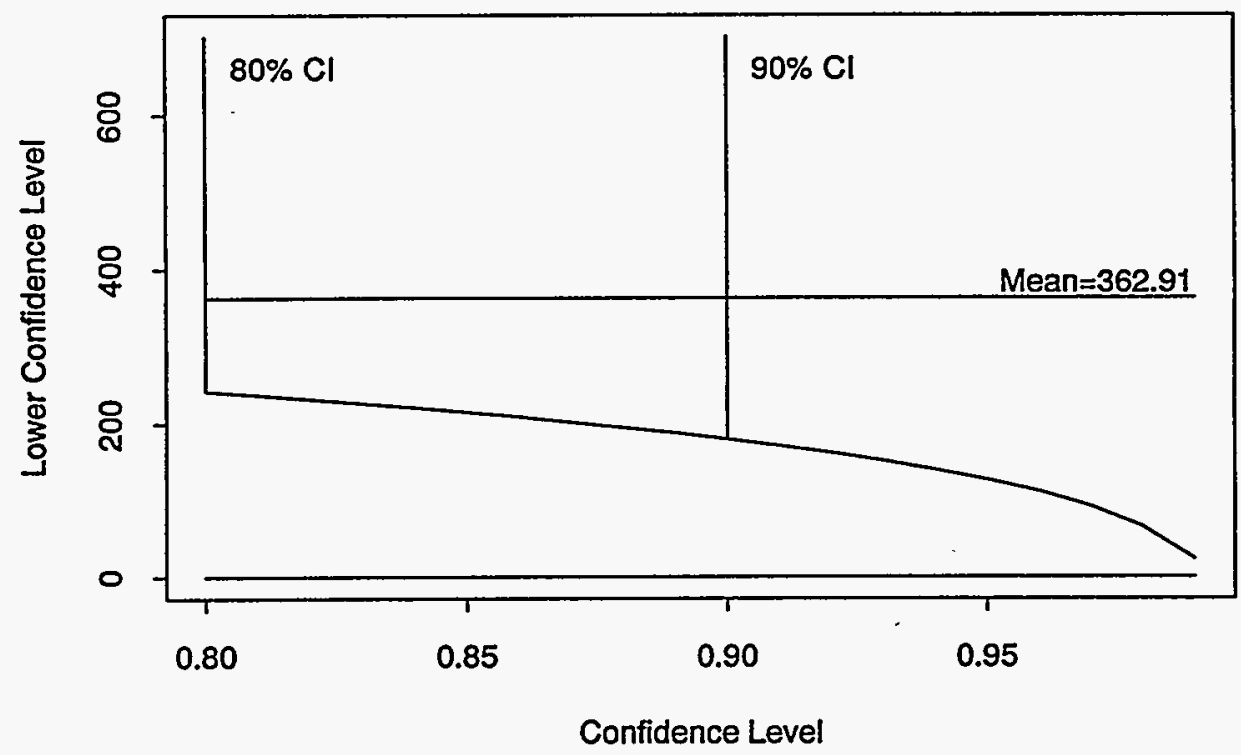

Figure E.14 Confidence Intervals for Differences in Savings for the Test and Control Populations

Although these results do not conclusively verify hot water energy-conserving actions by nonparticipants, the observed difference in means and their direction, along with other data, suggest that there was an effect. This analysis was undertaken using annual data. This level of aggregation tends to obscure effects that may be confined to less than whole-year periods. Qualitative analysis of hourly load shapes, both monthly and annual average, reveals an attenuation of hot-water heating loads during peak-use periods in the post-retrofit period control sample (Appendix I). Narrower peak load periods, especially when the peak loads fall off rapidly, is characteristic of a change in behavior, such as taking shorter showers. It contrasts with structural changes induced by the installation of water-saving devices in the test homes, which reduced energy use on a per-unit-of-water, rather than lapsed-time, basis. Characteristically, this shows up in load shapes as an overall decrease in loads, rather than as narrower peaks.

"Conservation" effects on the control sample load shapes appear to be confined to months early in the year, prior to the peak water-using months of summer (Appendix I, Figures I.6 through I.17). This short-lived effect could be a result of purely behavioral reactions to early warnings about the drought, which lapsed later as the crisis continued despite these sacrifices and as the crisis waxed and waned with each new rainstorm. This is speculation; however, post-hoc analyses of water use by water utilities appears to support modest average per-consumer savings even though all of them could not and did not participate in utility conservation programs. These results suggest that some conservation did occur voluntarily. To acknowledge this effect, and in the absence of better data, we assumed it was 
reasonable to use the observed difference in means for the comparison group as representative of these effects.

Typically, changes in energy use by a comparison group are used in evaluations to adjust gross savings estimates for program-induced, or net impacts. As indicated in the preceding section, the legitimacy of the results from the control group and the meaning of these results is open to interpretation. Even if the results observed are accepted as valid, it is not clear that they should be used to "net out" naturally occurring changes since they were derived during a drought-induced crisis, which is not normal. At best, they should probably only be used for adjusting gross savings for a short period of time, probably just for the first year.

\section{E.4.5 Other Effects}

Unexpected differences in flow rates between the two brands of retrofit showerheads occurred, as well as changes in water-heater efficiency, may account for some of the observed savings. These impacts were specifically evaluated and the results are presented in the following sections.

\section{E.4.5.1 Savings by Showerhead Brand}

Two brands of showerheads were used in the REMP study, one by Ondine rated at $2.5 \mathrm{gpm}$, which was verified in the field, and one by ETL, rated at $2 \mathrm{gpm}$, but performing at $1.7 \mathrm{gpm}$ in the field. This difference in rated and verified flow rates should result in different savings for each showerhead brand. However, the differences observed fail to support this conclusion for a variety of reasons (Table E.16).

Table E.16 Comparison of Savings by Showerhead Brand

\begin{tabular}{|l|c|c|c|c|c|c|c|}
\hline Brand & $\begin{array}{c}\text { No. of Shower- } \\
\text { heads }\end{array}$ & $\begin{array}{c}\text { No. of } \\
\text { Sites }\end{array}$ & $\begin{array}{c}\text { Pre-Flow } \\
(\mathrm{gpm})\end{array}$ & $\begin{array}{c}\text { Post-Flow } \\
(\mathrm{gpm})\end{array}$ & $\begin{array}{c}\text { Flow } \\
\text { Change } \\
(\mathrm{gpm})\end{array}$ & $\begin{array}{c}\text { Gross } \\
\mathbf{k W h} \\
\text { Savings }\end{array}$ & $\begin{array}{c}\text { Net (a) } \\
\text { kWh } \\
\text { Savings }\end{array}$ \\
\hline ETL & 136 & 73 & 3.09 & 1.67 & 1.42 & 511 & 358 \\
\hline Ondine & 22 & 12 & 3.89 & 2.55 & 1.34 & 542 & 389 \\
\hline Overall & 158 & 85 & & & 1.41 & 515 & 363 \\
\hline (a) Estimated control group savings $=153 \mathrm{kWh}$ \\
\hline
\end{tabular}

First, the sample of homes retrofit with the Ondine showerheads was limited (13 sites, 12 of which were used in this analysis). The standard error of the estimated energy savings for this small number of sites is broad enough to include the estimated savings from the ETL sites. In other words, the difference in results for both samples is not statistically significant. Second, energy savings are a function of gross flow rate change, not just the efficiency of the retrofit showerhead. Coincidentally, the preretrofit flow rates at the Ondine sites were higher than at the ETL sites by roughly the same flow rate 
difference as the two brands. In other words, the flow rate for the ETL was $.88 \mathrm{gpm}$ less than that for the Ondine; however, the pre-retrofit flow rates at the Ondine sites were $.8 \mathrm{gpm}$ more than at the ETL sites. These differences offset each other resulting in roughly the same flow rate change $(1.42 \mathrm{gpm}$ versus $1.34 \mathrm{gpm})$.

Oddly enough, the Ondine sites appear to have somewhat greater savings (542 $\mathrm{kWh}$ per year versus $511 \mathrm{kWh}$ per year) despite the fact that they had a slightly lower flow rate change. This difference is not statistically significant, but may have a valid basis. The design of the two showerheads is different, along with their design flow rate. There are two major showerhead designs, aerating and non-aerating. The Ondine model used in this study was a non-aerating showerhead. Although representatives for ETL claim it is not an aerating design, it has some features in common with those designs. There is speculation that the shower stream from aerating showers feels cooler on the skin than that from nonaerating designs. It is possible that the design of the Ondine showerhead produces a shower stream which bathers find satisfactory without having to modify their pre-retrofit behavior. In other words, they may be able to take a shower using their previous shower temperature settings and not altering the length of time they shower. The aerating features of the ETL showerhead, in contrast, may encourage bathers to adjust their normal temperature settings upward. Further, the final flow rates at the ETL sites were almost a gallon less than at the Ondine sites (1.67 versus 2.55$)$. It is possible that when showerhead flows are reduced too much, bathers are forced to take longer showers in order to achieve satisfactory results. As a consequence, the optimum, minimum flow rate may be in the 2-gpm range.

\section{E.4.5.2 Water-Heater Efficiency Changes}

Water heaters generally last 10 to 12 years before they fail. During the study period several water heaters were replaced. This could affect energy savings if more energy-efficient water heaters were installed during the post-retrofit period. Participants were asked if they replaced their water heater in the post-retrofit period. According to survey responses, 1 of the 56 control sites and 10 of the 85 participant sites replaced their water heater. These responses are difficult to verify, so their reliability is unknown. Nevertheless, if these sites are dropped from the analysis, this potential source of error would be eliminated (Table E.17).

Table E.17 Savings for Sites Where Water Heaters Were Not Replaced

\begin{tabular}{|l|c|c|}
\hline & Mean Savings (kWh) & Sample \\
\hline Participants & 491 & 75 \\
\hline Controls & 150 & 55 \\
\hline Net Savings & 341 & NA \\
\hline
\end{tabular}


The differences in savings that result from this analysis are not statistically different from those in the full sample. Descriptive statistics for this subset, (those that did not replace their water heaters) comparable to the full sample (Table E.11) are shown in Tables E.18 and E.19.

Table E.18 Summary Statistics for Subset of Test-Site Homes that Reported No Changes in Water Heaters

\begin{tabular}{||c|r|r|r||}
\hline \multirow{2}{*}{ Statistic } & \multicolumn{3}{|c|}{ Energy Use (kWh) } \\
\cline { 2 - 4 } & \multicolumn{1}{|c|}{ Pre } & \multicolumn{1}{c|}{ Post } & \multicolumn{1}{c|}{ Post-Pre } \\
\hline Mean & 4475.61 & 3986.65 & -491.21 \\
\hline Standard Deviation & 1813.91 & 1798.74 & 573.37 \\
\hline Count & 77.00 & 75.00 & 75.00 \\
\hline Minimum & 1018.84 & 362.45 & -2116.58 \\
\hline $25 \%$ & 3045.37 & 2552.18 & -878.71 \\
\hline $50 \%$ & 4403.37 & 3756.14 & -448.97 \\
\hline $75 \%$ & 5504.45 & 5246.91 & -83.19 \\
\hline Maximum & 9253.54 & 8791.32 & 710.08 \\
\hline Range & 8234.70 & 8428.87 & 2826.67 \\
\hline Skewness & 0.35 & 0.39 & -0.68 \\
\hline Kurtosis & -0.22 & -0.40 & 0.10 \\
\hline
\end{tabular}


Table E.19 Summary Statistics for Subset of Control Site Homes that Reported No Changes in Water Heaters

\begin{tabular}{|c|r|r|r|}
\hline \multirow{2}{*}{ Statistic } & \multicolumn{3}{|c|}{ Energy Use (kWh) } \\
\cline { 2 - 4 } & \multicolumn{1}{|c|}{ Pre } & \multicolumn{1}{c|}{ Post } & Post-Pre \\
\hline Mean & 4673.95 & 4526.20 & -149.72 \\
\hline Standard Deviation & 2186.11 & 2163.34 & 1097.43 \\
\hline Count & 56.00 & 55.00 & 55.00 \\
\hline Minimum & 1003.37 & 1440.64 & -4492.69 \\
\hline $25 \%$ & 2963.34 & 2835.38 & -597.37 \\
\hline $50 \%$ & 4325.47 & 4204.16 & -115.56 \\
\hline $75 \%$ & 5768.36 & 5104.45 & 294.02 \\
\hline Maximum & 11497.76 & 11388.35 & 2513.52 \\
\hline Range & 10494.38 & 9947.70 & 7006.22 \\
\hline Skewness & 0.77 & 1.14 & -0.90 \\
\hline Kurtosis & 0.49 & 1.25 & 3.92 \\
\hline
\end{tabular}

\section{E.5.0 Billing Data Analyses}

The primary benefit of the REMP study was the availability of end-use- level data. It is rare that such detailed data is available for evaluation. Due to limitations in the representativeness of the REMP sample, it was thought to be desirable to conduct analyses of a larger sample to ensure representativeness and confirm the validity of the REMP analyses. The most likely source for another sample would be utility records and the associated billing data. To determine the approximate size for a sample using billing data, end-use data from the REMP sites was used to determine the sample size needed to estimate hot water heating loads, changes, and conservation savings.

In a pure sense, billing data is derived monthly from the household billing meter, which records consumption in $\mathrm{kWh}$ increments. The REMP study does not include actual utility meter reading records; however, representative "bills" can be reconstructed using either the "total-load" data from the REMP meters or by summing up all of the end-use data. In either case, this data is collected in terms of watts per hour. Hence, it must be aggregated to one month, or another appropriate billing interval.

All of the REMP showerhead study sites had electric space heating. Space heating loads are sensitive to changes in outdoor temperature. These temperature-sensitive swings in load complicate analysis 
of changes in energy use from one year or month to the next. To simplify this analysis, reconstructed "bills" for the REMP sites excluded electric space-heating loads.

\section{E.5.1 Sample Sizes for Billing Data Analysis}

In this investigation we will be determining sample sizes necessary to detect differences in energy use similar to those observed in the REMP water heating end-use data, but using billing data instead of end-use data. These sample sizes will be calculated using summary statistics obtained from the REMP data and are assumed to be representative of the larger population. We will look at both the test sites and the difference of the test and control sites in order to investigate the sample sizes necessary to undertake a study to detect differences with specified confidence and accuracy. Using the values from just the pre- and post-retrofit period data in the test population, we see that sample sizes needed for each of the populations can be tabulated as shown in Table E.20.

To use this table, you select a combination of desired confidence and accuracy levels and the sample size is found in the intersection. For this table, the accuracy level is presented as a fraction of the mean estimate. In other words, if the expected difference were 500 , and the desired confidence interval were $90 \%$, a sample of 4,167 would produce an estimate that was plus or minus $10 \%$ of 500 , or plus or minus 50 .

Table E.21 is a similar table for calculating sample sizes necessary to investigate the difference in savings of billing data for the control and test populations. 
Table E.20 Sample Sizes for Detecting Differences in the Pre- and Post-Retrofit Data from the Test Sites with End-Use Metered Data

\begin{tabular}{|c|c|c|c|c|}
\hline \multirow[b]{2}{*}{ Accuracy Level } & \multicolumn{4}{|c|}{ Confidence Level } \\
\hline & $99 \%=2.576$ & $95 \%=1.960$ & $90 \%=1.645$ & $80 \%=1.282$ \\
\hline $100 \%$ & 26 & 15 & 11 & 7 \\
\hline $95 \%$ & 29 & 17 & 12 & 8 \\
\hline $90 \%$ & 32 & 19 & 13 & 8 \\
\hline $85 \%$ & 36 & 21 & 15 & 9 \\
\hline $80 \%$ & 40 & 24 & 17 & 10 \\
\hline $75 \%$ & 46 & 27 & 19 & 12 \\
\hline $70 \%$ & 53 & 31 & 22 & 13 \\
\hline $65 \%$ & 61 & 36 & 25 & 15 \\
\hline $60 \%$ & 71 & 42 & 29 & 18 \\
\hline $55 \%$ & 85 & 49 & 35 & 21 \\
\hline $50 \%$ & 103 & 60 & 42 & 26 \\
\hline $45 \%$ & 127 & 74 & 52 & 32 \\
\hline $40 \%$ & 160 & 93 & 66 & 40 \\
\hline $35 \%$ & 209 & 121 & 86 & 52 \\
\hline $30 \%$ & 284 & 165 & 116 & 71 \\
\hline $25 \%$ & 409 & 237 & 167 & 102 \\
\hline $20 \%$ & 639 & 370 & 261 & 159 \\
\hline $15 \%$ & 1,136 & 658 & 463 & 282 \\
\hline $10 \%$ & 2,555 & 1,480 & 1,042 & 633 \\
\hline $5 \%$ & 10,219 & 5,917 & 4,167 & 2,530 \\
\hline
\end{tabular}


Table E.21 Sample Sizes for Detecting Differences in the Savings for the Control and Test Sites Using household Billing Data (Without Billing Period Skewness)

\begin{tabular}{|c|c|c|c|c|}
\hline \multirow[b]{2}{*}{ Accuracy Level } & \multicolumn{4}{|c|}{ Confidence Level } \\
\hline & $99 \%=2.576$ & $95 \%=1.960$ & $90 \%=1.645$ & $80 \%=1.282$ \\
\hline $100 \%$ & 197 & 114 & 81 & 49 \\
\hline $95 \%$ & 219 & 127 & 89 & 54 \\
\hline $90 \%$ & 243 & 141 & 100 & 61 \\
\hline $85 \%$ & 273 & 158 & 112 & 68 \\
\hline $80 \%$ & 308 & 178 & 126 & 77 \\
\hline $75 \%$ & 350 & 203 & 143 & 87 \\
\hline $70 \%$ & 402 & 233 & 164 & 100 \\
\hline $65 \%$ & 466 & 270 & 190 & 116 \\
\hline $60 \%$ & 547 & 317 & 223 & 136 \\
\hline $55 \%$ & 651 & 377 & 266 & 161 \\
\hline $50 \%$ & 787 & 456 & 321 & 195 \\
\hline 4596 & 972 & 563 & 397 & 241 \\
\hline $40 \%$ & 1,230 & 712 & 502 & 305 \\
\hline $35 \%$ & 1,607 & 930 & 655 & 398 \\
\hline $30 \%$ & 2,187 & 1,266 & 892 & 542 \\
\hline $25 \%$ & 3,148 & 1,823 & 1,284 & 780 \\
\hline $20 \%$ & 4,919 & 2,848 & 2,006 & 1,218 \\
\hline $15 \%$ & 8,745 & 5,063 & 3,566 & 2,165 \\
\hline $10 \%$ & 19,675 & 11,392 & 8,023 & 4,871 \\
\hline $5 \%$ & 78,699 & 45,565 & 32,092 & 19,481 \\
\hline
\end{tabular}


The information in these tables is also presented in Figures E.15 and E.16 below.

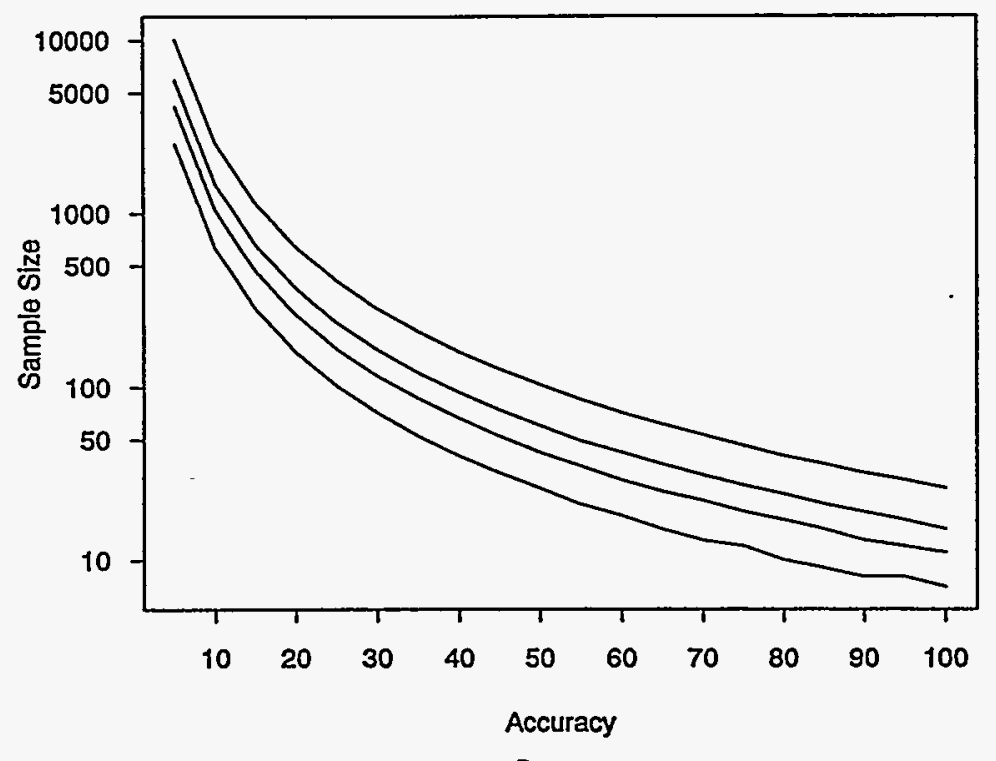

Figure E.15 Sample Sizes Necessary to Have Desired Confidence and Accuracy in Detecting Differences Between the Pre-Retrofit Period and Post-Retrofit Period Data in the Test Population

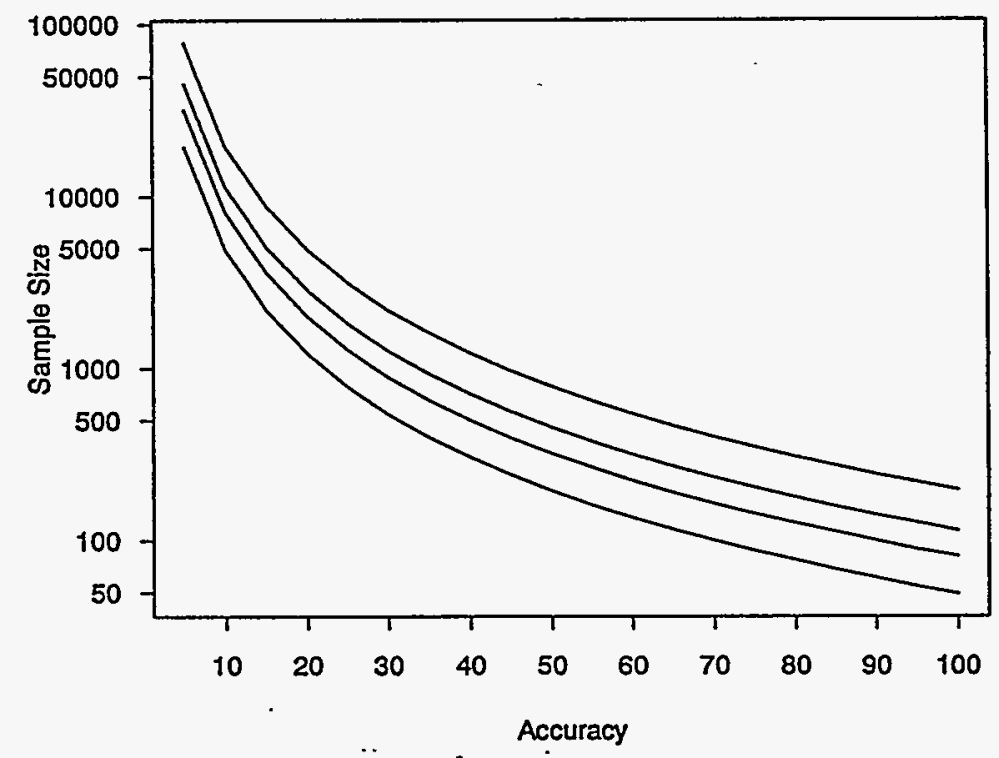

Figure E.16 Sample Sizes Necessary to Have Desired Confidence and Accuracy in Detecting Differences between the Savings of the Control Group and the Savings of the Test Group 


\section{E.5.2 "Billing Data" Analyses for REMP Sites}

The preceding discussion only addressed the issue of sample size for billing data analyses; it did not address the issue of the reasonableness of that approach. This is an issue since billing data is so highly aggregated and previous analyses of conservation effects using billing data have come under heavy criticism. The availability of reconstructed billing data for estimating sample sizes provided the opportunity to go the next step and address the issue of the reliability of billing data results compared to end-use metering, which is the subject of this section.

End-use metering among the REMP sites permits reconstruction of energy use to resemble data from billing meters. To remove any weather effects, the space heating end-use data were omitted, creating a data set that resembles billing data for customers with electric water heating, but not electric space heating. The results of this analysis are shown in Table E.22.

Table E.22 Savings Estimates from REMP Billing Data

\begin{tabular}{||l|c|c|}
\hline & Mean Savings (kWh)* & Sample \\
\hline Participants & 620 & 85 \\
\hline Controls & 387 & 56 \\
\hline Net Savings & 233 & NA \\
\hline$*$ Difference of means. All other tables have presented the mean of the differences. \\
\hline
\end{tabular}

The "billing data" estimate of savings is not a reliable substitute for the end-use metered estimate. This is due to the fact that the billing data estimate has much greater variance than its end-use counterpart. Summary statistics based on billing data for the test site and control homes are shown in Tables E.23 and E.24. This has a significant impact on statements relating to confidence ranges. For example, the $95 \%$ confidence range for savings is 83 to $643 \mathrm{kWh}$ when using the end use estimate. For the same level of confidence, the billing data estimate creates a range of -337 to $793 \mathrm{kWh}$ per year. Thus, we are confident the "true result" is contained within the billing data confidence interval (e.g., 363 is between 83 and 643), but we are equally confident the mean differences in the billing data are not the "true result" (e.g., 363 [end-use derived] is not equal to 233). In simple terms, analyses of results from end-use and metered data indicate that savings estimates based on billing data comparisons are not as accurate.

Confidence intervals for comparison of pre- and post-retrofit billing data and for savings for the test and control populations are shown in Figures E.17, E.18, and E.19. 
Table E.23 Summary Statistics for Test Site Homes (Billing Data)

\begin{tabular}{||c|r|r|r|}
\hline \multirow{2}{*}{ Statistic } & \multicolumn{3}{|c|}{ Energy Use (kWh) } \\
\cline { 2 - 4 } & \multicolumn{1}{|c|}{ Pre } & \multicolumn{1}{c|}{ Post } & \multicolumn{1}{c|}{ Post-Pre } \\
\hline Mean & 12993.57 & 12406.82 & -620.37 \\
\hline Standard Deviation & 4812.08 & 4806.42 & 1217.30 \\
\hline Count & 87.00 & 85.00 & 85.00 \\
\hline Minimum & 5166.22 & 4871.59 & -5038.55 \\
\hline $25 \%$ & 9939.40 & 9234.68 & -1410.59 \\
\hline $50 \%$ & 12666.53 & 12067.44 & -478.25 \\
\hline $75 \%$ & 14634.49 & 14325.17 & 130.66 \\
\hline Maximum & 39824.48 & 36600.01 & 2633.98 \\
\hline Range & 34658.25 & 31728.42 & 7672.53 \\
\hline Skewness & 2.10 & 1.61 & -0.60 \\
\hline Kurtosis & 9.38 & 5.98 & 1.10 \\
\hline
\end{tabular}

Table E.24 Summary Statistics for Control Site Homes (Billing Data)

\begin{tabular}{||c|r|r|r|}
\hline \multirow{2}{*}{ Statistic } & \multicolumn{3}{|c|}{ Energy Use (kWh) } \\
\cline { 2 - 4 } & \multicolumn{1}{|c|}{ Pre } & \multicolumn{1}{c|}{ Post } & Post-Pre \\
\hline \hline Mean & 14414.03 & 14062.06 & -387.40 \\
\hline Standard Deviation & 8054.45 & 8312.36 & 2109.59 \\
\hline Count & 57.00 & 56.00 & 56.00 \\
\hline Minimum & 4596.61 & 4621.70 & -9213.07 \\
\hline $25 \%$ & 9022.52 & 8885.37 & -1104.13 \\
\hline $50 \%$ & 12811.04 & 12308.35 & -7.92 \\
\hline $75 \%$ & 15923.03 & 16357.95 & 877.13 \\
\hline Maximum & 53365.03 & 54823.18 & 3221.29 \\
\hline Range & 48768.42 & 50201.48 & 12434.37 \\
\hline Skewness & 2.31 & 2.43 & -1.83 \\
\hline Kurtosis & 8.02 & 8.59 & 4.89 \\
\hline
\end{tabular}




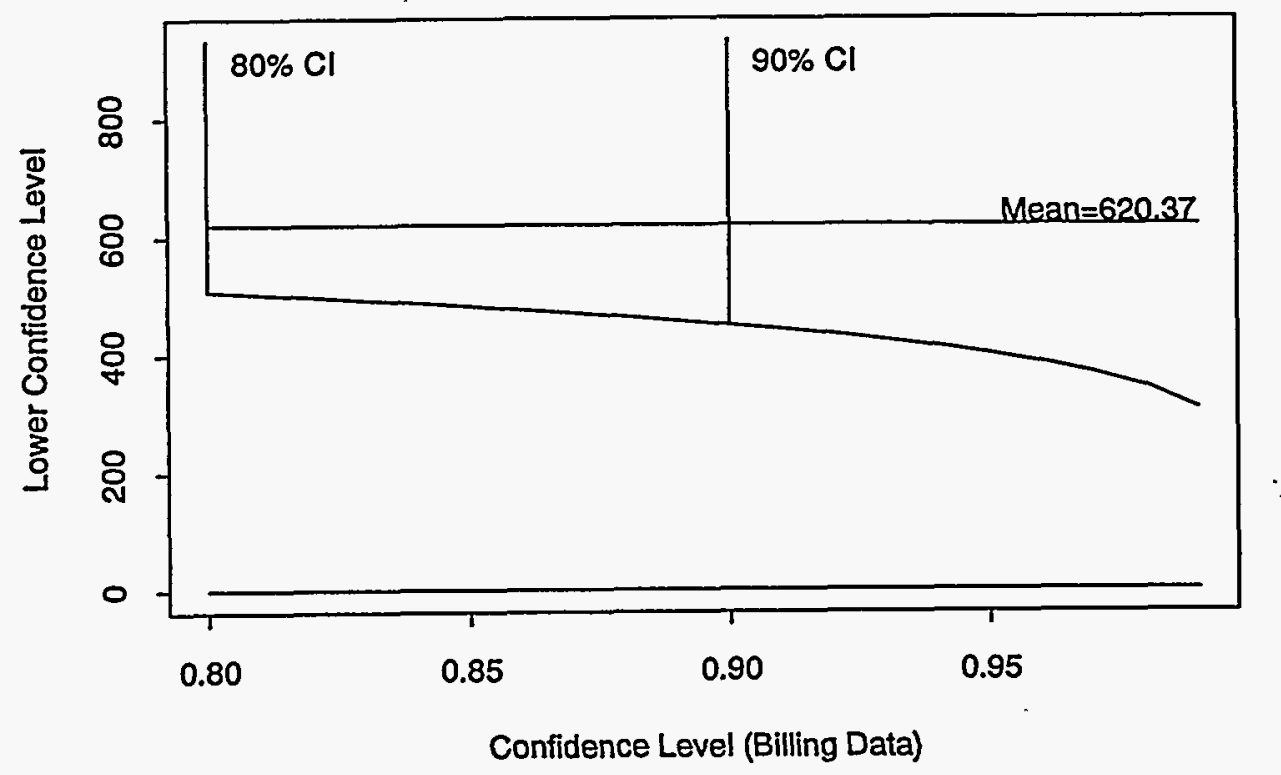

Figure E.17 Confidence Intervals for Paired Differences for the Test Population (comparing pre-retrofit and post-retrofit billing data)

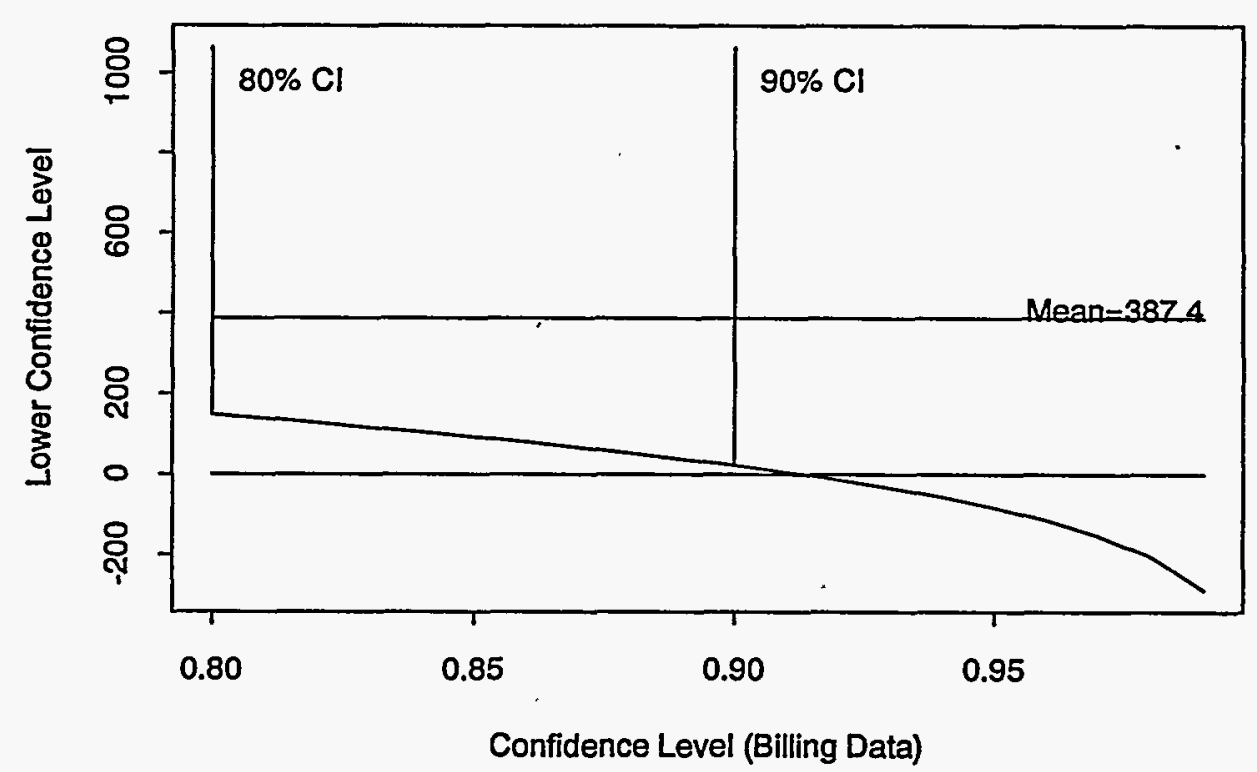

Figure E.18 Confidence Intervals for Paired Differences for the Control Population (comparing pre-retrofit and post-retrofit billing data) 


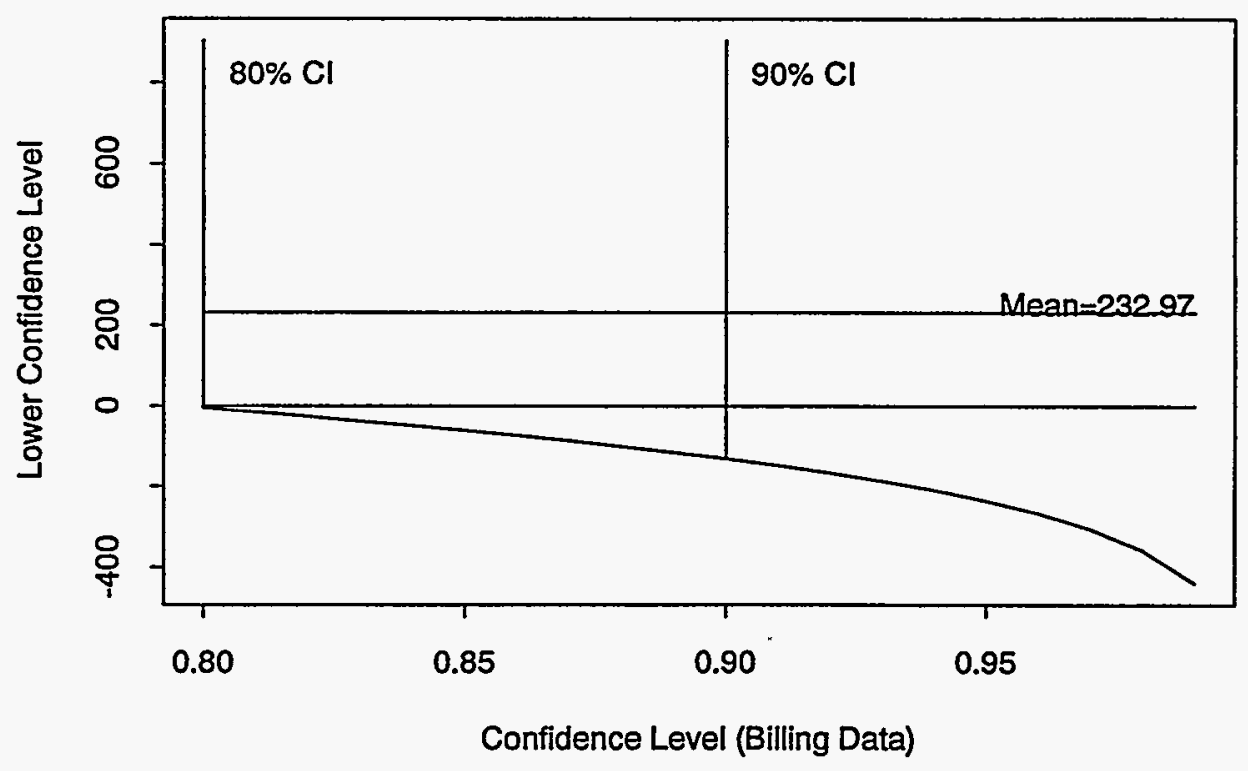

Figure E.19 Confidence Intervals for Differences in Savings for the Test and Control Populations using Billing Data

\section{E.6 Socioeconomic Analyses}

Previous studies of hot water heating energy use by PNL observed a correlation between hot water energy use and selected socioeconomic variables (Pratt and Ross 1991). This analysis used 4 years of data from the ELCAP sample of over 300 homes with end-use metering. The socioeconomic variables selected for this analysis included four age categories (less than 6, 6 through 17, 18 through 65, and over 65 ) and number of occupants. Key findings from the study were that the use per occupant, exclusive of standby losses, is about $1,100 \mathrm{kWh}$ annually. This average varies inversely with number of occupants, with single person households having the highest use per occupant and very large households having the lowest use per occupant. Use per occupant falls off markedly after the household exceeds five or so persons. This relationship is confounded by the age distribution of occupants in households over three persons, where the additional occupants tend to be children. Applications of regression models to the data produced the strongest correlations with age. Occupants in the under 6 and over 65 category had the lowest use per occupant; those in the 6 through 17 category had the highest use; and those in the 18 through 65 category the next highest. With this as background to the REMP field study, the researchers assumed that similar correlations with age and number of occupants would be present in the showerhead savings data. Although this early analysis did not look at gender-based differences in hot- water use, we assumed that there would be genderbased differences in shower use that would be reflected in hot-water energy savings. 


\section{E.6.1 Socioeconomic Models}

In the socioeconomic modeling work, we focus only on the test-site homes, since that is where data with the highest resolution were collected. Three different questionnaires were used with as many of these people as possible. One of these forms was an occupancy form, another was a 6-month progress telephone-interview survey form, and the third was a mailed-in questionnaire. Unfortunately, the absence of data from the control group sites leaves us in the position of having to estimate values for a model for the people who are in the test site without the benefit of being able to compare the results with another group that is so similar. What follows is the result of trying to model the test-site homes with various classification type variables.

We would like to be able to use as many continuous variables as possible to build a better model, but we simply do not have that type of data.

First, we wanted to see if we could model energy savings as a function of the number of males and females living at a given address. That model would look like the following:

$$
S A V I N G S=\mu+\beta_{1} \text { MALES }+\beta_{2} \text { FEMALES }
$$

The problem with this model is that it relies so heavily on the parameter $\mathrm{Mu}$ to explain the savings at a given location. Running this model we obtain an $\mathrm{R}^{2}$ value of .05 . The model is too simple for the underlying process that we would like to capture. This model says that there is a certain effect that each male and each female has on the overall model, but should the parameters be negative, the meaning is unclear. In fact, neither of the predictors is significant to the model (Table E.25).

Table E.25 Savings as a Function of Gender

\begin{tabular}{||l|r|r|r|r||}
\hline \multicolumn{1}{|c|}{ Coefficients } & \multicolumn{1}{c|}{ Value } & Standard Error & \multicolumn{1}{c|}{$\mathbf{t}$ value } & \multicolumn{1}{c|}{ Pr $>|t|$} \\
\hline Intercept & -55.0633 & 16.0211 & -3.4369 & 0.0009 \\
\hline MALES & -14.4112 & 7.5671 & -1.9044 & 0.0604 \\
\hline FEMALES & 11.0821 & 8.5653 & 1.2938 & 0.1994 \\
\hline
\end{tabular}

Due to the complexities introduced by the linear models, we next turned to tree-based models. These models have gained popularity primarily because:

- Tree-based models are sometimes easier to interpret and discuss than linear models when the predictors are a mix of numeric variables and factors.

- Tree-based models are invariant to monotone re-expressions of predictor variables. 
- Tree-based models allow for the modeling of factor response variables with more than two levels.

The last advantage is that the resulting model is very easy to use for estimating values for unknowns (for which you know the values of the predictor variables in the tree-based model). As an example, lets look again at the simple model where we explain the savings in terms of the number of males and females at the residence. The tree-based model is given in Figure E.20. Easily seen is that the estimate for the amount of energy saved in kilowatts for a year for any household with no males is $33.08 \mathrm{kWh}$. If there is one or less males and two or more females then the savings is $35.74 \mathrm{kWh}$. It is easy to see how the estimate is obtained by simply starting at the top of the tree and comparing the rules at each juncture to reach a decision as to which path you use to traverse the tree. Ultimately all inputs will reach a terminal node at which the estimate can be made.

If we add just a little more complexity and include the age groups in our model, then we can visualize the tree-based model in Figure E.21. The resulting tree-based model has an additional two nodes, reflecting occupants between 7 and 18 years of age (variable AGE 2) and those between 18 and 66 (AGE 3). Nevertheless, this is still a rather simple and clear approach to the problem.

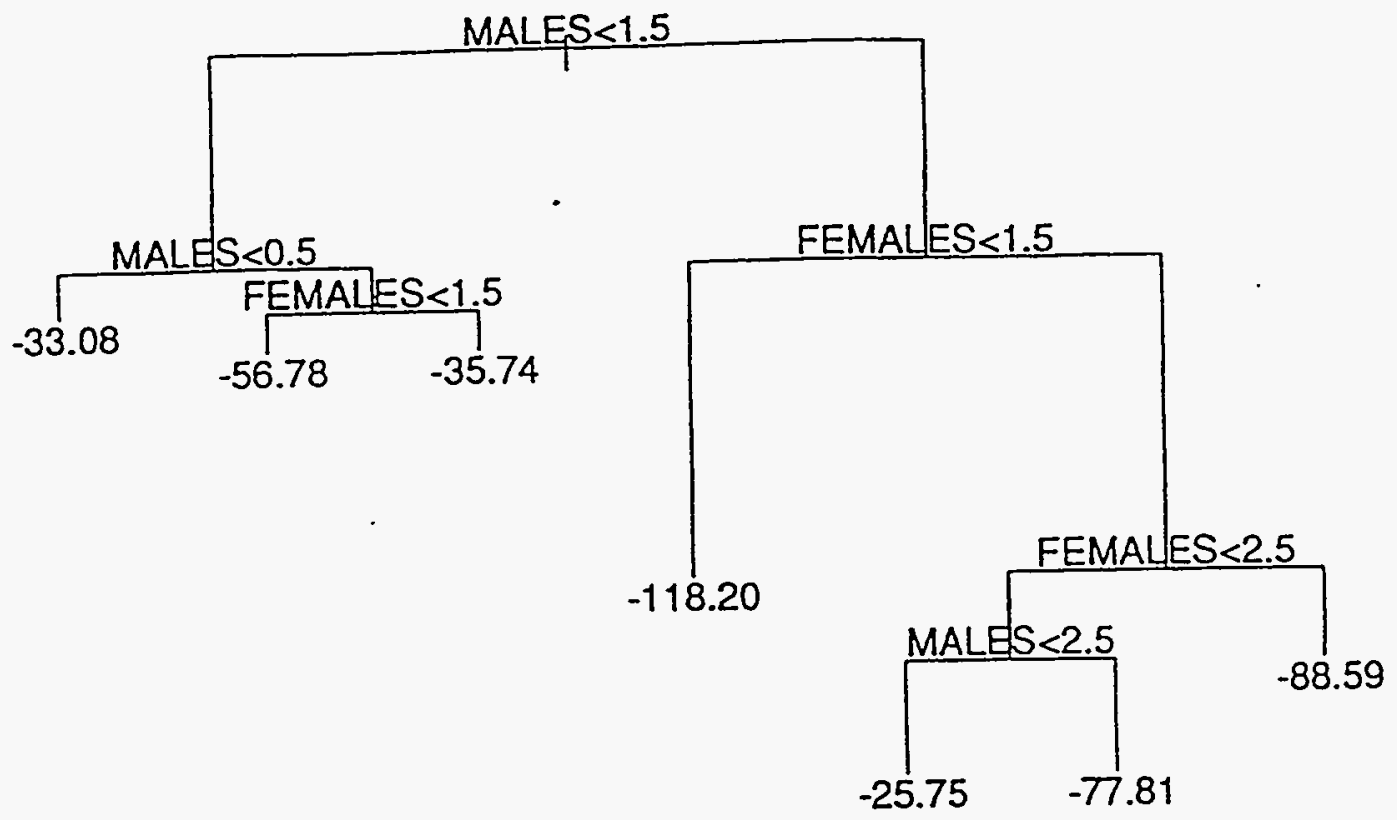

Figure E.20 Simple Tree-Based Model to Explain Savings Using only the Number of Males and Number of Females at a Residence 


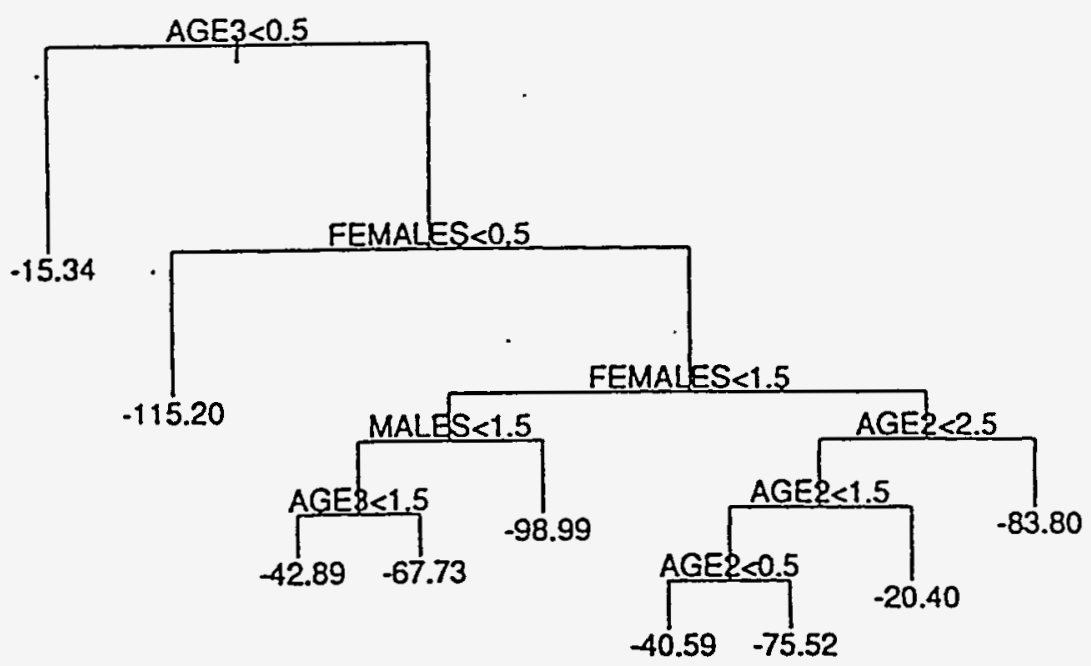

Figure E.21 Simple Tree-Based Model to Explain Savings Using only the Number of Males, Number of Females, and Number of People within Given Age Groups at a Residence (AGE $2=7-18$, AGE $3=18-66$ )

We decided against including variables on the number of showers per occupant per year since this type of information will not be readily available for forecasting the many unknown households. Instead, we limit ourselves to those variables that are easily obtainable. In the final model, we investigate modeling the savings in energy by adding the number of showerheads installed into our consideration of construction of the decision tree. The resulting model is depicted in Figure E.21. The problem with these models is the same with the better known linear regression models. We do not have data at a fine enough resolution to get an accurate representation. These tree models, while easy to understand and implement, do not capture the salient parts of the underlying process. The residuals of these models are on the order of the mean of the parameter that we are trying to model. To capture and explain the savings in $\mathrm{kWh}$ per household, we will need more data and we will need that data at better resolution. 


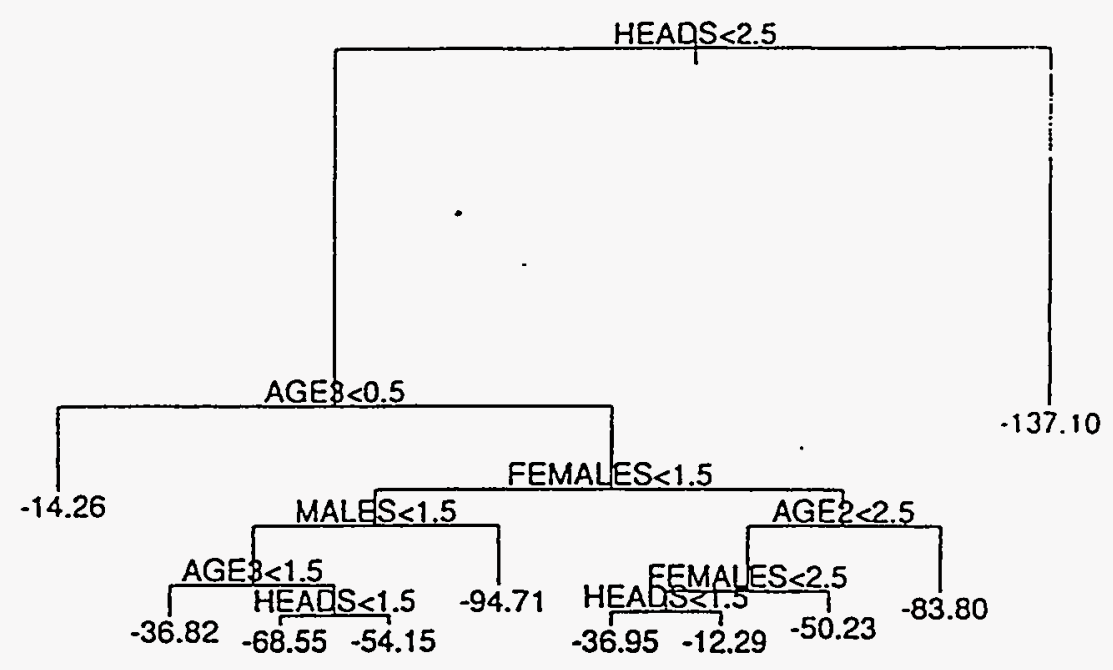

Figure E.22 Tree-Based Model to Explain Savings Using Number of Showerheads, Number of Males, Number of Females, and Number of People within Given Age Groups at a Residence

\section{E.6.2 Conclusions from Socioeconomic Analyses}

In previous analyses of ELCAP data (a larger sample), PNL observed correlations between the number of household occupants and age and water heating energy use. The REMP data did not reveal similar correlations between water heating energy savings and age and gender of occupants. The REMP analysis was a household-level analysis among households that did not display a wide variation in number of occupants. Thus, analyses of number of occupants was not pursued. As a result of these analyses, no demographic factors are proposed for the energy savings algorithm.

There is no obvious explanation for the results of the socioeconomic analysis. Speculation about these results focuses on compensatory mechanisms. For example, the hot-water capacity of a hot-water heater is finite. Bathers would be constrained by this capacity. It may be that multiple bathers are forced to take shorter showers, on average, than bathers in one- or two-occupant homes. This same constraint also exists for non-showering water uses, so that households with non-showerers, like infants, may be constrained by the hot water available after bathing a child in a tub, cleaning up after meals, or clothes washing, all of which are activities that tend to cluster during bathing times. (It should be noted that a subsequent analysis of water also failed to identify significant correlation of savings with socioeconomic factors (SBW Consulting, Inc. 1994).

\section{E.7 Alternative Estimates of Energy Savings}

Estimates of energy use from end-use metering data typically are derived by summing channellevel observations. This provides a useful estimate of total water-heating energy use, but it does not discriminate among the various components of energy or hot-water use. These include energy used to 
maintain water temperature in the heater (standby energy use) or energy used to heat water withdrawn for specific uses like showering, washing clothes and dishes, cooking, and other sanitary purposes.

Each of these uses requires a different amount of energy, which makes the hot-water heater a multipleuse appliance.

Shower hot-water usage is not directly observable through simple monitoring of water-heater energy use. Instead, hot-water use for showering has to be isolated from all other hot water uses. Previous PNL analyses of this data indicated that, within a household, patterns (load shapes) of appliance and energy use are relatively static, although these patterns vary greatly from house to house. A detailed household and occupant survey was mailed to each of the 158 single-family residences identified for the earlier Bonneville showerhead field study. Only 98 of these sites were retrofit with energyefficient showerheads during the field study. The remaining sites were surveyed for use as "controls" in this methodology test and for the program impact evaluation. A total of 74 surveys were returned; 17 from control households and 48 from homes retrofit during the field study. These responses accounted for 212 individual bathers. Survey responses indicated that showers tend to cluster in the morning and late evening hours (Figure E.23).

\section{E.7.1 Survey-Guided Load Data Analyses}

The hot water heater end use is composed of two states, re-heating associated with stand-by losses and heating associated with hot-water withdrawals and the subsequent influx of cold water. The amount of hot water withdrawn determines the "run-time" for the water heater to heat the new influx water. Hot-water withdrawal amount is associated with uses, such as clothes- and dish-washing cycles, how full the bathtub is filled, and shower duration. All of these uses would be reflected in one signature or energy-use observation, because these uses all come from the same end-use, the hot-water heater.

Hot-water uses can be derived for some end uses, such as clothes and dish washing, by correlating hot water loads with electricity use for these other uses. However, correlates for showering are difficult to find (bathroom lights are one possibility). Consequently, derivation of showering hot-water use from hot-water load data is left to indirect methods. PNL's approach utilized hourly load data for only the intervals survey respondents identified as showering times (Figure E.23). The survey responses approximate the estimated load shape for showerhead energy savings (Appendix I, Figure I.5). Survey responses were occupant-specific as well as site-specific. As a result, the number of independent "observations" was equal to the number of occupants (212) rather than the number of sites (48). 


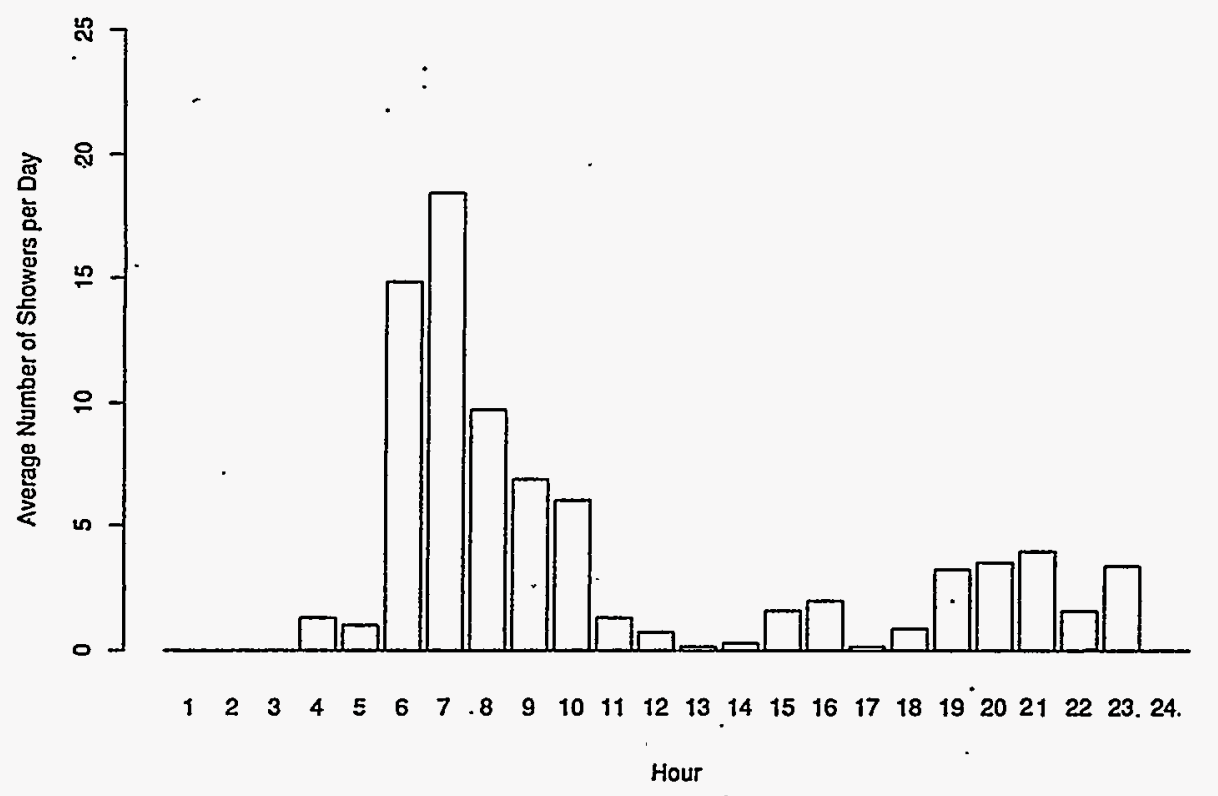

Figure E.23 Likely Shower Hour Distribution: Average Day Test Sample

The distinguishing feature of this method is that the data used for the analysis is selected using participant survey responses as a screen. The survey responses include two pieces of information that are used to select data, an occupant response that indicates a shower was taken ("likely shower" data) and the occupant's response to the time of the shower ("likely hour" data). This facilitated two alternative analytic approaches, one using likely shower data to estimate use per shower and another using the likely hours for showering to estimate shower energy use per hour.

\section{E.7.2 Savings Estimates}

Energy-savings estimates were based on a three-hour "shower window." We also took two different approaches: the likely shower method and the likely shower-hour method. Data collection and methods are described in detail below.

\section{E.7.2.1 Data Preparation}

A typical shower, if there is such a thing, uses about 15 gallons of hot water (i.e., a 7.5-minute shower at $2 \mathrm{gpm}$ of hot water or $2.5 \mathrm{gpm}$ with a ratio of $80 \%$ hot to cold). An electric water heater heats about 18 gallons of water per hour. The homes in the REMP study were equipped with load recorders using a one-hour recording interval. As a result, the only way for shower loads to show up in a single hour is for the shower to start on the hour and be of "normal" length. If the shower start time was shifted, the shower load was split between two hours. In order to capture the maximum number of showers, the initial shower window was set at three hours, starting the hour before the occupant said they took their shower to account for early risers. This had the effect of counting as showers all hot-water energy use in the three-hour window. This seemed like a safe assumption since the major hot-water uses (bathing and washing) compete for the same hot water, and these uses would likely be 
scheduled to avoid interfering with each other (i.e., not running the washing machine when someone was showering).

\section{E.7.2.2 The Likely Shower Method}

The likely shower method used the data for all reported showers. To ensure an accurate measurement of shower energy use, the data was screened to determine if the energy readings during the likely shower periods were large enough to be a "legitimate" shower. This was done to eliminate data that did not represent true showers, which would distort the results. This approach provided an estimate for both the energy use and the number of all showers in the pre- and post-retrofit periods. Subtracting the post-retrofit from the pre-retrofit estimates provided an estimate of savings. This analysis was conducted using both the "billing" data and the water-heater end-use data. The relative energy savings results or percent change in use, were consistent with REMP results from conventional analyses (Table E.26). In order to estimate annual savings comparable to the REMP results, it is necessary to multiply the per-shower results by the number of showers observed in the data for the year. When this calculation is performed, the result ( $260 \mathrm{kWh}$ per year) is considerably less than the REMP estimate of savings of $515 \mathrm{kWh}$ per year. The agreement on relative savings lends support to the estimate of savings per shower, leading us to suspect that the survey responses are not capturing all of the showers taken by the occupants. In fact, three separate interpretations of the number of showers taken are available. The first is the response to the survey question about the number of showers taken by the household; the second is the sum of the responses on the "likely shower" survey, which was in fact a schedule for the showers taken; and finally, there is the number of showers that were observed in the "likely shower" data (Table E.27).

Table E.26 Comparison of Likely Shower Method Results

\begin{tabular}{||l|c|c|c||}
\hline \multicolumn{1}{|c|}{ Results } & Mean & Standard Deviation & Percent Change \\
\hline $\begin{array}{l}\text { Billing Model results } \\
\text { (watts/shower) }\end{array}$ & 368 & 692 & $7.3 \%$ of total use \\
\hline $\begin{array}{l}\text { End Use Model } \\
\text { (watts/shower) }\end{array}$ & 280 & 455 & $12.6 \%$ of shower energy \\
\hline $\begin{array}{l}\text { REMP billing result } \\
\text { (kWh/yr.) }\end{array}$ & 620 & 1,217 & $5 \%$ of total use \\
\hline $\begin{array}{l}\text { REMP end use result } \\
\text { (kWh/yr.) }\end{array}$ & 515 & 588 & $13 \%$ of shower energy \\
\hline
\end{tabular}


Table E.27 Average Number of Showers per Year per Person

\begin{tabular}{|l|c|}
\hline \multicolumn{1}{|c|}{ Data Source } & Number of showers/person/year \\
\hline Occupant survey question & 262 \\
\hline Shower schedule responses & 134 \\
\hline Observed in the data & 108 \\
\hline
\end{tabular}

\section{E.7.2.3 The Likely Shower-Hour Method}

The second approach to estimating showering savings used the survey responses for the hour showers were taken. The data for each of these hours were summed to generate a load profile for the "likely showering hours" before and after showerhead retrofit. The resulting relative savings estimates were consistent with both the likely shower and REMP results (Table E.28). Again, when the number of shower hours is multiplied by the savings, the result falls short of the REMP savings estimate, (254 $\mathrm{kWh}$ per year compared to the REMP estimate of $515 \mathrm{kWh}$ per year), casting doubt on the showerschedule data.

Table E.28 Comparison of Likely Shower-Hour Method Results

\begin{tabular}{||l|c|c|l||}
\hline \multicolumn{1}{|c|}{ Results } & Mean & Standard Deviation & \multicolumn{1}{|c|}{ Percent Change } \\
\hline $\begin{array}{l}\text { "Hour" model results for } \\
\text { "billing" data(watts/hour) }\end{array}$ & 20 & 34 & $\begin{array}{l}7.2 \% \text { of total use during } \\
\text { the hour }\end{array}$ \\
\hline $\begin{array}{l}\text { "Hour" model results for end } \\
\text { use data(watts/hour) }\end{array}$ & 15 & 26 & $12.5 \%$ of shower energy \\
\hline $\begin{array}{l}\text { "Shower" model results for } \\
\text { "billing" data (watts/shower) }\end{array}$ & 368 & 692 & $\begin{array}{l}7.3 \% \text { of total use during } \\
\text { shower periods }\end{array}$ \\
\hline $\begin{array}{l}\text { "Shower" model results for } \\
\text { end use data (watts/shower) }\end{array}$ & 280 & 455 & $12.6 \%$ of shower energy \\
\hline REMP billing result (kWh/yr) & 620 & 1,217 & $5 \%$ of total use \\
\hline $\begin{array}{l}\text { REMP end use result } \\
\text { (kWh/yr) }\end{array}$ & 515 & 588 & $13 \%$ of shower energy \\
\hline
\end{tabular}




\section{E.8 Conclusions}

End-use metered data from water heaters provide an efficient and reliable basis for estimating savings from the retrofit of efficient showerheads or other measures that produce savings in waterheater use of 7\% or more. Similar analyses using billing data (household-level consumption data) will require much larger samples (e.g., 5,000 versus 100 homes) and may provide misleading answers or results that are not useful.

Although water heater end-use data proved to be extremely valuable, it is an aggregate statistic which includes impacts from activities that may not be a result of treatment. This is also a problem if multiple treatments are applied. This could happen by installing faucet aerators, or increasing the efficiency of the water-heater or other water-using appliances at the same time. Exploratory analyses using water-heater end-use data selectively to examine specific hot-water uses (survey-guided lead research) showed great promise as a means for distinguishing between specific hot-water uses and savings using aggregate data. 


\section{E.9 References}

Katzev, R. 1991. "'Does Low-Flow' Still Mean Low Satisfaction?" Home Energy, July/August.

Pratt, R. G., and B. A. Ross. 1991. Measured Electric Hot Water Standby and Demand Loads from Pacific Northwest Homes. PNL-7889, Pacific Northwest Laboratory, Richland, WA.

SBW Consulting, Inc. 1994. Energy Efficient Showerhead and Faucet Aerator Metering Study. Draft Report No. 9414, prepared by SBW Consulting, Inc. in association with NCAT-Development.

Corporation for Puget Sound Power and Light, Bellevue, Washington. 


\section{Appendix F}

Showerhead and Faucet Aerator Performance Assessment 


\begin{tabular}{|c|c|c|c|c|}
\hline \multicolumn{3}{|l|}{$\overline{\mathrm{TINE}}$} & $\begin{array}{l}\text { DAE } \\
\text { November 17, } 1994\end{array}$ & $\begin{array}{l}\text { REPORT NO. } \\
\text { TTL (M) 94-67.1 }\end{array}$ \\
\hline \multirow{3}{*}{\multicolumn{3}{|c|}{$\begin{array}{c}\text { SHOWER HEAD } \\
\text { AND FAUCET AERATOR } \\
\text { PERFORMANCE ASSESSMENT: } \\
\text { Final Report }\end{array}$}} & \multirow{2}{*}{\multicolumn{2}{|c|}{ G. Matthews - TTL }} \\
\hline & & & & \\
\hline & & & \multicolumn{2}{|l|}{ A. Sims - TTL } \\
\hline $\begin{array}{l}\text { REQORG. } \\
\text { RPEB }\end{array}$ & 87 & 488566 & $\begin{array}{l}\text { REMEWED GY } \\
\text { M. Johnson - TTL }\end{array}$ & \\
\hline
\end{tabular}

The BPA Division of Laboratories assessed the performance of low-flow shower heads and faucet aerators for the Program Evaluation Section. This data provided a baseline to estimate actual energy savings obtained under Bonneville's Efficient Shower Head Program.

The tests were performed at the Laboratories facilities on the Ross Complex in Vancouver, Washington. Previous studies identified water supply pressure as a key factor impacting shower head performance. Shower heads evaluated in this program were tested at ten different supply pressures ranging from 10 to 115 pounds per square inch (psi). The test method required measuring the time required to discharge a specified mass of water through the test sample and calculating the flow rate. Water preheated to nominally $40^{\circ} \mathrm{C}\left(105^{\circ} \mathrm{F}\right)$ was used for all tests. A minimum of three samples of each model were tested over the full range of pressures.

Flow rate performance curves were developed. The test results produced curve fit algorithms to model the performance of each unit at any interim pressure magnitude. Single estimates of the overall flow rate of the entire installed populations were produced. This required weighting the flow rate of each device by the distribution of water supply pressures of the entire region and the fraction that each model represents of the total number of units purchased. Approximately 150 old shower heads removed from program participants homes were also tested. The weighted average for these shower heads also reflects the Northwest pressure distribution, but, for lack of historical sales data, assumes that each model represents an equal share of the installed market. The following table depicts the overall weighted flow rates resulting from this study.

\begin{tabular}{|l|c|c|c|c|}
\hline \multicolumn{1}{|c|}{ Device: } & $\begin{array}{c}\text { Existing Shower } \\
\text { Heads Replaced }\end{array}$ & $\begin{array}{c}\text { BPA Provided Replacement } \\
\text { Shower Heads }\end{array}$ & $\begin{array}{c}\text { All Tested } \\
\text { Shower Heads }\end{array}$ & $\begin{array}{c}\text { BPA Supplied Faucet } \\
\text { Aerators }\end{array}$ \\
\hline Flow Rate [GPM] & 5.68 & 2.28155 & 1.86 & 2.03 \\
\hline Flow Rate [L/m] & 21.5 & 8.63658 & 7.04 & 7.68 \\
\hline
\end{tabular}

The flow listed for the Laboratory test of REPLACED SHOWER HEADS is higher than that reported for field studies. For example, the average flow rate for existing shower heads in the Regional End-Use Metering Study [REP] is 3.2 GPM. Flows were found to rarely exceed 4 GPM. Under laboratory conditions these same shower heads produced, on average, flows of 5.3 GPM.

\begin{tabular}{lll}
\hline DESCRIPTORS: & Conservation; Demand-side Management; Water Heaters \\
\hline DISTRIBUTON: & Official File - TTL (K-1) & M. Miller - MPPE \\
I. Thurein - TT & J. Holmstrom - MR/911 & L. Evans - MPMO \\
W. White - TTL & J. Cahill - MPMP & C. Hickman - MPME \\
Library - TT &
\end{tabular}




\section{SHOWER HEADS \& FAUCET AERATOR PERFORMANCE ASSESSMENT: FINAL REPORT}

\section{FOREWORD}

This revision reflects work performed prior to the original September, 1994 report. This version includes more shower head samples regulated to operate at flows up to $2.5 \mathrm{GPM}$. The majority of the samples included in the previous study consisted of shower heads and aerators that produce flow rates on the order of 2.0 gallons per minute (GPM). This is consistent with current BPA recommendations. However, at the onset of this program in 1991, Bonneville specified maximum flow rates "less than or equal to 2.5 GPM at 80 psi". The majority of the units were purchased early in the program, before the specification change. Many of the higher flow rate shower heads are no longer available. This report also includes additional analysis to establish results' correlation's with other evaluators.

\section{INTRODUCTION}

As a result of the findings of externally funded shower head efficiency studies, the Program Evaluation branch of the Office of Energy Resources RPEB requested that the BPA Laboratories develop flow rate performance curves for existing and energy efficient shower head and faucet aerator models. The objective was to provide data characterizing the flow-control performance of these devices operating at supply pressures from 70 to $840 \mathrm{KPa}$ (10 to $120 \mathrm{psi}$ ). Numerous consultants and BPA client distribution companies raised the issue that the actual installed performances of the shower heads do not meet BPA specifications. A representative sampling of shower heads tested by these consultants and old shower heads removed from service during Bonneville's Efficient Shower Head and Faucet Aerator Program were also included to compare in-situ and laboratory performance.

Accurate estimates of shower head and faucet aerator performance are necessary to calculate potential energy savings gained by the installation of the devices in residential applications. The consultant field data was typically collected using a water-flow measuring device called a microweir. Other variations of perforated collection vessels were also used. While theoretically 
elegant, the lack of agreement between competing data sets demonstrates a need to characterize shower head performance in a more repeatable manner.

The BPA laboratory test method is based on the collection of a specific mass of water and recording the time required for the collection. This data produces repeatable flow rate data and avoids the problems associated with making dynamic measurements of a flow process.

A single, bulk flow rate for all of the devices was calculated. This result is based on flow rate curves developed for each device, weighted by the fraction each model represents of the total number of devices installed, and field data characterizing supply pressure distributions over the BPA service area. In addition, and more relevantly, a separate analysis was conducted to assess the performance of the shower heads purchased early in the Bonneville program.

\section{SUMMARY OF RESULTS}

The overall flow rate for each sample category tested is listed in Table 1 . The flow rate results for all tested samples were combined using weighting values for the regional supply pressure distribution and, for the new devices, the fraction each device represented of total device population. Insufficient data is available to determine the population fraction that each old shower head represents of the total installed. For this case, each model was assumed to represent an equal portion of the population.

Table 1. Overall Weighted Flow Rate Values for Various Classes of Samples Device Classification

\begin{tabular}{|c|c|c|c|}
\hline Device Ciassincation & $\begin{array}{l}\text { How Rate } \\
\text { [Gallons per } \\
\text { Minute] }\end{array}$ & $\begin{array}{l}\text { Hlow Rate } \\
\text { [Liters per } \\
\text { Minute] }\end{array}$ & [m $\mathrm{m}^{3}$ per second] \\
\hline Existing Shower Heads Replaced ${ }^{1}$ & 5.68 & 21.5 & 0.000358 \\
\hline $\begin{array}{l}\text { All New Shower Heads Included in the Study } \\
\text { (Large Number of 2.0 GPM) Samples) }\end{array}$ & 1.86 & 7.04 & 0.000117 \\
\hline $\begin{array}{l}\text { Early BPA Supplied Replacement Shower } \\
\text { Heads (Large Number of } 2.5 \text { GPM) Samples) }\end{array}$ & 2.28155 & 8.63658 & 0.0001439 \\
\hline BPA Supplied Faucet Aerators & 2.03 & 7.68 & 0.000128 \\
\hline
\end{tabular}

Note that neither 'new' shower head set achieves the maximum flow rates. Most residences are supplied at water pressures significantly less than the 80 psi value stipulated by BPA specification.

1 Refer to "Discussion of Result". 
Figure 1 illustrates this points. The weighted flow rates represent the regional demographic supply pressure differences. All of these devices control flow by one on two mechanisms: regulating or restricting. Typical regulator and restrictor curves are displayed against a backdrop of the supply pressure distribution. Although the regulator curve shown is a 2 GPM device, the figure illustrates the predominant supply pressures and characteristic flows.

Flow rate curves for each model device are included at the end of this report. Figures 2-5 are composite graphs of these individual curves and summarize the results.

Figures 2 and 3 illustrate the performance of the 'new' shower heads. Figure 2 displays the flow performance curve for the regulators and Figure 3 presents the restrictor curves. Note the distinctly different profiles of the curves. This indicates that the shower heads control the flow rate by two different mechanisms. The restricting mechanisms respond almost linearly with increasing pressure, while the regulating mechanisms tend to dither around the set point independent of supply pressure.

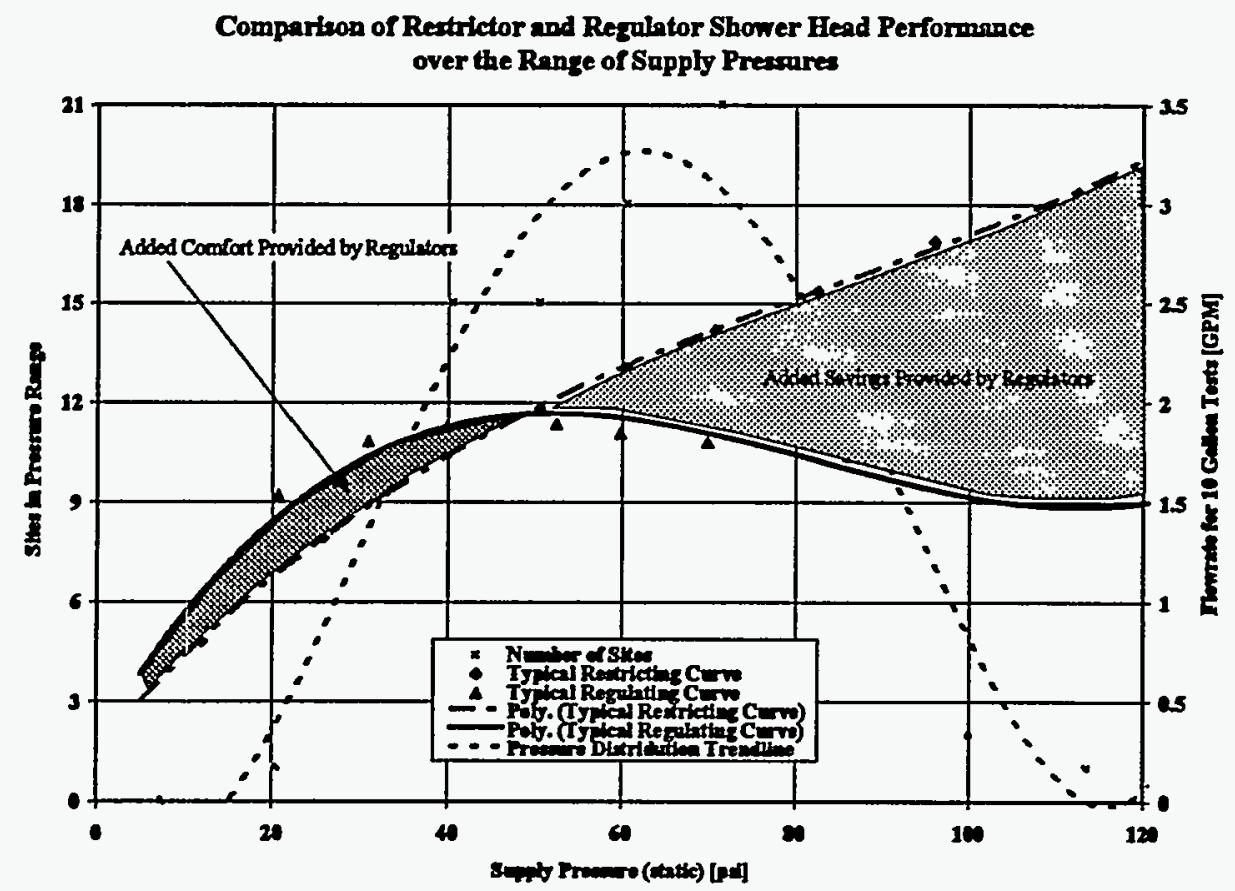

Figure 1. Explanation for Average Shower Head Flow Rates Less Than 2.5 GPM. 


\section{Overall Performance of New Regulator Shower Heads}

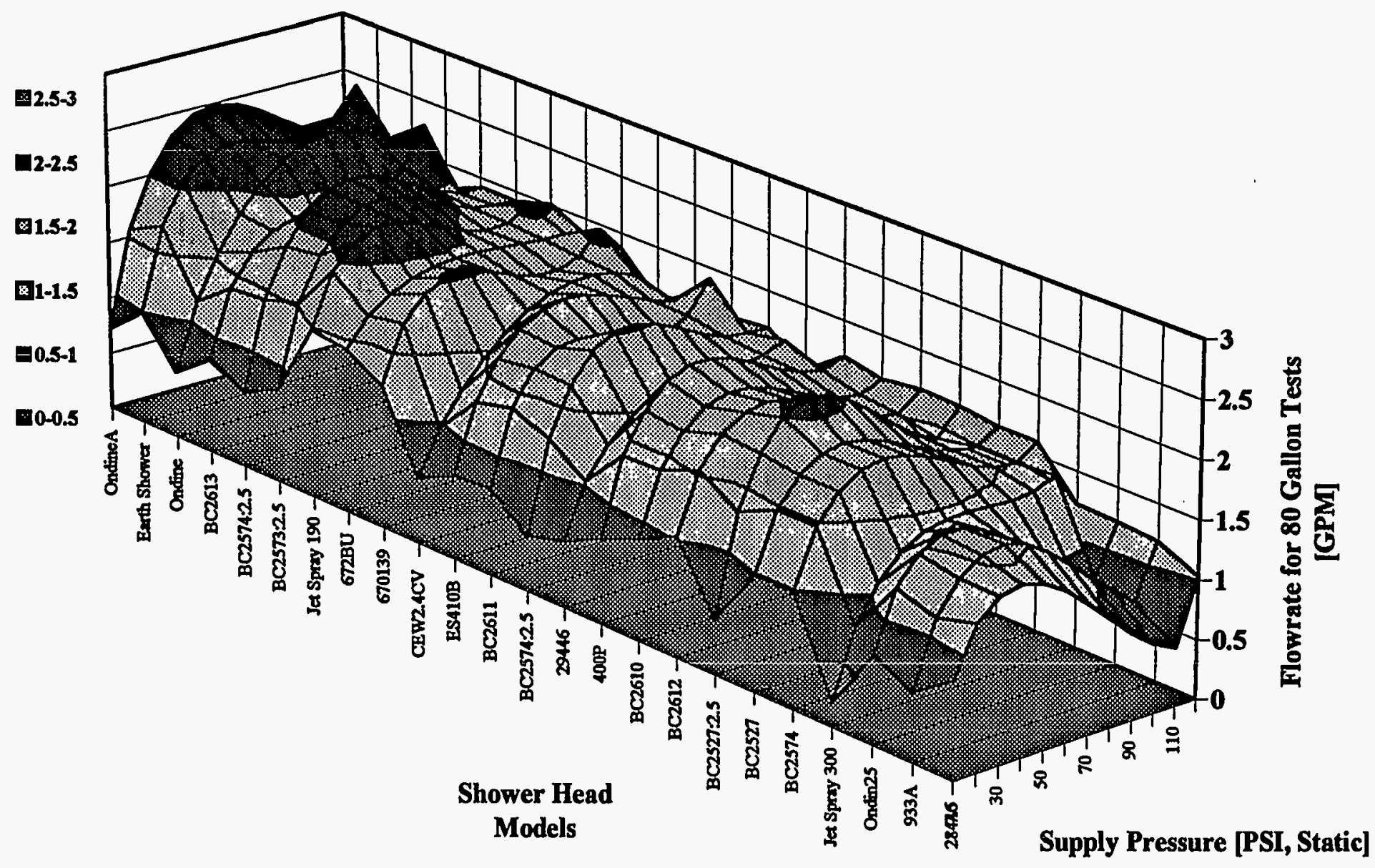




\section{Overall Performance of New Restrictor Shower Heads}

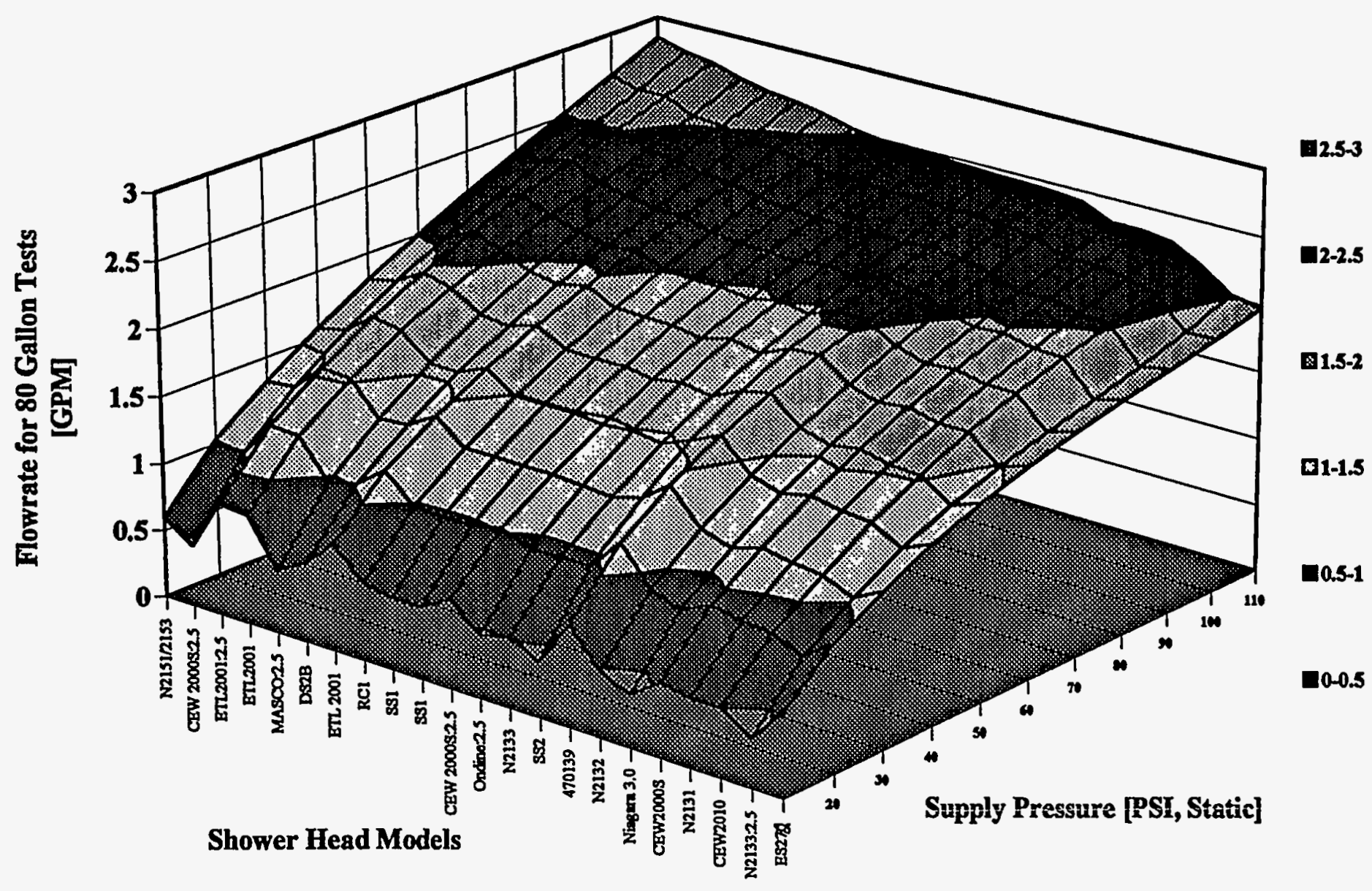


Figure 4 presents the data for selected old shower heads replaced over the course of the program. If these units are adjustable, they were tested 'as found'. They generally showed higher flow rates than the replacement units. Typically, the old shower heads performed like restrictors. Some of the replaced units actually were 'low-flow' models. New units were evaluated at the most energy efficient setting. Note the difference in the flow rate scale between this and the Figures for the new shower heads.

While many of the old shower heads can produce excessively high flows, demographic data demonstrates that the actual in-service flows rarely exceed 4 GPM. The following section, "DISCUSSION OF RESULTS", explores this apparent inconsistency in results.

Figure 4. Old Shower Head performance Summary Overall Performance of Old Shower Heads

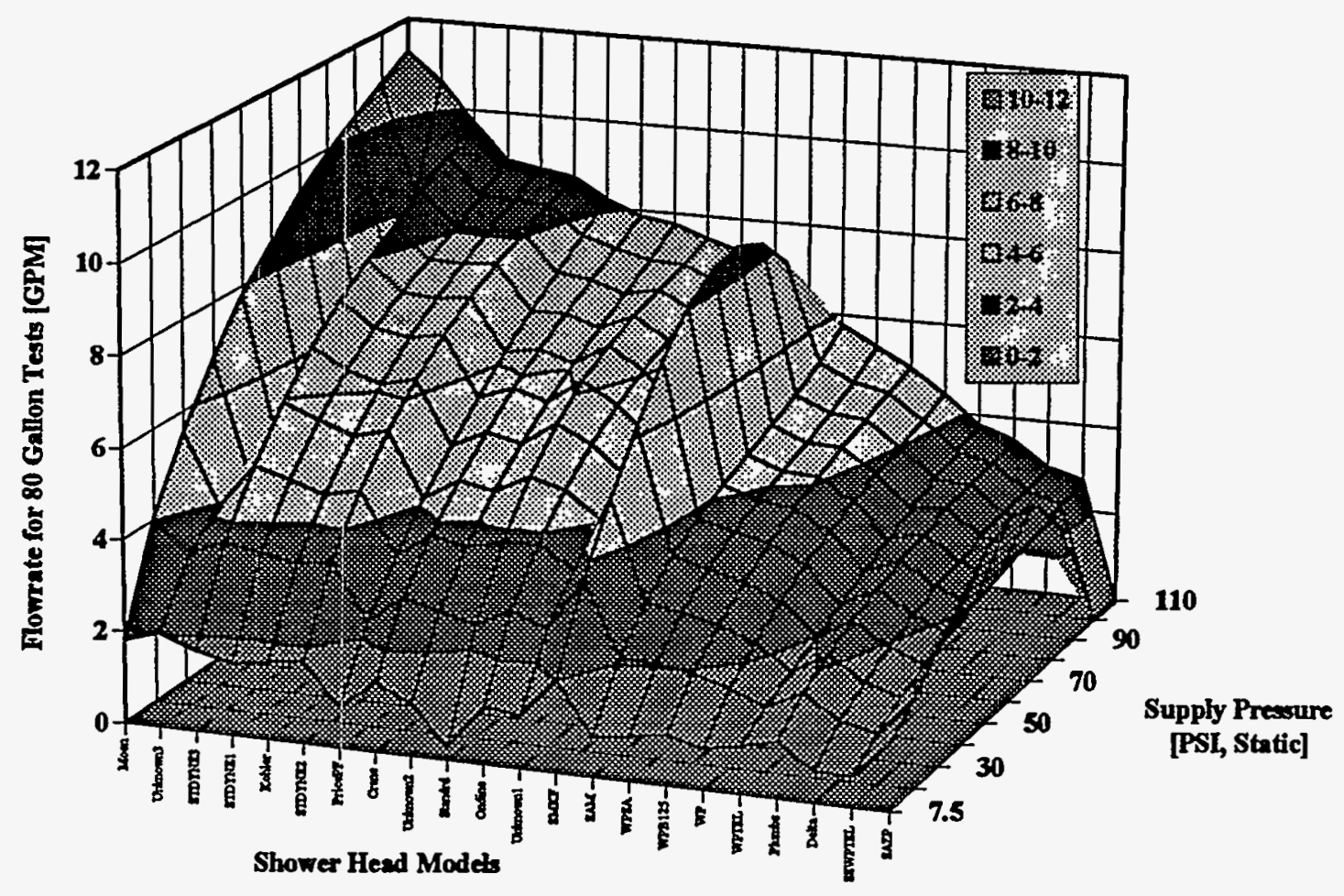


Figure 5 presents a summary of the flow performance of the new aerators included in this study. Faucet aerators all performed like restrictors

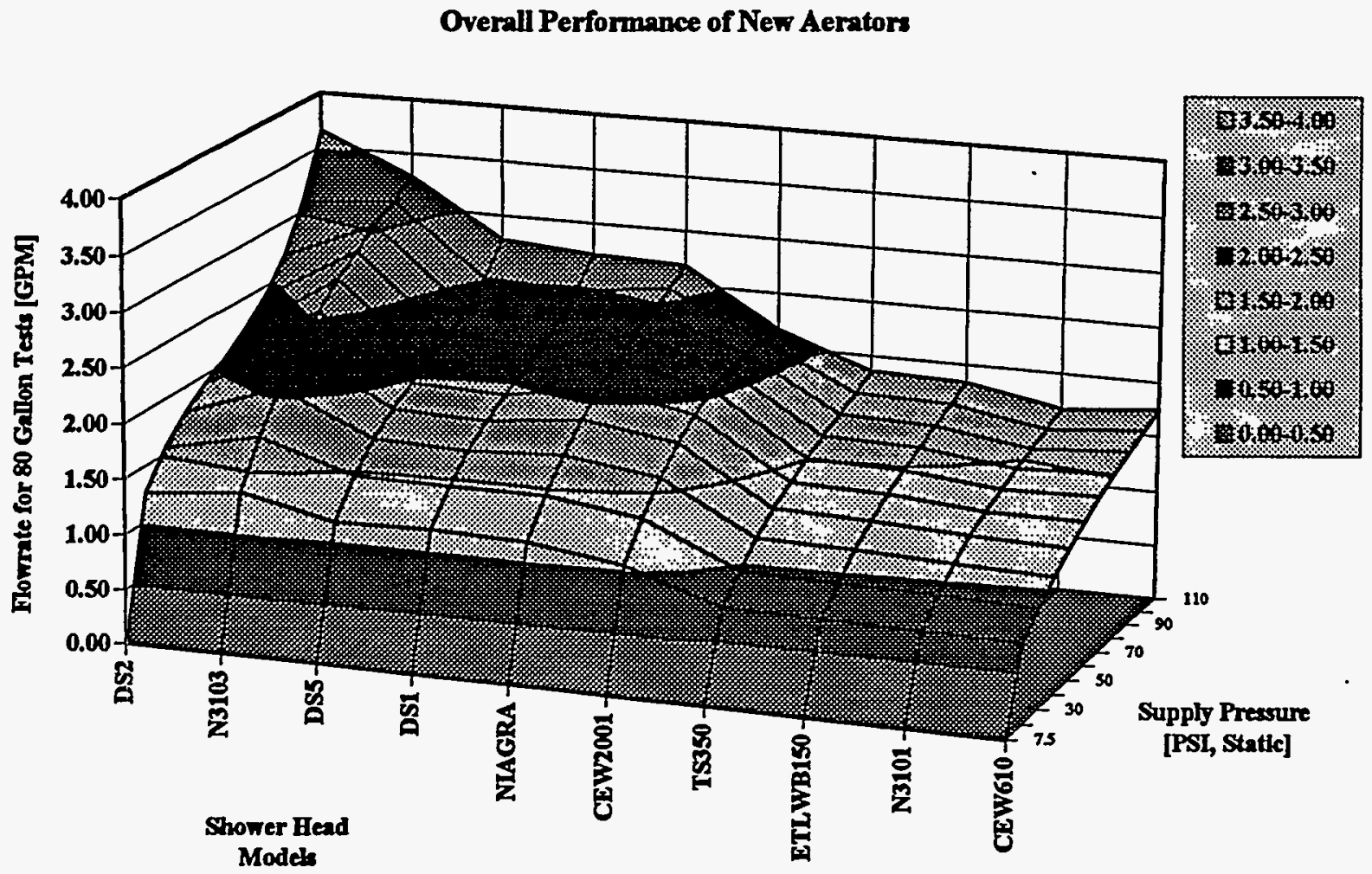

Figure 5. Overall Performance of New Aerators.

\section{DISCUSSION OF RESULTS}

The results of the Laboratory tests suggest greater savings potential than is actually achievable. Figure 6 summarizes the flow rates which contractors recorded for the old shower heads at field sites before installing the new units. Field data indicates that the average flow rate of all old shower heads is in the range of 3 to 4 gallons per minute[GPM], as opposed to the 5 GPM reported for the laboratory tests.

Figure 6 includes data from only about 200 sites, however, the majority of the existing shower heads produced flows in the range of those expected for the newer 'conservation' units. Several factors may account for this discrepancy between field and laboratory data: 


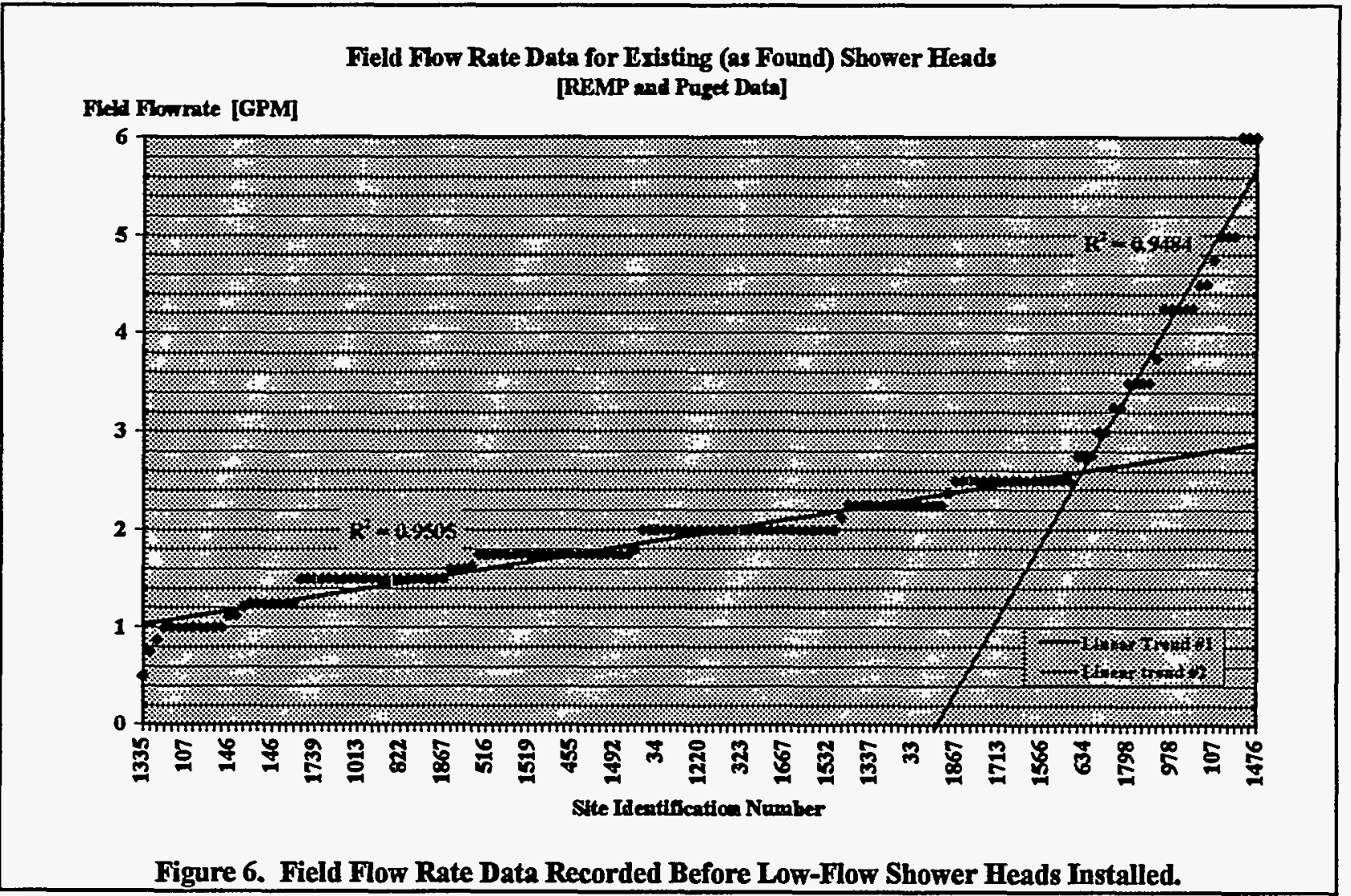

1. Residential pipe fouling factors. Older galvanized plumbing that predominates the older home market corrodes internally. The accumulated build-up of oxidized material effectively reduces the pipe size and flow capacity. In effect, the house plumbing serves as the flow restrictor.

2. Pipe fittings and shower control fixtures. 'Joystick' style shower controls are designed with small orifice valves and small diameter mixing tubes. 
Figure 7 presents a refined analysis of this disparity between the laboratory and field site results. The data consists of the flow rate recorded for a particular shower head in its field location and in the laboratory, when tested at the same supply pressure. The data is organized in order of increasing laboratory flow rates. Notice the two data sets maintain a rough equivalence until flow rates reach a magnitude of approximately 4 gallons per minute. At that point, the departure between the two data sets is dramatic.

\section{Comparison of Field \& Laboratory Data for Old Shower Heads Arranged in Order of Ascending Lab Flow Rate Data}

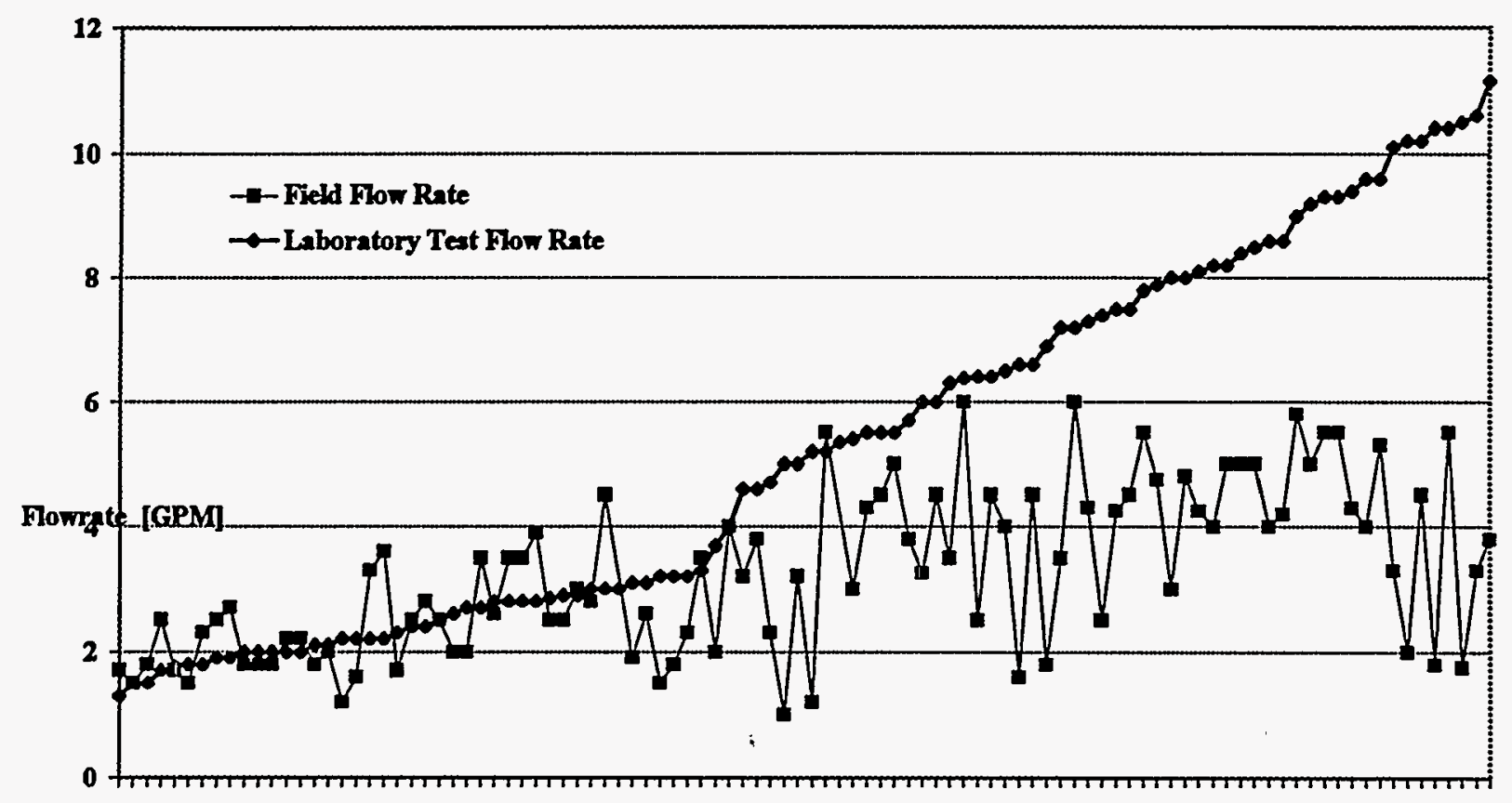

Figure 7. Comparison of Flow rates for Shower Heads Tested at Field Sites and in The Laboratory

Figure 8 presents the same two data sets and adds the magnitude of the supply pressure to each test point. Also included are two trend lines: one for the test pressure and one for the flow data recorded in the field. The test pressure used for this evaluation is the value recorded at the field site. Although the pressure data represents a high degree of scatter, there is a general upward trend. Note how closely the trend line for the field data matches the results obtained by the laboratory evaluation until flows reach a magnitude of approximately 3 gallons per minute. It appears that the performance of a given shower head or the supply pressure are less critical to the developed flow rate for flows beyond this value. This indicates that the attached plumbing circuit regulates the maximum achievable flow. For the case of a shower head installed in a home, with 


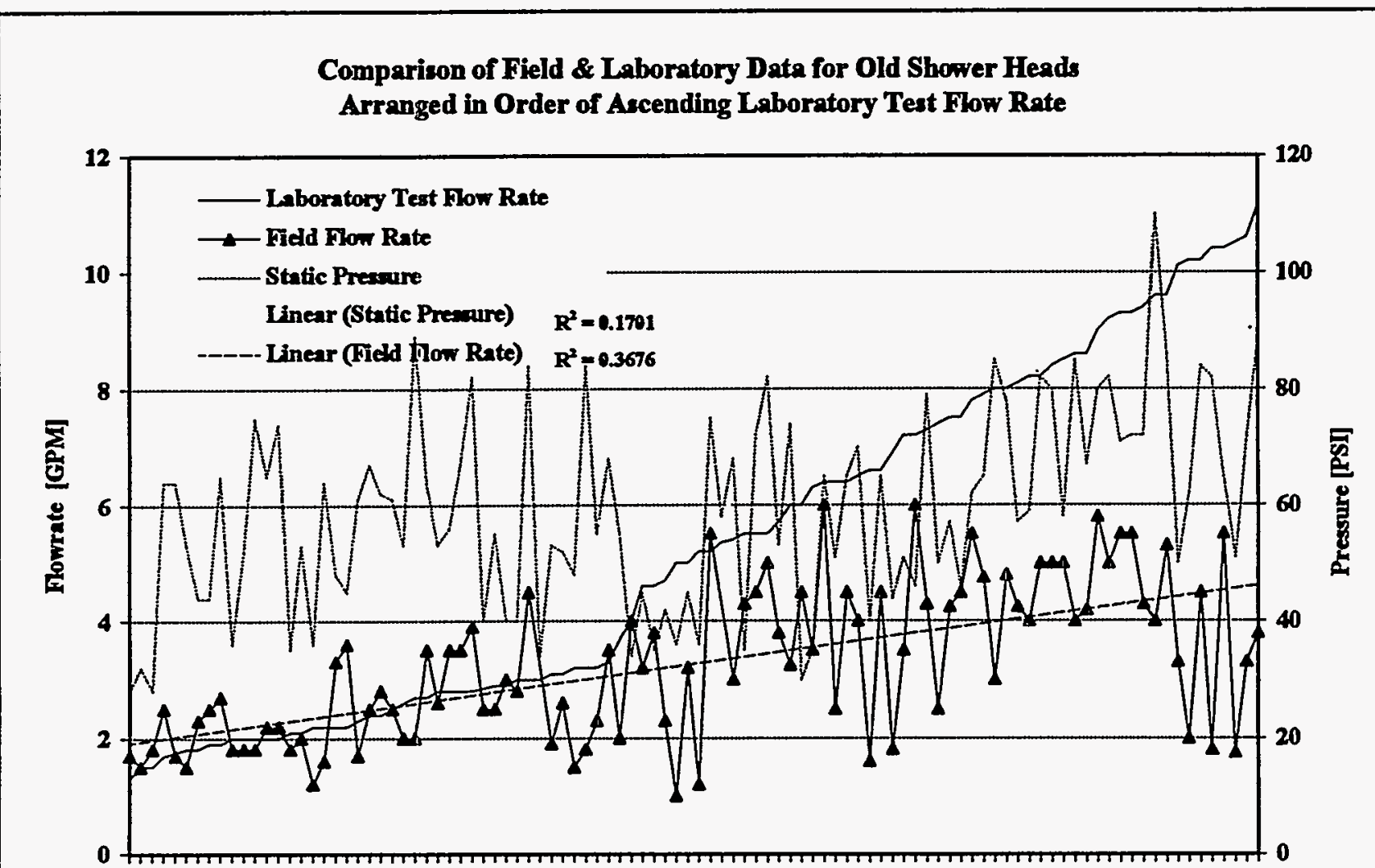

Figure 8. Comparison of Flow Rate Results Obtained for Old Shower Heads in Field Locations and in the Laboratory.

long lengths of pipe and the associated valving, this flow is regulated to a magnitude less than 6 gallons per minute. The median flow rates are actually less than 4 gallons per minute. The laboratory test stand, with significantly less pipe length and most important, no small-port regulating valves, allows shower heads to develop much higher flow rates than are characteristic of the devices installed in the field.

\section{DETAILED DESCRIPTION OF TESTING AND RESULTS}

\section{METHOD}

The time required to discharge a specified mass of water determined the test sample flow rate. The tests were conducted with water heated to a nominal temperature of $40^{\circ} \mathrm{C}\left(105^{\circ}\right.$ 
F). A minimum of 3 and maximum of 10 samples of each device were tested over the full pressure range of expected supply pressures [70 to $840 \mathrm{KPa}$ (10 to $120 \mathrm{psi})$ ] at ten preset pressure magnitudes. The number of samples evaluated depended on the data variation recorded for the initial three units. Once three samples were tested, the results were plotted and a third order curve fit applied to the data. The agreement of the fit, or " $\mathbf{R}$ " value was calculated. The higher the " $\mathbf{R}$ ", the better the agreement. To achieve a target of 0.90 agreement, additional samples could be tested, as summarized in the schedule shown as Table 2

Table 2. Determination of Number of Samples to Test.

The large number of samples included in the program prompted automating the test fixture to achieve significant savings. A personal computer

Number of Samples Allowable Variation

$\begin{array}{cll}\text { Schedule I } & 3 & \mathbf{R}^{2} \geq .90 \\ \text { Schedule II } & 3 & \mathbf{R}^{2} \geq .85 \\ \text { Schedule III } & 4 & \mathbf{R}^{2} \geq .85\end{array}$

(PC) running ViewDAC ${ }^{\mathrm{TM}}$, a data acquisition and control (DAC) package drove a Keithly Model 575 DAC unit. The DAC system sequenced the test fixture, collected and recorded mass, time, and pressure data, and calculated flow rates. The time required to fully test each sample was approximately 1 hour. The automation also included the capability to load five individual samples for sequential testing. This permitted additional unattended testing during non-working hours. The data was analyzed using EXCEL ${ }^{\pi 4}$. This package also produced the presentation graphics and curve-fit analysis.

A plumbing circuit, illustrated in Figure 9 was configured and instrumented to perform the tests. Ten adjustable pressure regulators installed in individual branch circuits equipped with solenoidoperated valves permitted sequential selection of preset test pressures. An additional solenoidoperated valve, located between the regulator assemblies and the test sample, controlled the test duration. Actually, five solenoids were installed in parallel at this location to permit unattended, sequential testing of up to five samples. A strain gage transducer located immediately before this main-line solenoid valve monitored supply pressure. Both the static pressure measured in the line without flow and the dynamic pressure were recorded during the test.

A calibrated, $450 \mathrm{~kg}$ (1000 pound) capacity strain-gage load cell measured water mass collected in a suspended container for a sample under test. A minimum of $38 \mathrm{~kg}$ ( 80 pounds) of water was collected for each test pressure. This mass corresponds to $0.038 \mathrm{~m}^{3}$ [38 $\left.\mathrm{L}\right]$ (10 gallons). A multi-staged centrifugal pump was used to supply water at 40 Liters per minute (10 GPM) at $830 \mathrm{KPa}(120 \mathrm{psi})$. 


\section{Shower Head Sample Description}

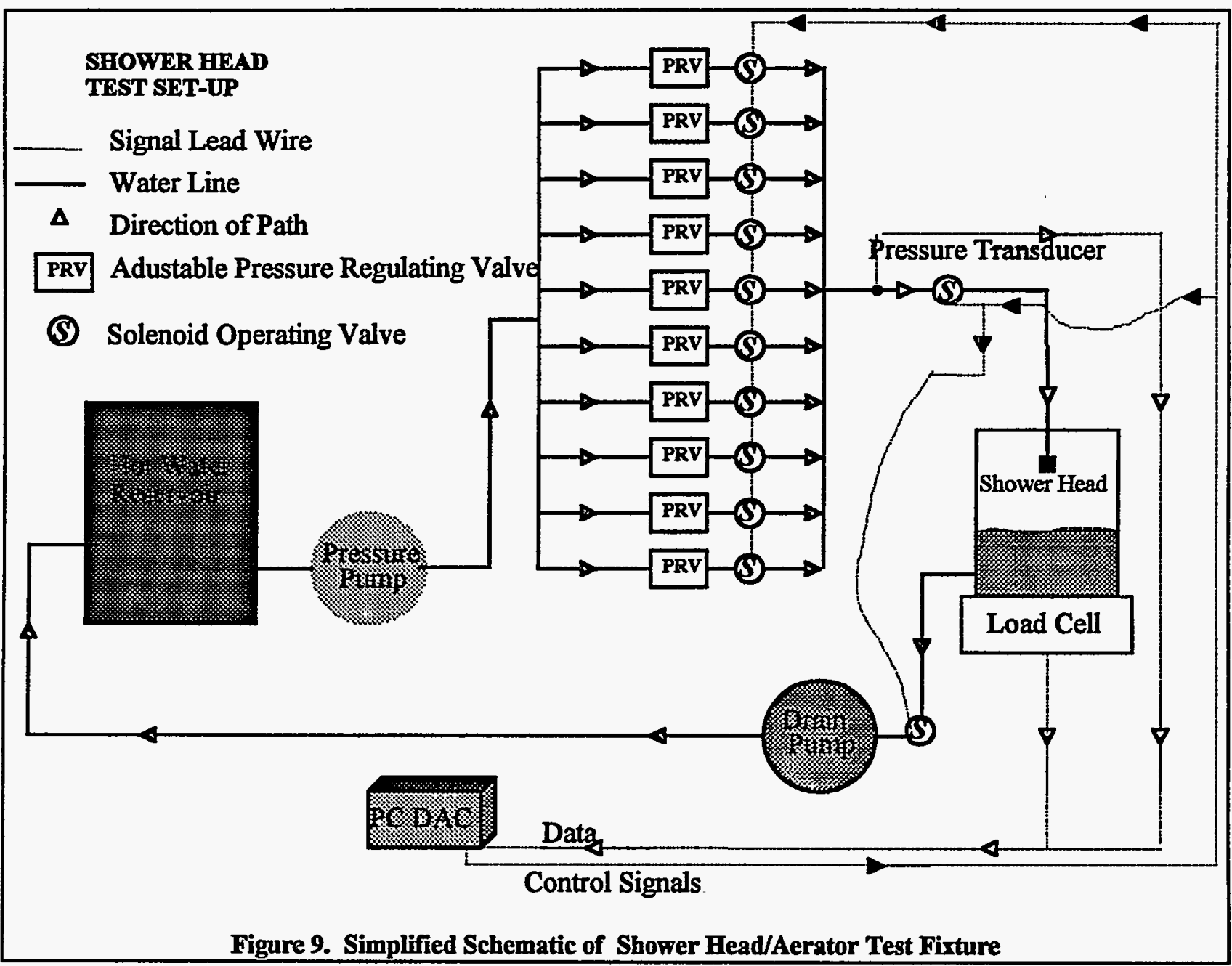

The performance of new shower heads and aerators representative of those distributed by BPA is characterized by two distinct types of flow curves:

- $\quad$ Restricting;

- Regulating.

The restrictor types typically showed linearly increasing flow rates with increased supply pressures. The regulator types typically approximated constant flow rates over the common range of supply pressures. Figure 10 illustrates the performance curve characteristic of each type. Each data point represents one test. Ten gallons of water were run through the device at each of 
the ten pressure steps. If the spray pattern of any of these devices was adjustable, it was set to the most conservative setting.

\section{Comparison of Regulating -ve-Restricting Flow Performance Curve}

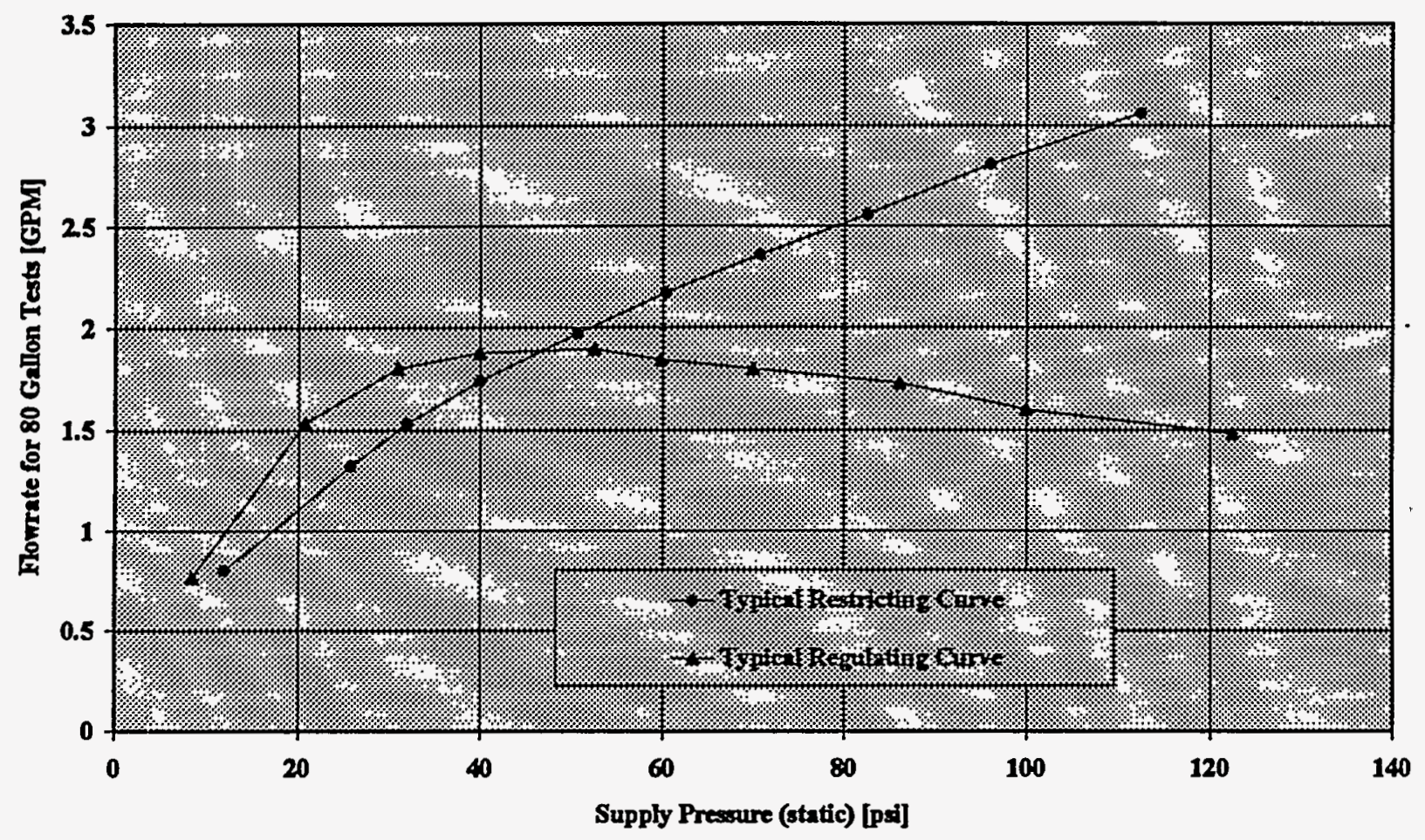

Figure 10. Flow rate Curves for Regulating and Restricting Shower Heads

All of the old shower heads removed from domestic service units were tested 'as found'. The spray patterns were not adjusted and any leaks not associated with connection to the test set or obviously resulting from removal from service were not corrected.

The individual model test results are reported graphically. Table 5 lists the flow rate for each device at each test pressure.

\section{DATA ANALYSIS}

A minimum of three of each device model was tested at ten different supply pressures. The test data for all samples of a particular model was plotted on a scatter graph against the static pressure 
recorded for each individual test run. A third order curve was fit to the values and the agreement, or $\mathbf{R}^{2}$ value calculated. The magnitude of $\mathbf{R}^{2}$ indicated how well the curve fits the data, higher values indicate a better match. In some cases additional samples were run. This decision was based on the agreement of the curve with the data. As an example, Figure 11 illustrates the test data recorded for three samples of the same model and the subsequently produced curve fit.

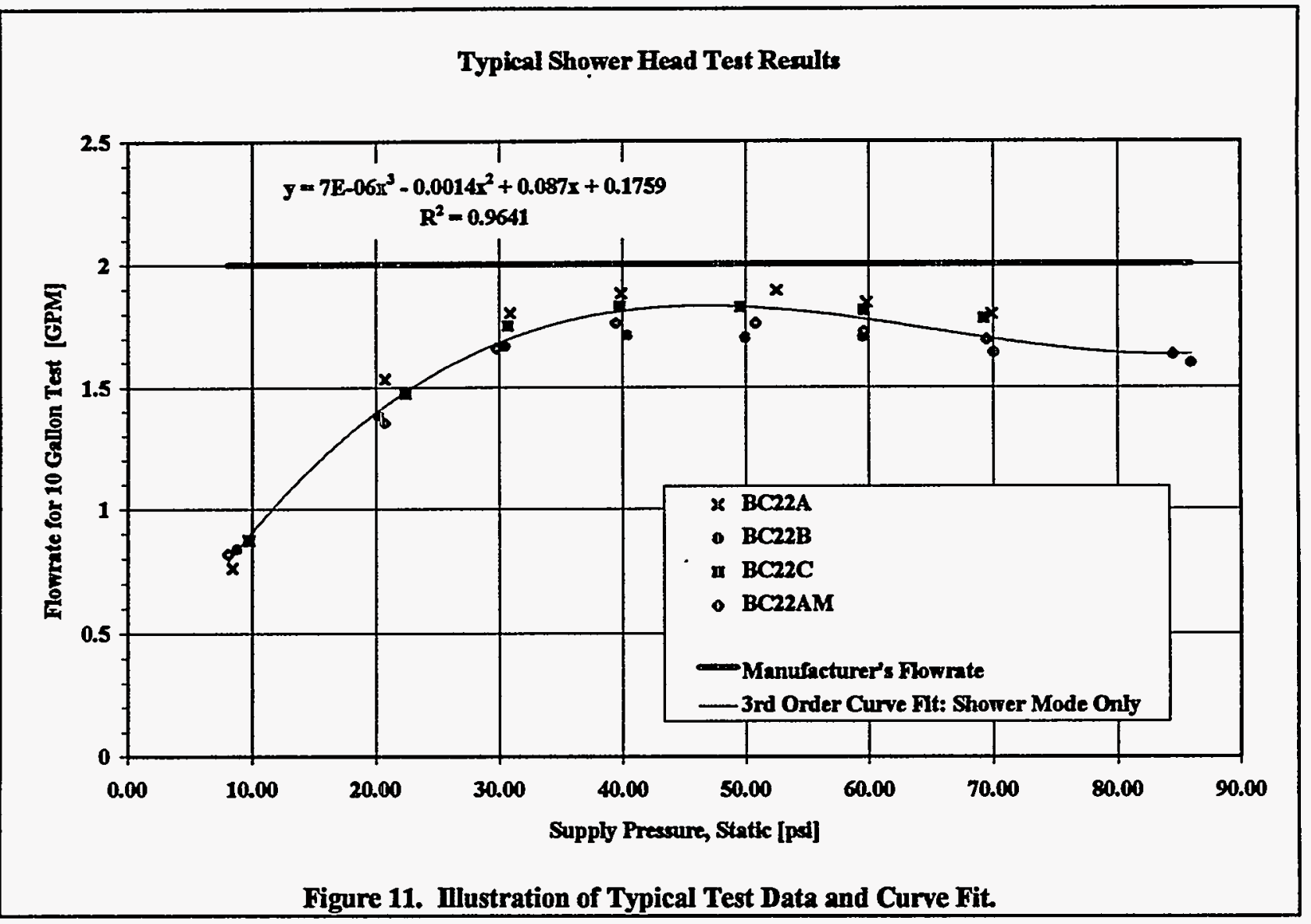

The object of the project was two-fold:

A. Assess the performance of each model purchased by BPA for distribution;

B. Determine the overall flow rate realized for all the shower heads installed over the entire BPA service area.

The first objective was met simply by testing each of the available shower heads. That data is presented in a following section. For each model, flow data is plotted against the static pressure. This is the pressure measured in a plumbing circuit with no flow. The dynamic pressure, or pressure magnitude measured during flow varies, with the flow rate. During periods of flow, some of the static head is converted to kinetic energy. However, the difference between the static 
and dynamic pressures primarily results from losses due to 'flow friction' within the piping and to components such as valves and fittings. Static pressure is a preferable comparative value as it is more easily measured. It is a valid comparative value as the losses within the supply piping are the same for all samples tested when the flow magnitudes are equal.

Accomplishing the second objective required determining two weighting factors. Data from the

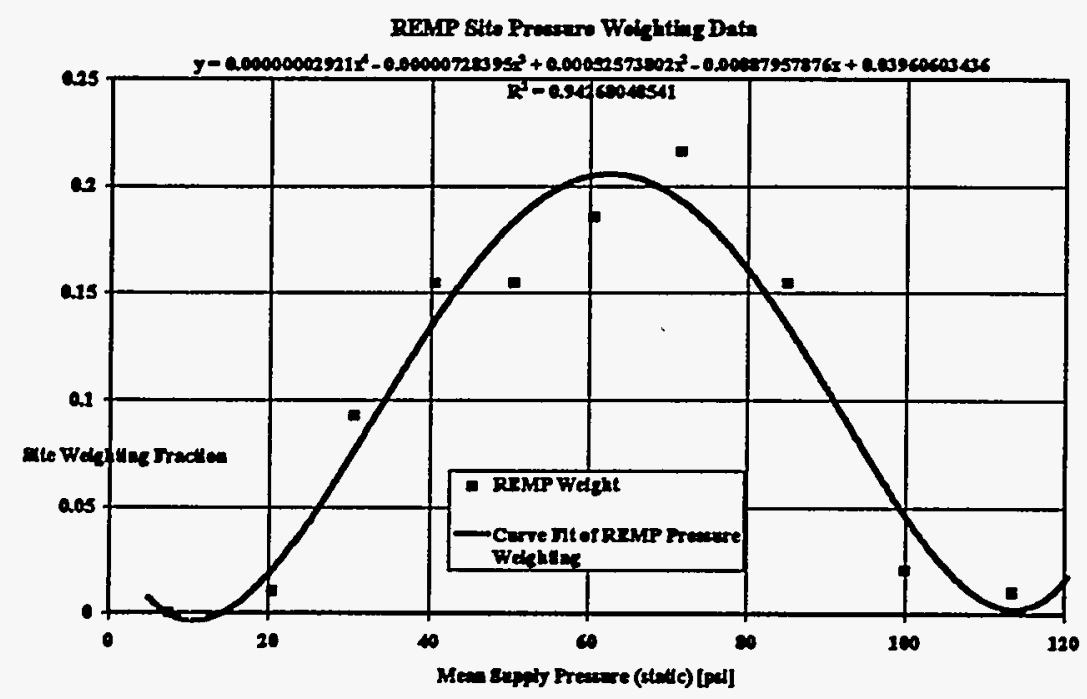

REMP field study was used to develop a curve fit approximation that models the typical pressure distribution in the service area. Figure 12 illustrates the supply pressure data points used to construct the model. The data resulted from a study group consisting of approximately 100 sites.

Figure 12. Distribution of Supply Pressures Reported for the REMP Study Group

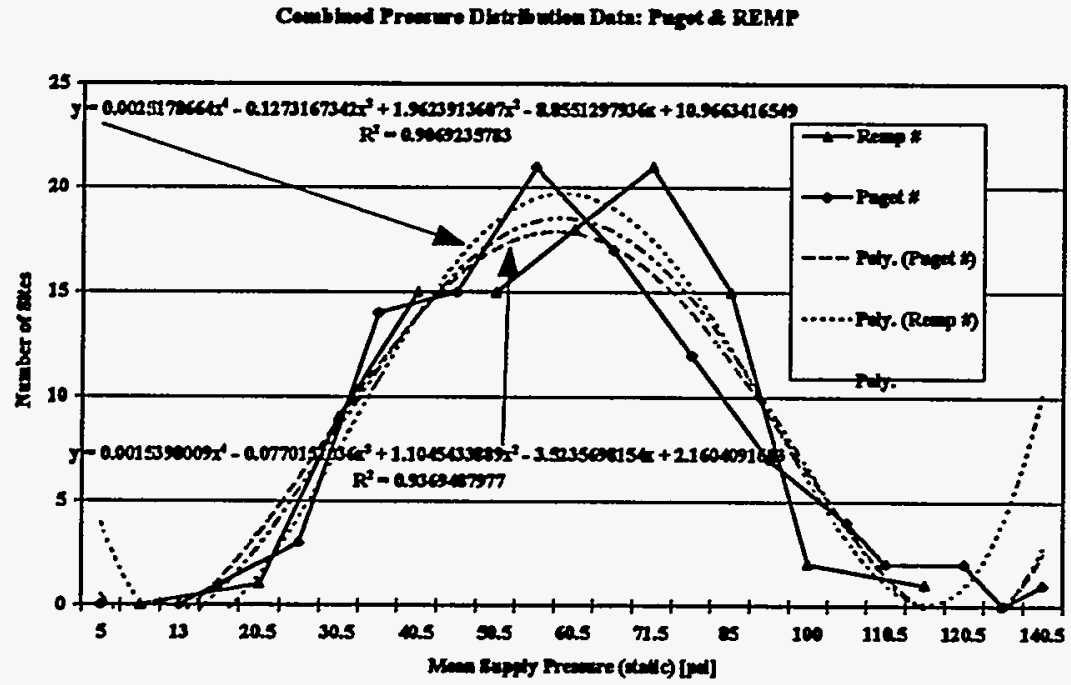

Figure 13. Comparison of Supply Pressures for the REMP and Puget Sound Area Study Groups. 
A second survey of water supply pressures was conducted in the Puget Sound area. This study group also consisted of approximately 100 sites. The Puget and REMP data sets are shown together as Figure 13. The good agreement between the two studies helps establish the validity of the relatively small sample size.

A second weighting factor was developed that reflects the fraction that each individual model represents of the entire population of purchased samples. This information evolved from tallying the purchasing logs. A listing of the different samples and the associated quantities are included in a following section. Note that the representative samples available and included in this test program represent more than $90 \%$ of units purchased for this program. For the purpose of this evaluation, the calculated, overall flow rates assume that this portion is representative of the total population. Therefore, the results are an approximation of the actual situation, but it is a good approximation, especially considering the limited field supply pressure data.

These weighting factors were applied to the results for all new shower heads tested according to the following algorithm:

$$
\sum_{j}^{D}\left[\sum_{i}^{P} \text { (Flowrate of a given device @ a Given Pressure) } * i\right] * j
$$

Where:

Flow rates at specific test pressures are from the test data and subsequently derived curve fits;

$\mathrm{i} \equiv$ fraction a pressure represents of the overall pressure distribution, as shown in Figure 4;

$\mathrm{P} \equiv$ the test pressure ranges, from 69 to $830 \mathrm{kPa}$ (10 to $120 \mathrm{psi}$ )

$j \equiv$ fraction a particular device represents of the total installed population of those devices tested;

$\mathrm{D} \equiv$ the population of all devices available for testing.

\section{DATA PRESENTATION}

Key information produced in the performance of this project or provided from other sources and used to develop analytical models is presented in tabular form. Where appropriate, the data is also provided graphically in the next section. 
Tabular Data

The following tables portray:

- The water conservation devices purchased by BPA. Those included in this study are noted.

- Flow rates for each tested device;

- Northwest static supply pressure distribution. 
NEW SHOWER HEAD DATA

Table 3. Listing of Devices Purchased and Tested.

\begin{tabular}{|c|c|c|c|c|c|}
\hline Manufacturer & Model & $\begin{array}{c}\text { Showers } \\
\text { Purchased }\end{array}$ & $\begin{array}{c}\text { Test } \\
\text { Showers }\end{array}$ & $\begin{array}{l}\text { Shower } \\
\text { Fraction }\end{array}$ & $\begin{array}{c}\text { Manufacturer's } \\
\text { Fraction }\end{array}$ \\
\hline \multirow{6}{*}{ ONDINE } & Ondine25 & 100 & 100 & 0.0002 & \multirow[b]{6}{*}{0.3240} \\
\hline & OndineA & 10000 & 10000 & 0.0177 & \\
\hline & 28446 & 124360 & 125260 & 0.2219 & \\
\hline & 29446 & 26505 & 26505 & 0.0470 & \\
\hline & $28446 / 27418$ & 900 & & & \\
\hline & $933 \mathrm{~A}$ & 21000 & 21000 & 0.0372 & \\
\hline \multirow{9}{*}{ BRASS CRAFT } & BC2527 & 6213 & 6213 & 0.0110 & \multirow[b]{9}{*}{0.4841} \\
\hline & $\mathrm{BC} 2530$ & 700 & & & \\
\hline & BC2531 & 12600 & & & \\
\hline & $\mathrm{BC} 2573$ & 198479 & 198479 & 0.3516 & \\
\hline & BC2574 & 43825 & 43825 & 0.0776 & \\
\hline & BC2610 & 3250 & 3250 & 0.0058 & \\
\hline & $\mathrm{BC} 2611$ & 19200 & 19200 & 0.0340 & \\
\hline & BC2612 & 950 & 950 & 0.0017 & \\
\hline & $\mathrm{BC} 2613$ & 1340 & 1340 & 0.0024 & \\
\hline \multirow[t]{7}{*}{ NIAGARA } & N2131 & 600 & 600 & 0.0011 & \multirow[b]{7}{*}{0.0662} \\
\hline & N2132 & 130 & 130 & 0.0002 & \\
\hline & N2133 & 3665 & 3665 & 0.0065 & \\
\hline & N2150 & 2612 & 2612 & 0.0046 & \\
\hline & $\mathrm{N} 2151 / 2153$ & 526 & 526 & 0.0009 & \\
\hline & $\mathrm{N} 2800$ & & & & \\
\hline & N2900EarthShower & 29850 & 29850 & 0.0529 & \\
\hline \multirow[t]{3}{*}{ ETL } & ETL2001/2.5 & 7615 & 13240 & 0.0235 & \multirow[b]{3}{*}{0.0252} \\
\hline & ETL2001/2.0 & 1000 & 1000 & 0.0018 & \\
\hline & BP01 2001 & 5625 & & & \\
\hline \multirow[t]{3}{*}{ ALSONS } & 672BX & 1689 & 1689 & 0.0030 & \\
\hline & 682BX & 40 & & & \\
\hline & 670BX & 10020 & 10020 & 0.0178 & \\
\hline \multirow[t]{3}{*}{ CEW } & CEW2000 & 18525 & 18525 & 0.0328 & \multirow[b]{3}{*}{0.0653} \\
\hline & CEW2010 & 5320 & 5320 & 0.0094 & \\
\hline & CEW24CV & 1319 & 1319 & 0.0023 & \\
\hline Whedon & DS2B & 850 & 850 & 0.0015 & 0.0015 \\
\hline RESOURCES & ES270 & 17590 & 17590 & 0.0312 & \multirow[b]{5}{*}{0.0336} \\
\hline CONSERVATION & ES410B & 1365 & 1365 & 0.0024 & \\
\hline & ES971 & 1365 & & & \\
\hline & PP315 & 300 & & & \\
\hline & $400 \mathrm{P}$ & 20 & 20 & 0.0000 & \\
\hline \multicolumn{2}{|l|}{ TOTALS } & 579428 & 564443 & 1.0000 & 1.42928 \\
\hline
\end{tabular}


Table 4. Flow Rntes for Niew Shower lieads Typical or Those Purchased for BPA Progran a! Ten Pressures

Population Weighting Factors Represent Actual BPA Program Purchascs of Shower Heads will Flow Rates Cireater than 2.0 GPa

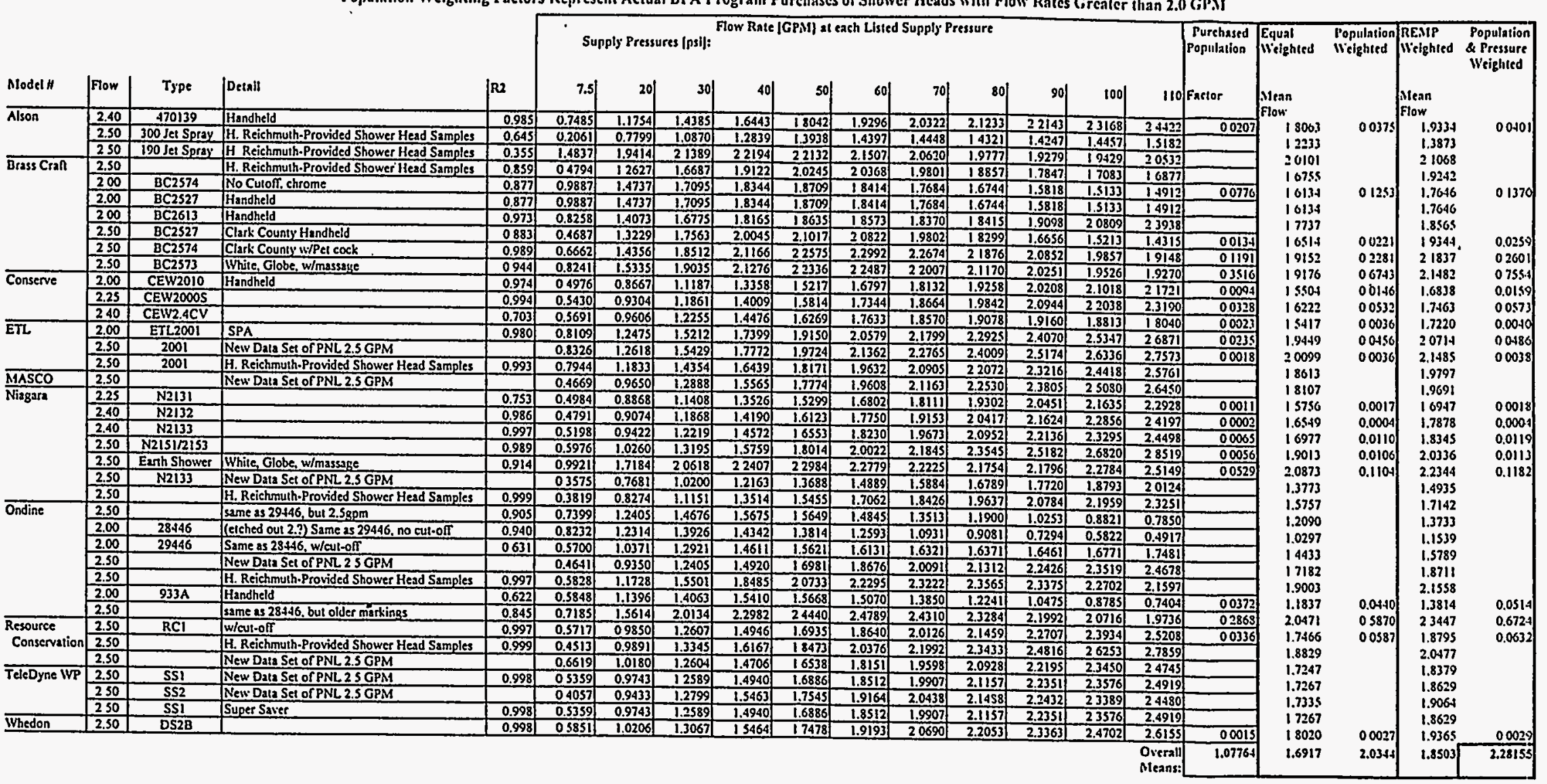




\section{IFLOW RATE CURVES FOR NEW SHOWER HEADS}

\begin{tabular}{|c|c|c|c|c|c|}
\hline \multicolumn{3}{|c|}{$\begin{array}{l}\text { Table 5. Field Study Pressure Data. } \\
\qquad \text { Supply Pressure [psi] }\end{array}$} & \multirow[b]{2}{*}{ High } & \multicolumn{2}{|c|}{ Number of Sites } \\
\hline & Low & Mean & & REMP & Weight \\
\hline \multirow[t]{10}{*}{ REMP } & 0 & 7.5 & 15 & 0 & 0 \\
\hline & 16 & 20.5 & 25 & 1 & 0.010309 \\
\hline & 26 & 30.5 & 35 & 9 & 0.092784 \\
\hline & 36 & 40.5 & 45 & 15 & 0.154639 \\
\hline & 46 & 50.5 & 55 & 15 & 0.154639 \\
\hline & 56 & 60.5 & 65 & 18 & 0.185567 \\
\hline & 66 & 71.5 & 77 & 21 & 0.216495 \\
\hline & 78 & 85 & 92 & 15 & 0.154639 \\
\hline & 93 & 100 & 107 & 2 & 0.020619 \\
\hline & 107 & 113.5 & 120 & 1 & 0.010309 \\
\hline & & & \multicolumn{2}{|l|}{ Totals: } & \\
\hline \multirow{15}{*}{$\begin{array}{l}\text { Puget } \\
\text { Sound }\end{array}$} & 0 & 5 & 10 & 0 & 0 \\
\hline & 11 & 13 & 15 & 0 & 0 \\
\hline & 16 & 20.5 & 25 & 1 & 0.010101 \\
\hline & 26 & 30.5 & 35 & 3 & 0.030303 \\
\hline & 36 & 40.5 & 45 & 14 & 0.141414 \\
\hline & 46 & 50.5 & 55 & 15 & 0.151515 \\
\hline & 56 & 60.5 & 65 & 21 & 0.212121 \\
\hline & 66 & 70.5 & 75 & 17 & 0.171717 \\
\hline & 76 & 80.5 & 85 & 12 & 0.121212 \\
\hline & 86 & 90.5 & 95 & 7 & 0.070707 \\
\hline & 96 & 100.5 & 105 & 4 & 0.040404 \\
\hline & 106 & 110.5 & 115 & 2 & 0.020202 \\
\hline & 116 & 120.5 & 125 & 2 & 0.020202 \\
\hline & 126 & 130.5 & 135 & 0 & 0 \\
\hline & 136 & 140.5 & 145 & 1 & 0.010101 \\
\hline & & & \multicolumn{2}{|l|}{ Totals: } & \\
\hline
\end{tabular}

Table 6. Combined Field Pressure Data Used to Develop Weighting Factors

\begin{tabular}{|c|c|c|c|c|c|}
\hline & \multicolumn{3}{|c|}{ Supply Pressure Ipsi] } & \multirow{2}{*}{$\begin{array}{l}\text { Number } \\
\text { of Sites } \\
\text { REMP }\end{array}$} & \multirow[b]{2}{*}{ Weight } \\
\hline & Low & Mean & High & & \\
\hline \multirow{15}{*}{$\begin{array}{c}\text { Combined } \\
\text { Data }\end{array}$} & 0 & 5 & 10 & 0 & 0 \\
\hline & 11 & 13 & 15 & 0 & 0 \\
\hline & 16 & 20.5 & $\overrightarrow{25}$ & 2 & 0.010204 \\
\hline & 26 & 30.5 & 35 & 12 & 0.061224 \\
\hline & 36 & 40.5 & 45 & 29 & 0.147959 \\
\hline & 46 & 50.5 & 55 & 30 & 0.153061 \\
\hline & 56 & 60.5 & 65 & 39 & 0.19898 \\
\hline & 66 & 70.5 & 75 & 38 & 0.193878 \\
\hline & 76 & 80.5 & 85 & 12 & 0.061224 \\
\hline & 86 & 90.5 & 95 & 22 & 0.112245 \\
\hline & 96 & 100.5 & 105 & 6 & 0.030612 \\
\hline & 106 & 110.5 & 115 & 3 & 0.015306 \\
\hline & 116 & 120.5 & 125 & 2 & 0.010204 \\
\hline & 126 & 130.5 & 135 & 0 & 0 \\
\hline & 136 & 140.5 & 145 & 1 & 0.005102 \\
\hline & & & Totals: & .196 & 1 \\
\hline
\end{tabular}


The data for the shower heads removed from service is listed in the following Tables. Table 8 lists the flow rate for each old model at the ten test pressures tested. Table 9 presents the data, weighted to reffect the regional supply pressure conditions. Flows at the 7.5 psi pressure were forced to zero to prevent reporting negative values developed from the curve fits.

Table 7. Flow Rates for Old Shower Heads Typical or Those Removed from Honies During BPA Program Implementation Ten Pressures

\begin{tabular}{|c|c|c|c|c|c|c|c|c|c|c|c|c|c|c|}
\hline \multirow[b]{2}{*}{ Model H } & \multirow[b]{2}{*}{ R2 } & \multicolumn{11}{|c|}{ Equal Wejghted Old Home Shower Head Flow Rales /GPMI } & \multirow{2}{*}{$\begin{array}{l}\text { Equal } \\
\text { Weighted } \\
\text { Mean Flow }\end{array}$} & \multirow{2}{*}{$\begin{array}{l}\text { TREMP } \\
\text { Weighted } \\
\text { Mean How }\end{array}$} \\
\hline & & 7.5 & 20 & 30 & 40 & Supply Pres: & 5(psi): & 70 & 80 & 90 & 100 & 110 & & \\
\hline Crane & 0.4415 & 1.5128 & 2.8948 & 3.8200 & 4.6060 & 5.2727 & 5.8396 & 6.3265 & 6.7530 & 7.1380 & 7.5037 & 7.8673 & 5.4123 & 5.8728 \\
\hline Delta & 0.7034 & 0.6912 & 1.2868 & 1.6618 & 1.9590 & 2.1939 & 2.3761 & 2.5191 & 2.6354 & 2.7374 & 2.8378 & 2.9490 & 2.1680 & 2.3647 \\
\hline Kohler & 0.5765 & 1.6813 & 3.3603 & 4.4595 & 5.3711 & 6.1222 & 6.7399 & 7.2511 & 7.6830 & 8.0625 & 8.4168 & 8.7729 & 6.1746 & 6.7411 \\
\hline Moen & 0.875 & 1.8186 & 4.0576 & 5.5371 & 6.7736 & 7.7981 & 8.6420 & 9.3364 & 9.9127 & 10.4021 & 10.8358 & 11.2451 & 7.8508 & 8.6292 \\
\hline Ondine & 0.1269 & 1.2580 & 2.8606 & 3.8565 & 4.6384 & 5.2436 & 5.7092 & 6.0725 & 6.3706 & 6.6409 & 6.9205 & 7.2467 & 5.1652 & 5.6762 \\
\hline Plumbs & 0.5599 & 1.2360 & 1.7807 & 2.1366 & 2.4309 & 2.6725 & 2.8702 & 3.0327 & 3.1689 & 3.2875 & 3.3973 & 3.5071 & 2.6837 & 2.8725 \\
\hline PricepF & 0.3958 & 0.8860 & 2.2858 & 3.2611 & 4.1233 & 4.8869 & 5.5662 & 6.1756 & 6.7293 & 7.2418 & 7.7274 & 8.2005 & 5.1895 & 5.6472 \\
\hline$\overline{S A M}$ & 0.2548 & 0.8763 & 2.1134 & 2.8518 & 3.4113 & 3.8329 & 4.1574 & 4.4259 & 4.6793 & 4.9585 & 5.3046 & 5.7585 & 3.8518 & 4.1748 \\
\hline SAZP & 0.1396 & 1.4438 & 1.9723 & 2.6015 & 3.2560 & 3.7898 & 4.0570 & 3.9114 & 3.2072 & 1.7984 & -0.4611 & -3.7171 & 1.9872 & 3.2216 \\
\hline SMKF & 0.8278 & 2.0100 & 3.7028 & 5.0101 & 6.2071 & 7.2303 & 8.0161 & 8.5011 & 8.6219 & 8.3148 & 7.5166 & 6.1637 & 6.4813 & 7.6209 \\
\hline SSWPTEL & 0.9034 & 0.6591 & 1.1135 & 1.4077 & 1.6507 & 1.8519 & 2.0208 & 2.1671 & 2.3002 & 2.4296 & 2.5648 & 2.7155 & 1.8983 & 2.0366 \\
\hline Standard & 0.9476 & 0.2805 & 2.4660 & 3.8059 & 4.8360 & 5.6053 & 6.1630 & 6.5582 & 6.8399 & 7.0574 & 7.2596 & 7.4958 & 5.3051 & 6.0389 \\
\hline STDYNE! & 0.4335 & 1.5579 & 3.5156 & 4.7146 & 5.6432 & 6.3529 & 6.8954 & 7.3222 & 7.6849 & 8.0351 & 8.4244 & 8.9044 & 6.2773 & 6.8699 \\
\hline STDYNE2 & 0.3821 & 1.7658 & 3.5062 & 4.6300 & 5.5471 & 6.2868 & 6.8785 & 7.3516 & 7.7355 & 8.0597 & 8.3535 & 8.6462 & 6.2510 & 6.8492 \\
\hline STDYNE3 & 0.5970 & 1.7511 & 3.6998 & 4.9497 & 5.9658 & 6.7862 & 7.4487 & \begin{tabular}{|l|l|}
7.9913 \\
\end{tabular} & 8.4519 & 8.8684 & 9.2788 & 9.7209 & 6.8102 & 7.4438 \\
\hline Unknown! & 0.2082 & 1.1611 & 2.5380 & 3.3888 & 4.0550 & 4.5775 & 4.9736 & 5.2962 & \begin{tabular}{|l|l}
5.5746 \\
\end{tabular} & 5.8439 & 6.1392 & 6.4955 & 4.5489 & 4.9655 \\
\hline Unknown2 & 0.2569 & 1.1371 & 2.6625 & 3.6396 & $\begin{array}{l}4.4366 \\
\end{array}$ & 5.0865 & 5.6224 & 6.0776 & 6.4857 & 6.8782 & 7.2899 & 7.7534 & 3.1881 & 5.6511 \\
\hline Unknown3 & 0.3121 & 2.0526 & 3.3604 & 3.9510 & 4.2820 & 4.4878 & 4.7026 & 5.0607 & 5.6965 & 6.7442 & 8.3381 & 10.6126 & 5.3899 & 5.1547 \\
\hline WP & 0.9981 & 0.9003 & 1.7115 & 2.2393 & 2.6754 & 3.0347 & 3.3320 & 3.5821 & 3.8000 & 4.0004 & 4.1981 & 4.4081 & 3.0802 & 3.3425 \\
\hline WPBI2S & 0.5082 & 1.0952 & 1.9511 & 2.5269 & 3.0173 & 3.4327 & 3.7836 & 4.0805 & 4.3339 & 4.5542 & 4.7520 & 4.9377 & 3.4968 & 3.7950 \\
\hline WPSA & 0.4907 & 0.9780 & 2.0614 & 2.7123 & 3.2084 & 3.5879 & 3.8828 & 4.1292 & 4.3622 & 4.6169 & 4.9284 & 5.3318 & 3.6182 & 3.9032 \\
\hline WPTEL & 0.7029 & 1.0416 & 1.4042 & 1.6976 & 1.9906 & 2.2802 & 2.5630 & 2.8361 & 3.0963 & 3.3404 & $3.565 \mathrm{~s}$ & 3.7679 & 2.5076 & 2.6337 \\
\hline & & & & & & & & & & & & & 4.6062 & 5.0684 \\
\hline
\end{tabular}


Table 8. Flow Rates @ Ten Pressures for New Nerators Typical of Those Purchased for DPA Program Aeras

\begin{tabular}{|c|c|c|c|c|c|c|c|c|c|c|c|c|c|c|c|c|}
\hline \multirow[b]{4}{*}{ Model H } & \multirow[b]{4}{*}{$\mathbf{R 2}$} & \multirow{2}{*}{\multicolumn{14}{|c|}{$\begin{array}{l}\text { Aerator Flow Rates } \\
\end{array}$}} & \multirow{4}{*}{$\begin{array}{c}\text { Population } \\
\text { \& REMP Pressure } \\
\text { Weighted Flow Ruse } \\
\text { Fraction }\end{array}$} \\
\hline & & \multirow{2}{*}{\multicolumn{12}{|c|}{ Supply Pressures (psi): }} & & & \\
\hline & & & & & & & & & & & & & & \multirow{2}{*}{$\begin{array}{l}\text { Equal Pressure } \\
\text { Weighted Atean } \\
\text { Flow Rate }\end{array}$} & \multirow{2}{*}{$\begin{array}{l}\text { REMiP Pressure } \\
\text { Weighted Mean } \\
\text { Flow Rate }\end{array}$} & \\
\hline & & Total Aerators & 7.5 & 20 & 30 & 40 & so & 60 & 70 & 80 & 90 & 100 & 110 & & & \\
\hline CEW610 & 0.8566 & 0.1848 & 0.4460 & 0.7222 & 0.9078 & 1.0664 & 1.2019 & 1.3183 & 1.4196 & 1.5096 & 1.5925 & 1.6720 & 1.7522 & 1.2371 & 1.3285 & 0.2455 \\
\hline N3101 & 0.8684 & 0.0064 & 0.4287 & 0.7369 & 0.9329 & 1.0909 & 1.2174 & 0.3188 & 1.4017 & 1.4723 & 1.5373 & 1.6030 & 1.6760 & 1.2196 & 1.3189 & 0.0084 \\
\hline ETLWB150 & 0.9988 & 0.2482 & 0.4316 & 0.7462 & 0.9519 & 1.1.1228 & 1.2648 & 1.3838 & 1.4854 & 1.5755 & 1.6598 & 1.7442 & 1.8344 & 1.2909 & 1.3914 & 0.3454 \\
\hline TS350 & 0.9983 & 0.0255 & 0.4541 & 0.7669 & 0.9719 & 1.1429 & 1.2853 & 1.4048 & 1.5068 & 1.5970 & 1.6808 & 1.7639 & 1.8517 & 1.3115 & T.4123 & 0.0360 \\
\hline CEW2001 & 0.9575 & 0.0251 & 0.5872 & 1.0498 & 1.3500 & 1.5939 & 1.7866 & 1.9337 & 2.0402 & 2.1115 & 2.1529 & 2.1697 & 2.1672 & 1.7221 & 1.9037 & 0.0477 \\
\hline NIAGARA & 0.4520 & & 0.7144 & 1.1671 & 1.4635 & 1.7100 & 1.9142 & 2.0839 & 2.2268 & 2.3508 & 2.4635 & 2.5727 & 2.6861 & 1.9412 & 2.0909 & \\
\hline DS1 & 0.8911 & 0.0212 & 0.7158 & 1.1868 & 1.4626 & 1.6686 & 1.8233 & 1.9451 & 2.0525 & 2.1641 & 2.2981 & 2.4732 & 2.7078 & 1.8634 & 1.9692 & 0.0418 \\
\hline DSS & 0.9840 & 0.1397 & 0.6590 & 1.1762 & 1.4747 & 1.6937 & 1.8543 & 1.9777 & 2.0852 & 2.1978 & 2,3369 & 2.5235 & 2.7789 & 1.8871 & 2.0005 & 0.2795 \\
\hline $\mathrm{N3103}$ & 0.6167 & 0.1212 & 0.7667 & 1.3542 & 1.7420 & 2.0663 & 2.3359 & 2.5596 & 2.7460 & 2.9041 & 3.0425 & 3.1701 & 3.2957 & 2.3621 & 2.5630 & 0.3106 \\
\hline ES971B & 0.9684 & & 0.4617 & 0.7939 & 1.0213 & 1.2184 & 1.3888 & 1.5360 & 1.6636 & 1.7752 & 1.8742 & 1.9643 & 2.0490 & 1.4315 & 1.5464 & \\
\hline DS2 & 0.9584 & 0.2280 & 0.7113 & 1.2631 & 1.5620 & 1.7719 & 1.9272 & 2.0626 & 2.2127 & 2.4120 & 2.6952 & 3.0970 & 3.6518 & 2.1242 & 2.1597 & 0.4924 \\
\hline & & & & & & & & & & & & Overall & verages: & 1.6719 & 1.7895 & 1.8072 \\
\hline
\end{tabular}




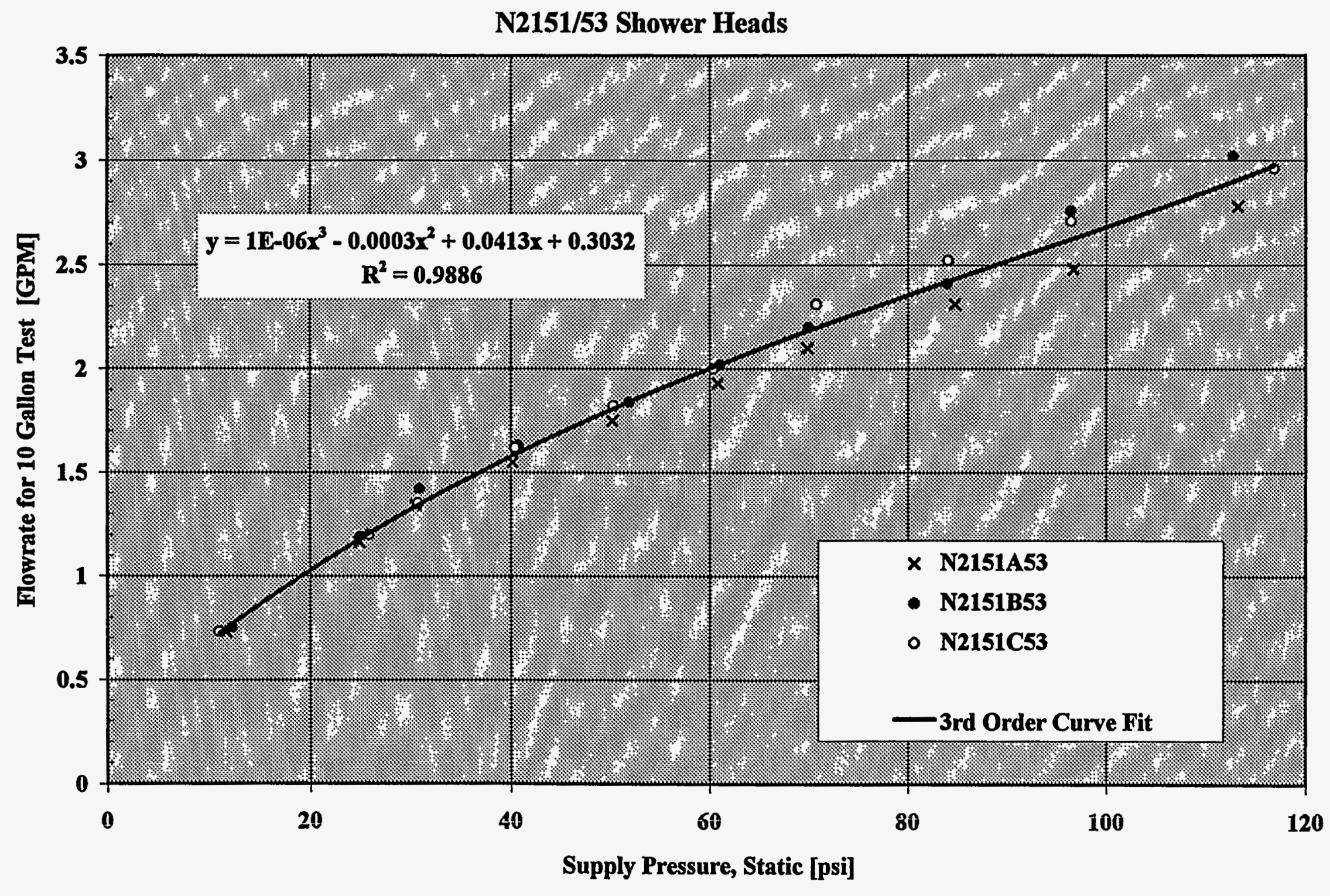

Figure 14. Niagara 2151 and 2153 Model Shower Head. 


\section{Flowrate for 10 Gallon Test [GPM]}

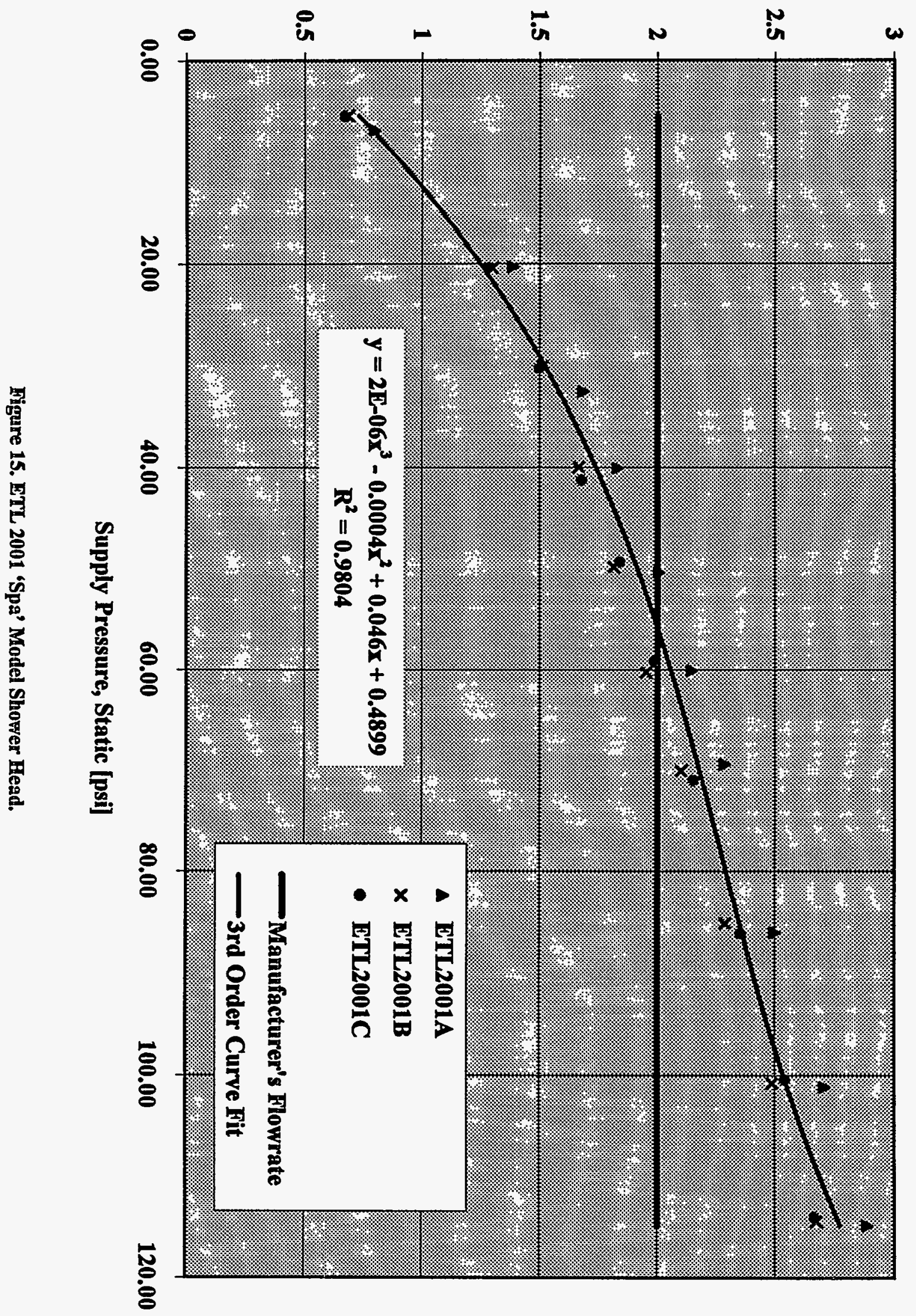

年

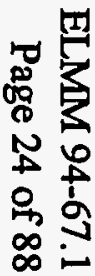




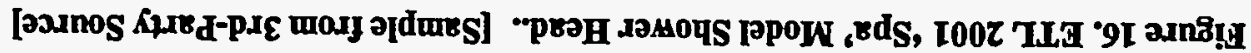

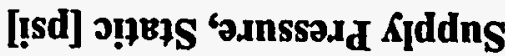

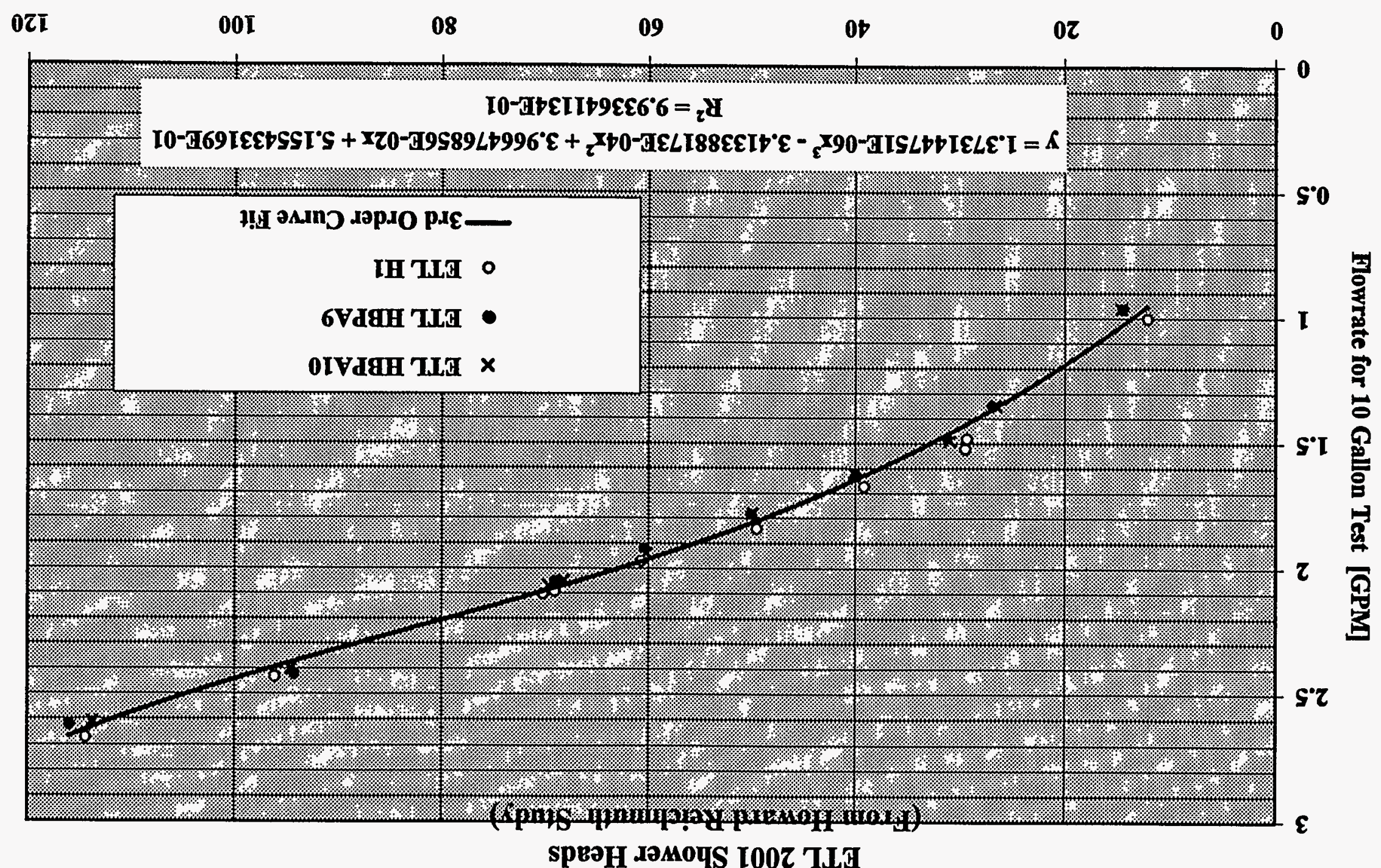

88 Jo $\varsigma$ วรిణd

['L9-ヤ6 WWTH 


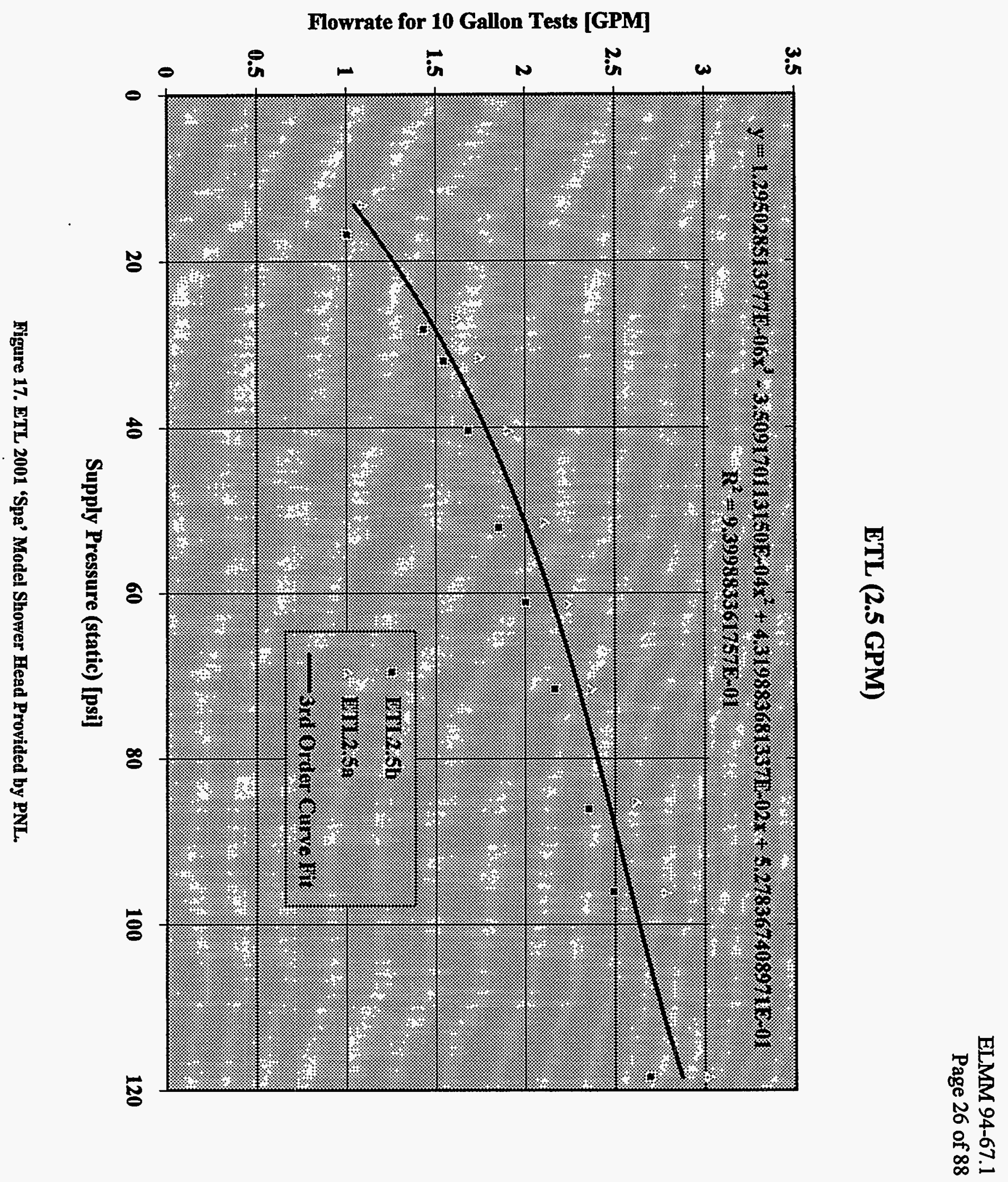




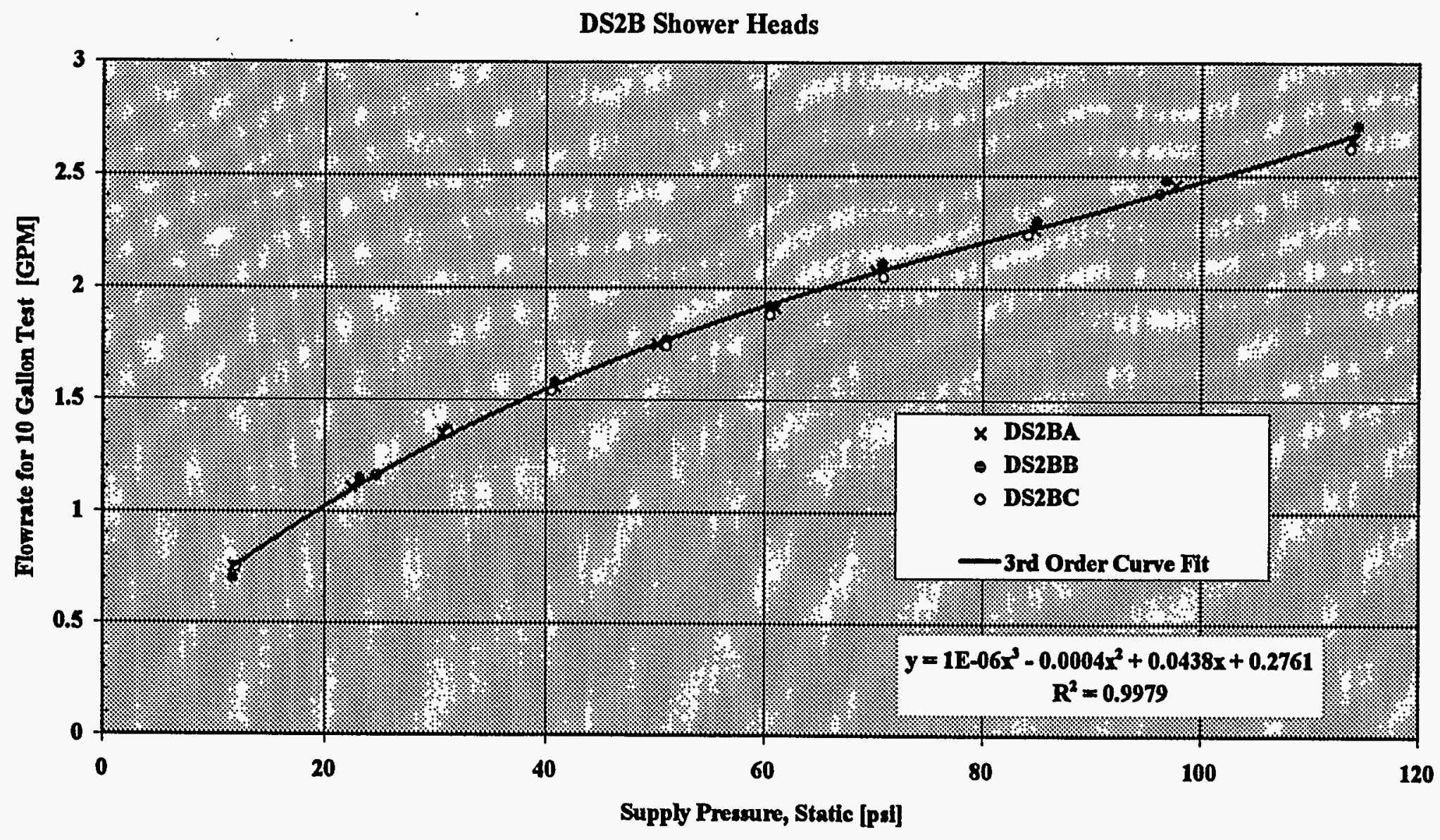

Figure 18. Whedon Model DS2B Shower Head.

The DS2B flow rate was a bit higher then expected, but some of the shower heads were from an earlier program specification. The earlier program specified a flow rate of 2.5 GPM. 


\section{RC1 Shower Heads}

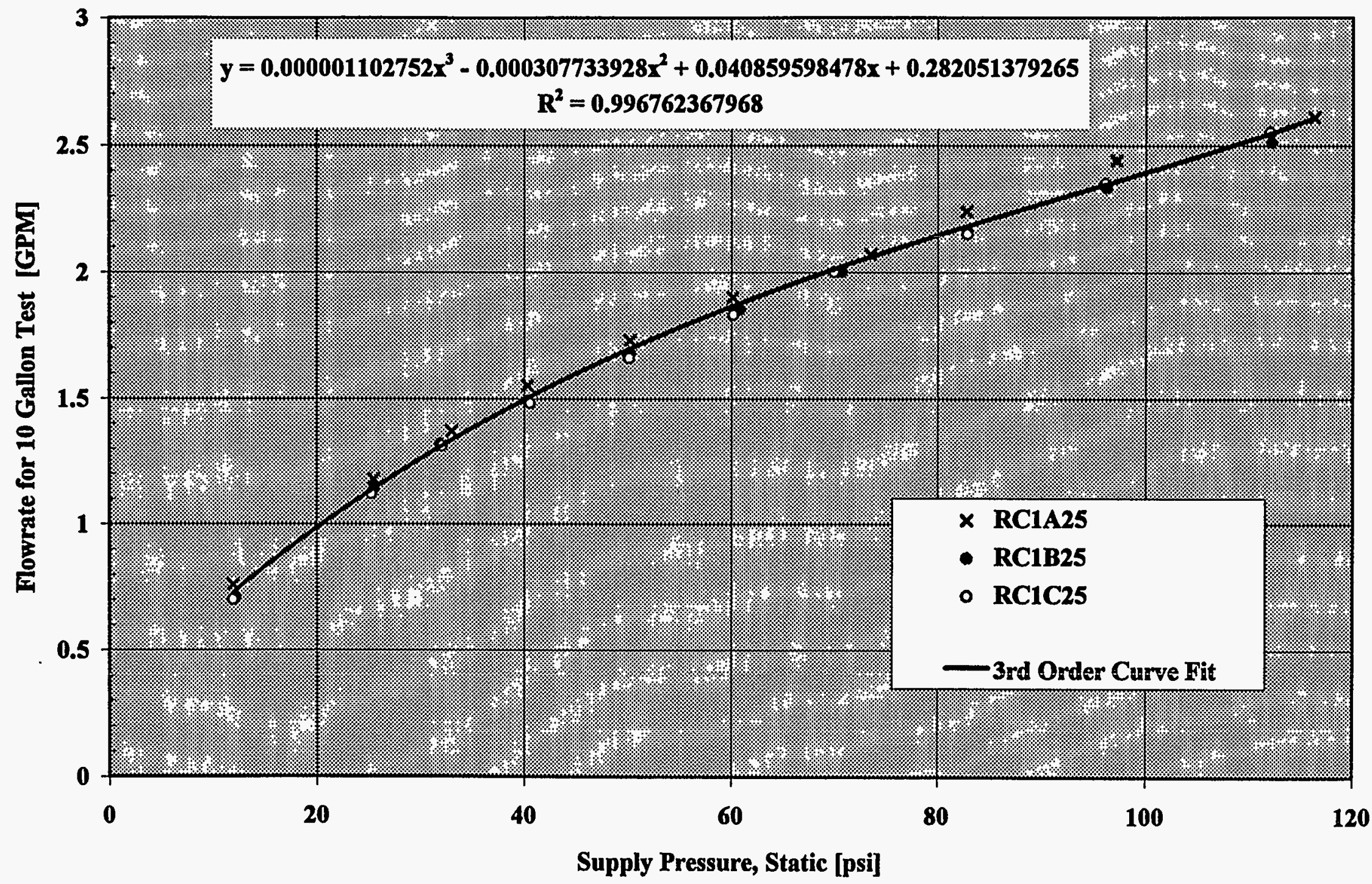

Figure 19. Resources Conservation Model RC1 Shower Head. 
్ㅗㅇ

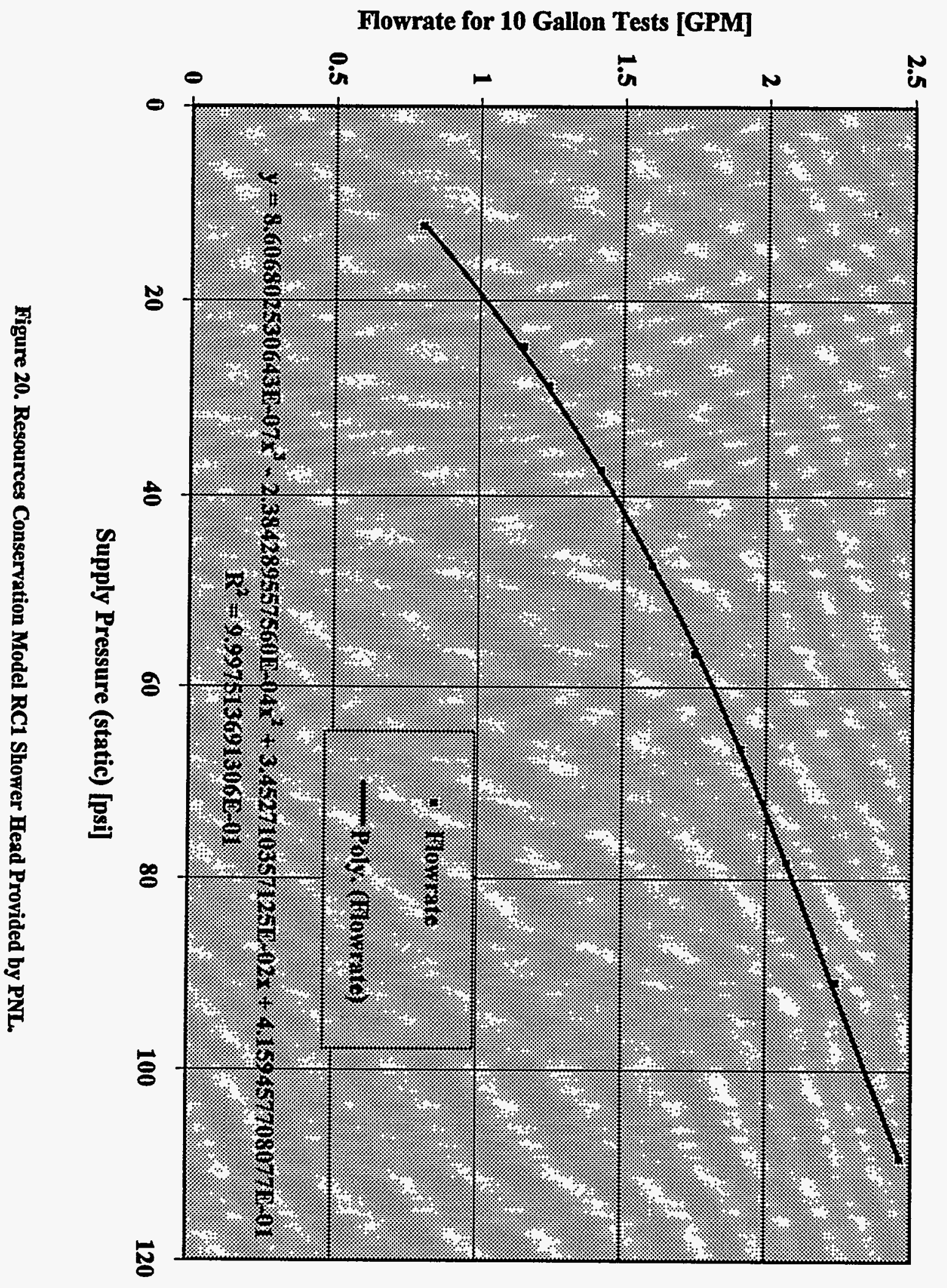

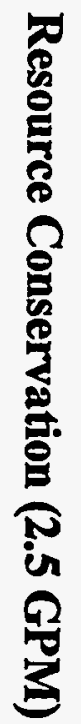

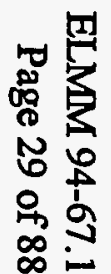




\section{Super Saver Water Pik Shower Heads}

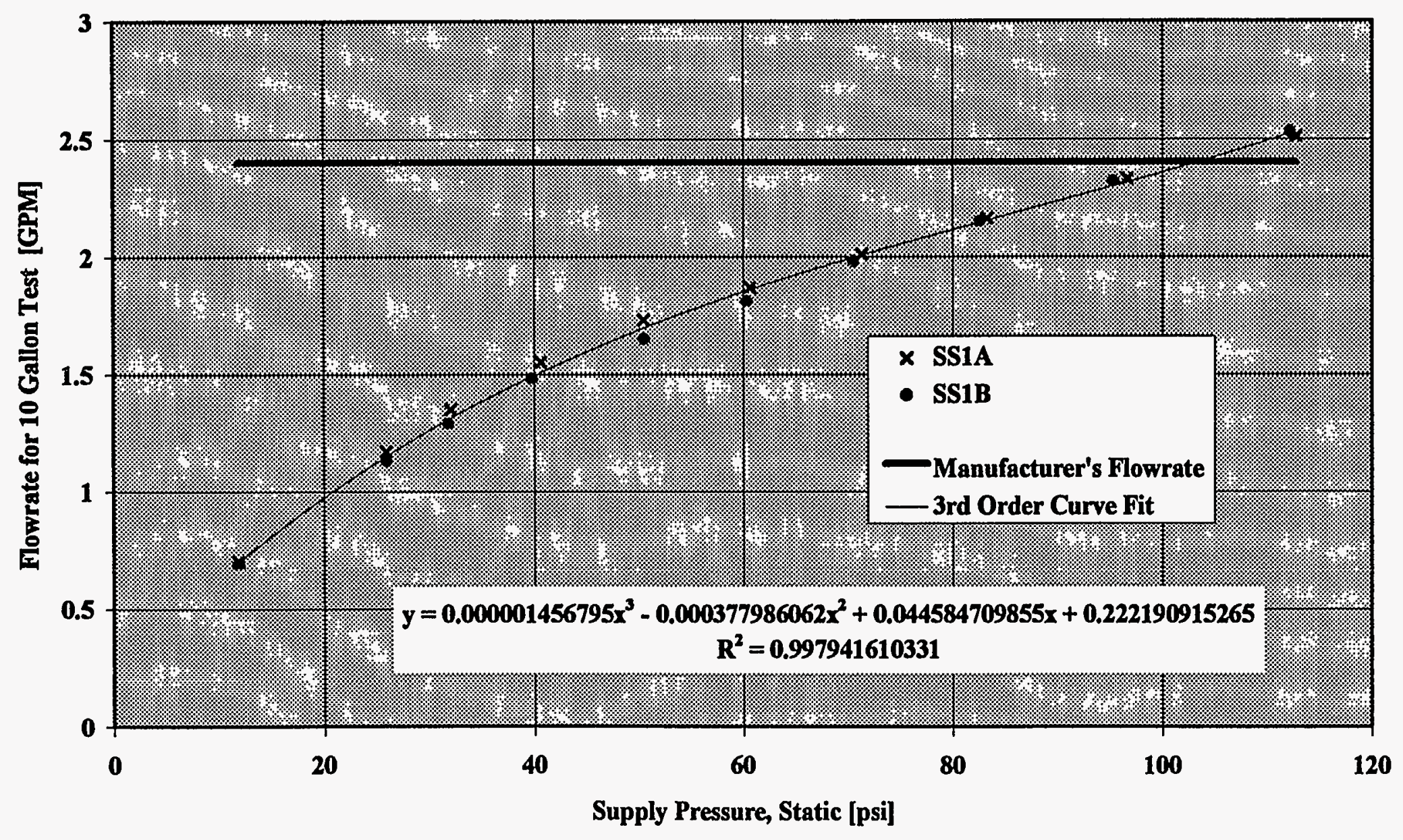

Figure 21. Teledyne WaterPik Model SS1 Shower Head. 


\section{TeleDyne Water Pik(2.5 GPM)}

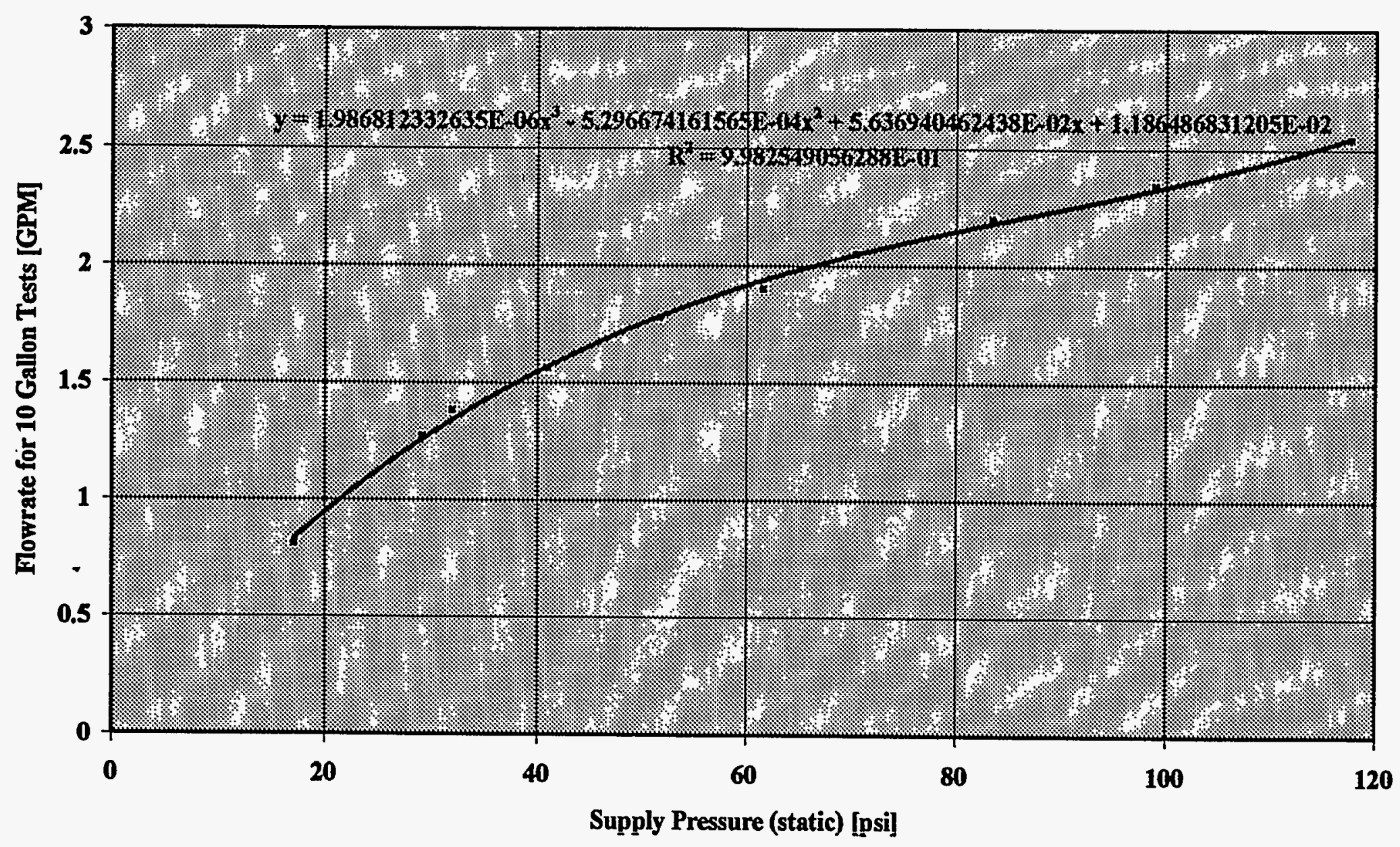

Figure 22. Teledyne WaterPik Sample provided by PNL. 


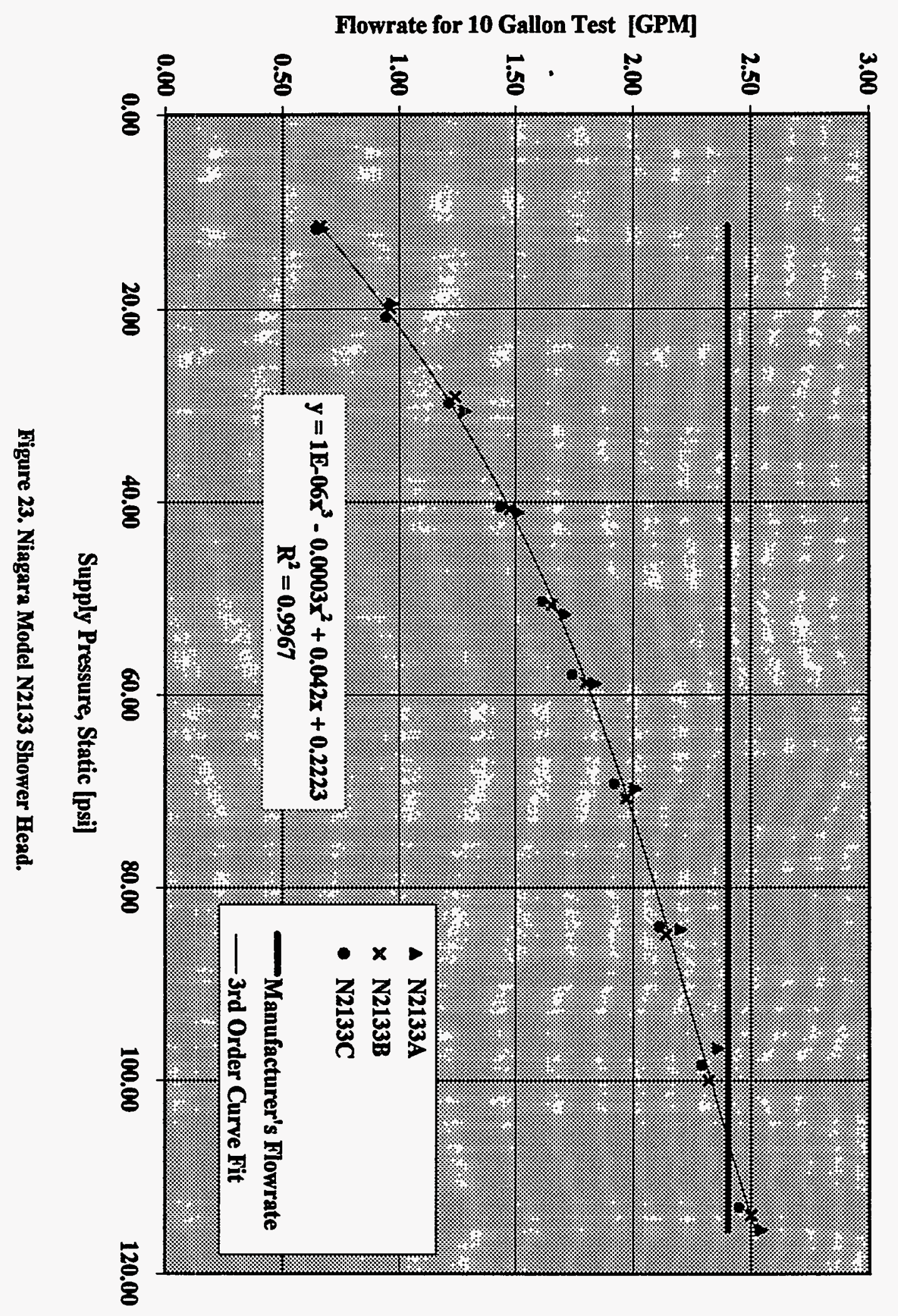

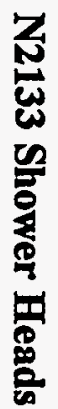

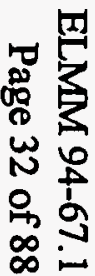




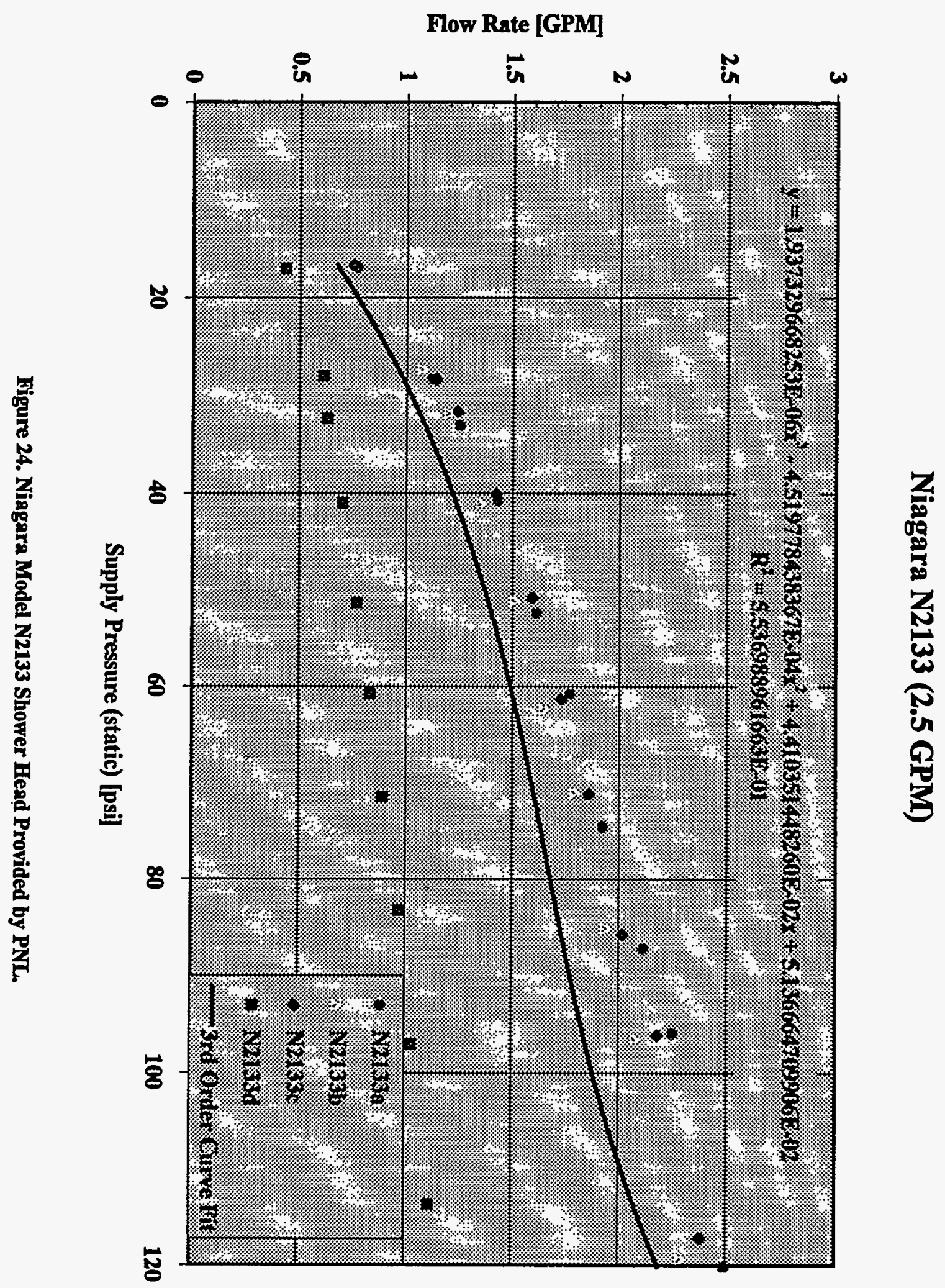

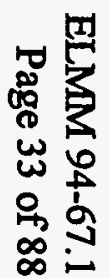




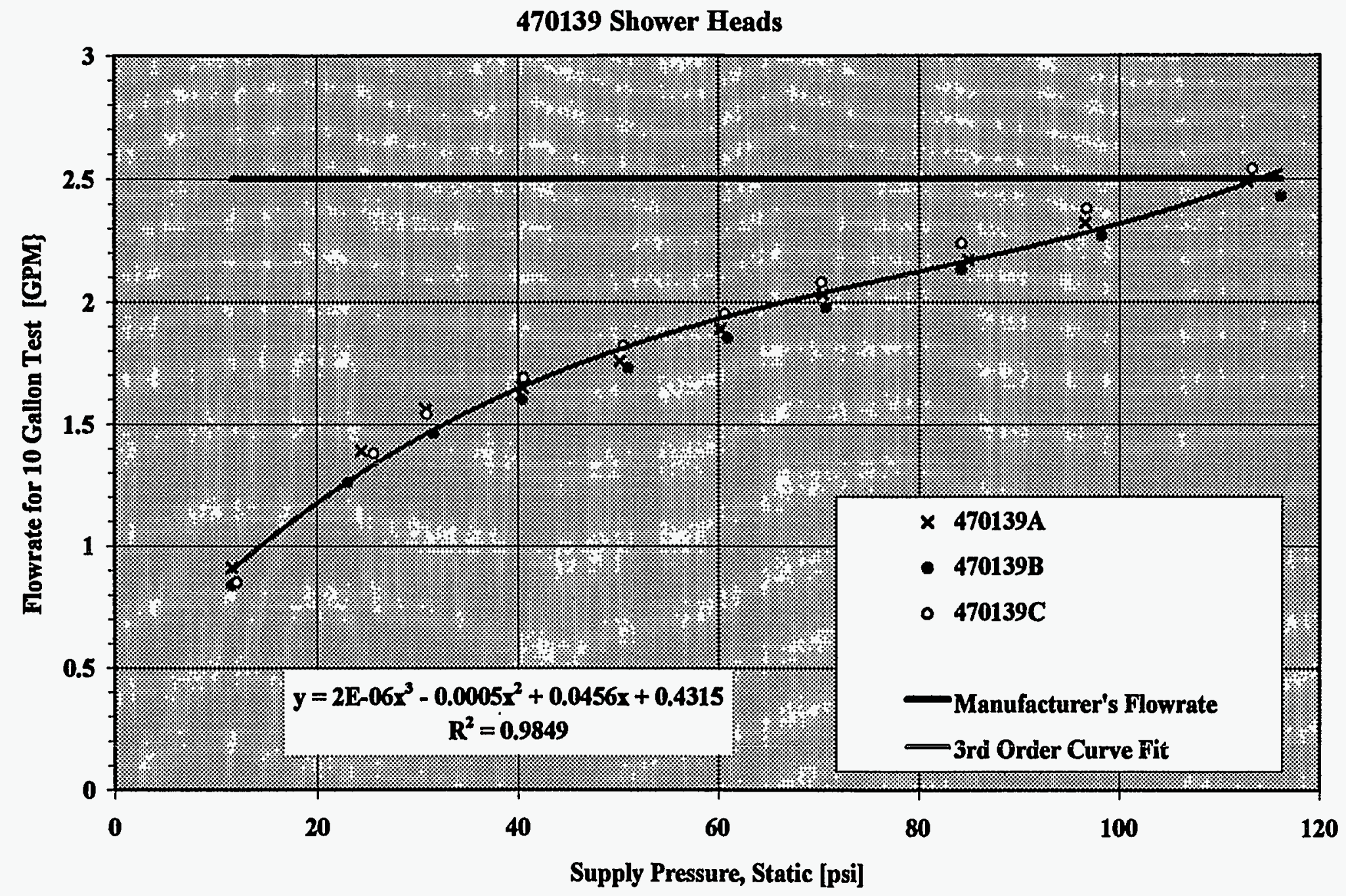

Figure 25. Alson's Model 470139 (Handheld) Shower Head. 
2000 Supreme Shower Heads

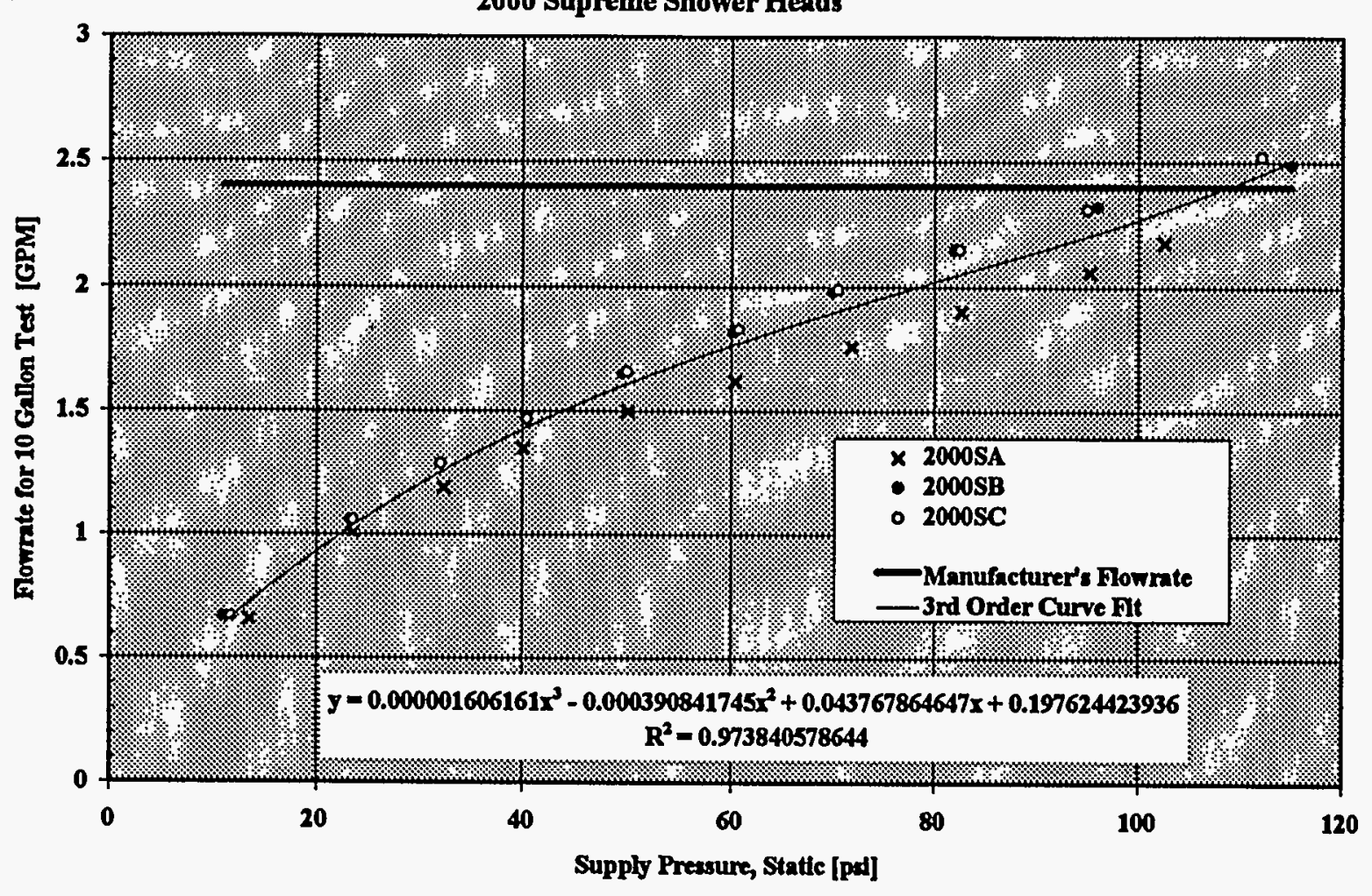

Figure 26. CEW Model 2000-S Shower Head. 


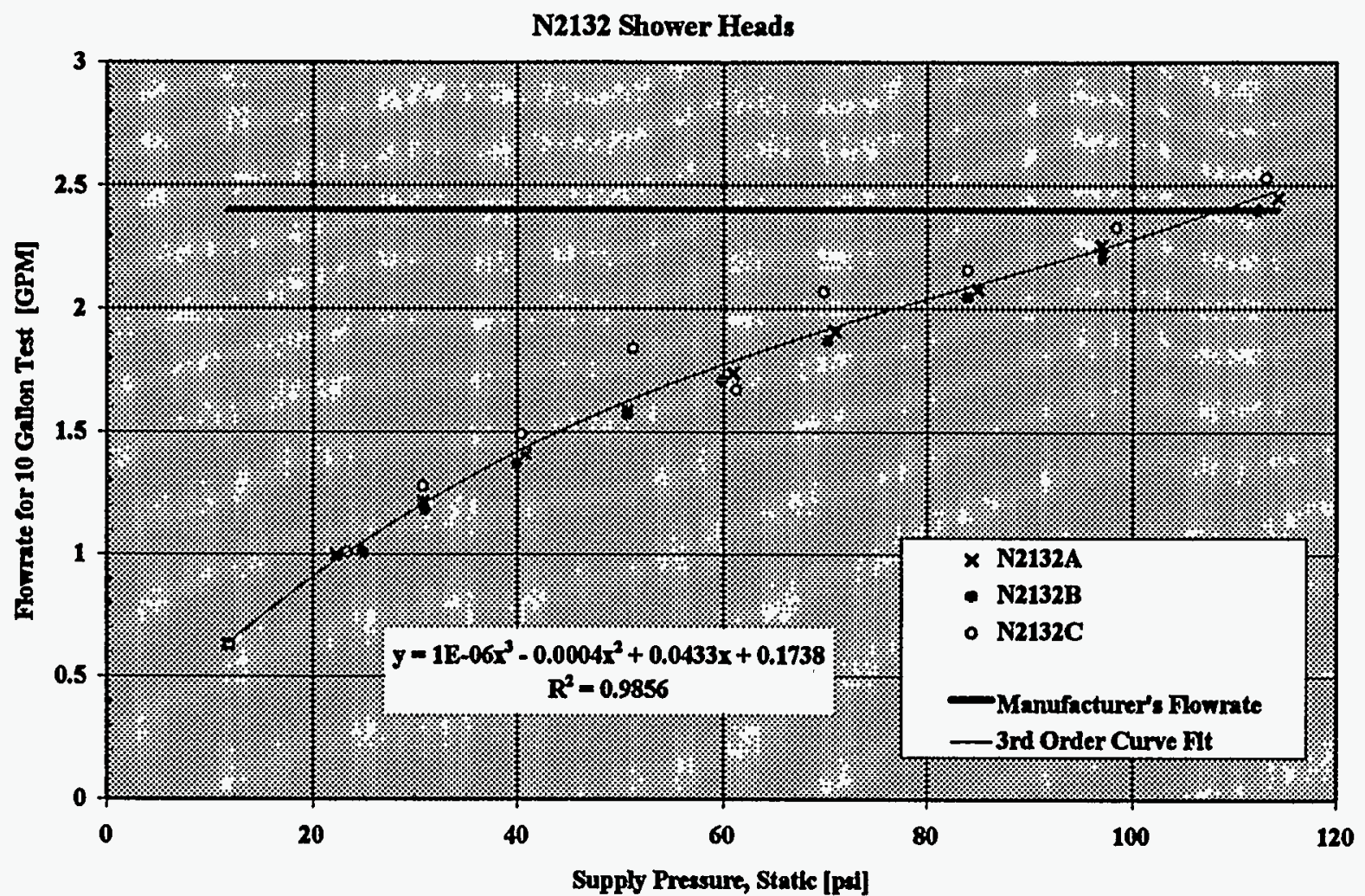

Figure 27. Niagara Model N2132 Shower Kfead. 


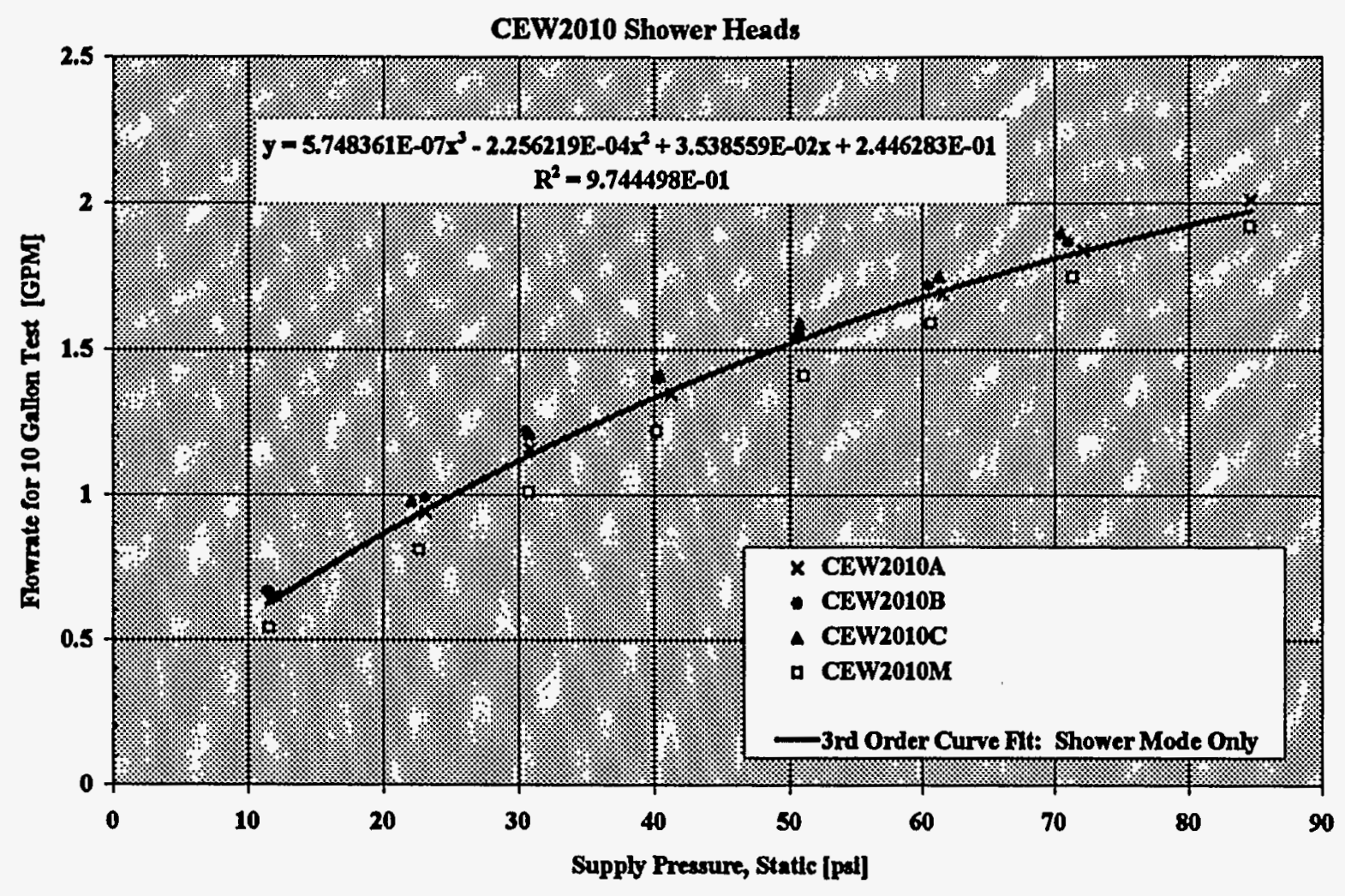

Figure 28. CEW Model 2010 (Handheld) Shower Head. 


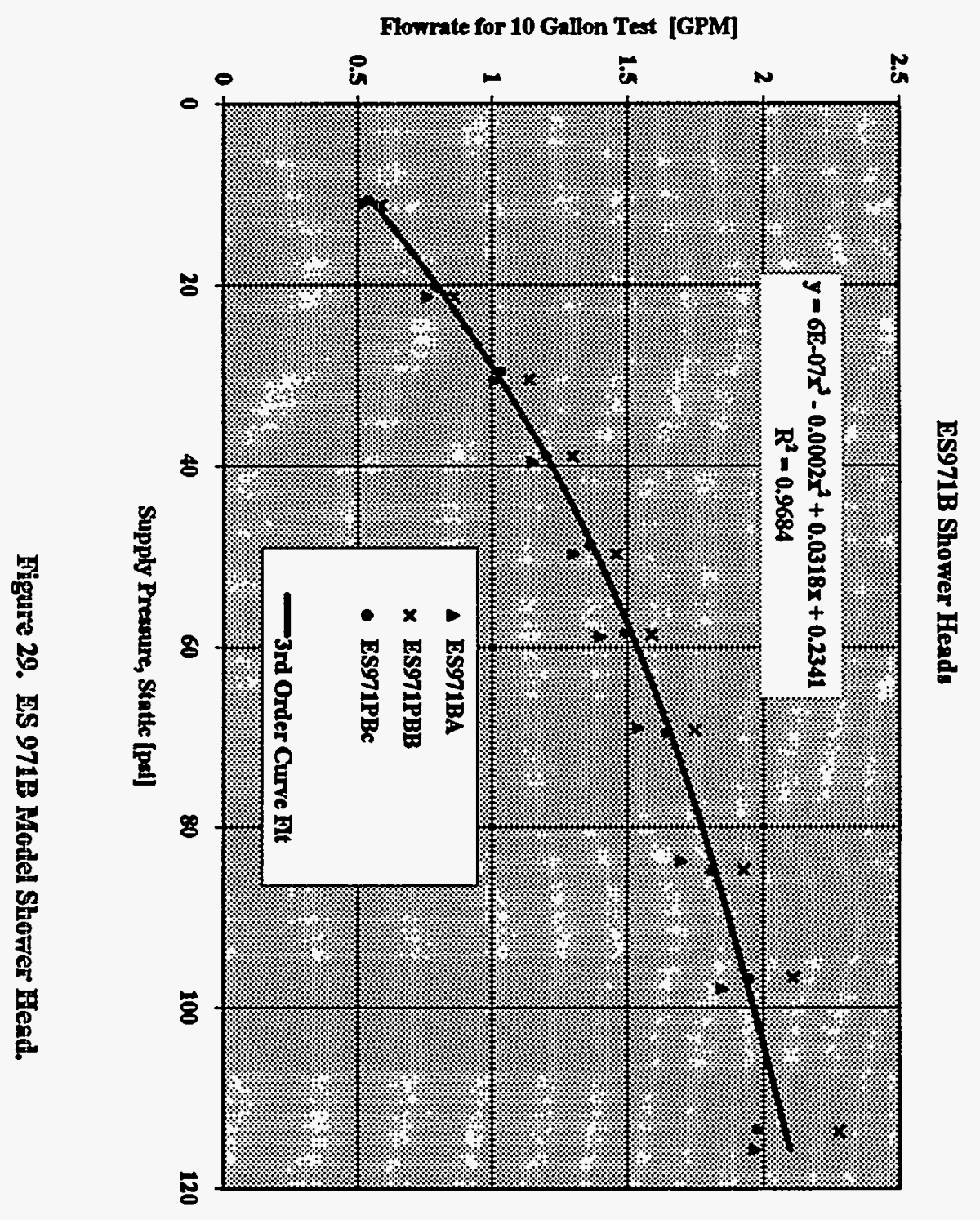

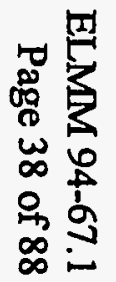




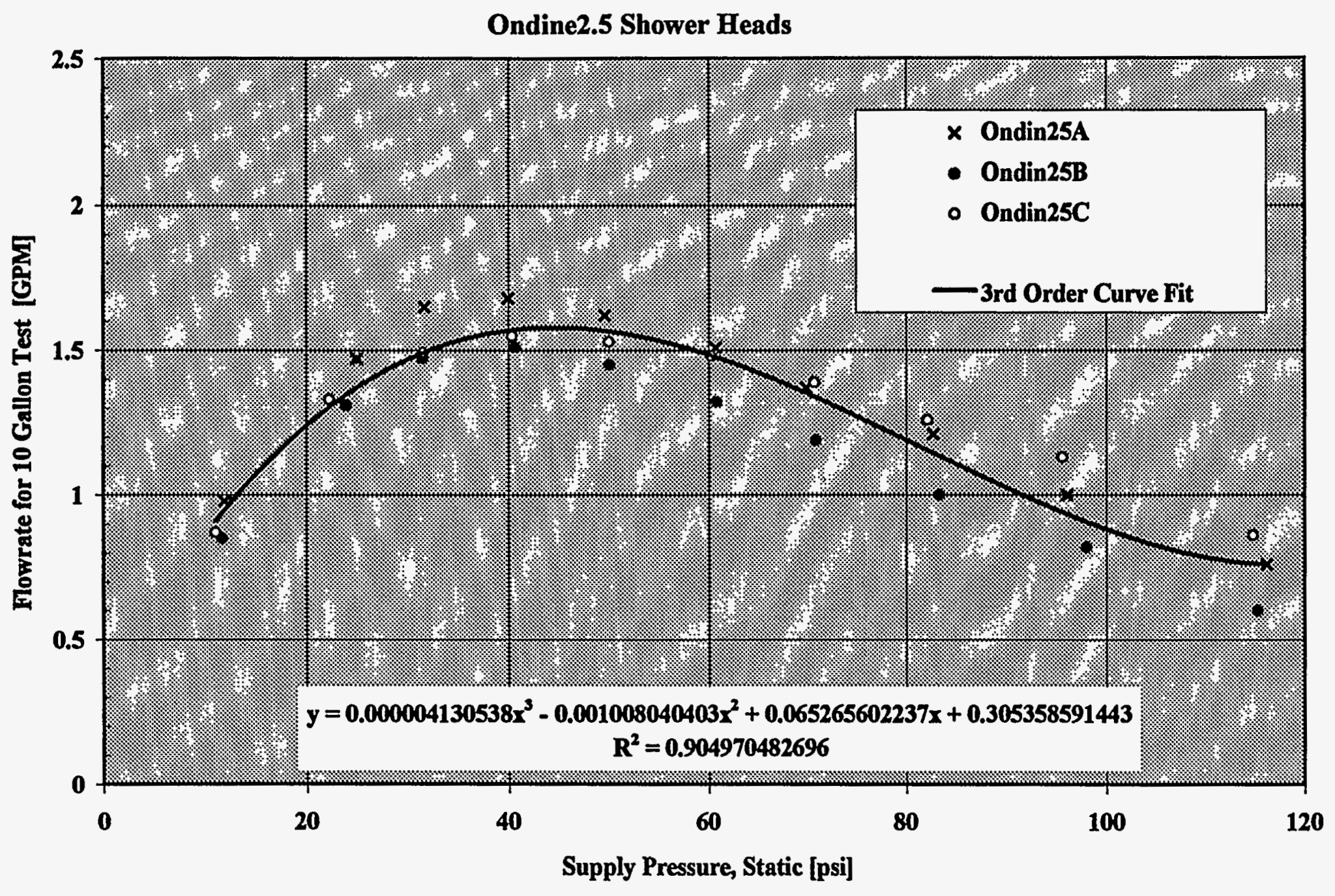

Figure 30. Ondine25 Model Shower Head.

This shower head was adjustable and had a maximum manufacturer's flow rate of $2.5 \mathrm{GPM}$. All tests were conducted with the adjustment set to the most conserving setting. 


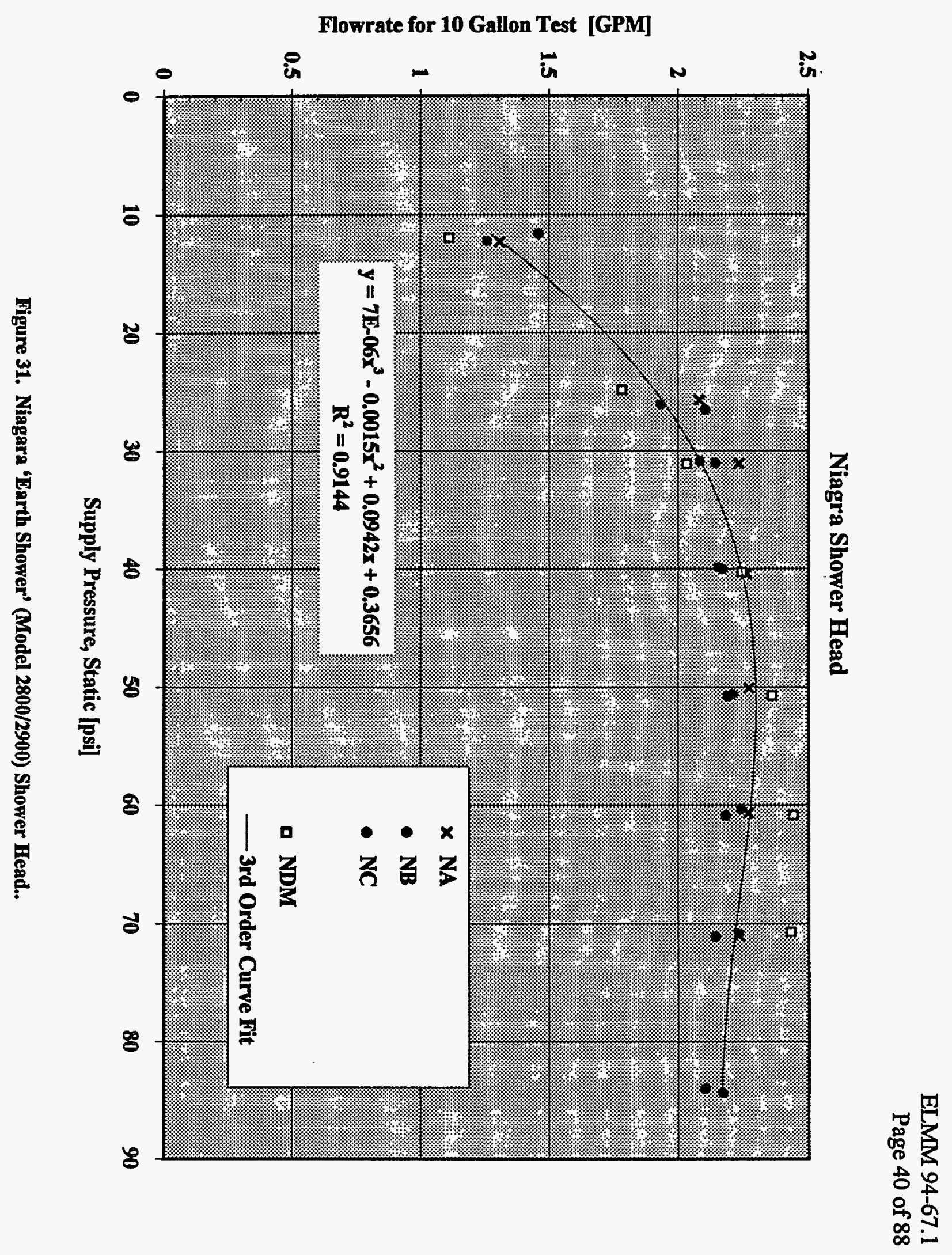




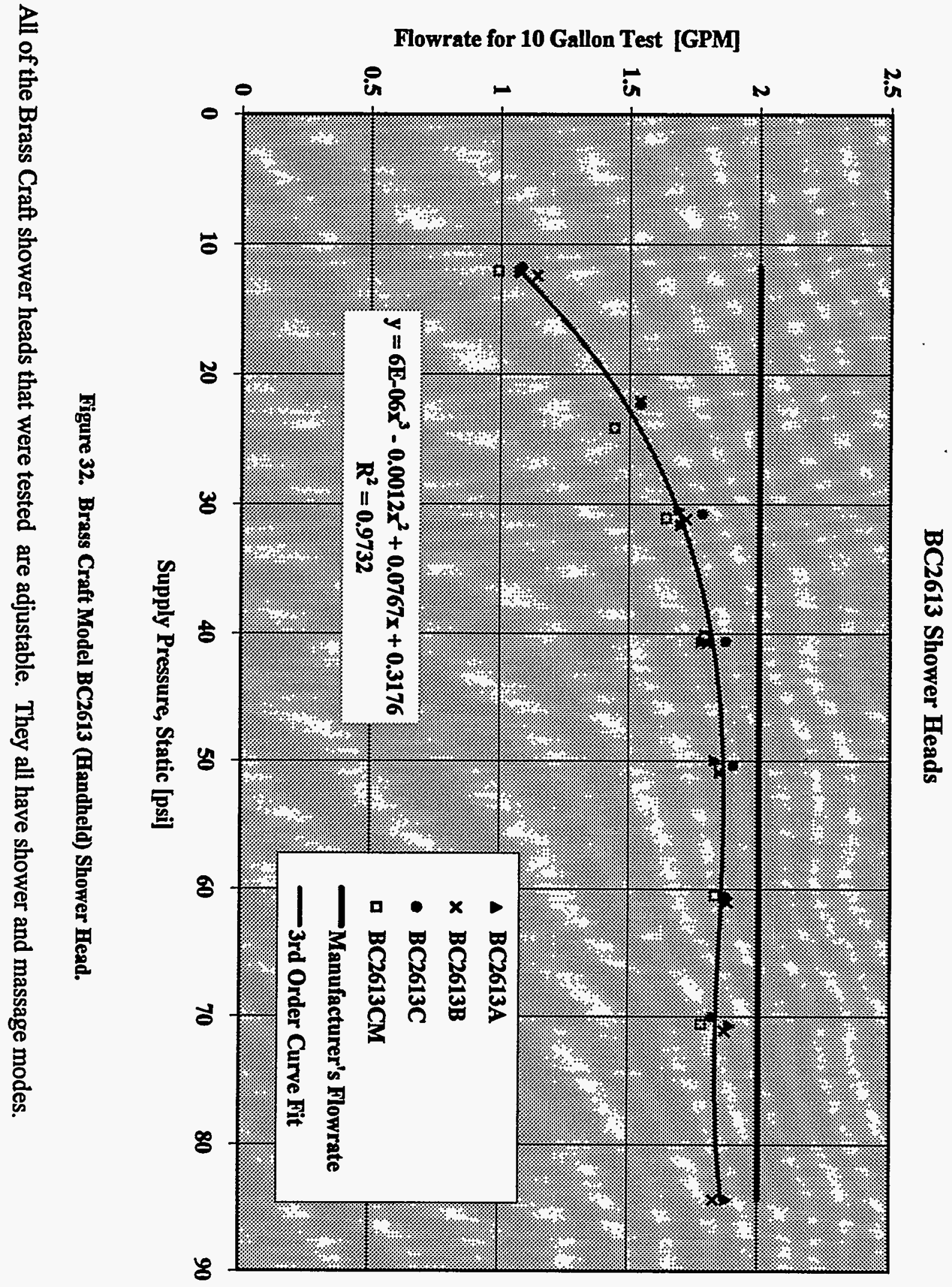

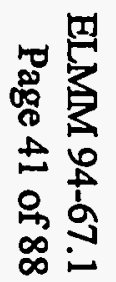




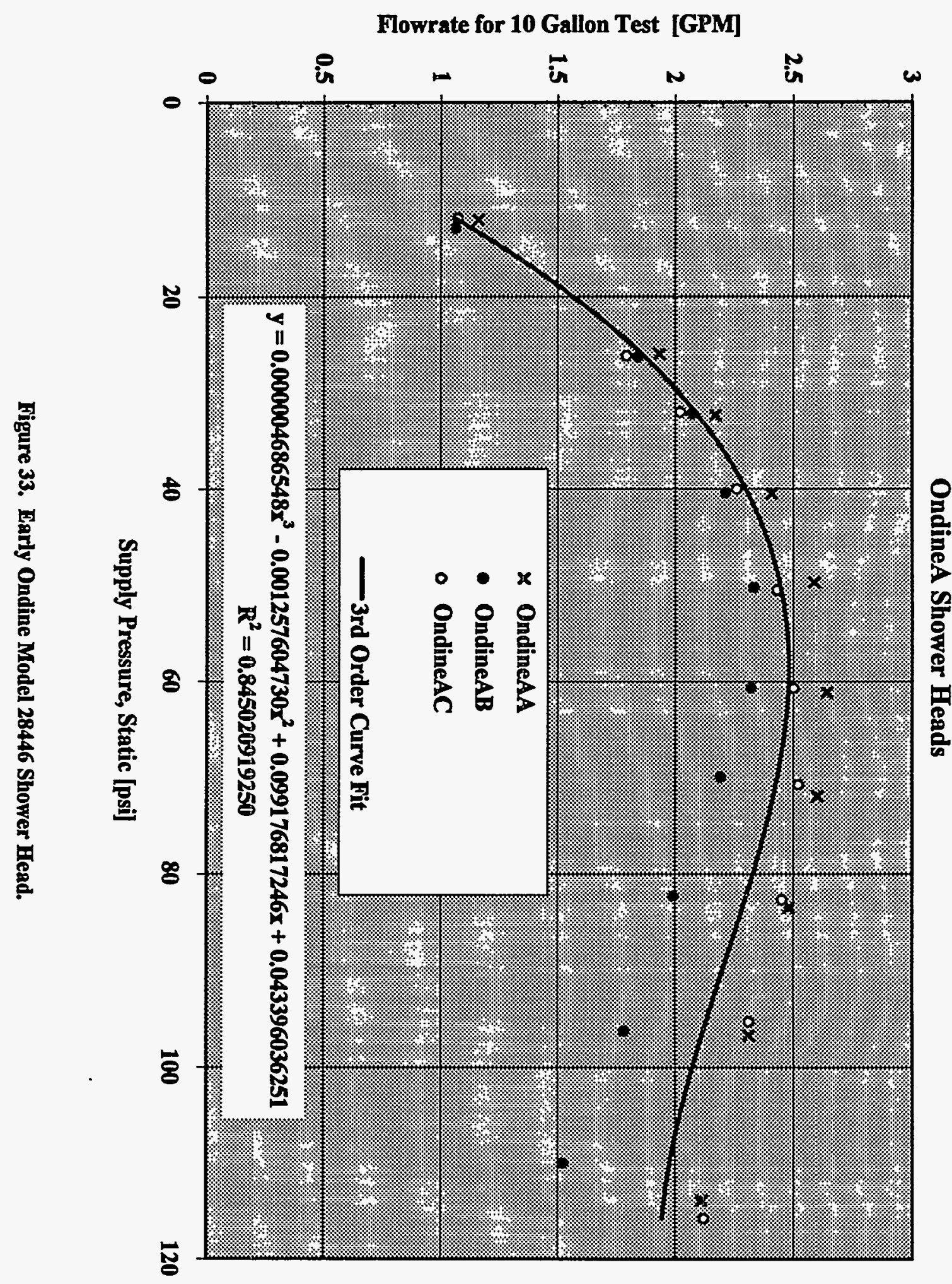

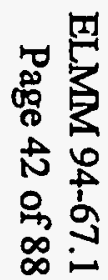




\section{Ondine (2.5 GPM)}

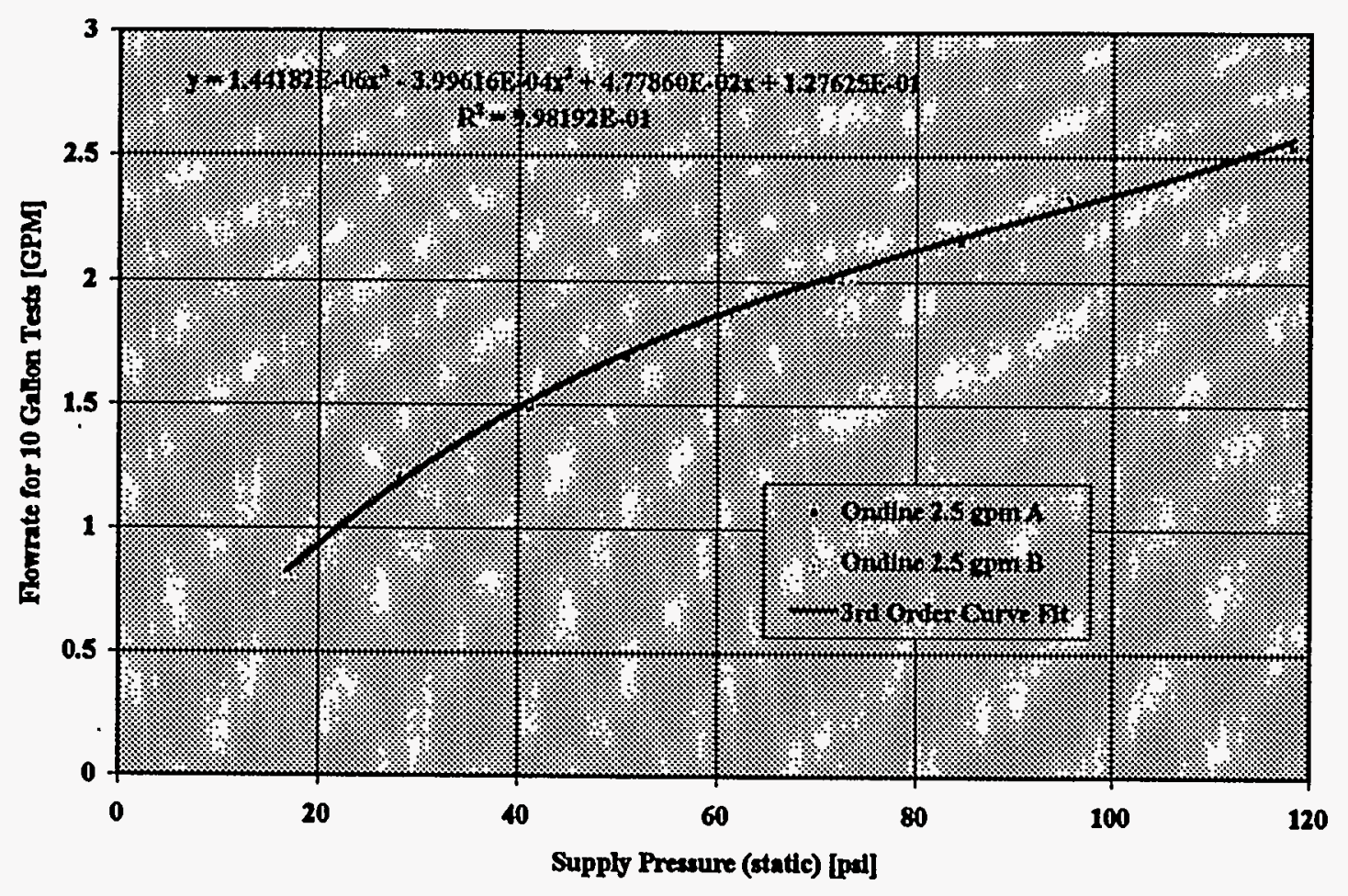

Figure 34. Early Ondine Model 28446 Shower Head Provided by PNL. 


\section{ES270 Shower Heads}

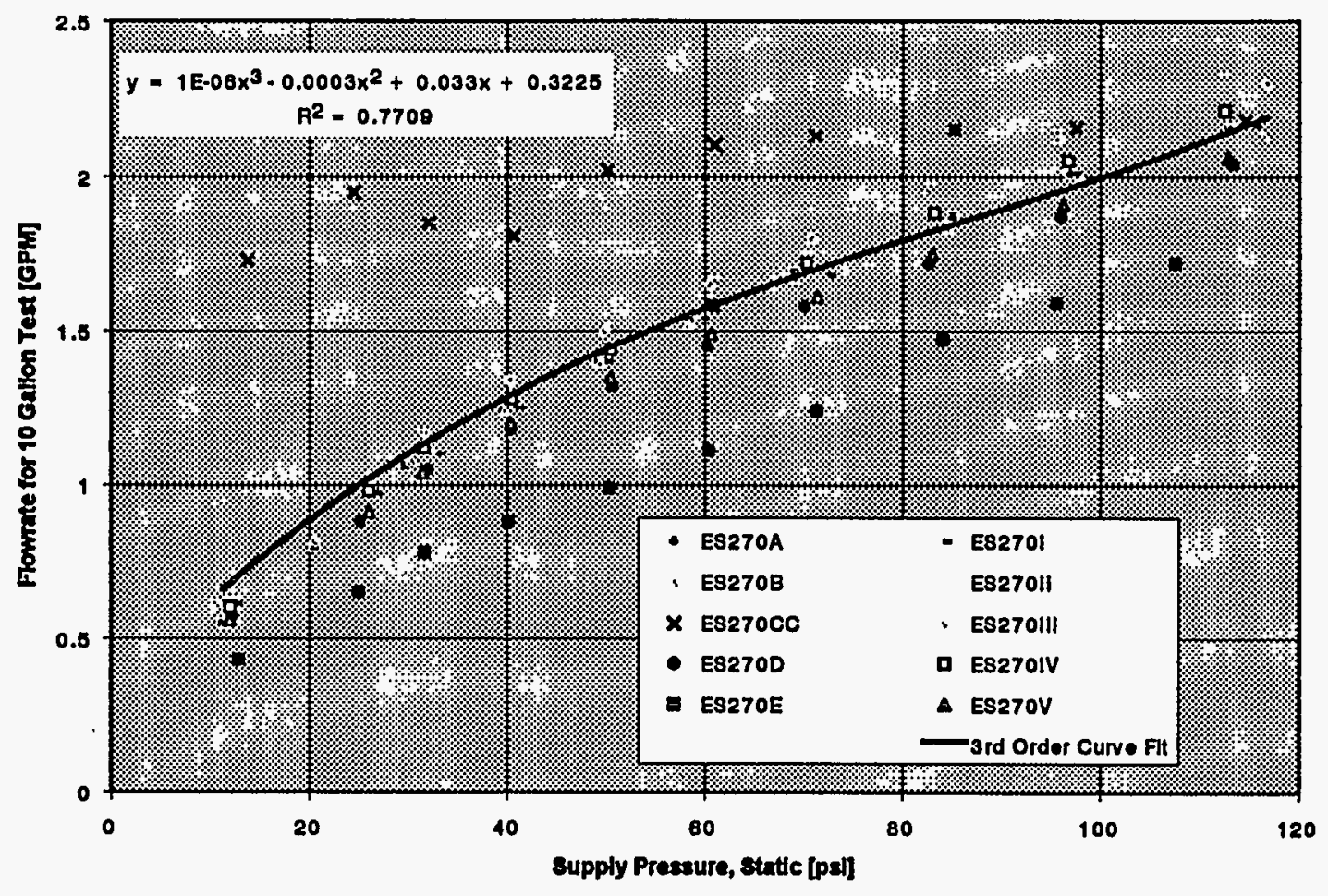

Figure 35. Resource Conservation Model ES270 Shower Head.

Sample ES270CC is the re-run of sample ES270C. All of the ES270 samples were run, because of the large amount of scatter and variations in the flow curves from the earlier test runs. The restrictor in this particular model had a tendency to shift during testing. 


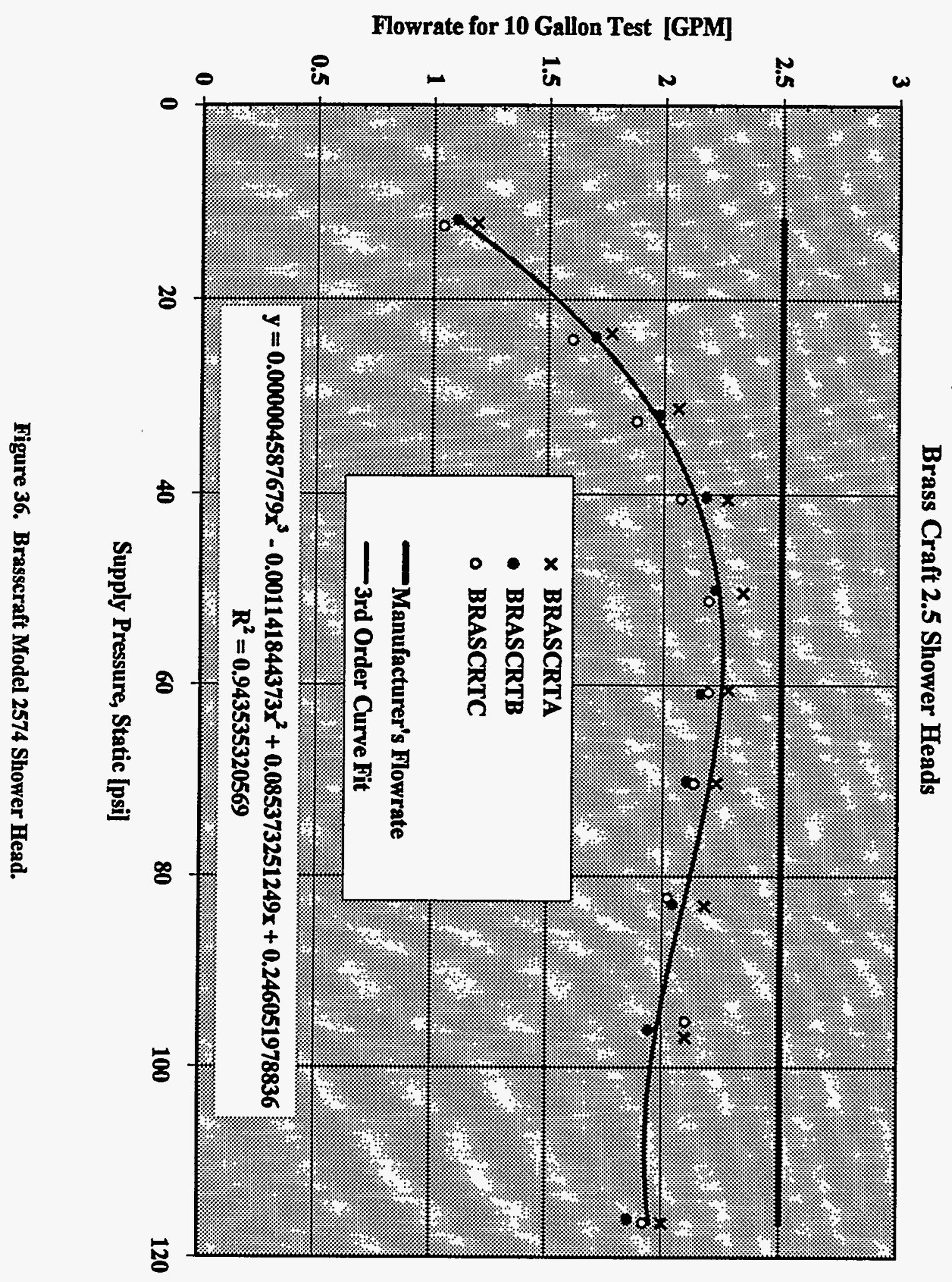

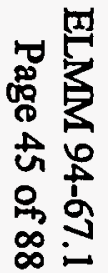




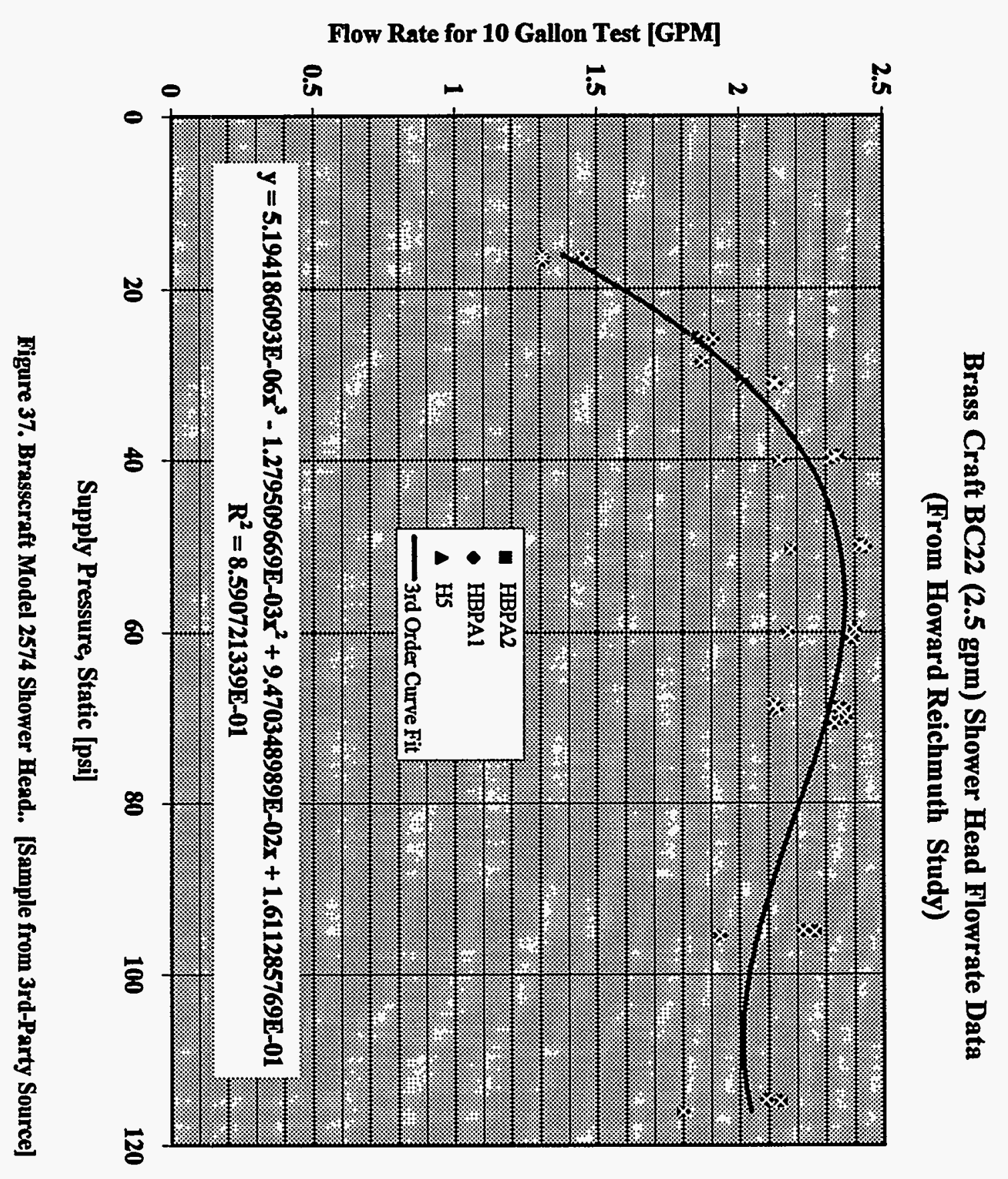

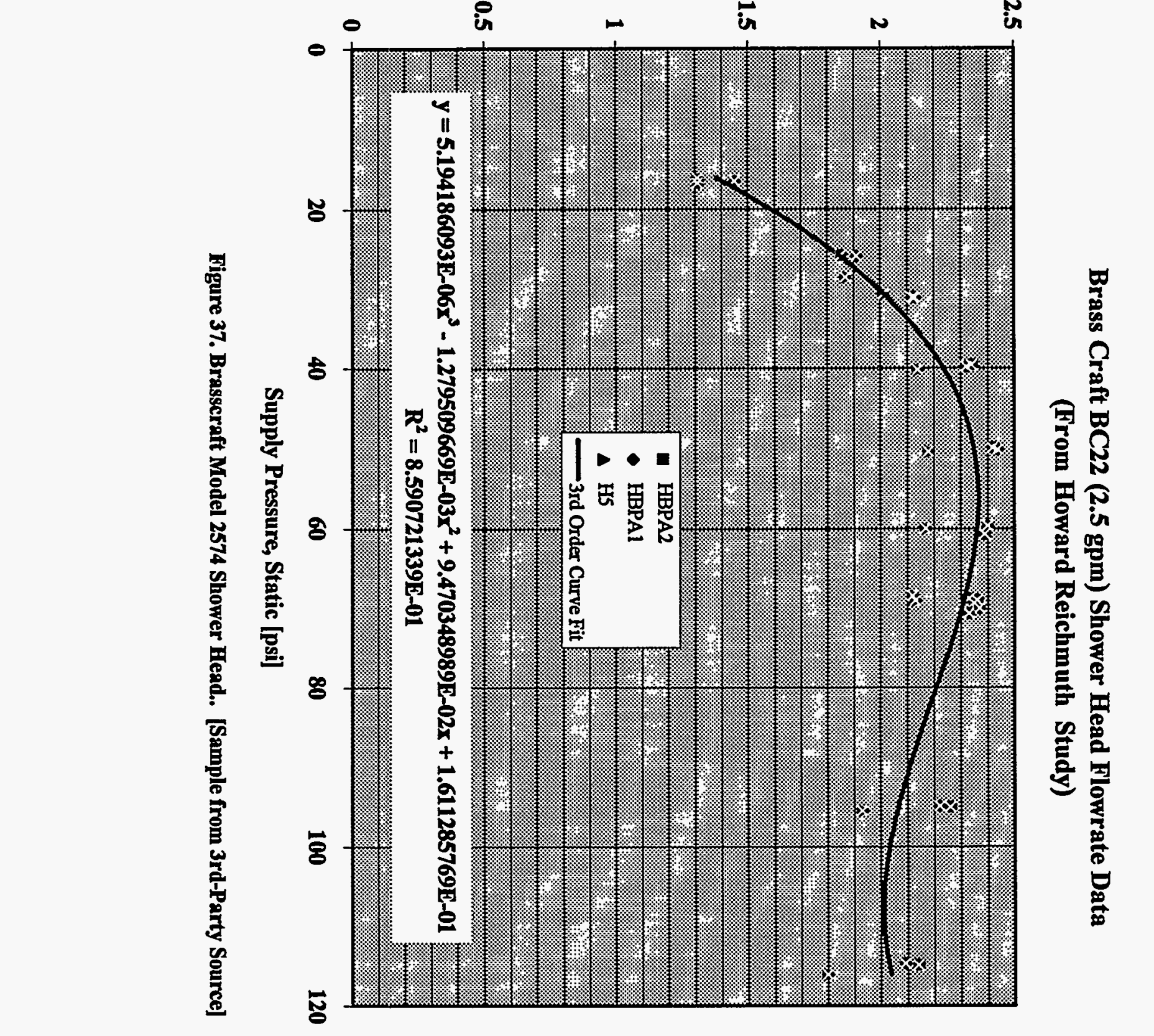

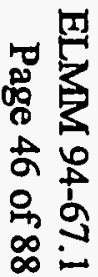


672BU Shower Heads

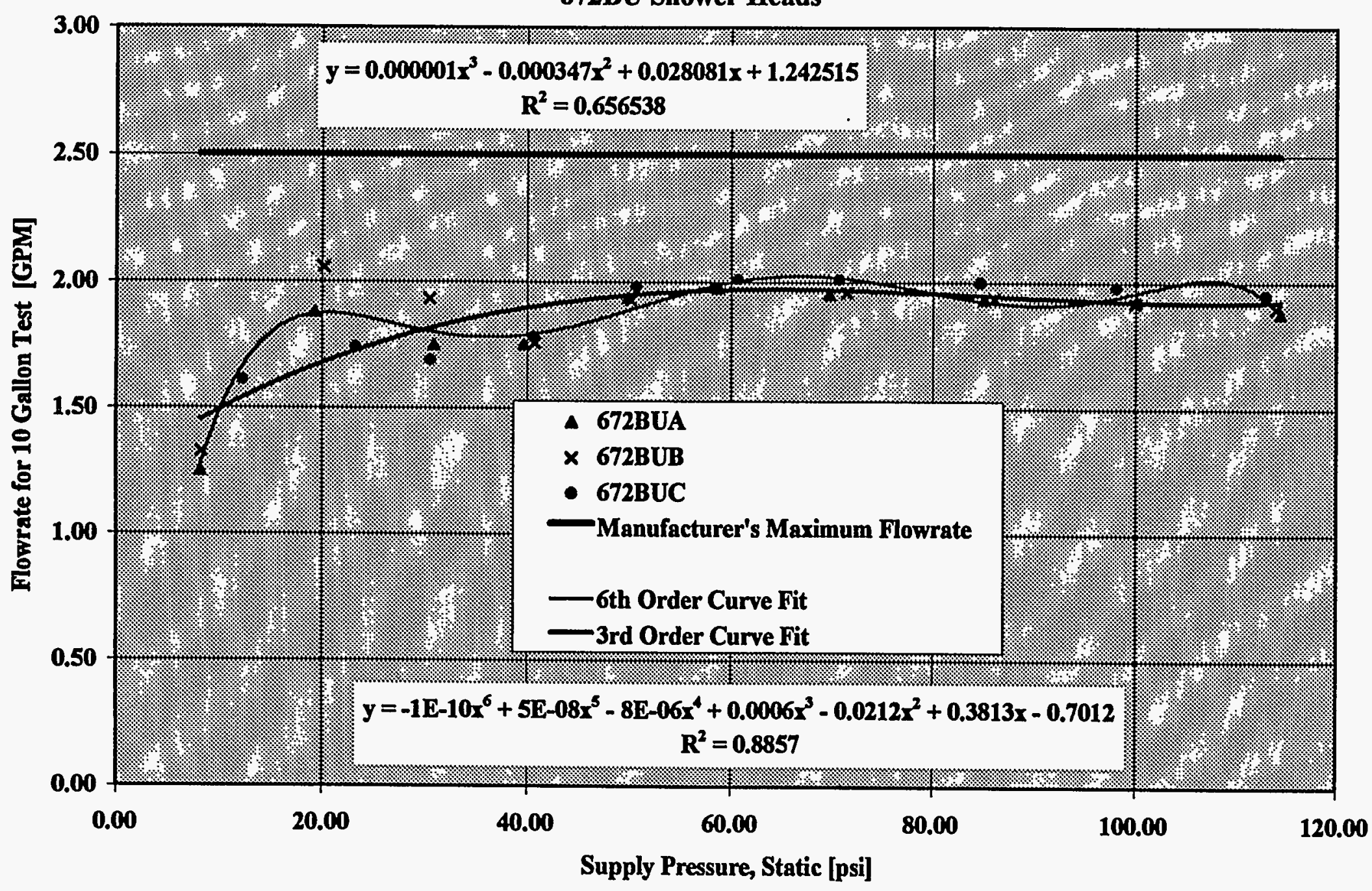

Figure 38. Alson's Model 190 Shower Head.

Two polynomial curve fits were used for this shower head in order to obtain a better R-squared value. As can be seen in the chart above, the regulator in this particular shower head attempts to maintain a 2.0 GPM flow rate. 


\section{Alson's JetSpray 190 Shower Head Flowrate Data (From Howard Reichmuth Study)}

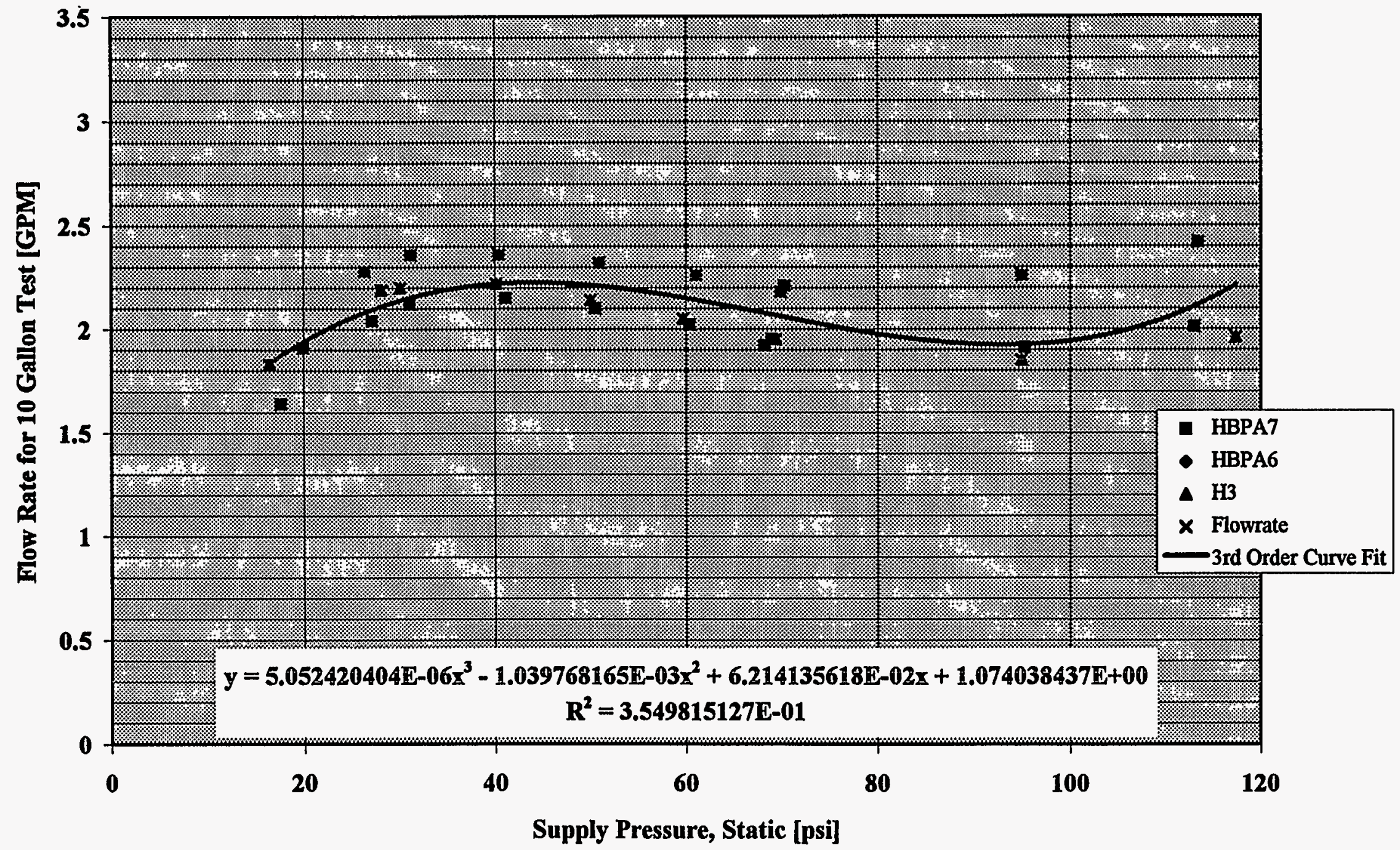

Figure 39. Alson's Model 190 Shower Head.. [Sample from 3rd-Party] 


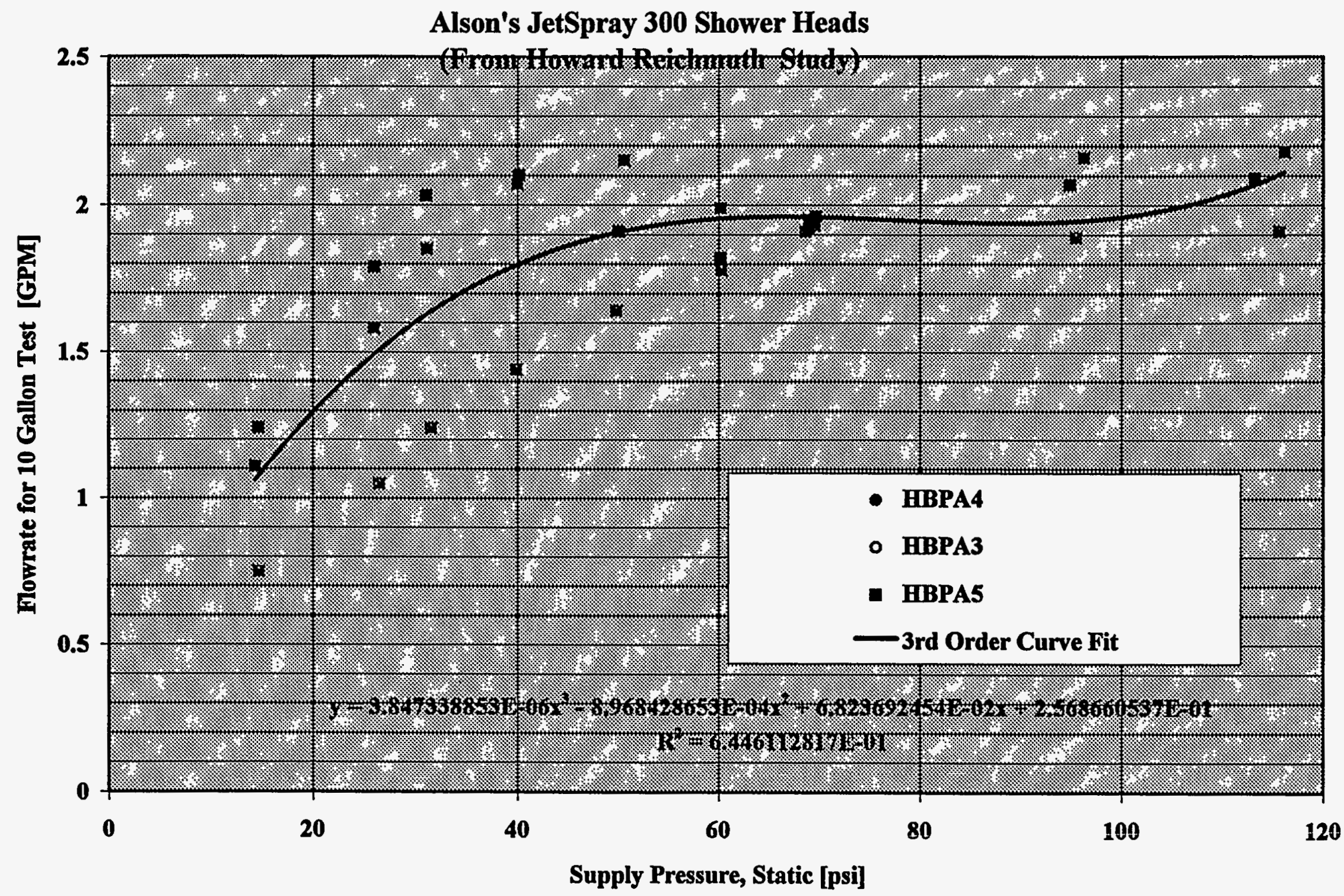

Figure 40. Alson's Model JetSpray 300 Shower Head.. [Sample from 3rd Party Source.] 


\section{CEW 2.4 CV Shower Heads}

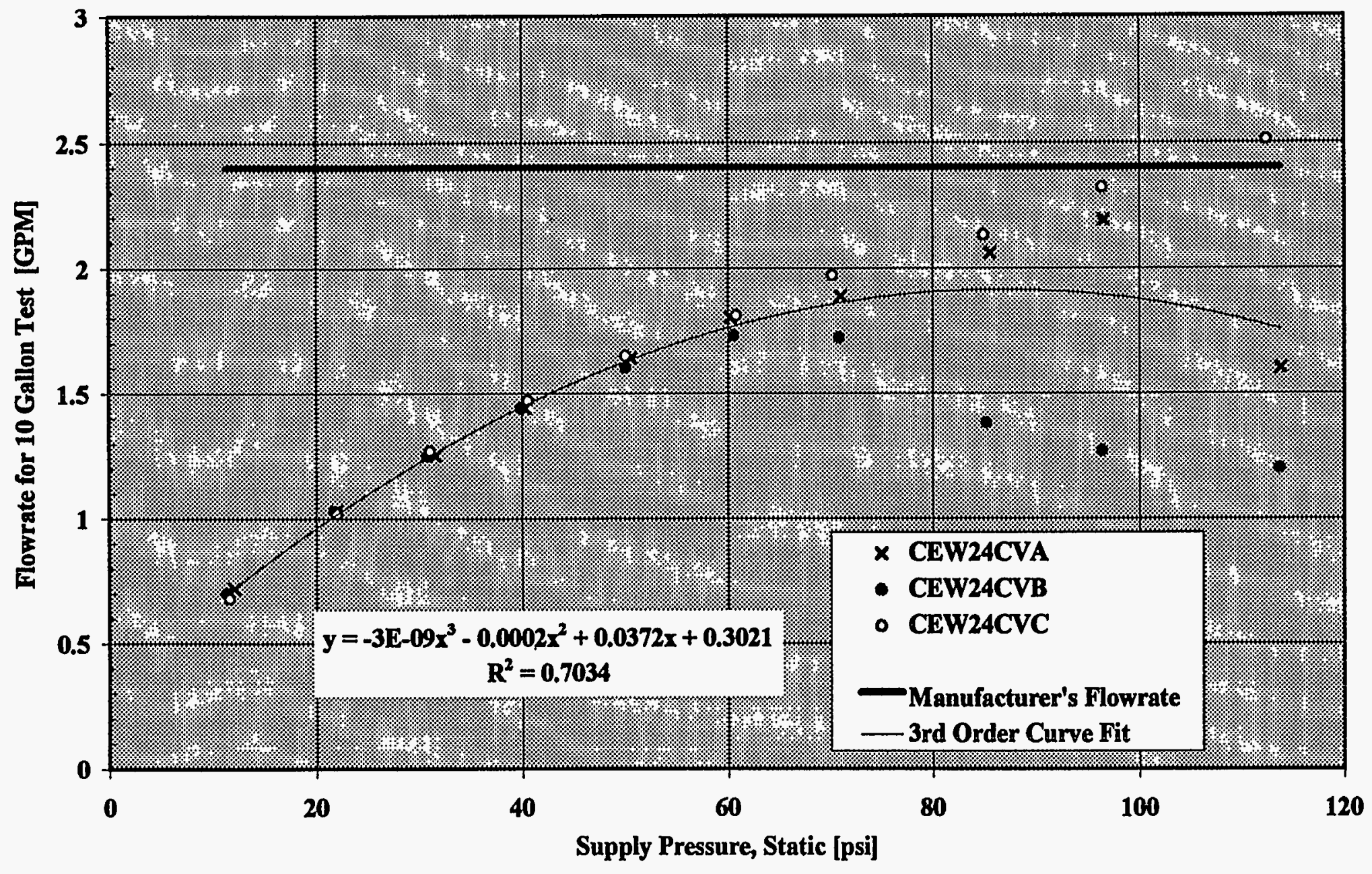

Figure 41. CEW Model 2.4 CV Shower Head.

It is not really known why there is so much scatter at the higher pressures for this shower head model. Regardless of the scatter from this shower head, the flow rate is with in the allowable parameters that the manufacturer advertised. 


\section{Shower Heads At Various Settings}

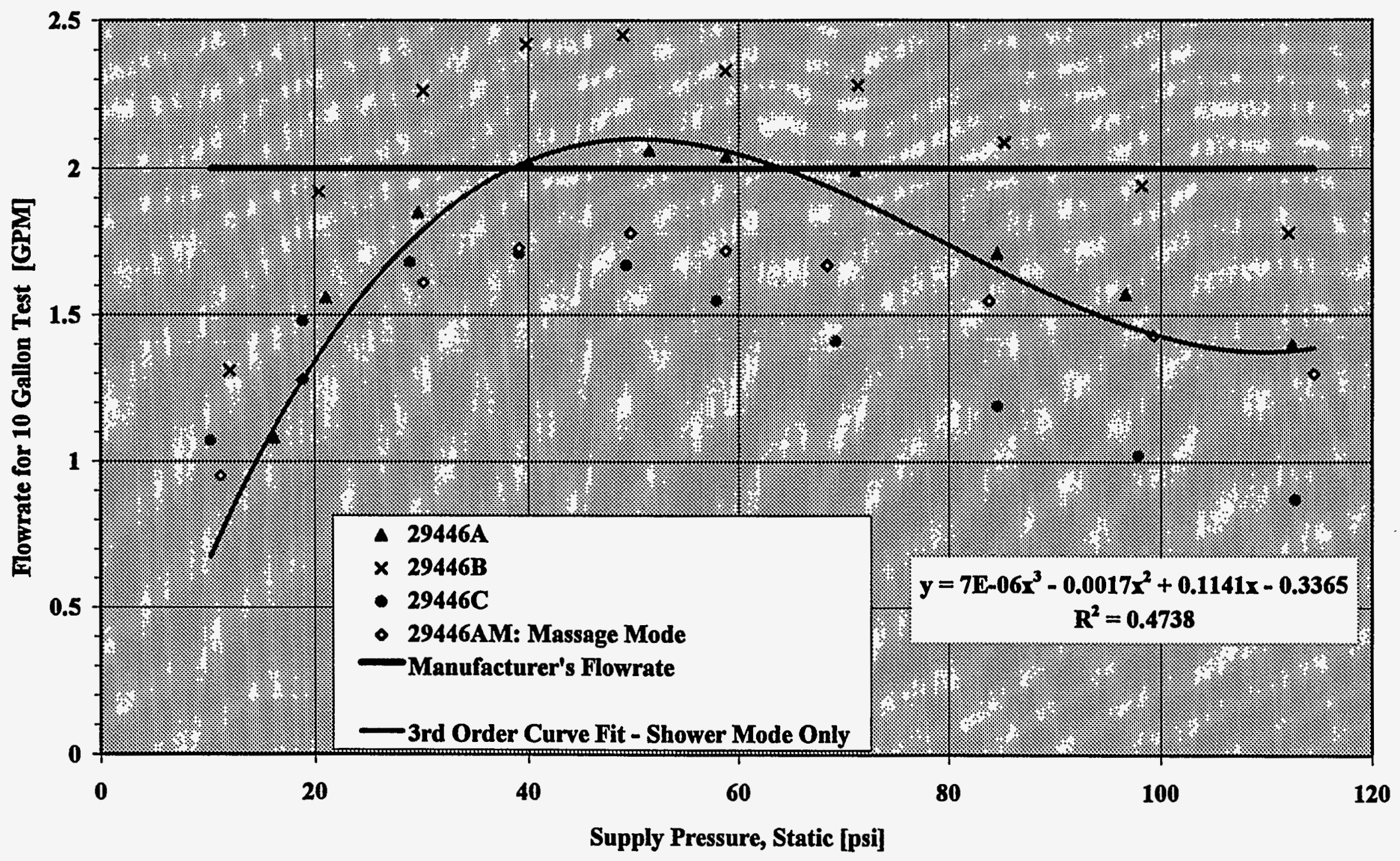

Figure 42. Niagara Model 29446 Shower Head.

This is an adjustable shower head and there is an enormous amount of scatter. 


\section{ES410B Shower Heads}

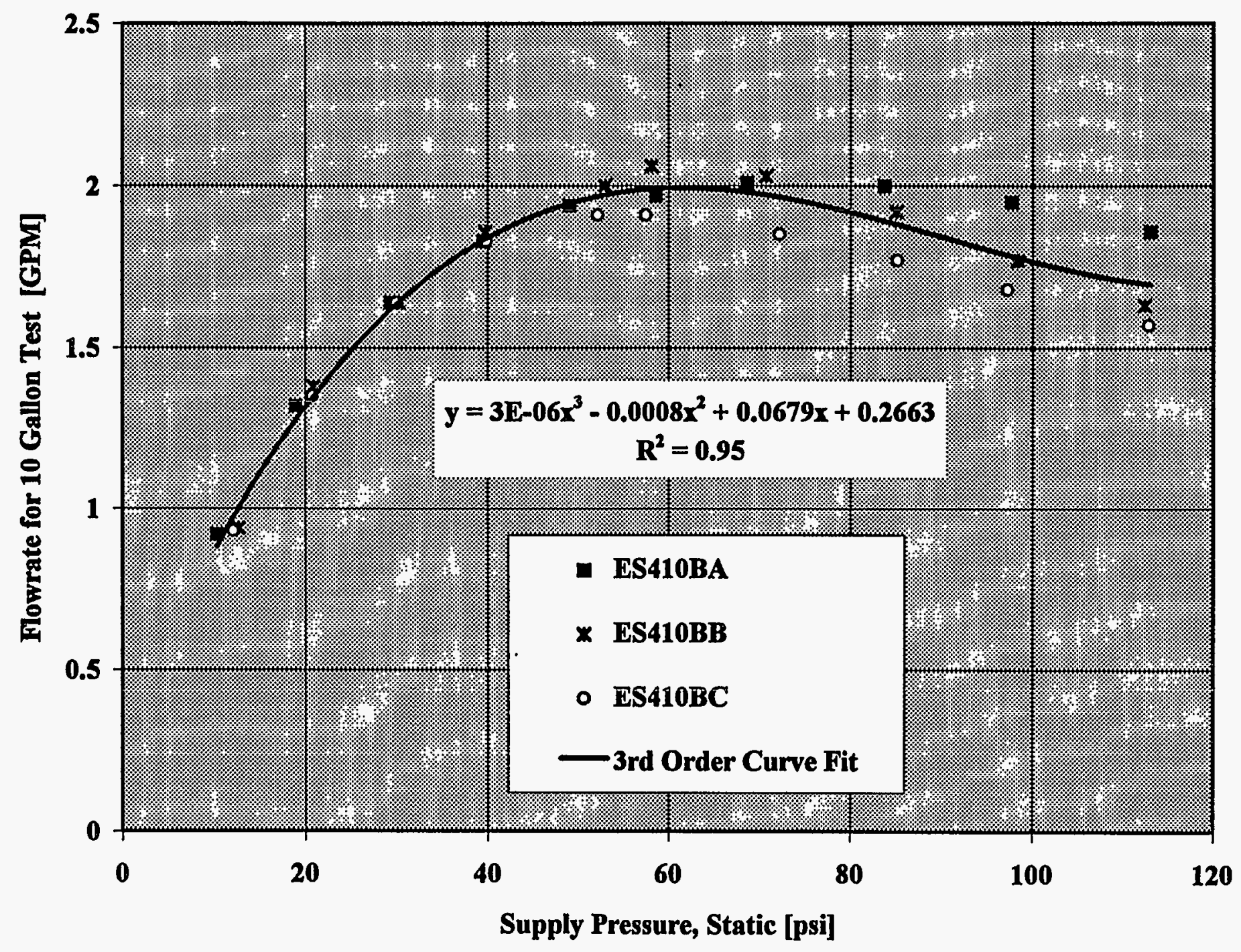

Figure 43. Resource Conservation Model ES 410B Shower Head. 


\section{BC2612 Shower Heads}

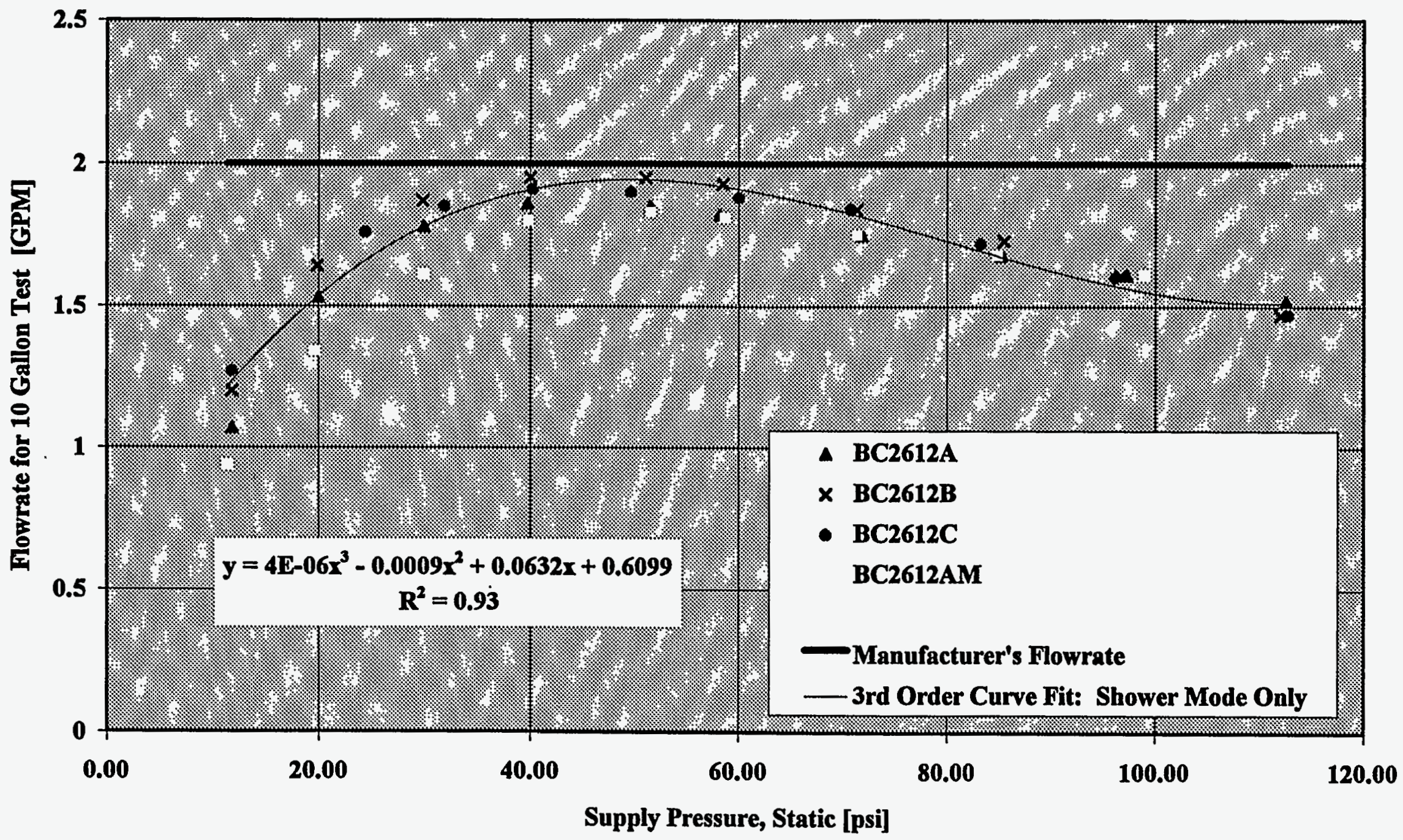

Figure 46. Brass Craft Model BC2612 Shower Head. 


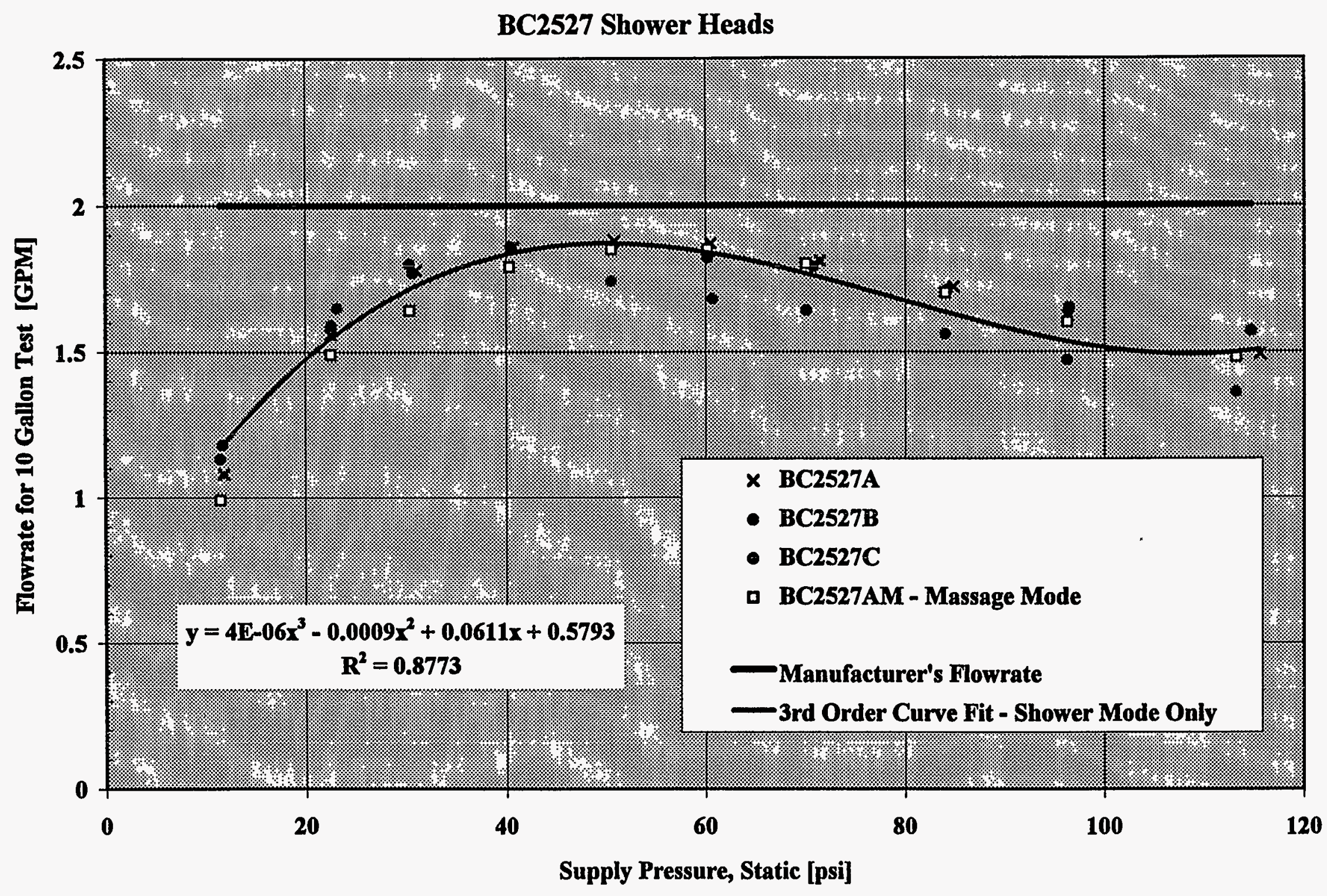

Figure 47. Brass Craft Model BC2527 (Handheld) Shower Head. 


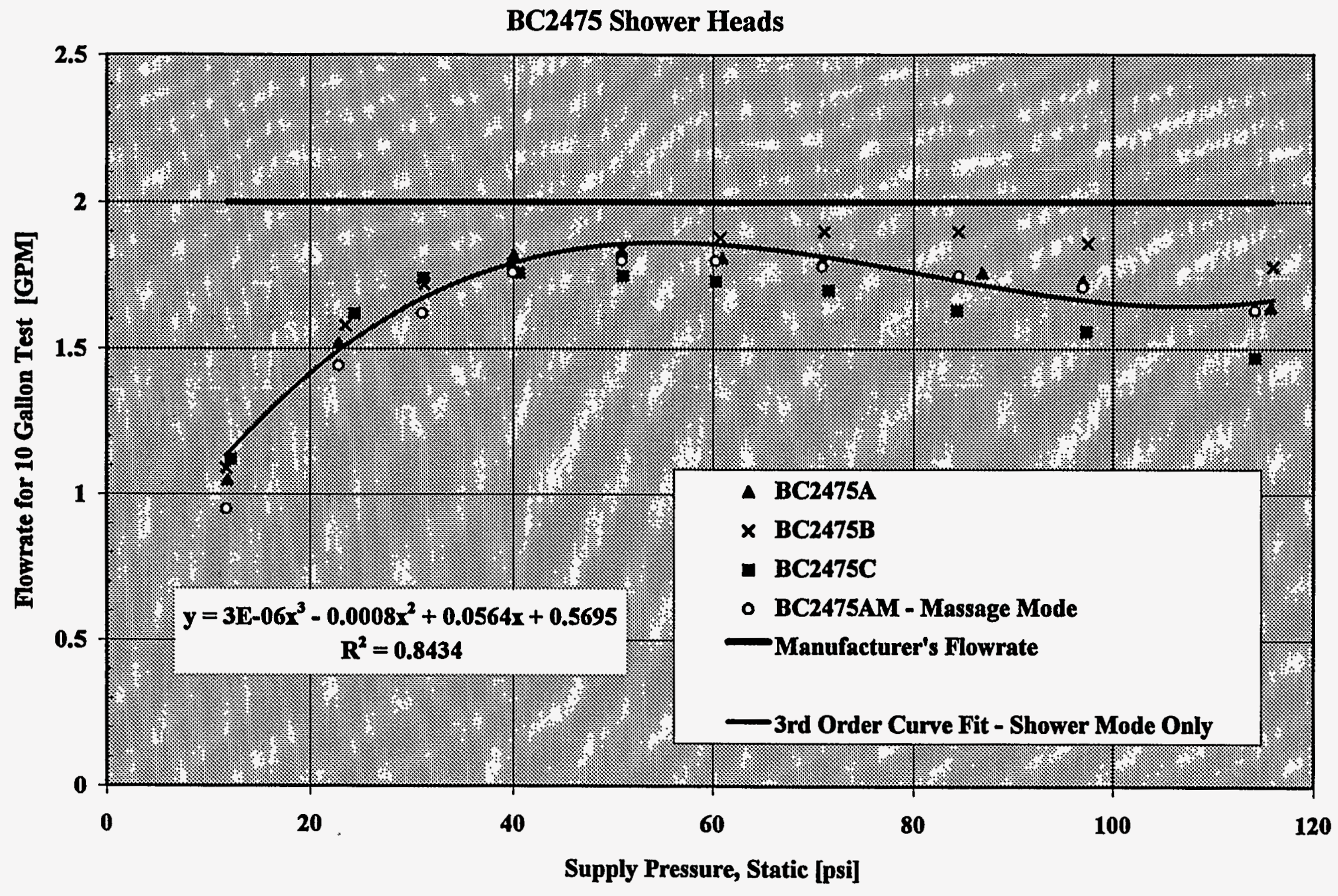

Figure 48. Brass Craft Model BC2475 Shower Head. 


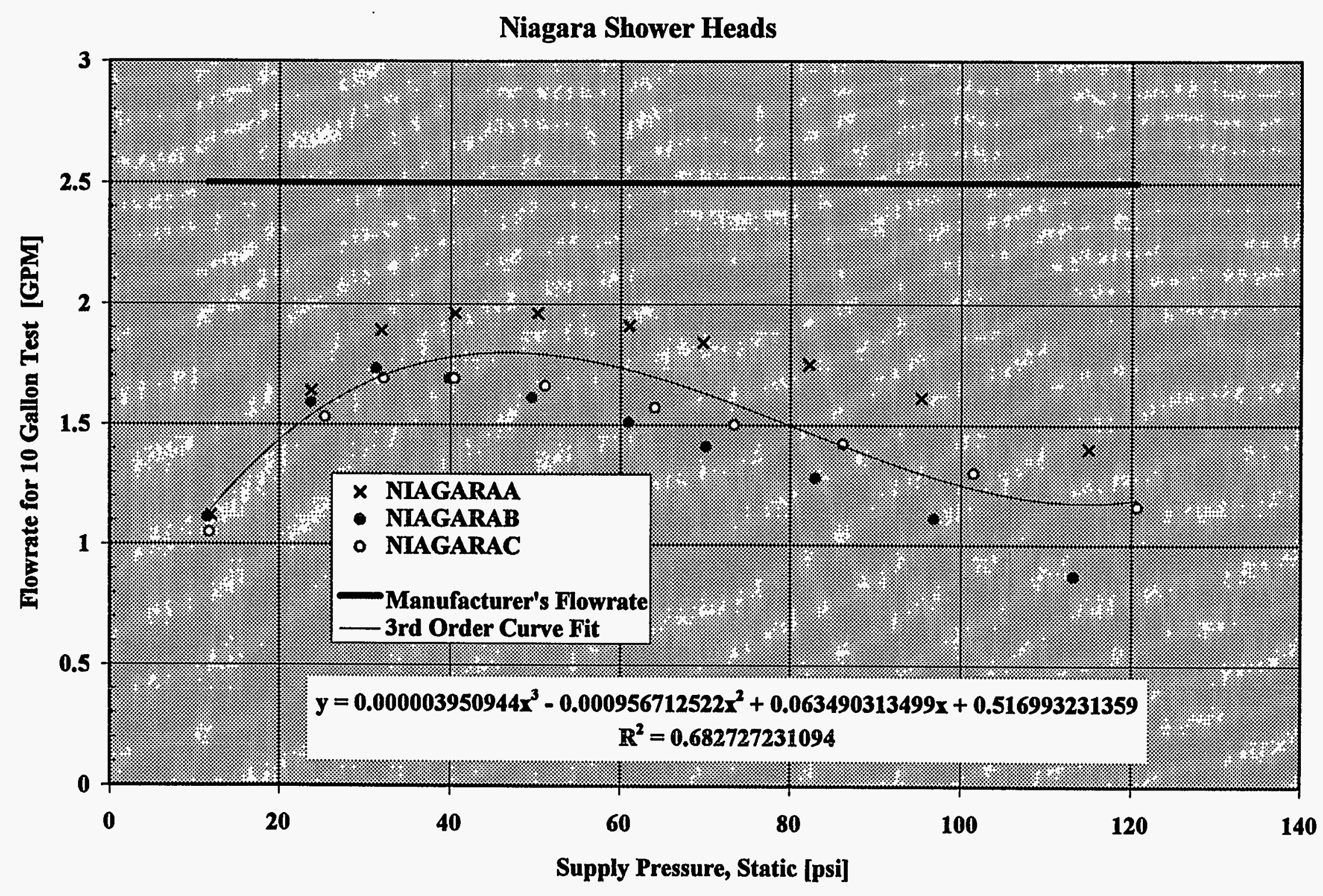

Figure 49. Niagara Model Shower Head. 


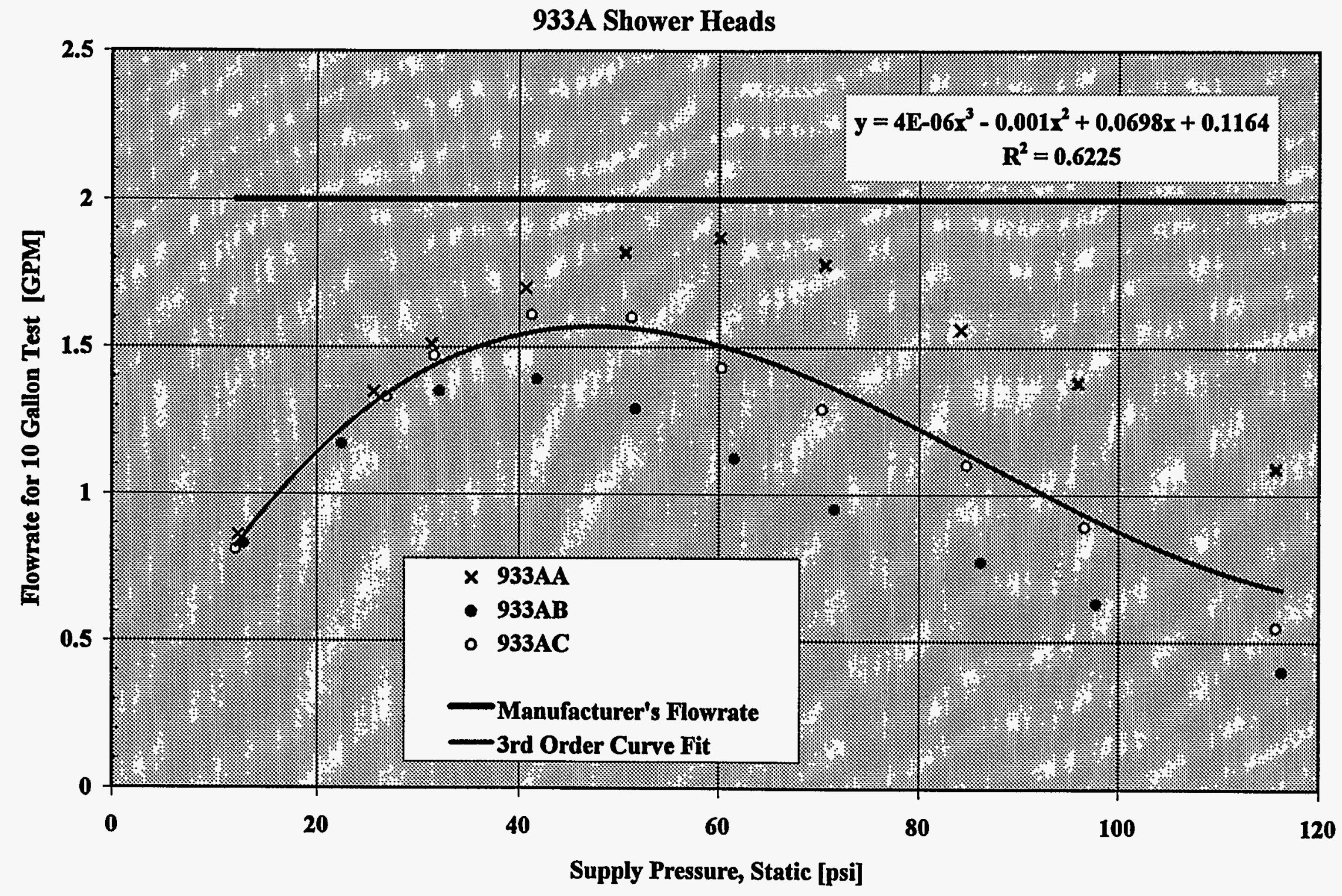

Figure 50. Ondine Model 933A Shower Head. 


\section{T Shower Heads With Zero Turns}

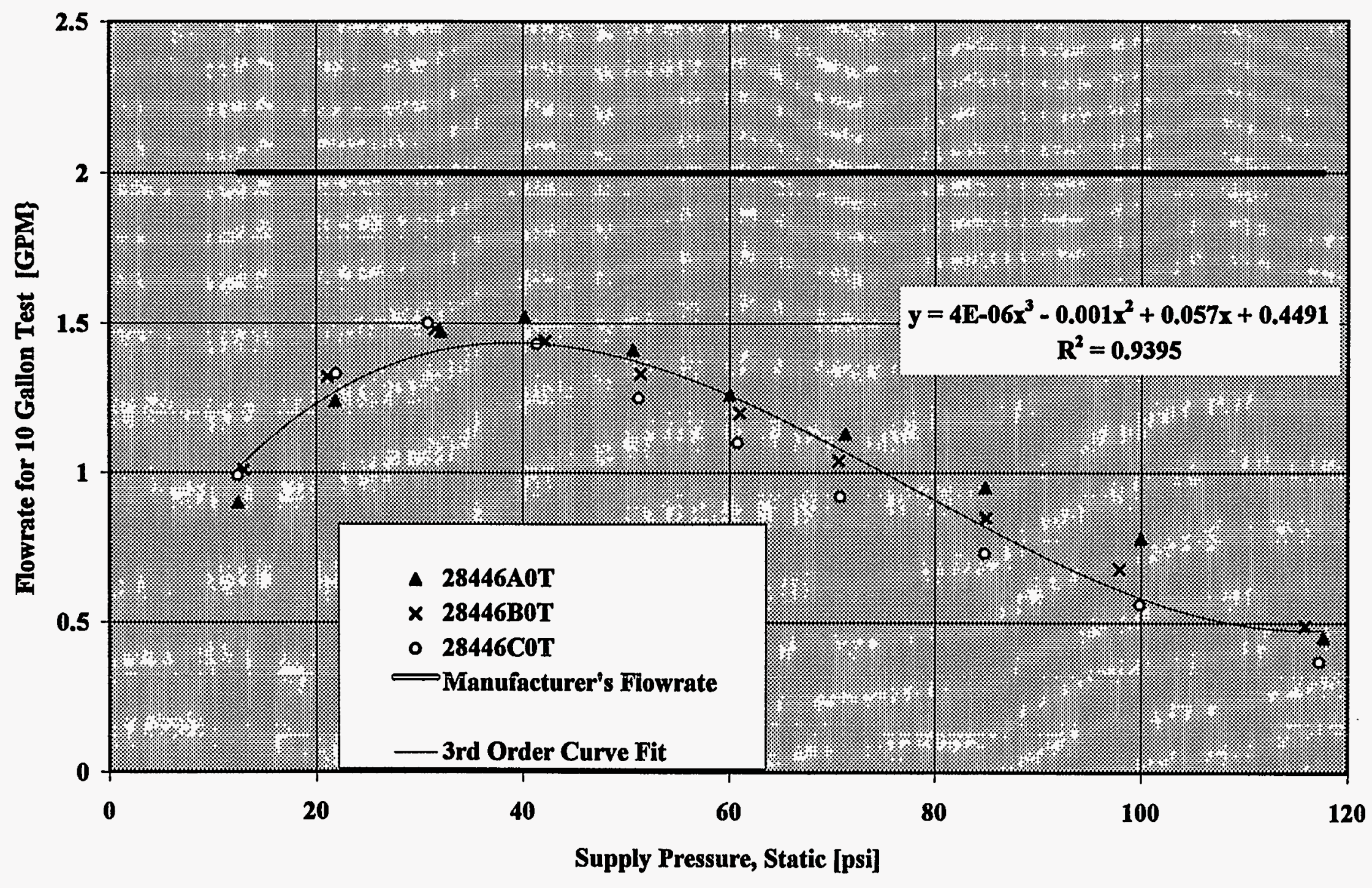

Figure 51. Niagara Model 28446 Shower Head. 
Flow Rate for 10 Gallon Test [GPM]



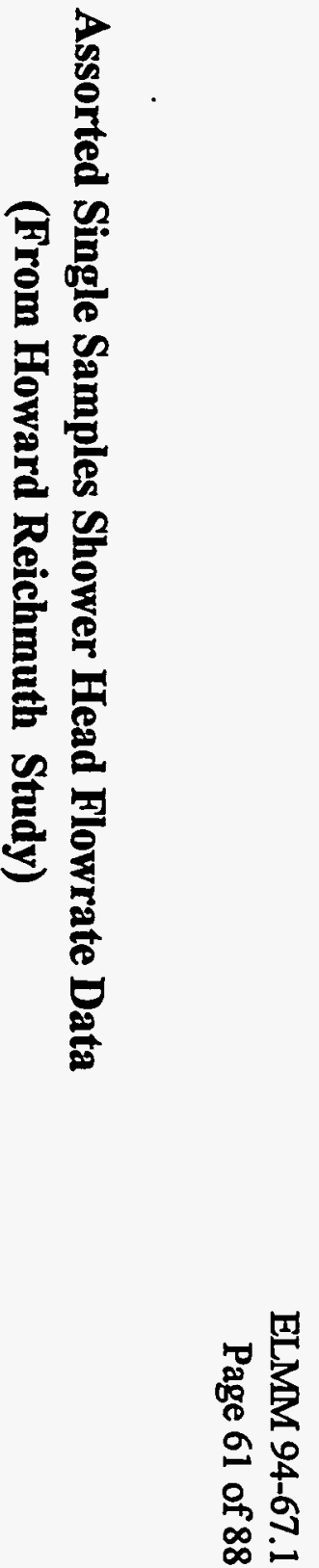




\section{MASCO (2.5 GPM)}

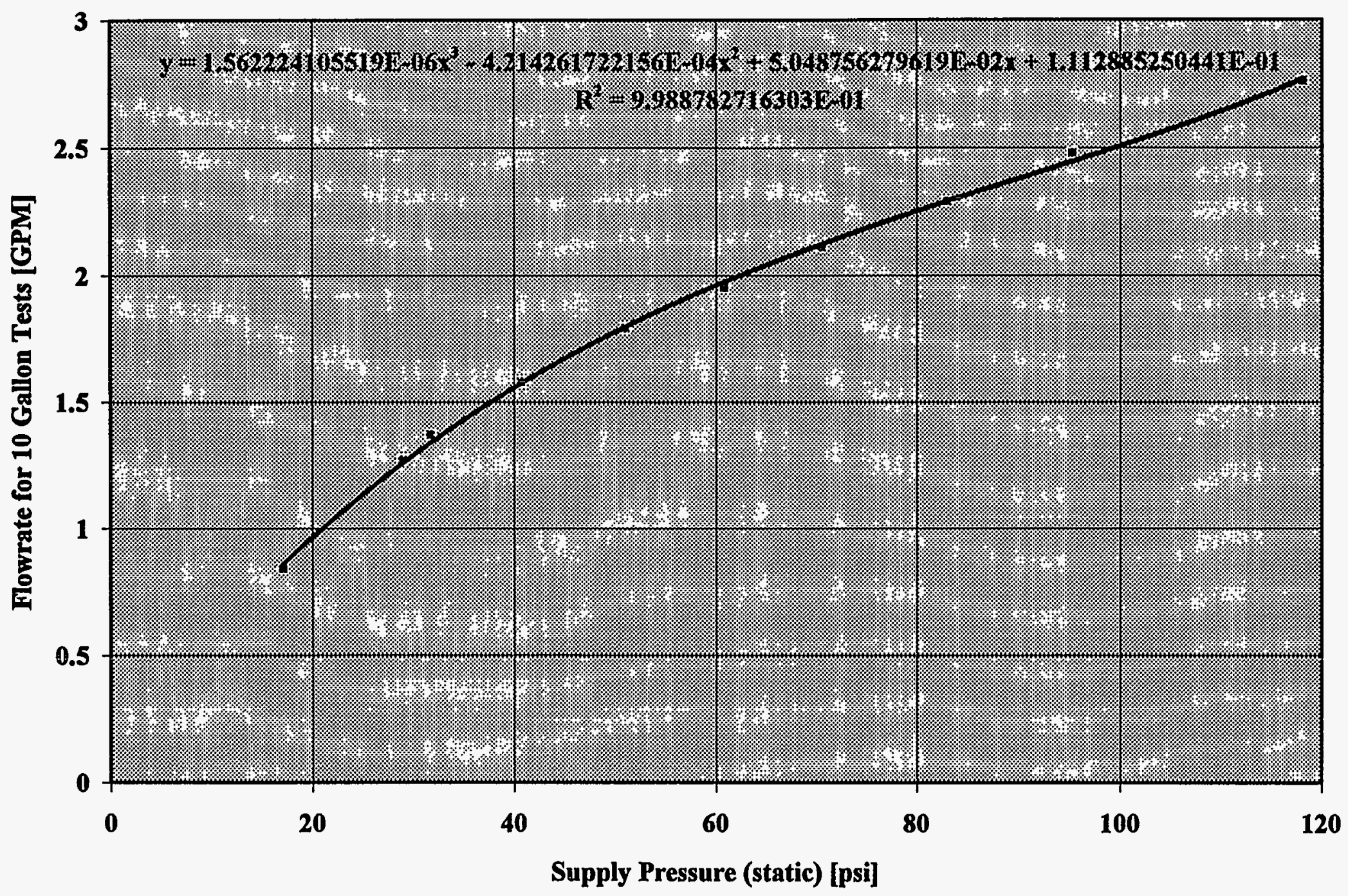

Figure 53. Masco Sample Provided by PNL. 
Tested at settings as they were removed.

Old Home Moen Shower Heads

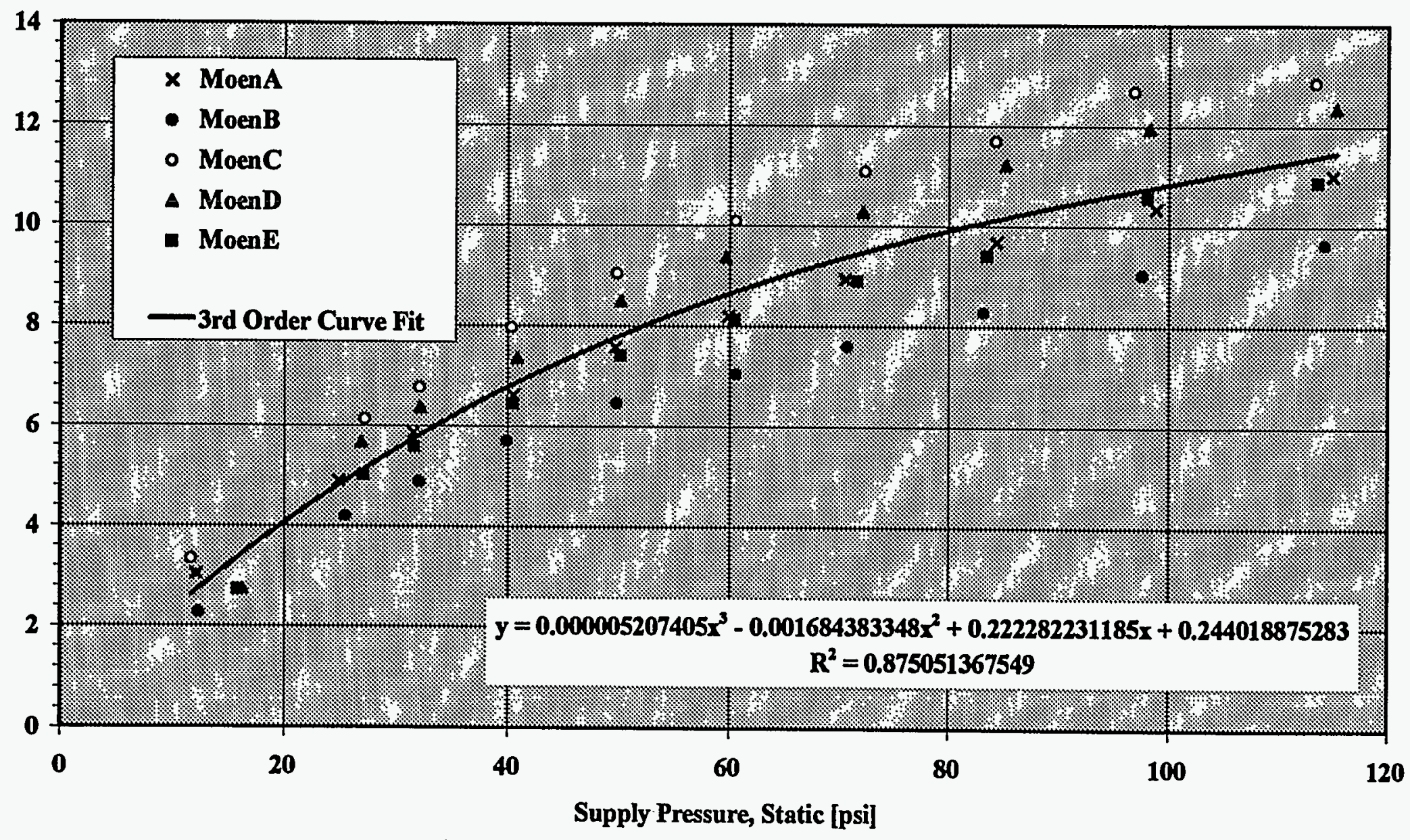

Figure 54. Moen Model Shower Head. 


\section{Old Home Stanadyne Shower Heads}

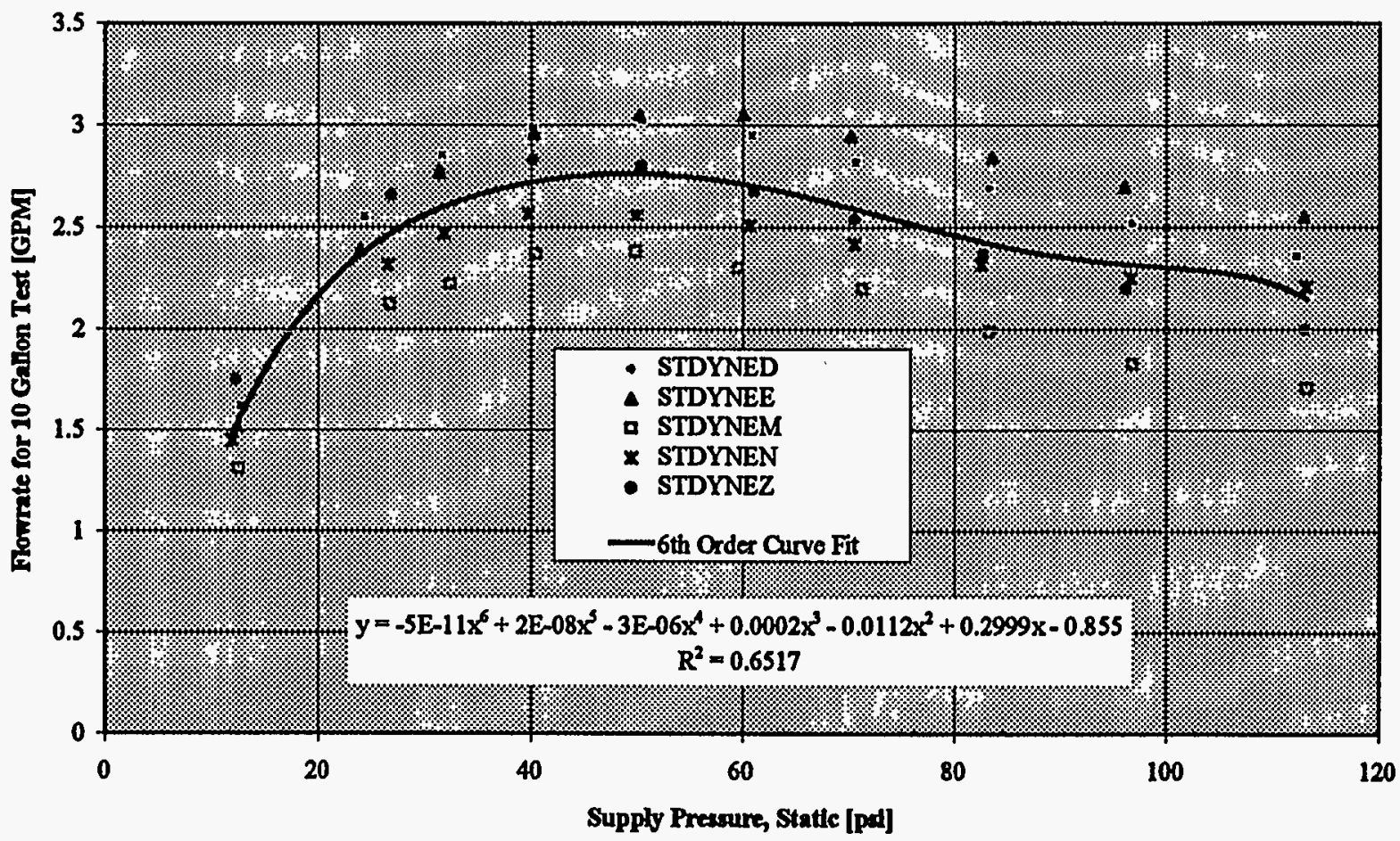

Figure 55 Stanadyne Group ' $A$ ' Shower Head.

The Stanadyne shower heads consisted of two distinct models, which were grouped into several different flow rates. The two models were distinctive only by size and not actual performance. The actual performance of each individual shower head greatly depended on the particular restrictor that was used with the shower head. There were two different types of restrictors used with the Stanadyne shower heads. The shower heads with the most conservative flow rates are shown above. These shower heads consisted of both Stanadyne models and had a rubber restrictor $6 \mathrm{~cm}$ thick, with five equally spaced holes, that were 2 mm in diameter. The over all diameter of the restrictor was approximately $1.8 \mathrm{~cm}$. An example of the discussed restrictor can be seen in Figure 42 below.

Figure 56. Five holed conservative flow rate restrictor. 
Old Home Stanadyne Shower Heads

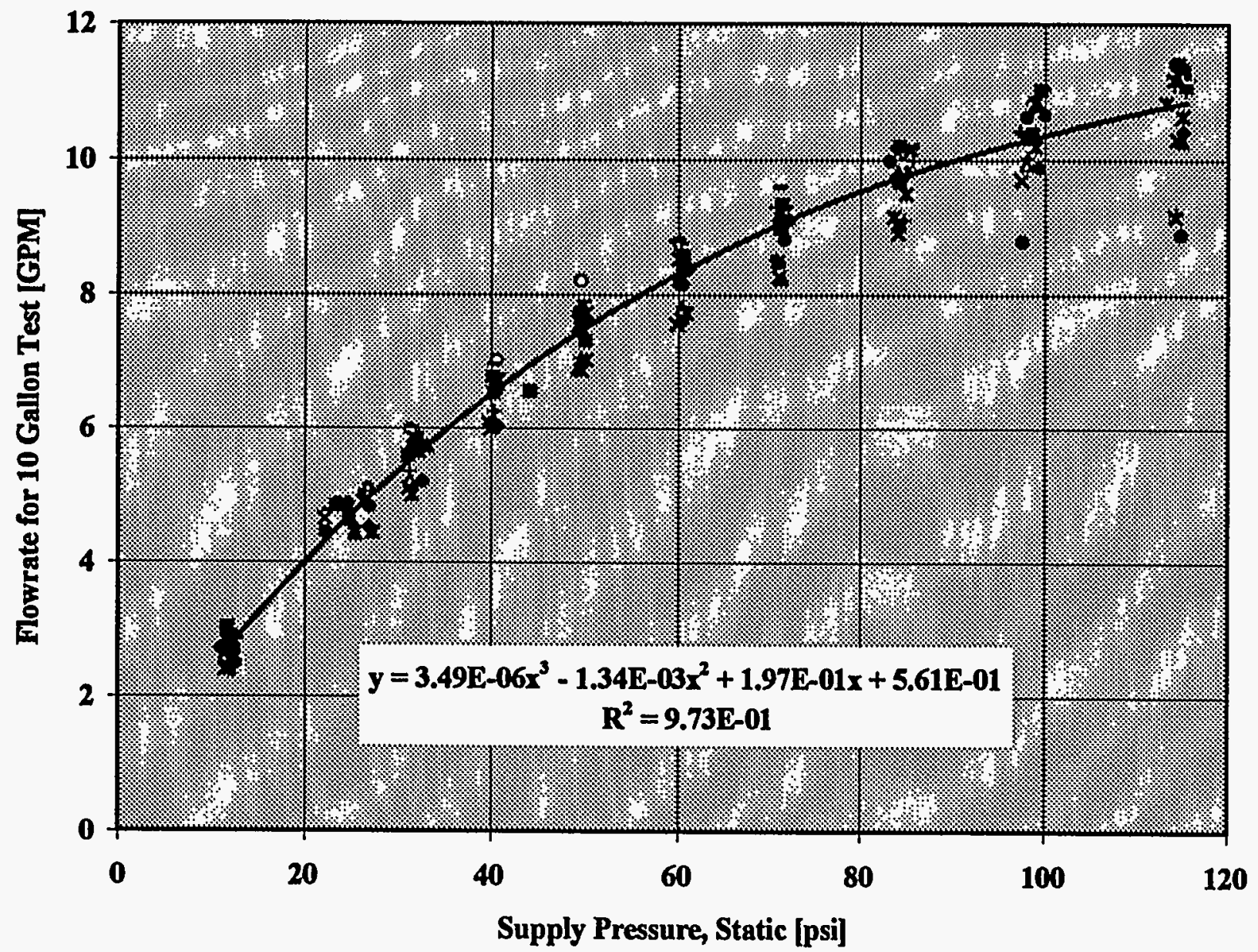

- STDYNEAA

- STDYNEB

- STDYNEC

- STDYNEF

+ STDYNEG

- STDYNEH

- STDYNEI

- STDYNEK

$\triangle$ STDYNEL

$\times$ STDYNEO

$\times$ STDYNEP

- STDYNEQ

+ STDYNER

- STDYNES

- STDYNEU

- STDYNEV

A STDYNEW

$\times$ STDYNEX

* STDYNEY

- STDYNEYY

+ STDYNEZZ

-3rd Order Curve Fit

Supply Pressure, Static [psi]

Figure 57. 1 Stanadyne Group B Shower Head.

Stanadyne Group B had a significantly higher flow rate than Group A does. The restrictor used with these shower heads was a stainless steel, one holed restrictor. The hole was approximately $3.5 \mathrm{~mm}$ in diameter, while the over all diameter of the restrictor was $1.8 \mathrm{~cm}$ or .75 inches. The restrictor used in the above chart can be seen in Figure 44 below. 


\section{Old Home Stanadyne -3 Shower Heads}

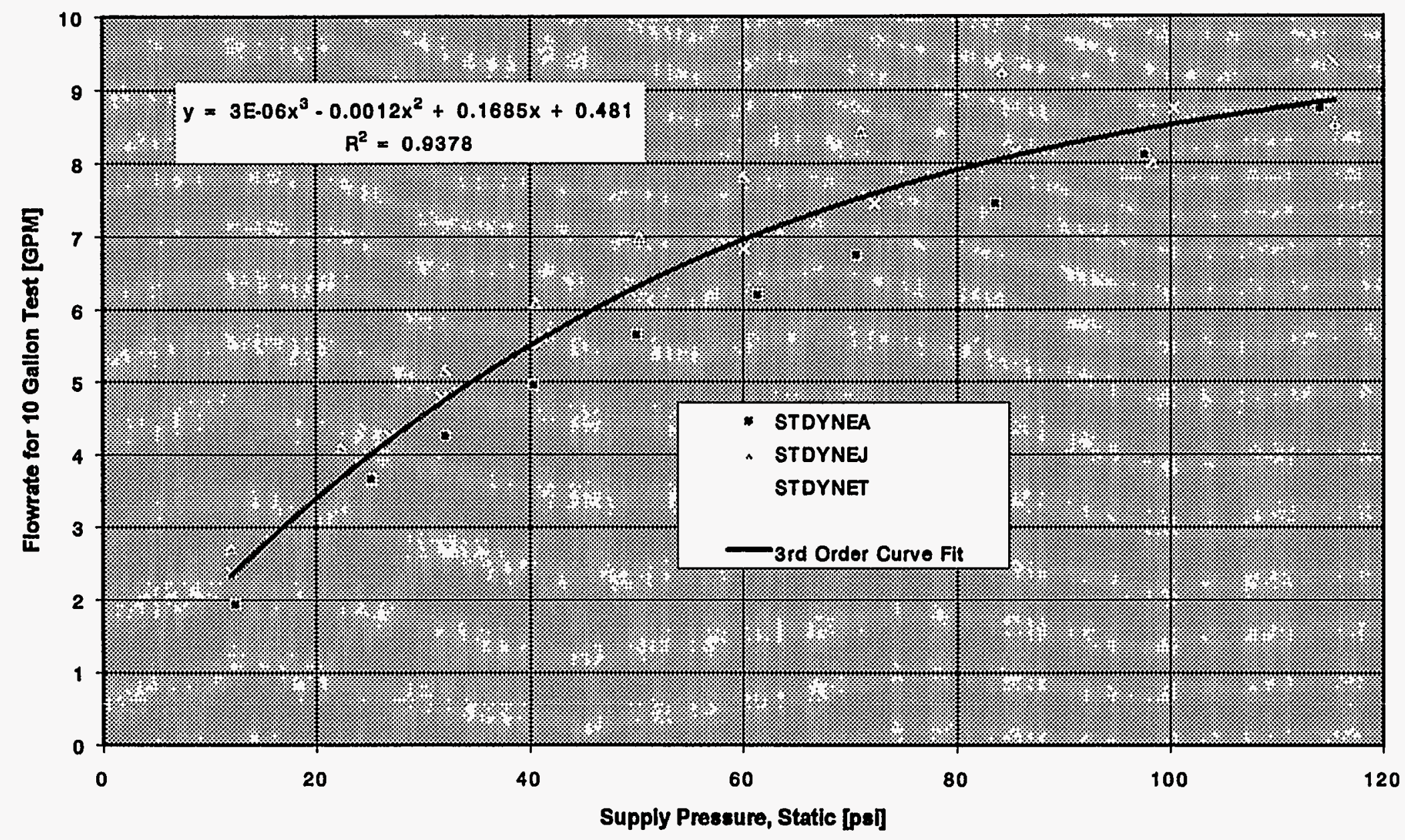

Figure 58. Stanadyne Group C Shower Head..

The Stanadyne shower heads used to produce this chart did not have a restrictor in them when they were received. As a result, the shower heads were run as they were received. This group of shower heads had a higher flow rate than the other two groups. 
훙

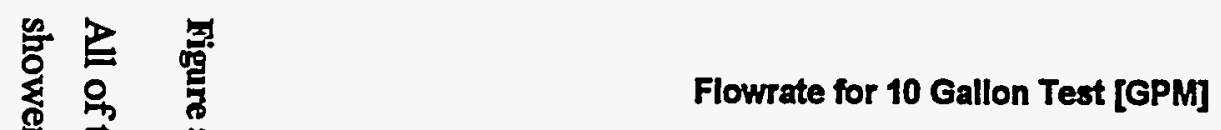

官 究

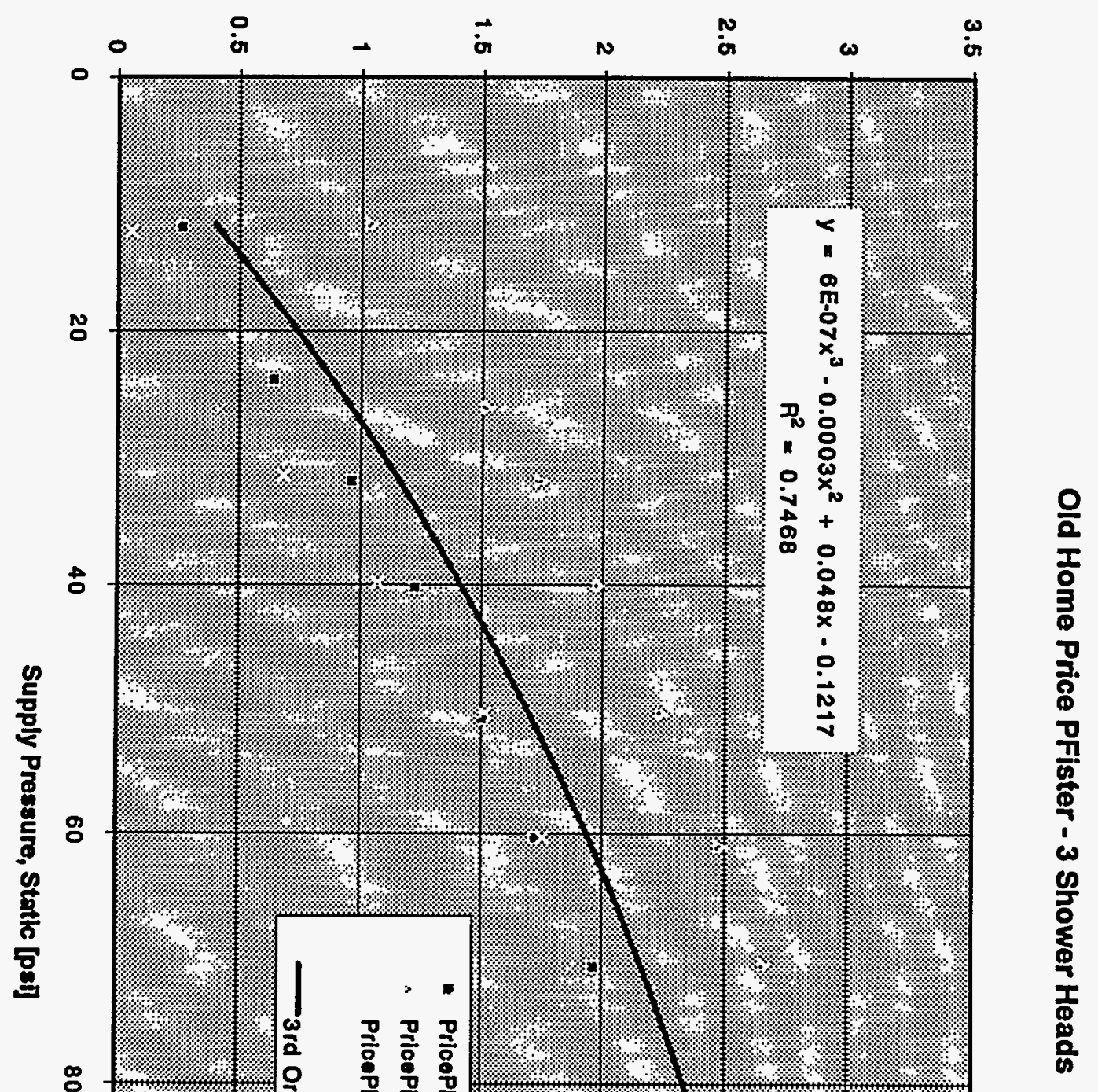



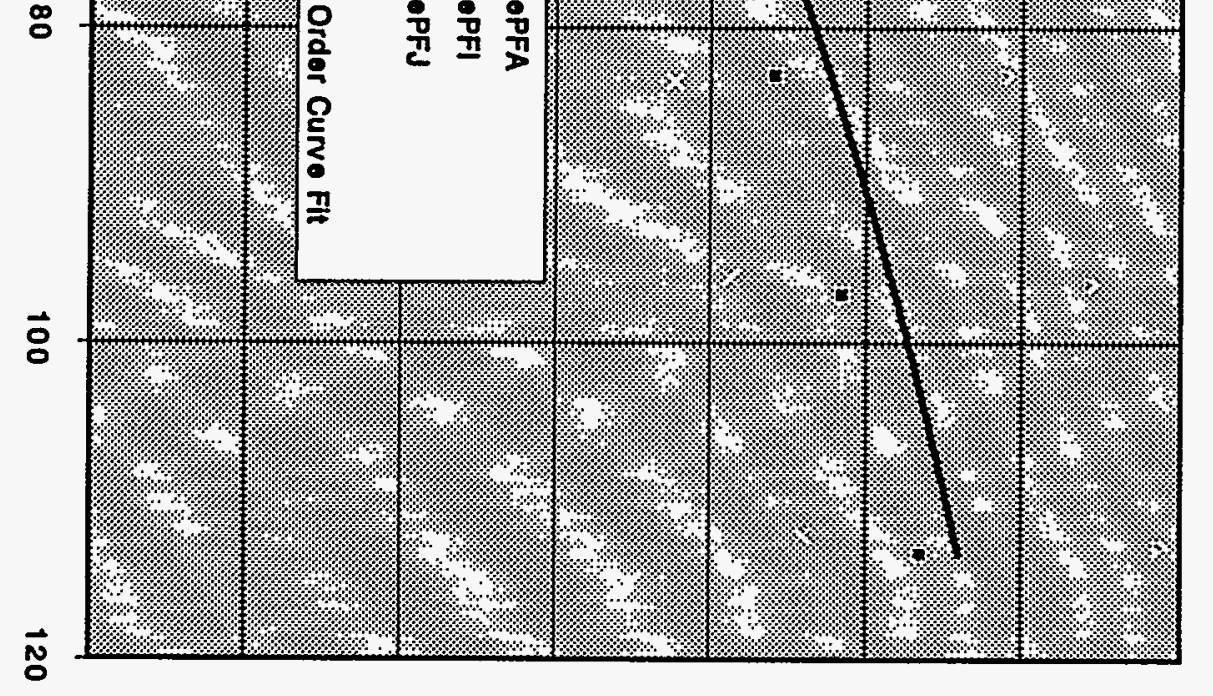

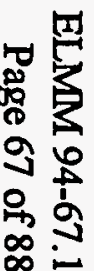




\section{Old Home Price PFister - 7 Shower Heads}

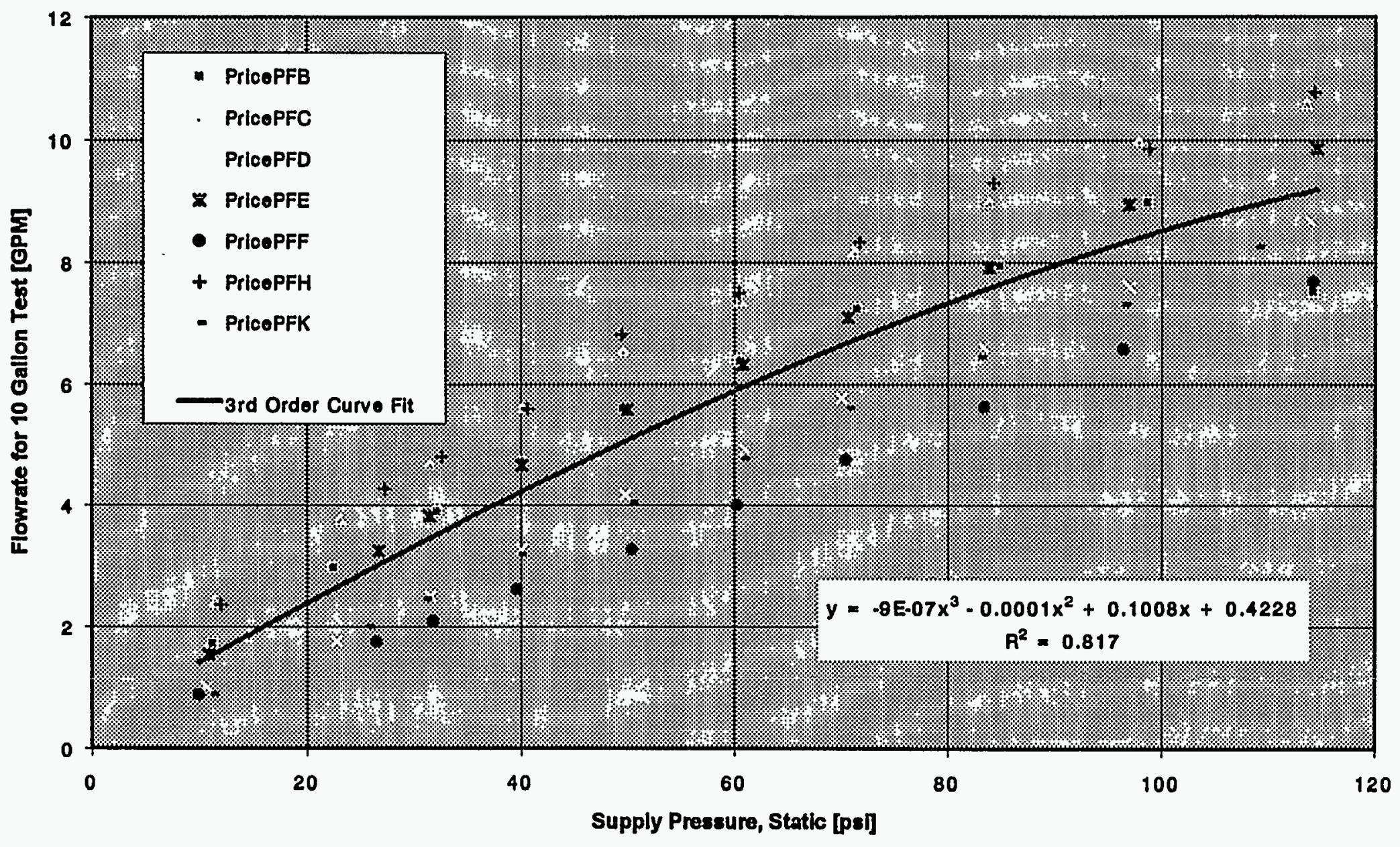

Figure 60. Price Pfister Group B Shower Head..

The charts for the Price Pfister shower heads were grouped according to flow rates. 


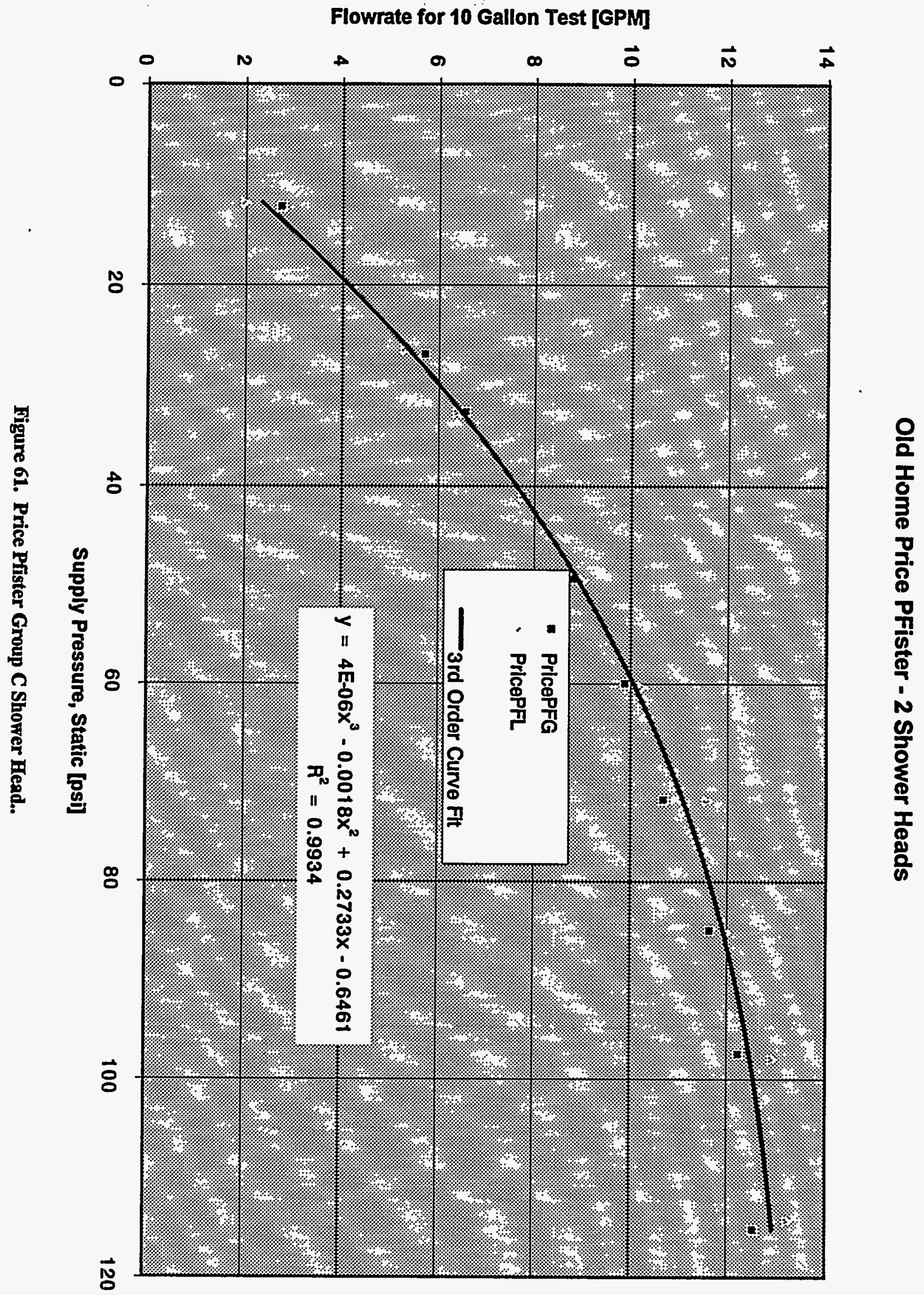

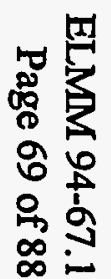




\section{Old Home Standard Shower Heads}

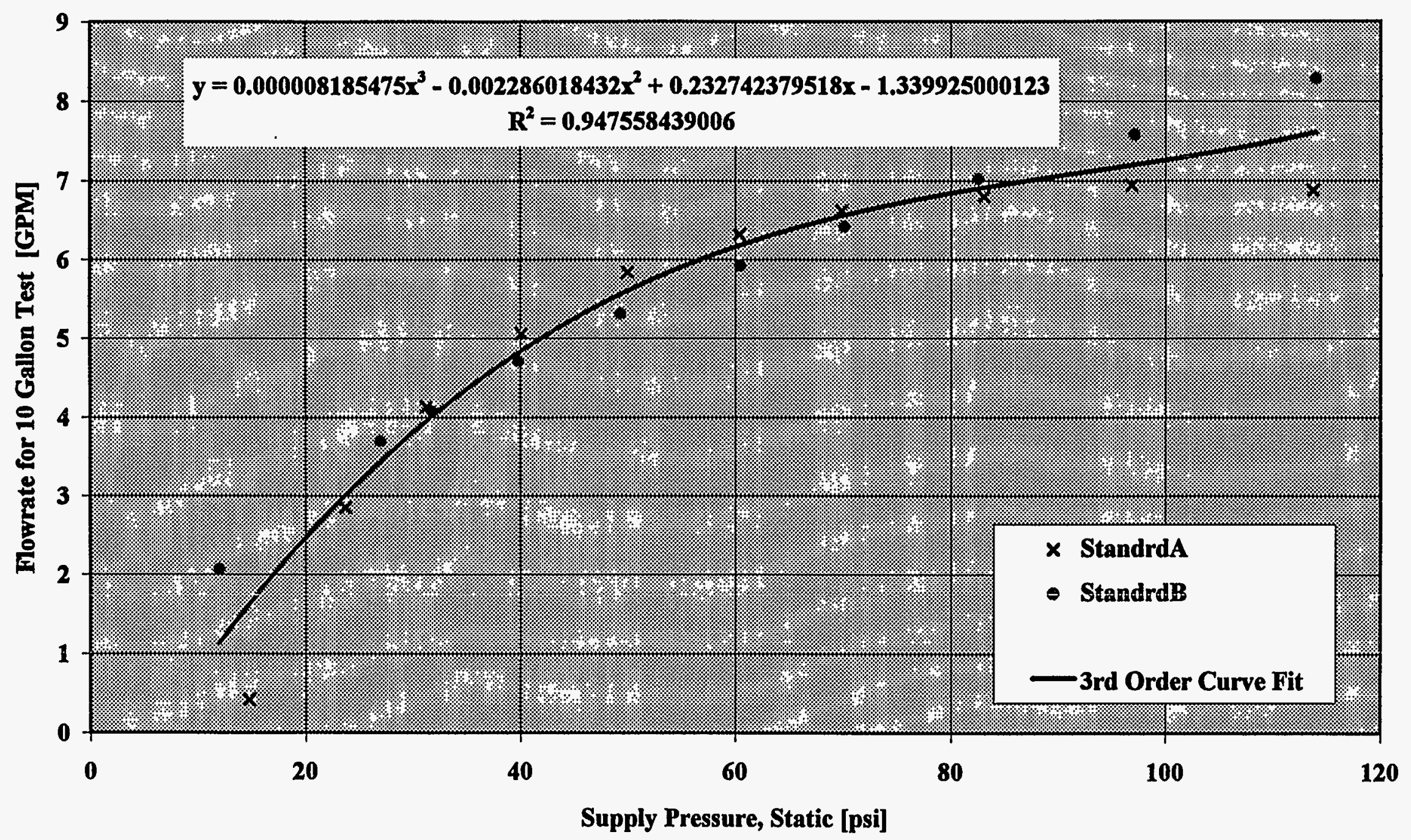

Figure 62. Standard Model Shower Head. 


\section{Old Home Ondine Shower Heads}

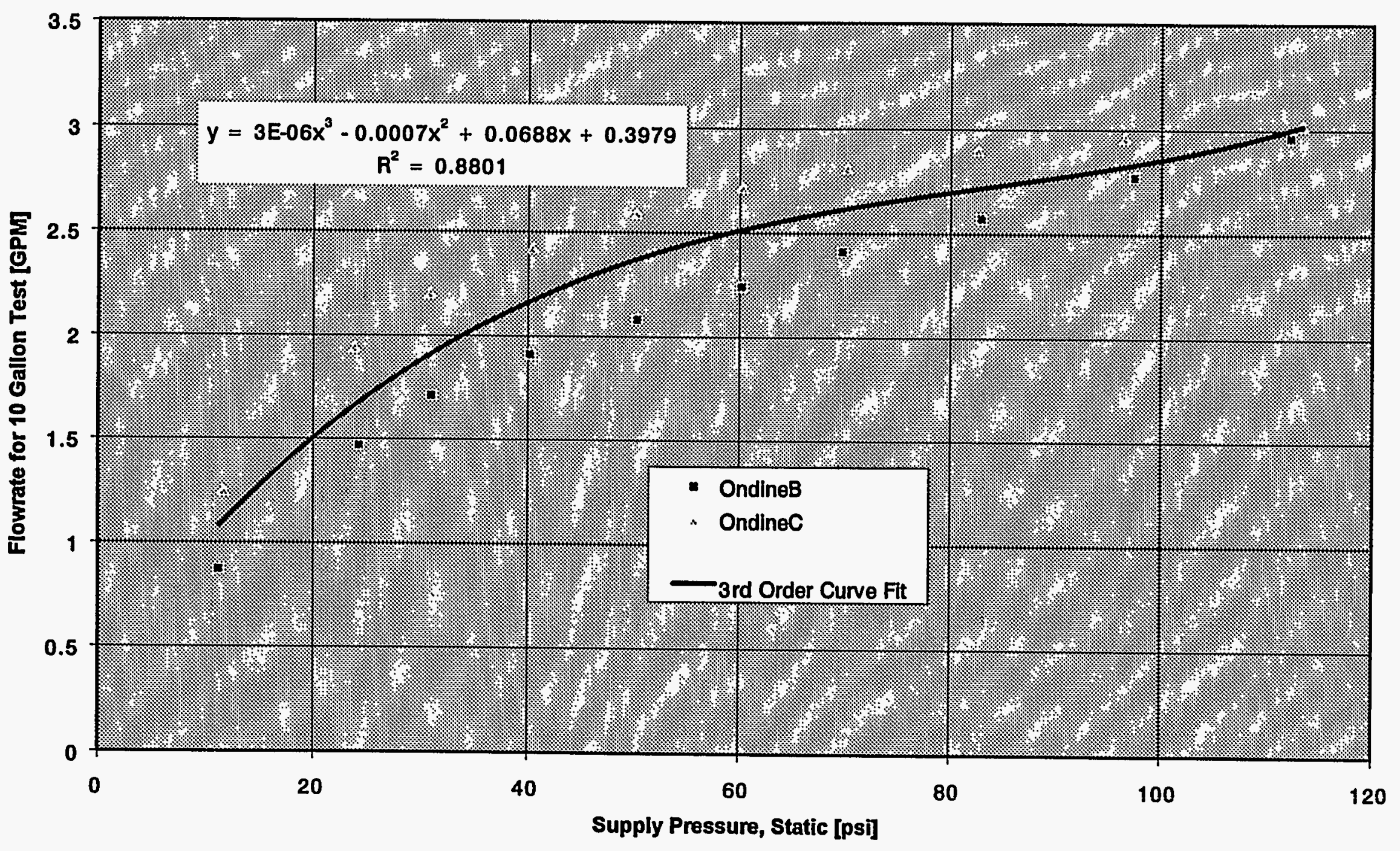

Figure 63. Ondine Model 1 Shower Head. 


\section{Old Home Ondine Type II Shower Head}

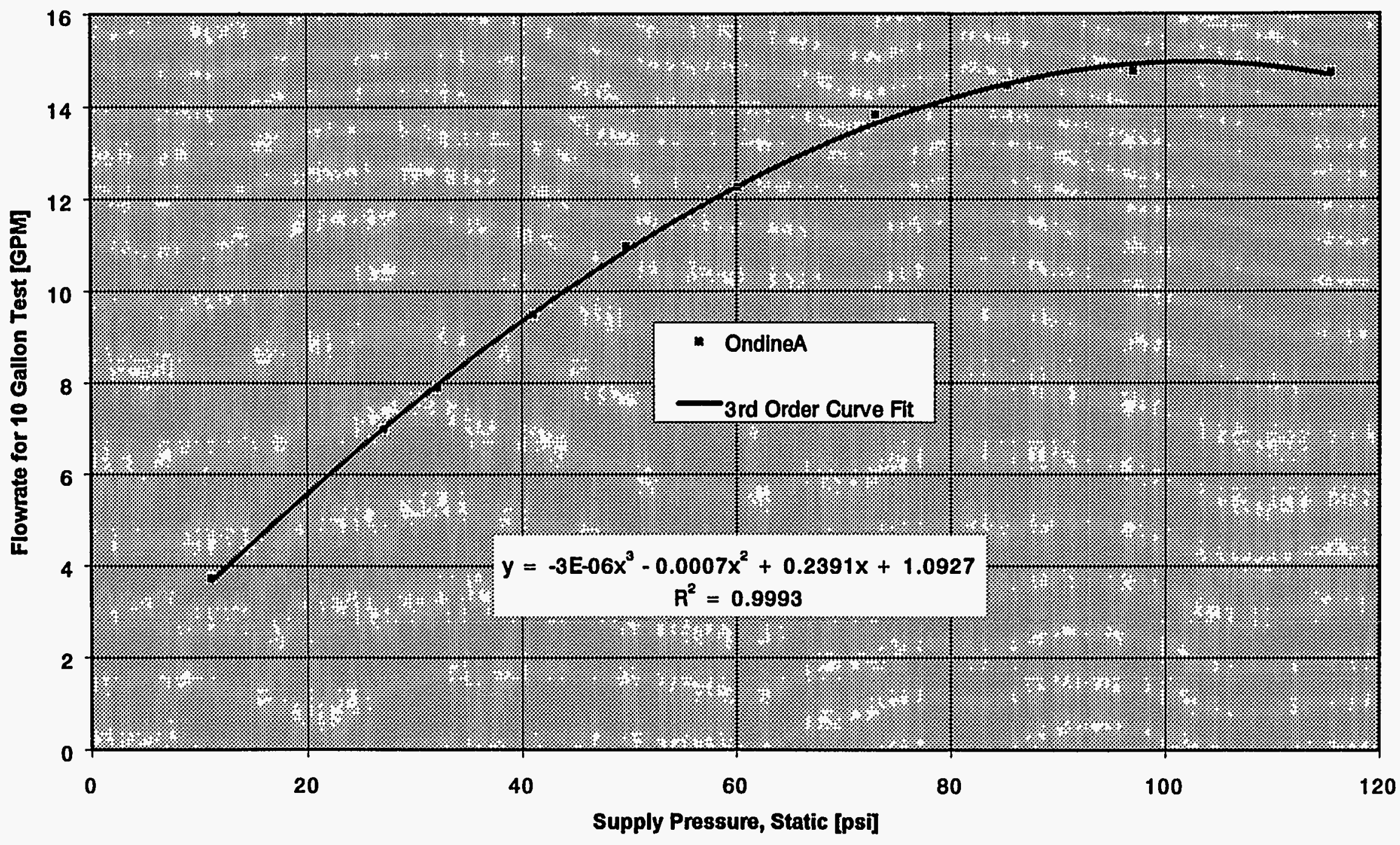

Figure 64. Ondine Model 2 Shower Head Flow Rate Performance.

The Ondine Model 2 shower head, was broken and leaked like an open water hose. 


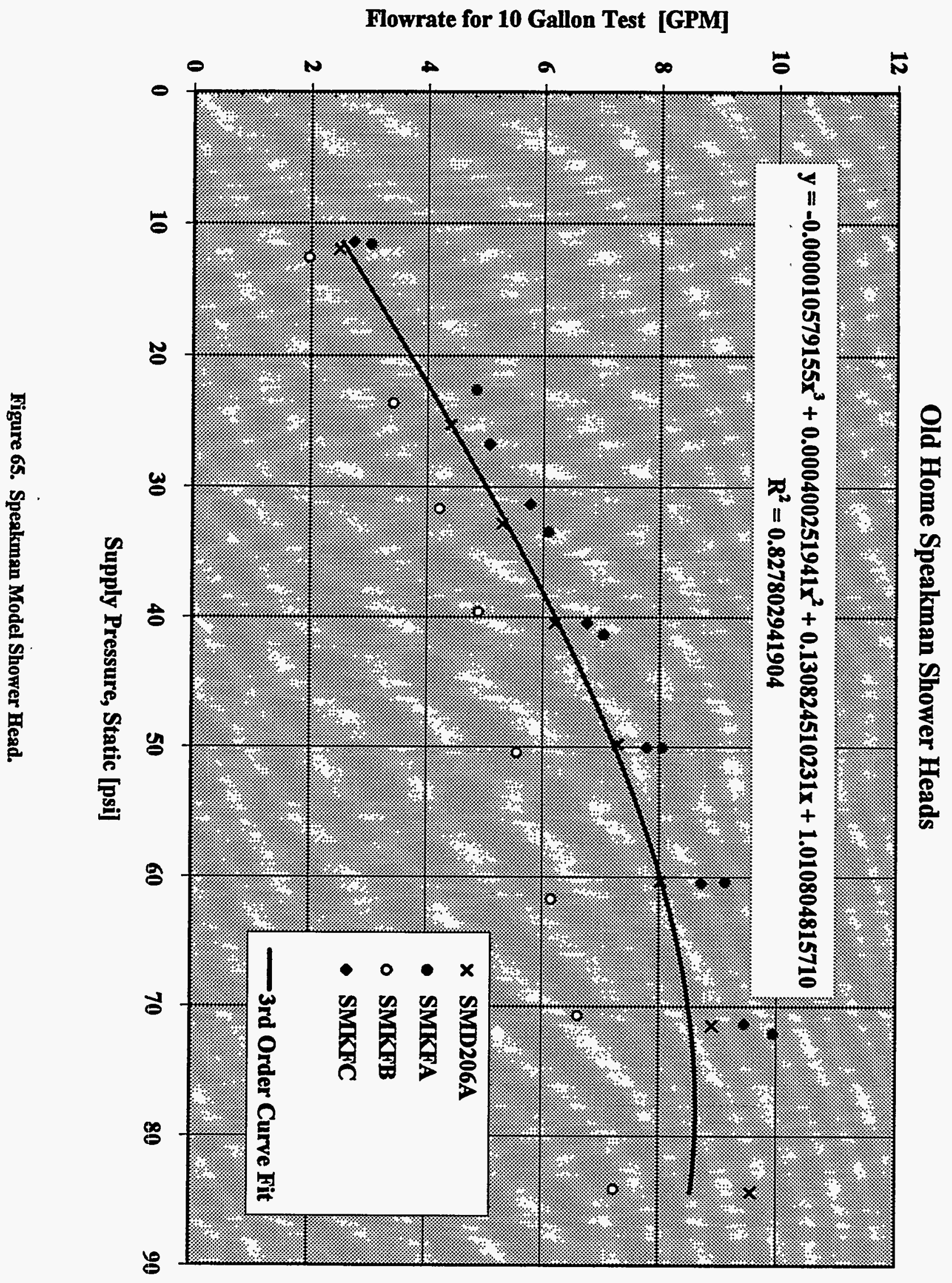

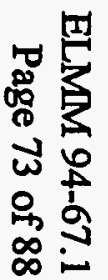


ま

造

总

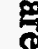

官

寕

亏

อิ

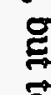

.

를

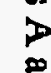

言

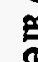

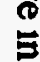

c.

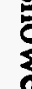

흥

ह.

吉

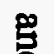

$\Omega$

รั

క.

曼

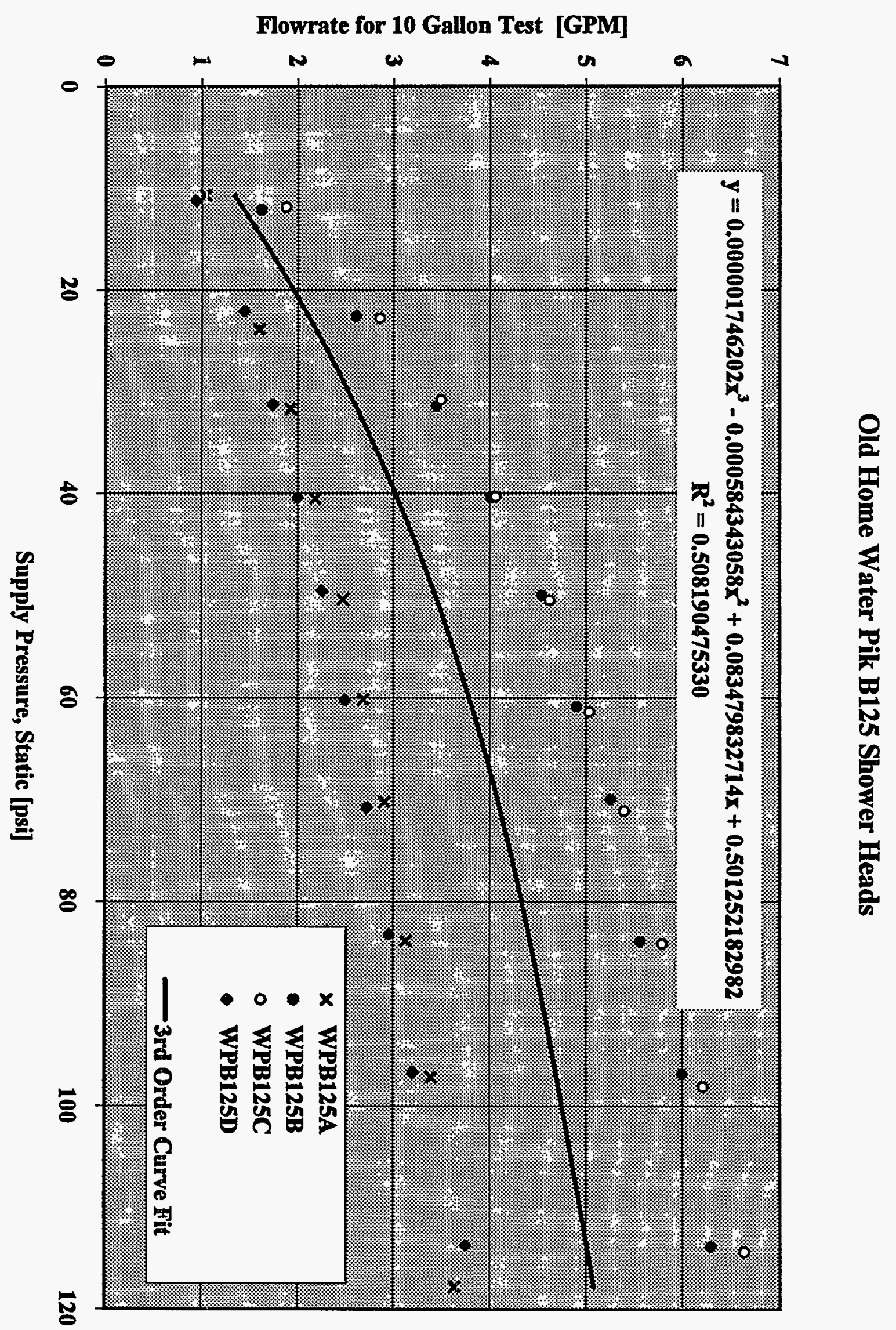

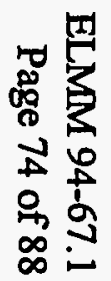




\section{Old Home Water Pik Shower Heads}

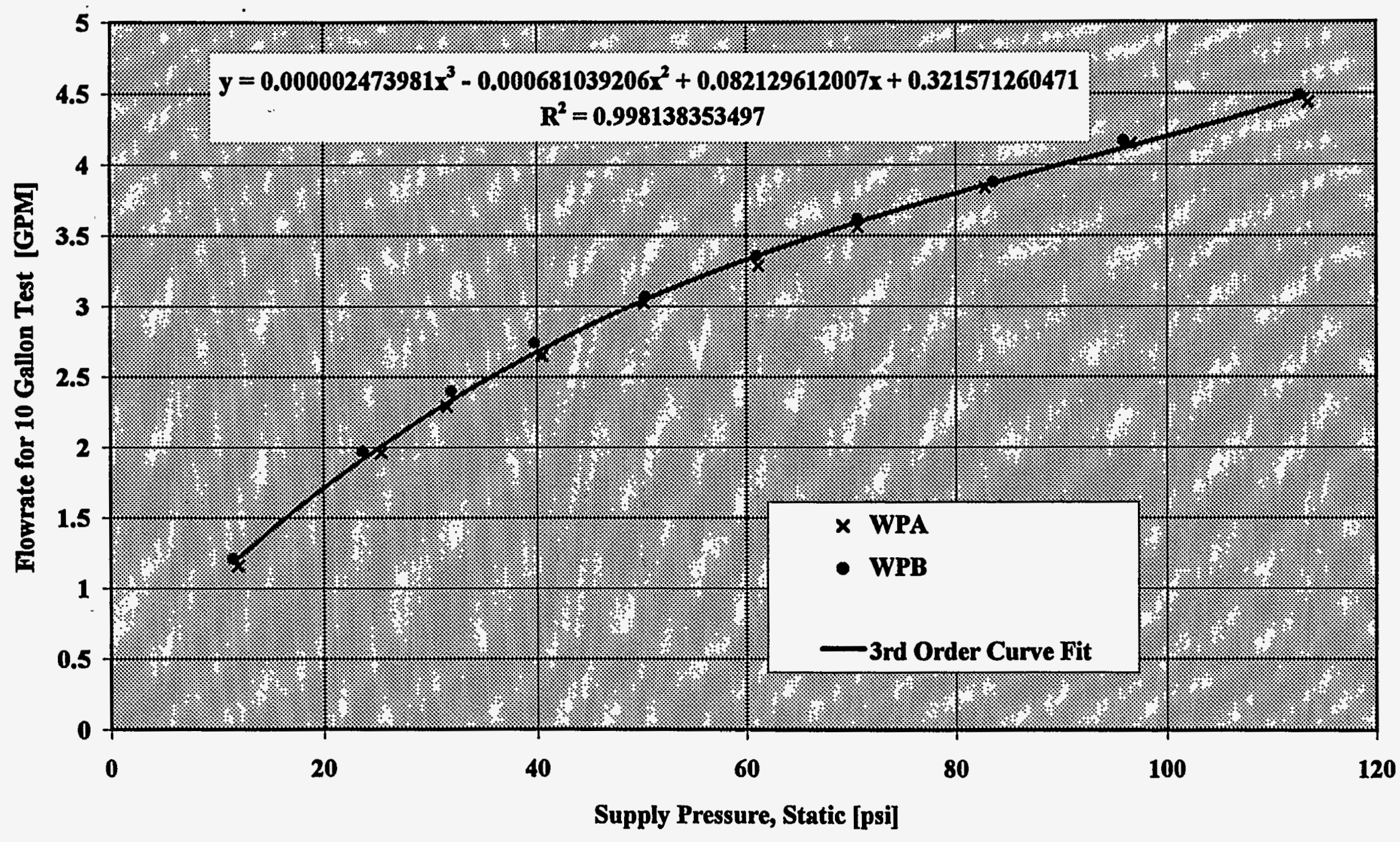

Figure 67. WaterPik Model Shower Head.

The WaterPik shower heads are adjustable. 


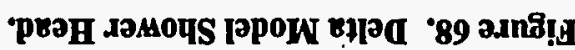

[!sd] כ!̣ष7S 'כansse.dd KIddnS

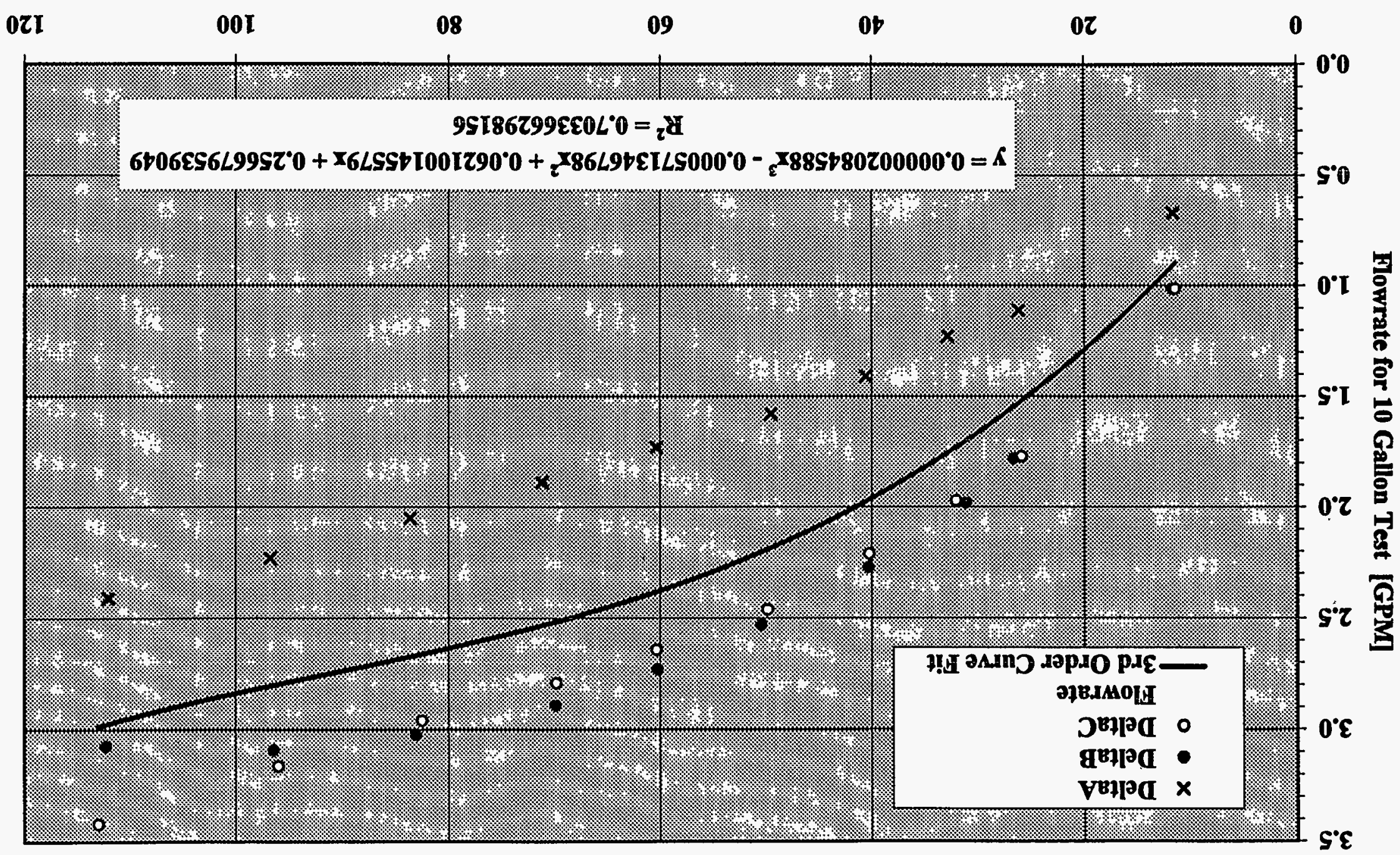

sрвәН дәмочS вұәव әшоН РIO 



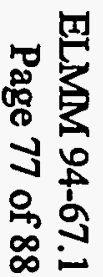




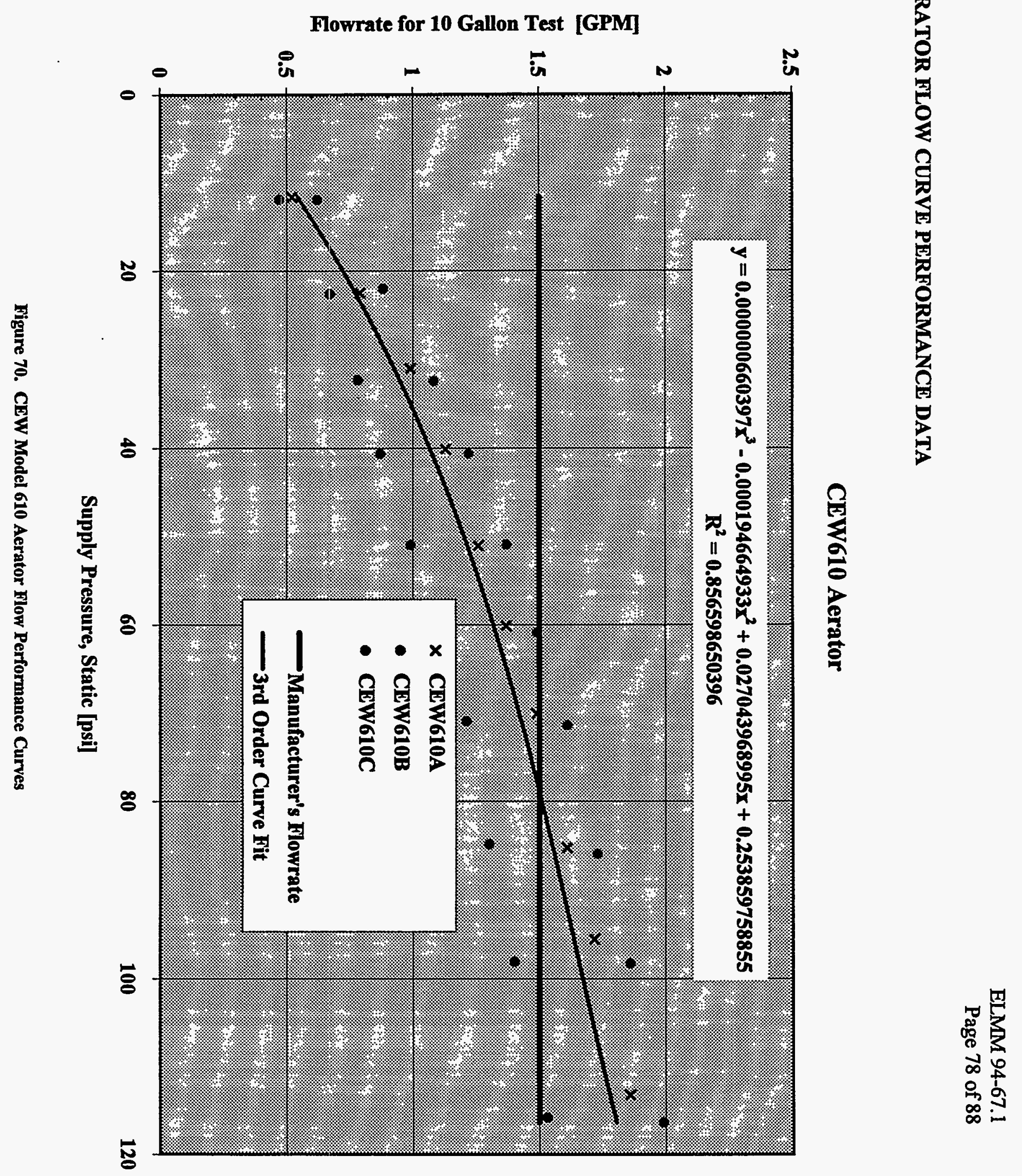




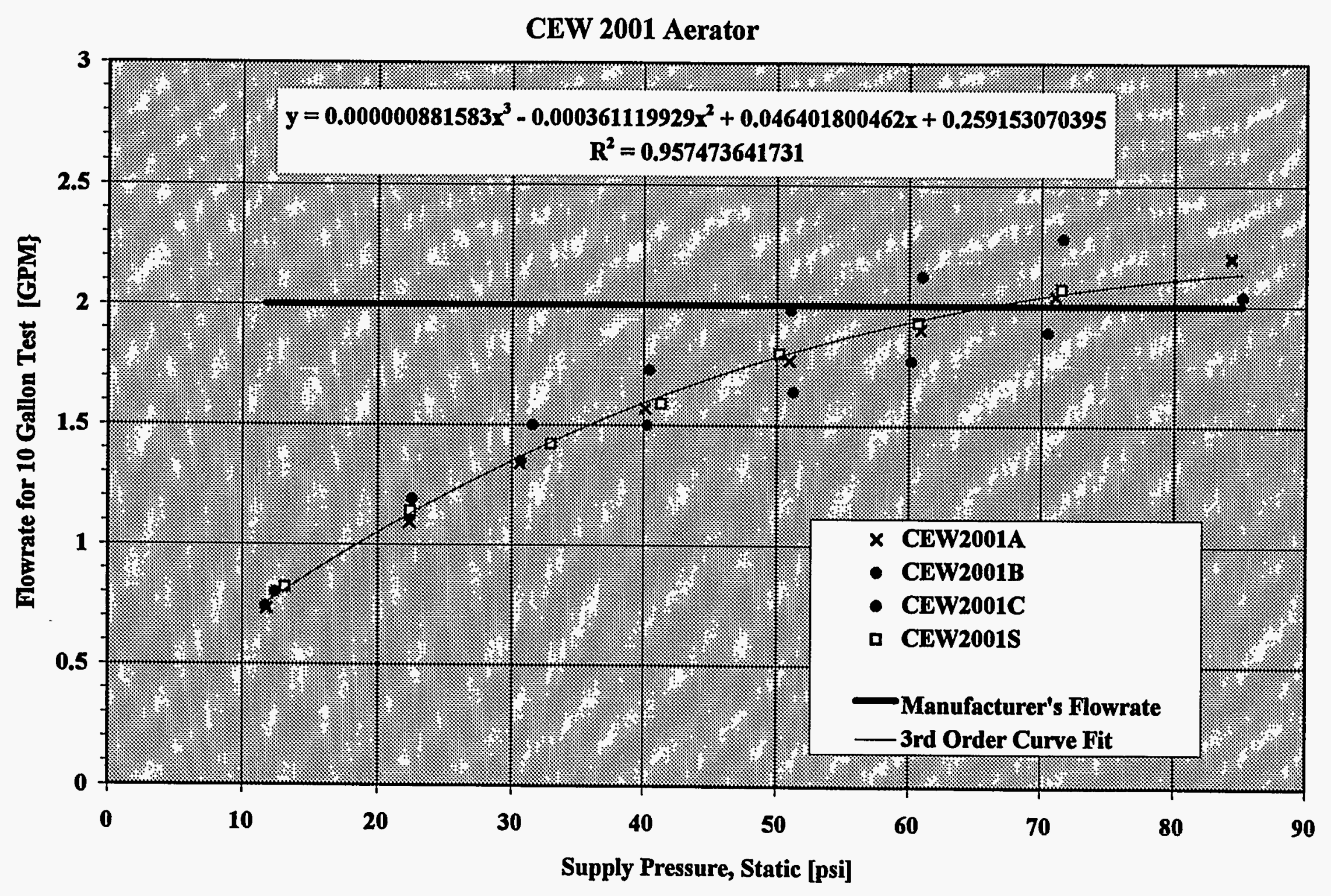

Figure 71. CEW Model 2001 Aerator Flow Performance Curves 


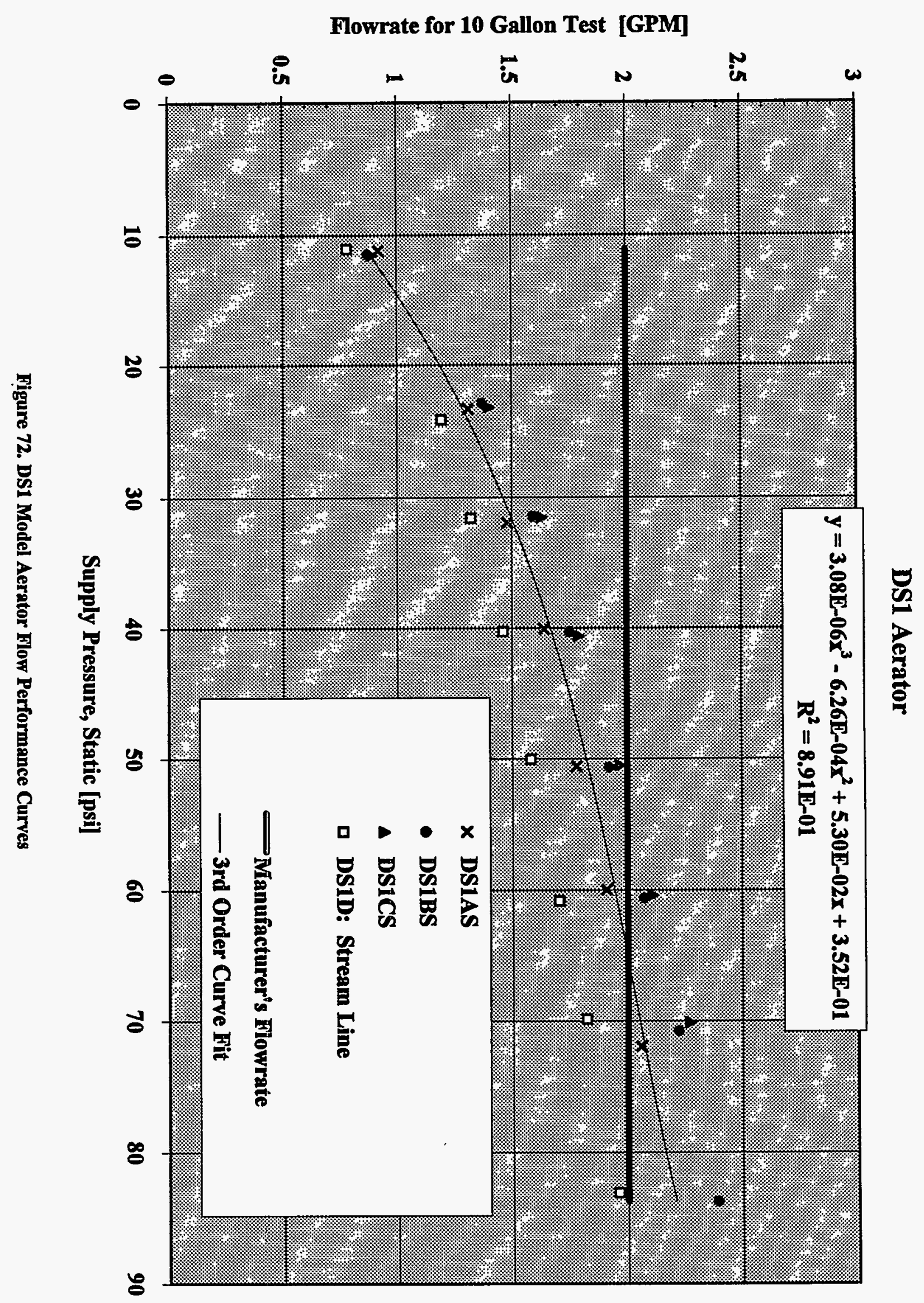

点

क

염

$\infty$ : 


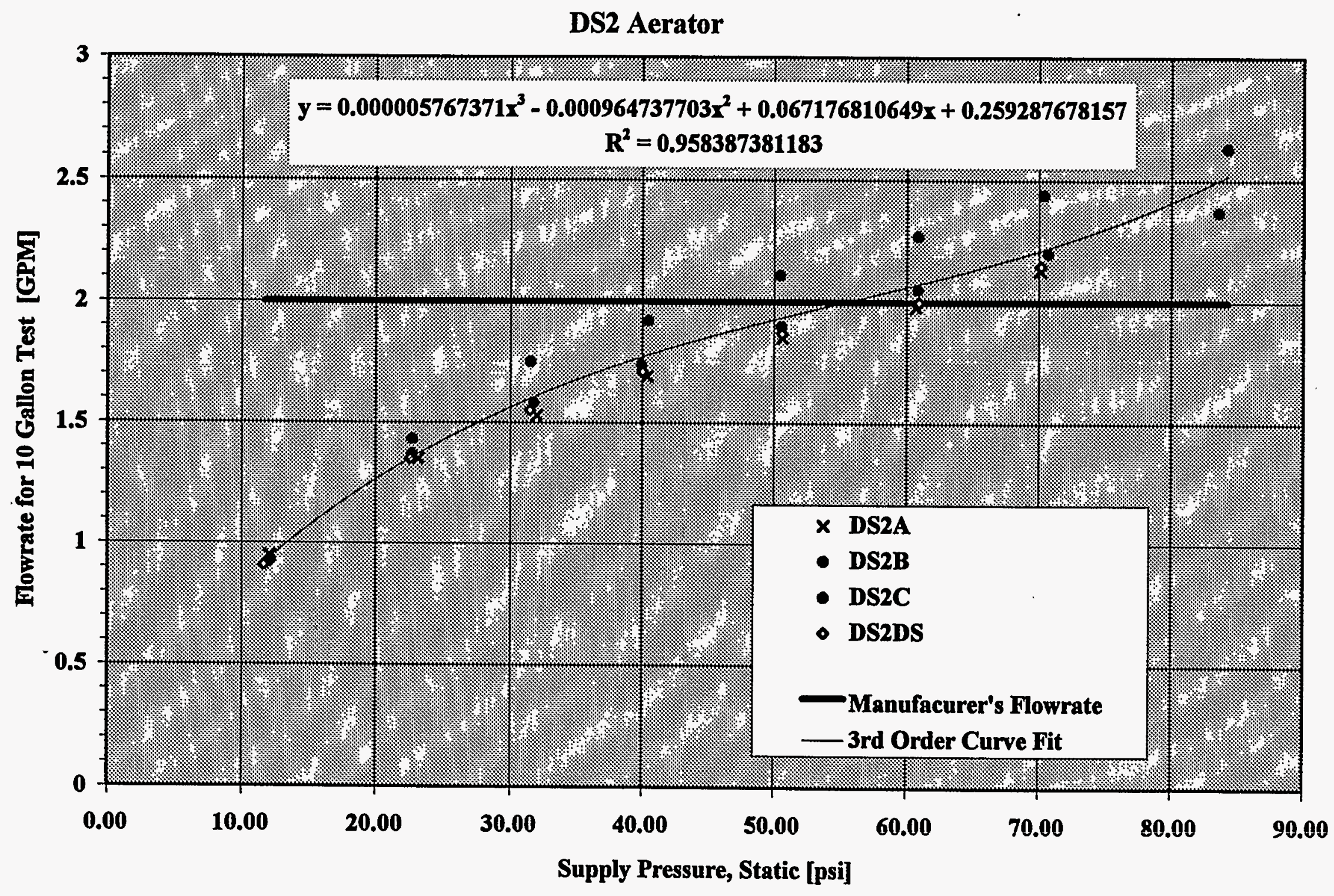

Figure 73. DS2 Model Aerator Flow Performance Curves 
울

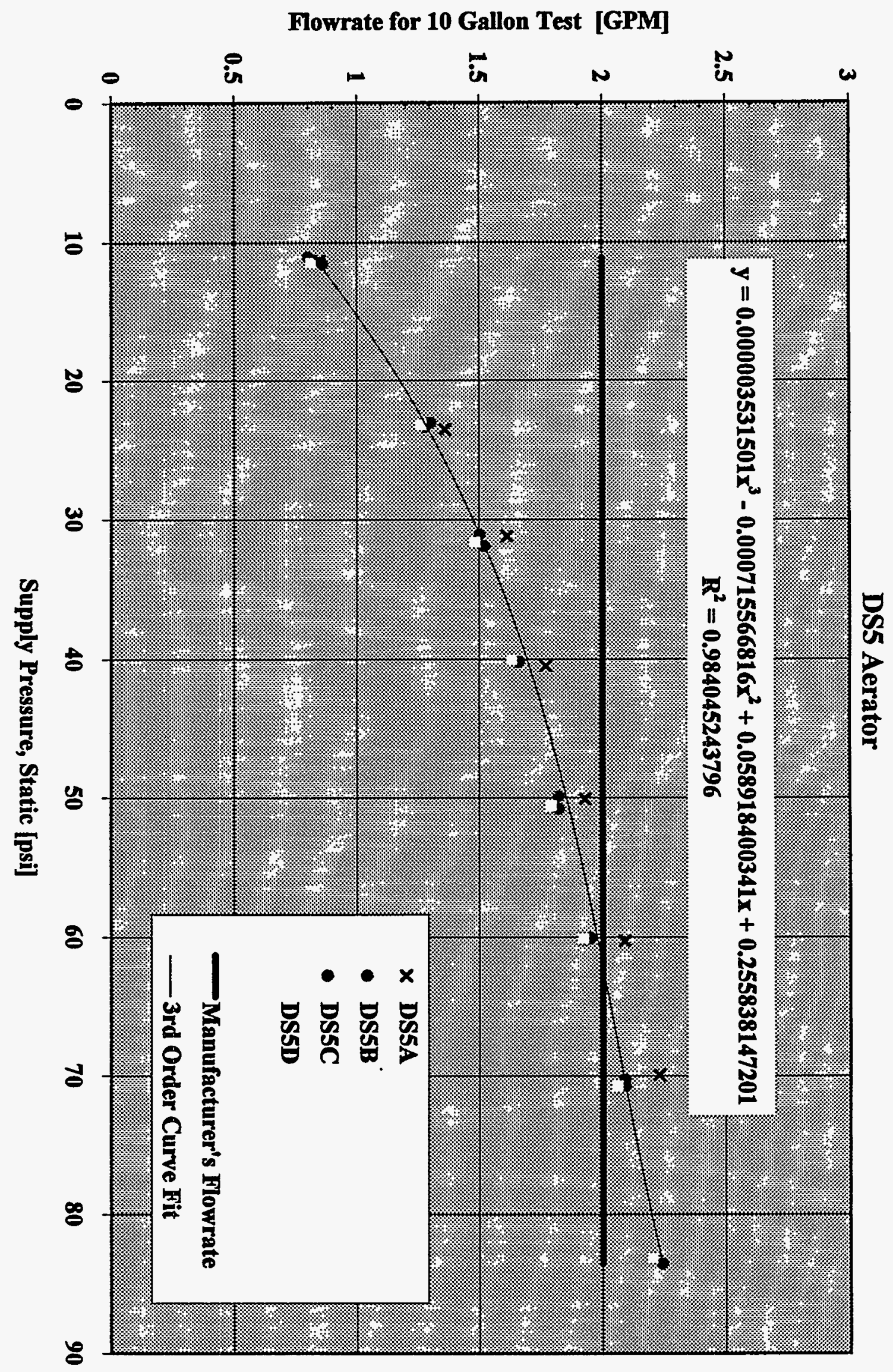

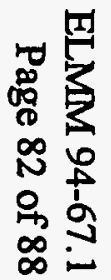




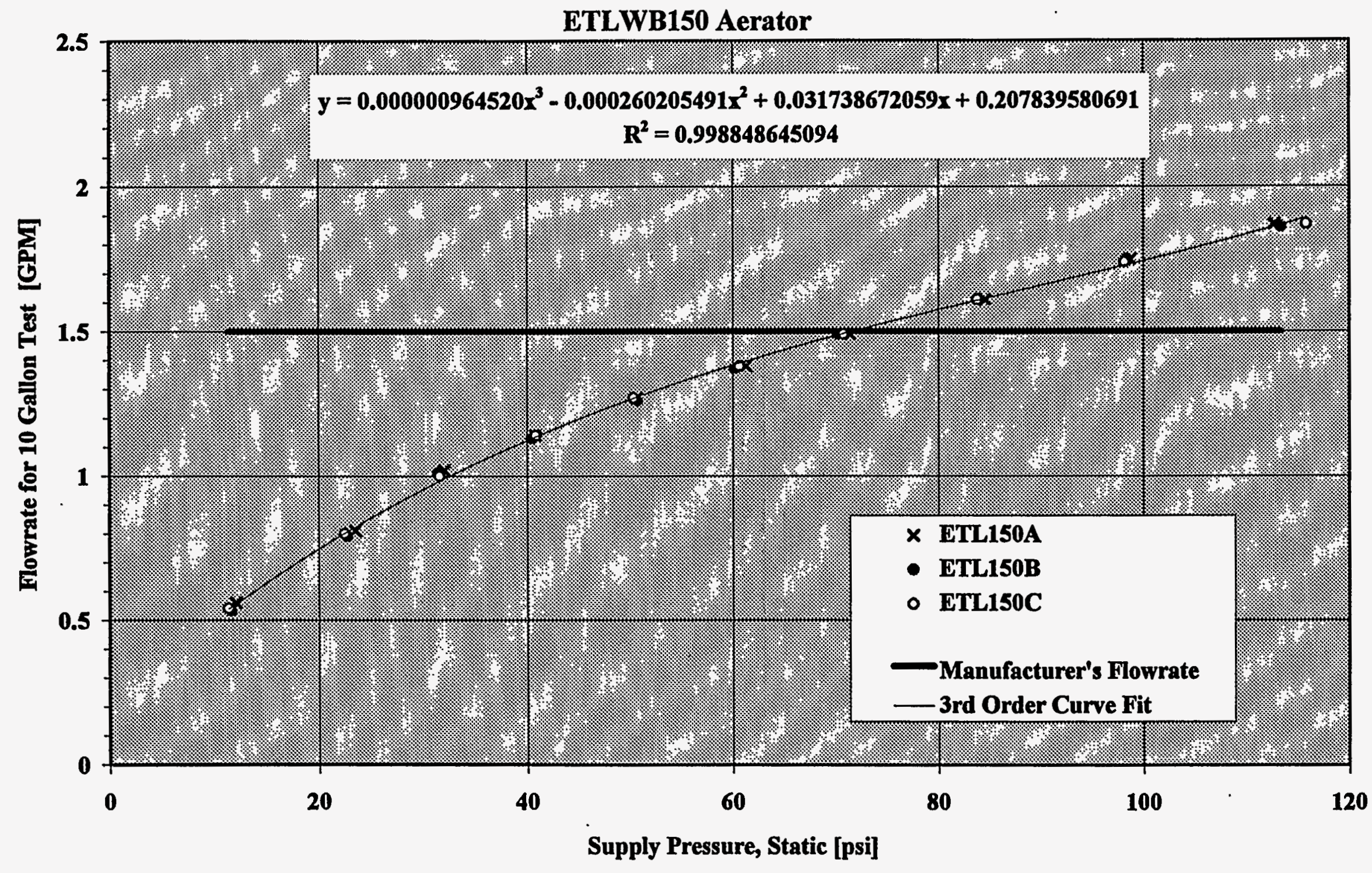

Figure 75. ETL WB 150 Model Aerator Flow Performance Curves. 
Flowrate for 10 Gallon Test [GPM]

봉

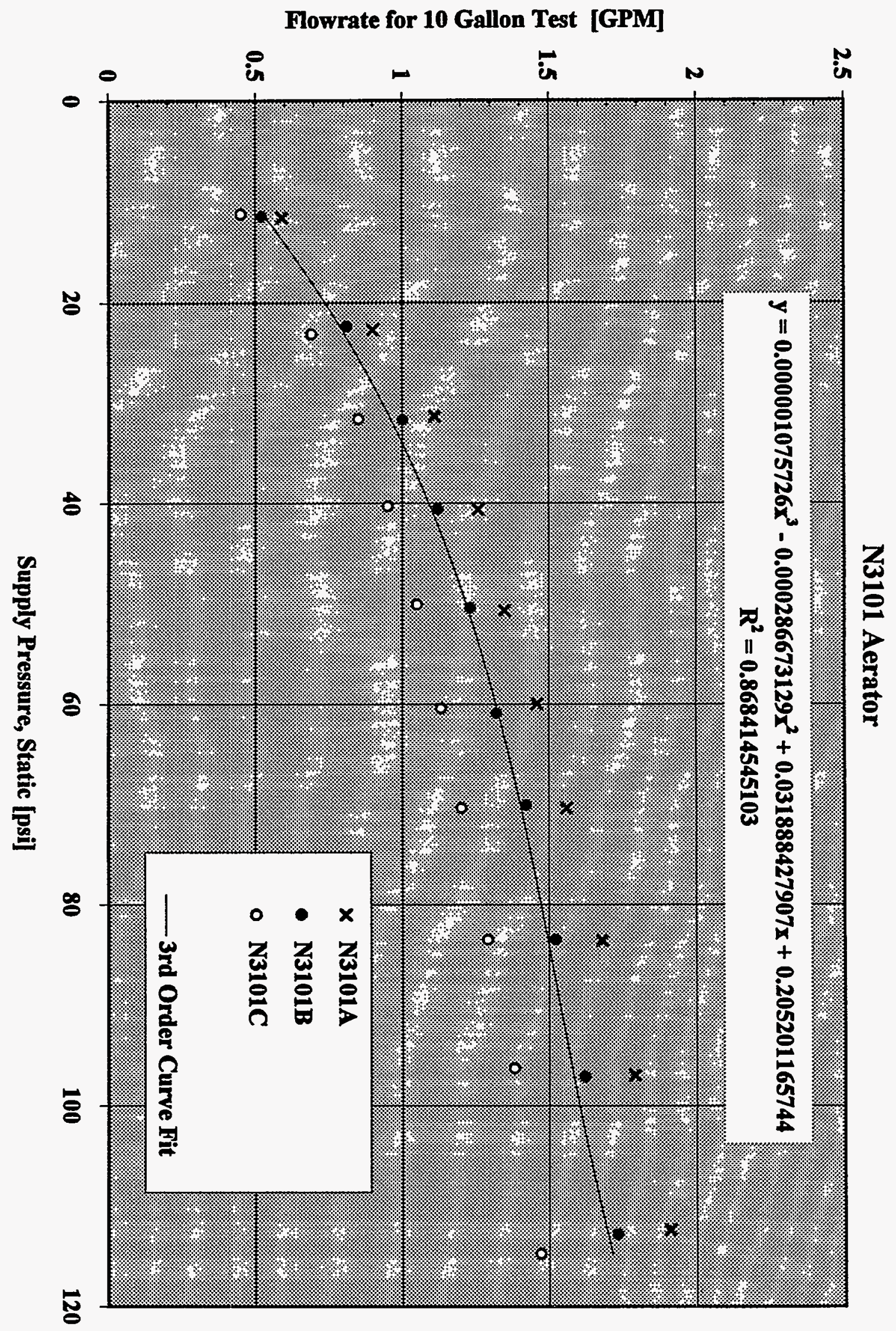

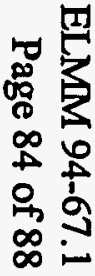


芯

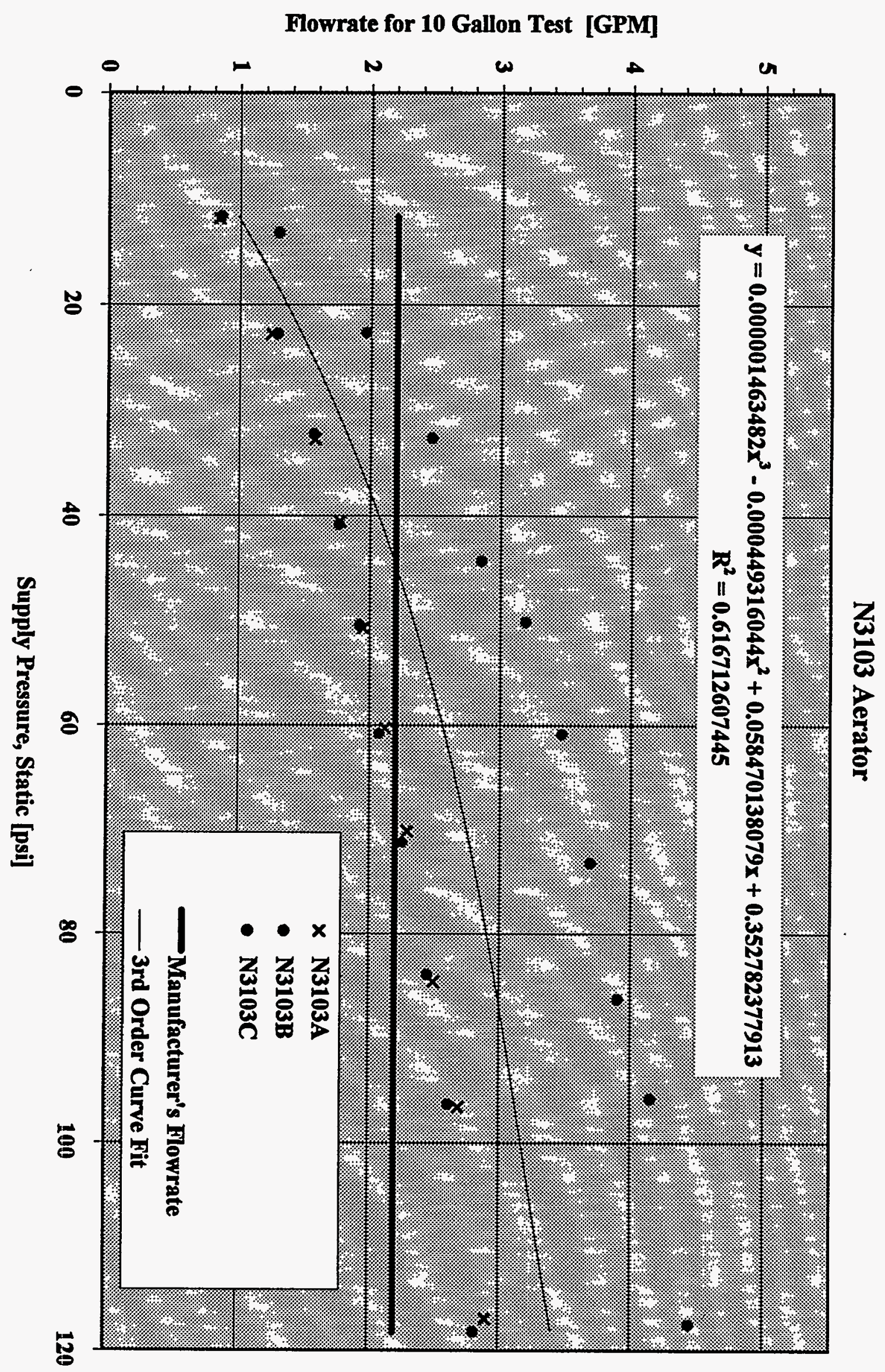

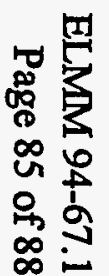




\section{Niagra Aerator}

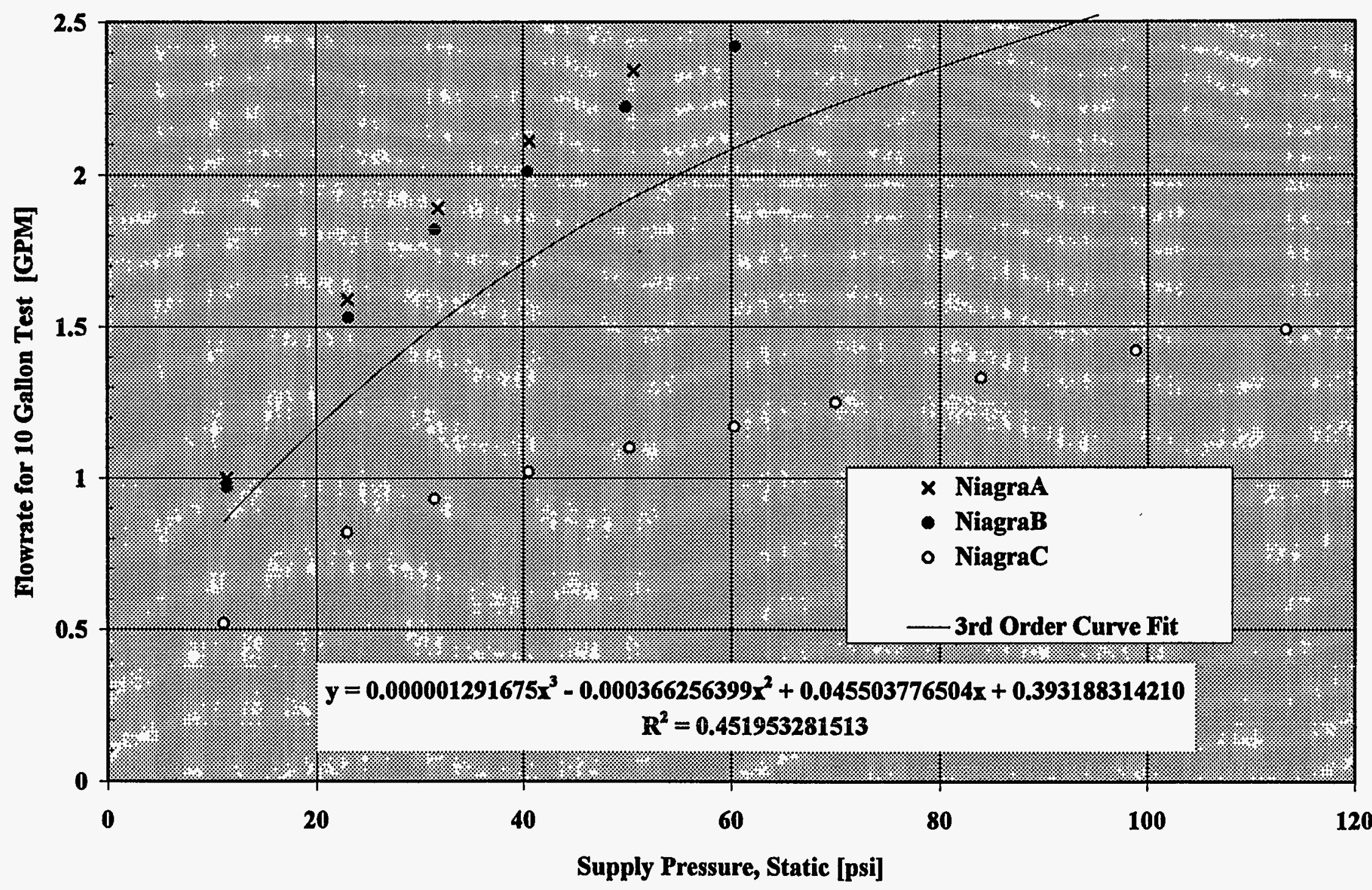

Figure 78. Niagara Model Aerator Flow Performance Curves. 
홍
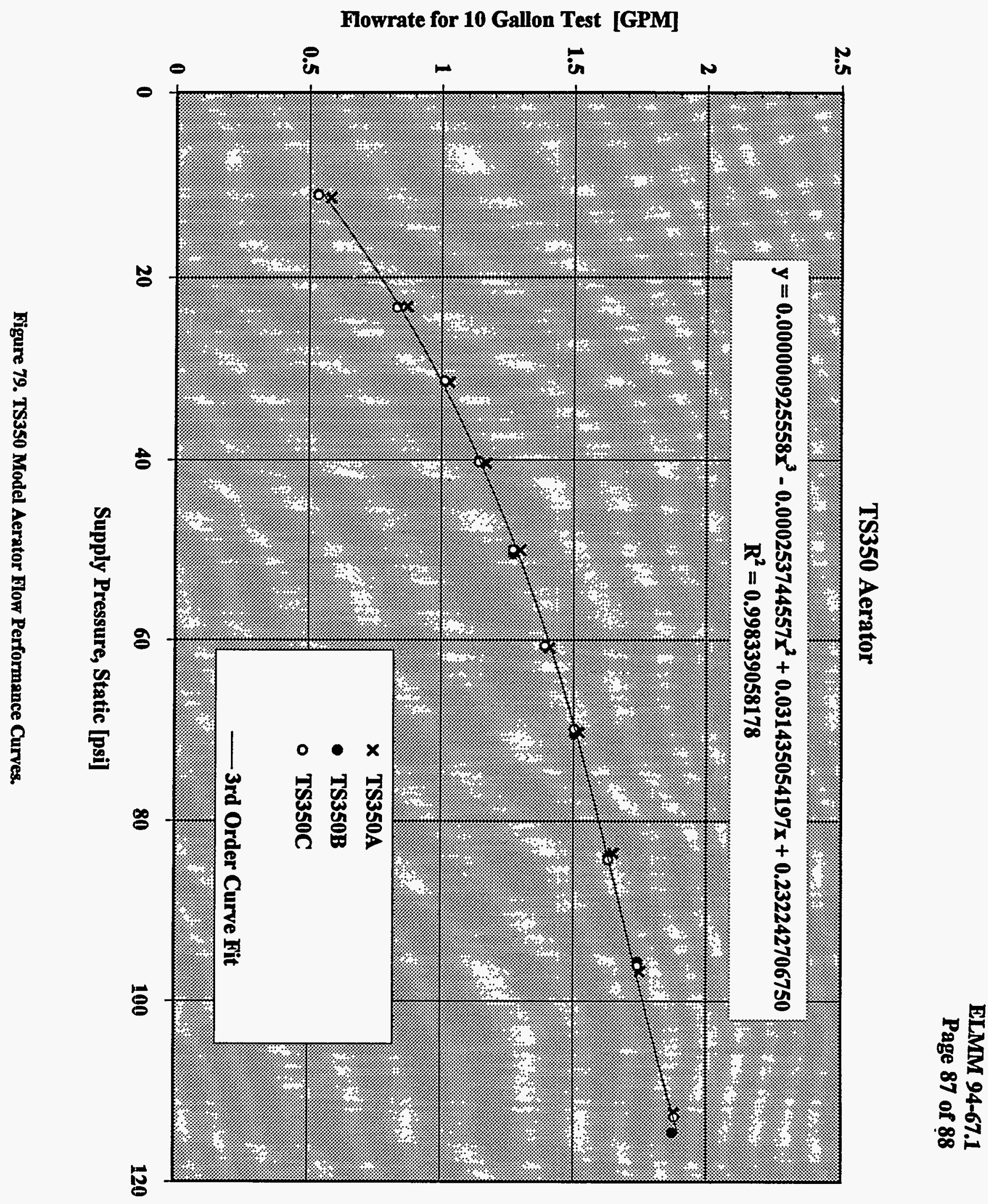


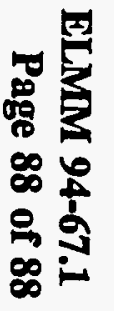




\section{Appendix G}

Bonneville Showerhead Program Distribution Methods by Participating Utility 


\section{Appendix G}

Table G.1 Bonneville Showerhead Program Distribution Methods by Participating Utility(a)

\begin{tabular}{|c|c|c|c|c|}
\hline Participating Utility ${ }^{(2)}$ & $\begin{array}{l}\text { Direct- } \\
\text { Install }\end{array}$ & $\begin{array}{c}\text { Consumer- } \\
\text { Demand }\end{array}$ & Canvass & $\begin{array}{c}\text { Inventory/ } \\
\text { Depot }\end{array}$ \\
\hline Ashland, City of & $\mathbf{X}$ & & & $\because$ \\
\hline Bandon, City of & & $\mathbf{x}$ & & \\
\hline Benton Rural Electric Association & & & $\mathbf{x}$ & \\
\hline Big Bend Electric Co-op, Inc. (WA) & $\mathbf{x}$ & & & \\
\hline Blachly-Lane County Co-op & $\mathbf{x}$ & & & \\
\hline Blaine, City of (WA.) & $\mathbf{x}$ & & & \\
\hline Canby Utility Board, City of & & & $\mathbf{x}$ & \\
\hline Cascade Locks, City of & $\mathbf{x}$ & & & \\
\hline Central Electric Co-op & $\mathbf{x}$ & $\mathbf{X}$ & & \\
\hline Central Lincoln PUD & $\mathbf{x}$ & & & $\mathbf{x}$ \\
\hline Centralia, City of & $\mathbf{X}$ & $\mathbf{X}$ & & \\
\hline Cheney, City of & $\mathbf{x}$ & $\mathbf{x}$ & & $\mathbf{X}$ \\
\hline Clallam County PUD \#1 & $\mathbf{x}$ & & & \\
\hline Clark County PUD \#1 & $\mathbf{X}$ & & & \\
\hline Clatskanie PUD & $\mathbf{x}$ & & & \\
\hline Clearwater Power Company & $\mathbf{x}$ & $\mathbf{x}$ & & \\
\hline Columbia Basin Electric Co-op & $\mathbf{X}$ & $\mathbf{x}$ & & \\
\hline Columbia River PUD & $\mathbf{x}$ & & & \\
\hline Columbia Rural Electric Assoc. & $\mathbf{X}$ & $\mathbf{X}$ & & \\
\hline Coos-Curry Electric Co-op, Inc. & $\mathbf{x}$ & & & \\
\hline Consumers Power, Inc. & $\mathbf{x}$ & & & \\
\hline Coulee Dam, City of & $\mathbf{x}$ & & & \\
\hline Cowlitz County PUD \#1 & $\mathbf{x}$ & & & \\
\hline Douglas Electric Co-op, Inc. & $\mathbf{x}$ & & & \\
\hline East End Mutual Electric Co-op & $\mathbf{X}$ & $\mathbf{X}$ & & \\
\hline
\end{tabular}




\begin{tabular}{|c|c|c|c|c|}
\hline Participating Utility ${ }^{(2)}$ & $\begin{array}{l}\text { Direct- } \\
\text { Install }\end{array}$ & $\begin{array}{c}\text { Consumer- } \\
\text { Demand }\end{array}$ & Canvass & $\begin{array}{c}\text { Inventory/ } \\
\text { Depot }\end{array}$ \\
\hline Eatonville, Town of (WA) & $\mathbf{x}$ & & & \\
\hline Ellensburg, City of (WA) & $\mathbf{x}$ & & & \\
\hline Elmhurst Mutual Power \& Light & $\mathbf{x}$ & & & \\
\hline Emerald People's Utility District & $\mathbf{x}$ & $\mathbf{X}$ & & \\
\hline Eugene Water \& Electric Board & $\mathbf{x}$ & $\mathbf{x}$ & & $\mathbf{x}$ \\
\hline Fall River Rural Electric Co-op & & $\mathbf{X}$ & & \\
\hline Ferry County PUD \#1 & $\mathbf{x}$ & $\mathbf{x}$ & & \\
\hline Fircest, City of (WA.) & $\mathbf{x}$ & & & \\
\hline Flathead Electric Co-op, Inc. & $\mathbf{x}$ & & & \\
\hline Forest Grove, City of & $\mathbf{x}$ & & & \\
\hline Grays Harbor County PUD \# & & $\mathbf{x}$ & & \\
\hline Heybum, City of (ID) & $\mathbf{x}$ & $\mathbf{x}$ & & \\
\hline Hood River Electric Co-op & $\mathbf{x}$ & $\mathbf{x}$ & & \\
\hline Idaho County Light \& Power Company & $\mathbf{x}$ & & & \\
\hline Idaho Falls, City of (ID) & $\mathbf{x}$ & & & \\
\hline Inland Power \& Light Company & $\mathbf{x}$ & $\mathbf{x}$ & & \\
\hline Kittitas County PUD \#1 & & $\mathbf{x}$ & & \\
\hline Klickitat County PUD \#1 & $\mathbf{x}$ & $\mathbf{x}$ & & \\
\hline Kootenai Electric Co-op & $\mathbf{x}$ & $\mathbf{x}$ & & \\
\hline Lane Electric Co-op, Inc. & $\mathbf{x}$ & $\mathbf{x}$ & & \\
\hline Lewis County PUD & $\mathbf{x}$ & $\mathbf{x}$ & $\mathbf{x}$ & $\mathbf{x}$ \\
\hline Lincoln Electric Co-op, MT & $\mathbf{x}$ & $\mathbf{x}$ & & \\
\hline Lincoln Electric Co-op, WA & $\mathbf{x}$ & $\mathbf{x}$ & & \\
\hline Lower Valley Power \& Light, Inc.(ID) & $\mathbf{x}$ & & & \\
\hline Mason County PUD \#1 & $\mathbf{x}$ & & & \\
\hline Mason County PUD \#3 & $\mathbf{x}$ & $\mathbf{x}$ & & $\mathbf{x}$ \\
\hline Midstate Electric Co-op & & $\mathbf{x}$ & & \\
\hline Milton, City of & & $\mathbf{x}$ & & \\
\hline Milton-Freewater, City of & $\mathbf{x}$ & $\mathbf{x}$ & & \\
\hline Mission Valley Power, MT & $\mathbf{x}$ & & & \\
\hline Missoula Electric Co-op, Inc. & $\mathbf{x}$ & & & \\
\hline Monmouth, City of & $\mathbf{x}$ & $\mathbf{x}$ & & \\
\hline Nespelem Valley Electric Co-op & $\mathbf{x}$ & $\mathbf{x}$ & & \\
\hline
\end{tabular}




\begin{tabular}{|c|c|c|c|c|}
\hline Participating Utility ${ }^{(2)}$ & $\begin{array}{l}\text { Direet- } \\
\text { Install }\end{array}$ & $\begin{array}{c}\text { Consumer- } \\
\text { Demand }\end{array}$ & Convass & $\begin{array}{c}\text { Inventory } \\
\text { Depot }\end{array}$ \\
\hline Northern Lights Inc. & & $\mathbf{x}$ & & \\
\hline Northern Wasco County PUD & $\mathbf{X}$ & $\mathbf{X}$ & & $\mathbf{X}$ \\
\hline OHOP Mutual Light Company & $\mathbf{x}$ & $\mathbf{x}$ & $\mathbf{x}$ & \\
\hline Okanogan Electric Co-op, WA & $\mathbf{x}$ & & & \\
\hline ORCAS Power \& Light Company & $\mathbf{X}$ & $\mathbf{x}$ & & \\
\hline Oregon Trail Electric Consumer & $\mathbf{X}$ & $\mathbf{x}$ & & \\
\hline Pacific County PUD $\# 2$ & & $\mathbf{x}$ & & \\
\hline Parkland Light \& Power Company, WA & $\mathbf{x}$ & & & \\
\hline Pend Oreille County PUD & $\mathbf{x}$ & $\mathbf{x}$ & & \\
\hline Peninsula Light Company, Inc. & $\mathbf{x}$ & & & \\
\hline Port Angeles Light Dept., City of & $\mathbf{x}$ & $\mathbf{x}$ & & \\
\hline Ravalli County Electric Co-op, MT & $\mathbf{x}$ & & & \\
\hline Richland, City of & & $\mathbf{X}$ & & \\
\hline Rural Electric Company & $\mathbf{X}$ & $\mathbf{X}$ & & \\
\hline Salem Electric & $\mathbf{x}$ & $\mathbf{X}$ & & \\
\hline Seattle, City of & $\mathbf{x}$ & $\mathbf{x}$ & $\mathbf{x}$ & \\
\hline Snohomish County PUD \#1 & $\mathbf{x}$ & $\mathbf{x}$ & & \\
\hline South Side Electric Lines,Inc.(ID) & $\mathbf{x}$ & & & \\
\hline Springfield Utility Board & $\mathbf{x}$ & & & \\
\hline Steilacoom, Town of (WA.) & $\mathbf{x}$ & & & \\
\hline Sumas, City of (WA.) & $\mathbf{x}$ & & & \\
\hline Surprise Valley Electrical Corp. & $\mathbf{x}$ & $\mathbf{x}$ & & \\
\hline Tacoma, City of & $\mathbf{x}$ & & $\mathbf{x}$ & \\
\hline Tanner Electric & $\mathbf{x}$ & $\mathbf{x}$ & & \\
\hline Tillamook PUD & $\mathbf{X}$ & $\mathbf{x}$ & & \\
\hline Troy, City of (MT) & $\mathbf{X}$ & & & \\
\hline Umatilla Electric Co-op Assoc. & $\mathbf{X}$ & & $\mathbf{X}$ & \\
\hline Unity Light \& Power Company, ID & $\mathbf{x}$ & & & \\
\hline Vera Irrigation District \#15 & $\mathbf{x}$ & $\mathbf{x}$ & & \\
\hline Vigilante Electric Co-op & $\mathbf{x}$ & & & \\
\hline Wasco Electric Co-op, Inc. & & $\mathbf{x}$ & & \\
\hline Wells Rural Electric Company & $\mathbf{x}$ & $\mathbf{x}$ & & \\
\hline (a) Excludes customer-designed & & & & \\
\hline
\end{tabular}




\section{Appendix $\mathbf{H}$}

Water- and Energy-Saving Measure Distribution Methods Literature Review 


\section{Appendix H Water- and Energy-Saving Measure Distribution Methods Literature Review}

Residential Conservation Service (RCS) programs have included water conservation measures for many years. These measures were common in the early residential weatherization programs frequently offered by utilities in conjunction with the RCS programs, as mandated by Congress in 1976.

Typically, RCS programs consisted of low, or no-cost measures distributed during the course of, or as a result of, the RCS-required home-energy audit. Success rates for these measures are difficult to derive from historic data, because results were typically reported for the program rather than for each measure.

\section{H.1 Overview of Distribution Methods}

Residential energy efficiency measures can be distributed to interested participants in a variety of ways. High-efficiency measures and delivery mechanisms were the subjects of a recent report by the Rocky Mountain Institute (RMI) (Jones 1993). Information from that report is summarized in the following sections. In simple terms, there are five primary distribution mechanisms that are used. Variations on each, plus combinations of approaches, provide a wide range of program options. The five basic mechanisms are

- canvass and delivery

- direct installation

- depot pick-up

- direct mail

- rebate.

The success of each of these mechanisms depends the vigor with which the overall program is delivered. Program success can be determined by customer participation and by actual measure installations. These can, in turn, be monitored a variety of ways. Although there is no reason that both participation and measure installation cannot be $100 \%$, participation and installation rates can vary based on delivery mechanisms for several reasons. Participation requires an awareness of the program and its benefits. This necessitates advertising, which is more effective if it demonstrates the program responding to some crisis or need that the population is aware of (for example, water-conservation measures, drought and water rationing, rising water and sewer costs, or water-table problems are all strong motivators that can be used in advertising). Creating a sense of urgency and importance for 
water conservation is easier when the basis for the appeal is immediate rather than general. As a result, the larger the geographic scale for the program, the more difficult it is to link participation to specific local needs. Thus, programs operated at a local scale are likely to have better success than those run at a regional scale.

The five distribution mechanisms require varying degrees of activity. The depot and rebate approaches require participants to leave their home to obtain measures. The other three approaches require different levels of participant actions including coordination with program staff. Program participation, by itself, does not guarantee measure installation. Participants may obtain, but not install measures. Further, incomplete measure installation can result from programs that do not provide participants with sufficient measures or incentives to replace all inefficient fixtures.

Sections H.1.1 through H.1.6 describe each of the major distribution mechanisms, common variations, and reported successes. Current information about the relevance of each approach to this evaluation is provided when available. Note that the statistics provided in the following tables are not consistent. Each implementation of a program affects results differently. Further, since each distribution mechanism produces results at different points in time, preliminary results may not be a good indicator of how successful a mechanism is. True participation would be determined by what fraction of the total population participates when the program has been fully implemented. To illustrate, Seattle City Light in Seattle, Washington, implemented a pilot canvass program that achieved a $40 \%$ participation rate. Results from the pilot were used to revise program delivery, and participation in a subsequent program included $65 \%$ of all customers. Eventually, over $90 \%$ participation was achieved (Jones 1993). ${ }^{(a)}$

\section{H.1.1 Canvass and Delivery}

The distinguishing characteristic of a canvass program is that it includes wholesale distribution of measures in one area during the same period of time. Typically, this means door-to-door contact to solicit interest and simultaneous measure delivery. Variations include door-to-door solicitation followed by delivery and solicitation by mail or other means followed by door-to-door delivery. The strength of this method is that a large number of measures can be distributed in a short period of time inexpensively. The weakness of this method is that it is difficult to screen drop-off sites for waterheating fuel types, and number of showers, as well as recipients' interest and their ability to install retrofit measures. As a result, the number of measures replaced may fall short of the maximum because recipients cannot (e.g., no tools or wrong parts) or do not install the measures, and/or an insufficient number of measures are provided to retrofit all fixtures. Further, measures may be distributed to sites that do not qualify, which increases measure costs without direct benefit.

Participation rates for this approach vary widely, as indicated in Table H.1. The statistics presented in this and subsequent tables on participation rates are based on information provided to RMI by program staff. Some are based on staff estimates and others on objective evaluations. Available data are not sufficient to determine whether these statistics are for completed programs, or for

(a) Personal communication with Debra Tachibani of Seattle City Light. 
programs in the early stages. Further, it is not clear from available data whether these statistics are for participation in the program or for the fraction of fixtures replaced. The text in RMI's report, HighEfficiency Showerheads and Faucets, generally indicates these statistics are for program participation, rather than for measure replacement.

Table H.1 Participation Rates from Canvass and Delivery Distribution Method

\begin{tabular}{||l|c|}
\hline \multicolumn{1}{|c|}{ Source } & Rate \\
\hline Tampa, Florida & $59 \%$ \\
\hline San Jose, California & $\sim 80 \%$ \\
\hline Connecticut Water Company & NA \\
\hline Seattle City Light (pilot) & $40 \%$ \\
\hline Seattle City Light (program) & $65 \%$ \\
\hline Pinellas, Florida & $74 \%$ \\
\hline Edmonton, Alberta & $40 \%$ \\
\hline
\end{tabular}

The Bonneville Residential Appliance Efficiency Program (the Program), included the canvass method. Summary documents for the Program indicate that 163,458 participants were reached through this delivery mechanism. This represents 29\% of all Program participants during the 1992-1993 evaluation period.

\section{H.1.2 Direct Installation}

Direct installation programs are those in which third parties install the measures as part of the program design. Participants can be recruited through a variety of mechanisms, including canvassing and direct mail. Direct installation is sometimes included as a feature in canvass and delivery programs to ensure the participation of individuals who are unable to replace measures on their own (e.g., the disabled or elderly). The strength of this method is that it ensures replacement of the measures. It can also include features that maximize the number of measures replaced and screen out inappropriate sites, which increases the savings per site. The primary weakness of this approach is that it requires on-site visits, which can be difficult to arrange. On-site visits are also costly when compared to other distribution methods.

Participation rates with this method are generally quite high, and participation always translates into measure installation (Table H.2).

\section{H.4}


Table H.2 Participation Rates from Direct

Installation Distribution Method

\begin{tabular}{|l|l|}
\hline \multicolumn{1}{|c|}{ Source } & \multicolumn{1}{|c|}{ Rate } \\
\hline REMP Sites & $66 \%$ \\
\hline REMP Showers & $90 \%$ \\
\hline Pasadena, California & NA \\
\hline Massachusetts Water Authority & $59 \%$ \\
\hline Boston (Mass.) Edison & NA \\
\hline North Marin (Calif.) Water Dist. & $85 \% \max$. \\
\hline Edmonton, Alberta & $40 \%$ \\
\hline San Diego (Calif.) Utilities & $94 \%$ \\
\hline Northeast Utilities (Connecticut) & NA \\
\hline
\end{tabular}

Direct installation was one of the more popular distribution approaches among Bonneville customer utilities and accounted for the largest number of Program participants, 349,967, or 62\% of the total. The installation method did not exclude other methods, and utilities in the Program combined it with other approaches.

\section{H.1.3 Depot Pick-up}

Depot distribution utilizes a central depot for distributing measures. In this approach, participants have to go to the depot to receive the measures. This method can also be combined with others. For example, canvass and direct-mail methods can be used to reach large segments of the population generating interest in measures and distributing retrofit kits, which may not be sufficient to replace all fixtures in each home. Participants who want more measures may then be directed to a depot to pick up the remaining measures. The strength of a depot approach is its low cost. In addition, access to customer records permits some screening of participants to ensure that measures are distributed appropriately. The primary limitation of this method is the same as for all self-installation programs; namely, measures that are distributed may not be installed. Some programs address this issue by requiring the exchange of old fixtures for new ones. The depot method takes longer to saturate a market with measures than other approaches do, because participants have to visit the depot to receive the measures. Without sufficient incentives, customers may defer this visit until they have to replace a fixture, which could take years. As a result, statistics for program achievements are difficult to compare with statistics for programs using other methods except in those that have been operating for many years (Table H.3). 
Table H.3 Participation Rates from Depot Distribution Method

\begin{tabular}{|l|c|}
\hline \multicolumn{1}{|c|}{ Source } & Rate \\
\hline Goleta (California) Water District & NA \\
\hline East Bay (Calif.) Municipal Utility District & NA \\
\hline Osage (lowa) Municipal Utilities & $65 \%$ \\
\hline
\end{tabular}

Although "depot" describes the method used to distribute measures, it does not require any specific program design. In the Bonneville service area, two program designs use depot distribution. The first has been termed the "consumer-demand" method by Bonneville staff. The consumer-demand program includes advertising and consumer incentives to encourage participation. As implemented by Bonneville utilities, it often includes participant screening using customer records to verify eligibility and requires the exchange of old fixtures for new. The alternative depot program design, called the "inventory-depot" method, includes no customer incentives and very little promotion to generate interest in the measures or program. The consumer-demand approach is the more popular of the two designs, largely because Bonneville reimburses utilities that offer that method for their costs. No reimbursement is provided for utilities using the inventory-depot method. Forty eight utilities employed the consumer depot design to distribute measures to 44,058 participants, or $8 \%$ of the Program participants. In contrast, five utilities operated an inventory depot program and reached 1,714 participants, or $0.3 \%$ of the Program total. Bonneville utilities employing depot methods often used them to supplement other distribution approaches.

\section{H.1.4. Direct Mail}

Direct mail distribution methods rely on the use of mail mechanisms (including vendors other than the U.S. Postal Service) to solicit participants and request and distribute measures. Typically, participants are solicited through bill stuffers or direct-mail appeals using the utility mailing list. Consumers who respond to these solicitations generally receive a water conservation kit, which contains a mix of measures and some of the materials necessary to install them (generally no tools). The strength of this approach is that it does not require a local base, so mail programs can be operated directly by vendors or other remote third parties. This reduces costs for transporting and storing measures. The primary weakness of this approach is that it relies on self-installation and makes screening of eligible participants difficult. Accessing utility records may address this issue. Another weakness to this approach is that vendor-based programs limit the measures customers can select. It is not clear that customer input in selecting measures increases participation and installation rates; however, it seems reasonable that it may (Table H.4). 
Table H.4 Penetration Rates from Direct

Mail Distribution Method

\begin{tabular}{|c|c|}
\hline Source & Rate \\
\hline Connecticut utilities (various) & $30-50 \%$ \\
\hline
\end{tabular}

None of Bonneville's customer utilities are using direct-mail approaches, although at least one of the region's major private utilities (Pacific Power) is doing so. The Pacific Power program includes features designed to ensure both efficiency and effectiveness. The standard kit includes one highefficiency showerhead and aerators for one kitchen and one bathroom faucet. The packet also requests the return of the old showerhead for testing and disposal. The showerhead return mailer includes a form for additional measures printed on it. As a result, participants wanting more than one of each type of measure have to return at least one showerhead. It is expected that the returned showerheads will be tested to estimate potential savings.

\section{H.1.5 Rebate Programs}

Rebate programs typically offer to pay for a fraction of the cost of replacing an existing device with a more efficient device. Utilities commonly use rebates to induce consumers to purchase highefficiency products as they replace their current stock of energy-using devices. The administrative costs associated with rebate programs are often substantial and may equal or exceed the value of lowcost measures. Comparing rebate approaches to other mechanisms is complicated by the fact that rebates are typically used to replace measures that are at the end of their useful life. As a result, it may take a long time to achieve high participation for long-lasting measures (Table H.5). Bonneville is using rebates for high-efficiency water heaters.

Table H.5 Participation Rates from

Rebate Distribution Method

\begin{tabular}{|c|c|}
\hline Source & Rate \\
\hline Pacific Gas \& Electric (California) & $6-12 \%$ \\
\hline
\end{tabular}

\section{H.1.6 Discounts and Other Program Options}

The RMI report did not include programs that rely on discounted purchase mechanisms, perhaps because they resemble the subsidy feature of rebate programs. However, many utilities operate programs that offer discounted prices on measures purchased from the utility or substantial rebates for low-cost measures. Some of Bonneville's customers required a token payment for showerheads, although that is not a specific program design feature. There is not a central source for the myriad program design variations, so it is not clear how common this was. Customer payment for efficient light bulbs and showerheads is a fairly common program feature among utilities outside the region. The Bonneville program also permitted utilities to offer alternative program designs with Bonneville's consent. Additionally, utilities could purchase measures directly, rather than receive them from 
Bonneville. Participation for these alternative programs was tracked by Bonneville, although the specific program design features were not. Bonneville identifies these program options as "customerdesigned" and "customer-purchased," respectively.

\section{H.2 Summary}

Bonneville utility customers used four different distribution methods during 1992 and 1993 to deliver hot-water conservation measures. Two of these methods were depot methods. Many utilities used more than one method during the course of each year. The favored methods were direct installation and customer demand (Table H.6).

Table H.6 Bonneville Utility Use of Alternative Distribution Methods

\begin{tabular}{||l|c|c|c||}
\hline \multicolumn{1}{|c|}{ Method } & Number of Utilities & $\begin{array}{c}\text { Number of } \\
\text { Participants }\end{array}$ & $\begin{array}{c}\text { Program } \\
\text { Participants (\%) }\end{array}$ \\
\hline Direct Install & 79 & 349,967 & 62 \\
\hline Depot (Consumer Demand) & 48 & 44,058 & 8 \\
\hline Canvass & 7 & 163,458 & 29 \\
\hline Depot (Inventory) & 5 & 1,714 & 0.3 \\
\hline Total & & 557,483 & \\
\hline
\end{tabular}

Reviewing results from the other programs and the RMI report did not produce a single, reliable answer to the question, "How many showerheads will be replaced under each distribution method?" The REMP field study (Warwick and Bailey 1993) and the Puget persistence study (Bailey and Warwick 1993) confirmed that direct installation programs achieve high installation rates (replacement of all eligible measures), although both also identified barriers that limited maximum installation to less than $100 \%$. The REMP study was designed to replace the maximum number of showerheads, and it achieved a $90 \%$ installation rate. As a result, this value ( $90 \%$ installation rate) was used as the assumed installation rate for all direct-installation participants in the Program. The Puget persistence study provided evidence that self-installation of showerheads results in retrofits about half of the time. This rate is consistent with the participation rate data reviewed in this appendix, which reveals a wide range in participation rates. Bonneville's utilities generally required consumers to verify that the measures they received through the Program were installed, typically through the return of an old showerhead. This increased confidence that participation in the Program translated into installation. Based on this information, a measure installation rate of $45 \%$ (50\% of the REMP installation rate of 90\%) was assumed in evaluating the Program: 


\section{H.3 References}

Bailey, S. A., and W. M. Warwick. 1993. Persistence of Energy-Efficient Showerheads: Field Study Results. PNL-8432, prepared for the Bonneville Power Administration under a Related Services Agreement with the U.S. Department of Energy by Pacific Northwest Laboratory, Richland, Washington.

Jones, A. P. 1993. High-Efficiency Showerheads and Faucets. Water Efficiency Technology Report $\$ 2$, Rocky Mountain Institute, Snowmass, Colorado.

Warwick, W. M., and S. A. Bailey. 1993. Results from an Energy-Efficient Showerhead Field Study. PNL-8715, prepared for the Bonneville Power Administration under a Related Services Agreement with the U.S. Department of Energy by Pacific Northwest Laboratory, Richland, Washington. 


\section{Appendix I}

\section{REMP Study Load Shape Results}




\section{Appendix I REMP Study Load Shape Results}

This appendix depicts energy use in the Regional End-Use Metering Project (REMP) as load shapes. These are based on results from the REMP field study (Warwick and Bailey 1993).

\section{I.1 Introduction}

The typical water heater uses a constant amount of power when it is on, about 4,500 watts, and no power when it is off. Accordingly, an hour-by-hour picture of energy use for a single water heater would look like a series of spikes or lines separated by periods of no load (Figure I.1 [Pratt 1991]). When these loads are aggregated over longer time intervals the loads are averaged to include the zero load, or no-load periods. This has the effect of reducing the apparent load. When loads are averaged across multiple sites, a similar effect occurs. Averaging across sites is called diversification and the resulting picture of loads is called a diversified load shape. Pacific Northwest Laboratory represented the diversified loads in composite load shapes that reflected average loads for the year across the sample. Load shapes were prepared to reflect the pre- and post-retrofit loads and the post-retrofit loads were subtracted from the pre-retrofit loads to derive a load shape for the gross energy savings. The annual load shapes of the hot water loads for the test or participant sample are presented in Figure 1.2. The annual load shapes for the control sample are presented in Figure I.3. The shape of the annual gross savings from the test and control groups is presented in I.4. The net annual load shape, derived by subtracting the savings load shapes in Figure I.4, is presented in Figure I.5.

\section{I.2 Control Group: Net Load Shape}

The savings apparent in the control group profiles and, thus the "net" load shape (Figures I.3 and I.5) were observed during a drought throughout the region in the post-retrofit monitoring period (Appendix E). These results are open to interpretation for two reasons. First, the statistical significance of the control group savings were slightly below the confidence level we selected for this study. Nevertheless, we used them in the evaluation because they appeared to confirm anecdotal evidence of drought-induced savings. Second, whatever savings are apparent result from an unusual event, namely, the drought. The region had been haunted by drought conditions for six years prior to the field study, however, the seventh year was the worst and resulted in the first response involving the entire region. It was not deemed appropriate to assume that these effects would persist beyond the immediate emergency. Finally, the shape of these apparent savings (Figure I.3) suggests that participants simply took shorter showers and thereby shortened the amount of time the water heater needed to recover. This is a behavioral change that is easily reversed, rather than a structural change that persists over time. It contrasts with the change in load shapes observed in the test group (Figure I.2), where the loads decrease across the board due to the showerhead retrofit. Another perspective on these savings is revealed by examining load shape changes for each month of the year. 


\section{I.2 Load Shape Changes for Each Month}

Hot-water heating loads vary over the course of the year (Figure I.6-I.17). PNL's earlier analyses of water-heating energy use attributed all of this variation to seasonal changes in hot-water heating requirements rather than to standby heating requirements (Pratt 1991). Analysis of monthly load shapes instead of annual averages reinforces our interpretation that the changes in loads and load shapes observed for the control sites are transient phenomena. The control sites reveal their characteristic peak clipping load shape beginning with the January profile (Figure I.6). (The legend "net savings" on Figures I.6-29 refers to the net difference between the monthly pre- and post-period consumption.) However, this change becomes less pronounced by late spring and disappears altogether by August (Figures I.6-13). In contrast, the test sites reveal a persistent downward shift in water-heating loads for all months (Figures 1.18-29).

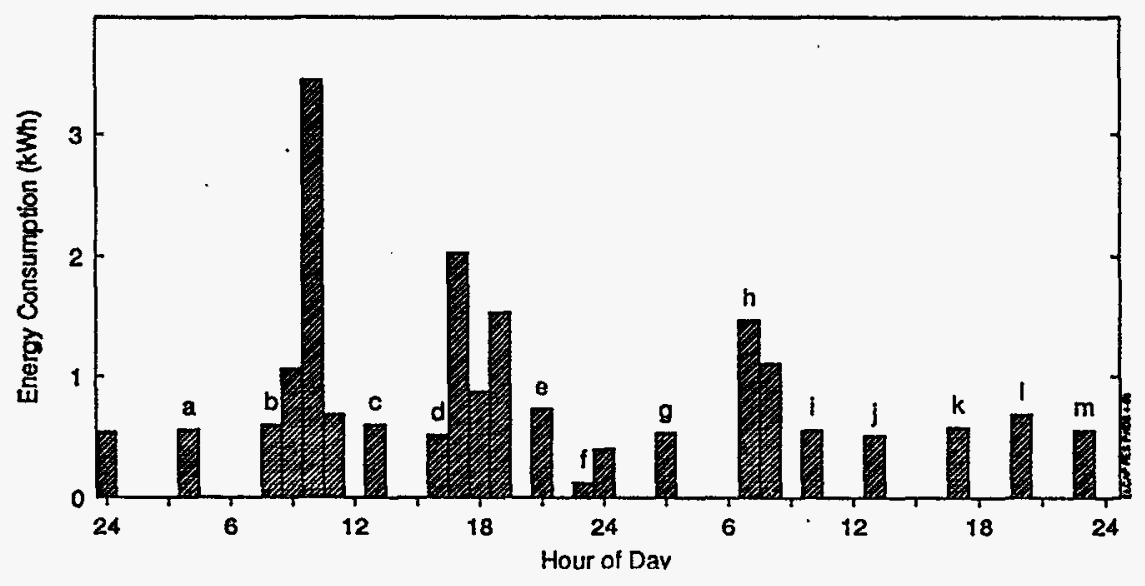

Figure I.1 Typical Hot-Water Load: Two Occupied Days

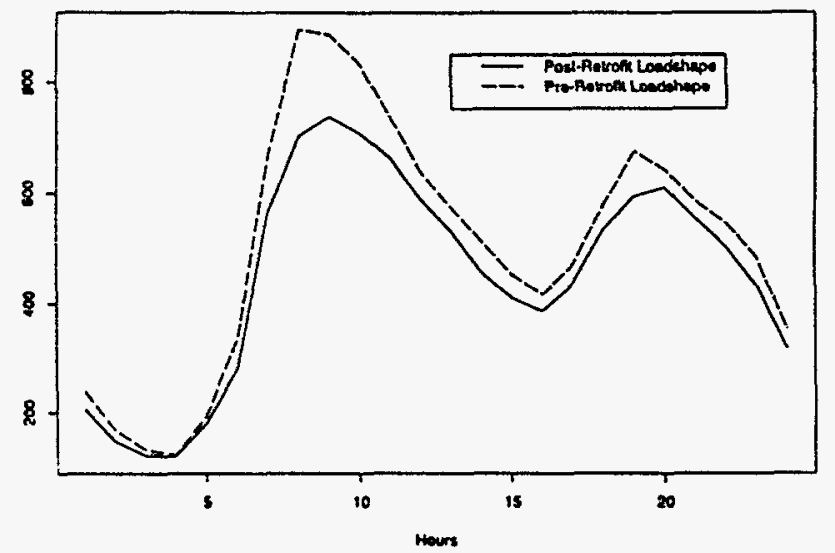

Figure 1.2 Pre/Post Hot-Water Profile for Test Sample 


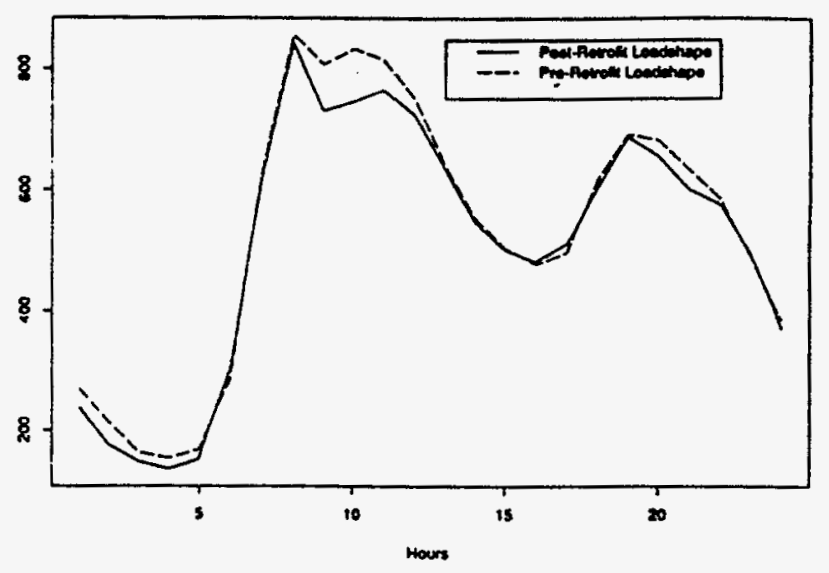

Figure 1.3 Pre/Post Hot-Water Profile for Control Sample

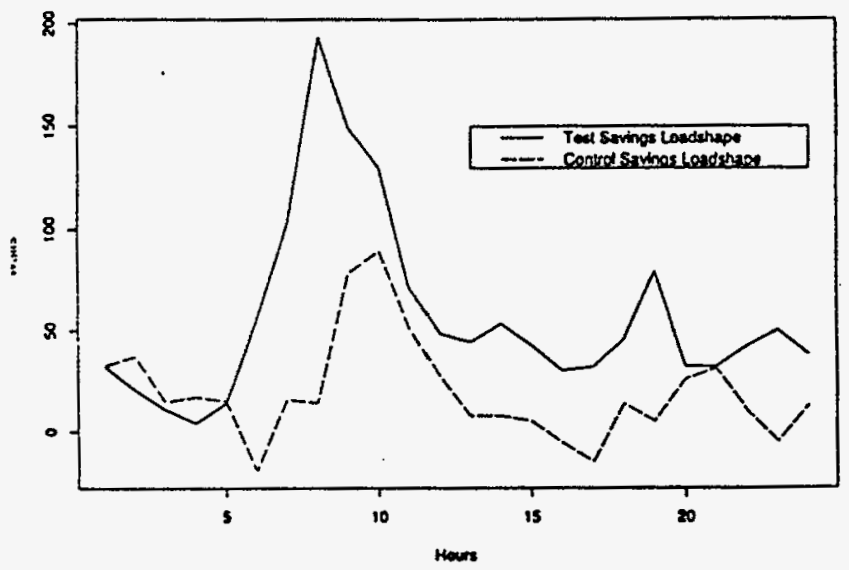

Figure 1.4 Annual Hot-Water Savings Profile: Test and Control

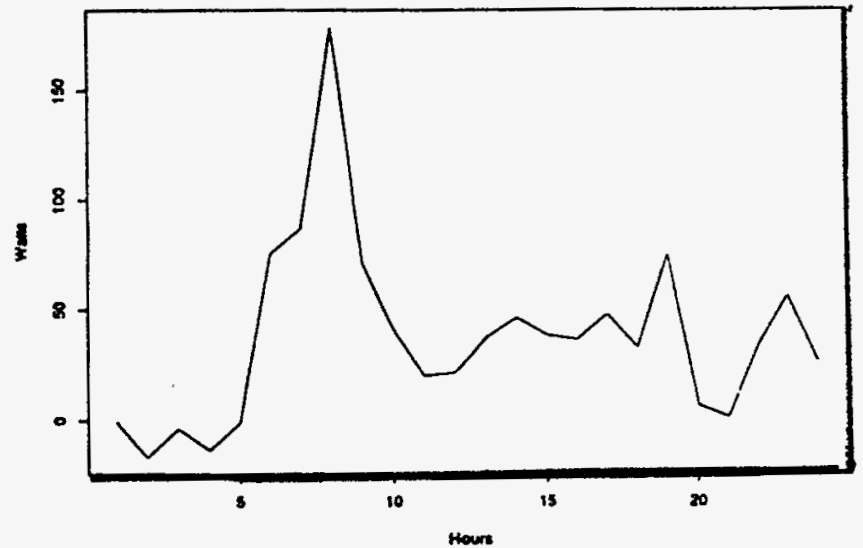

Figure I.5 Net Hot-Water Savings Profile 


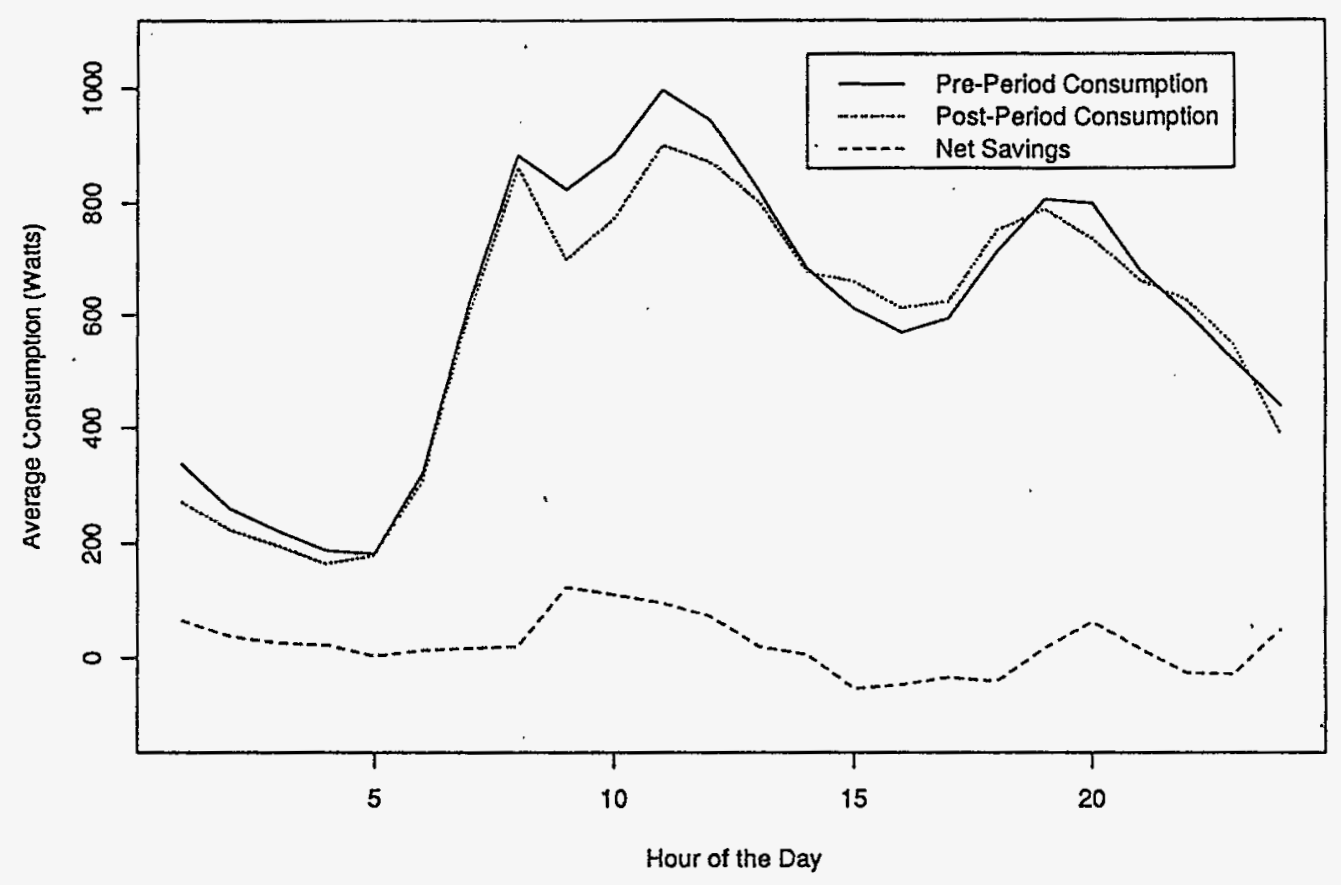

Figure I.6 January Hot-Water Profiles: Control Sites, All Days

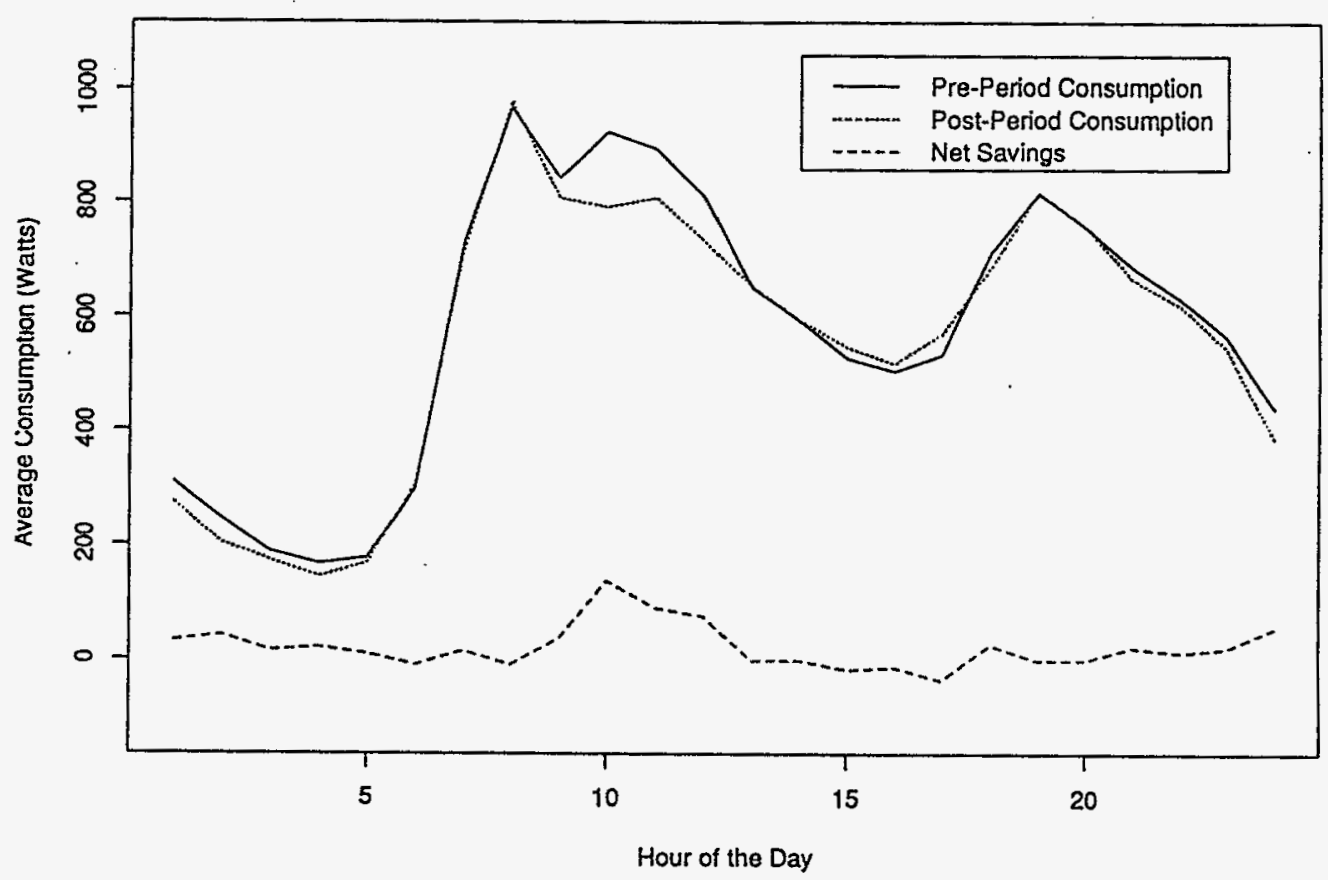

Figure 1.7 February Hot-Water Profiles: Control Sites, All Days 


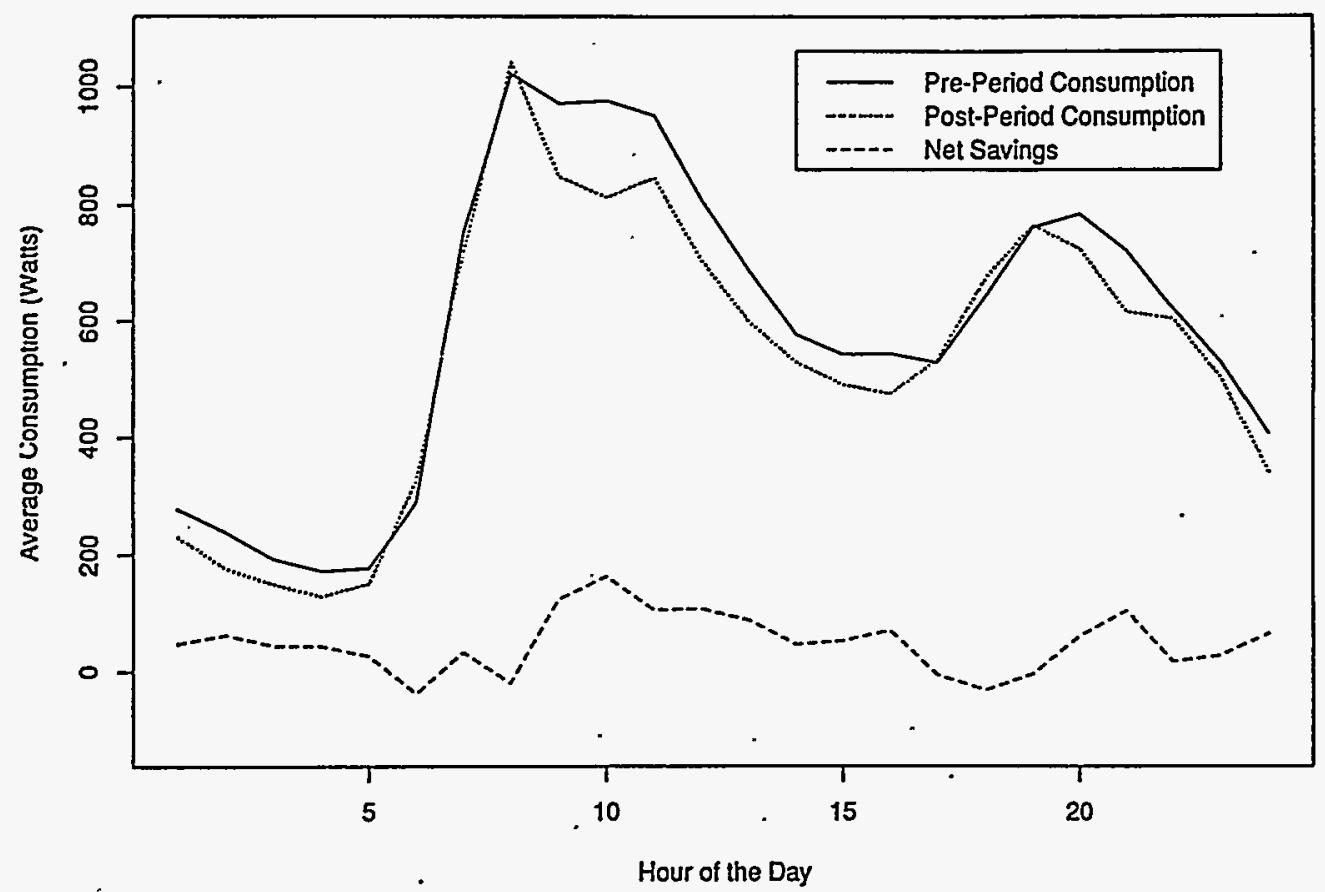

Figure I.8 March Hot-Water Profiles: Control Sites, All Days

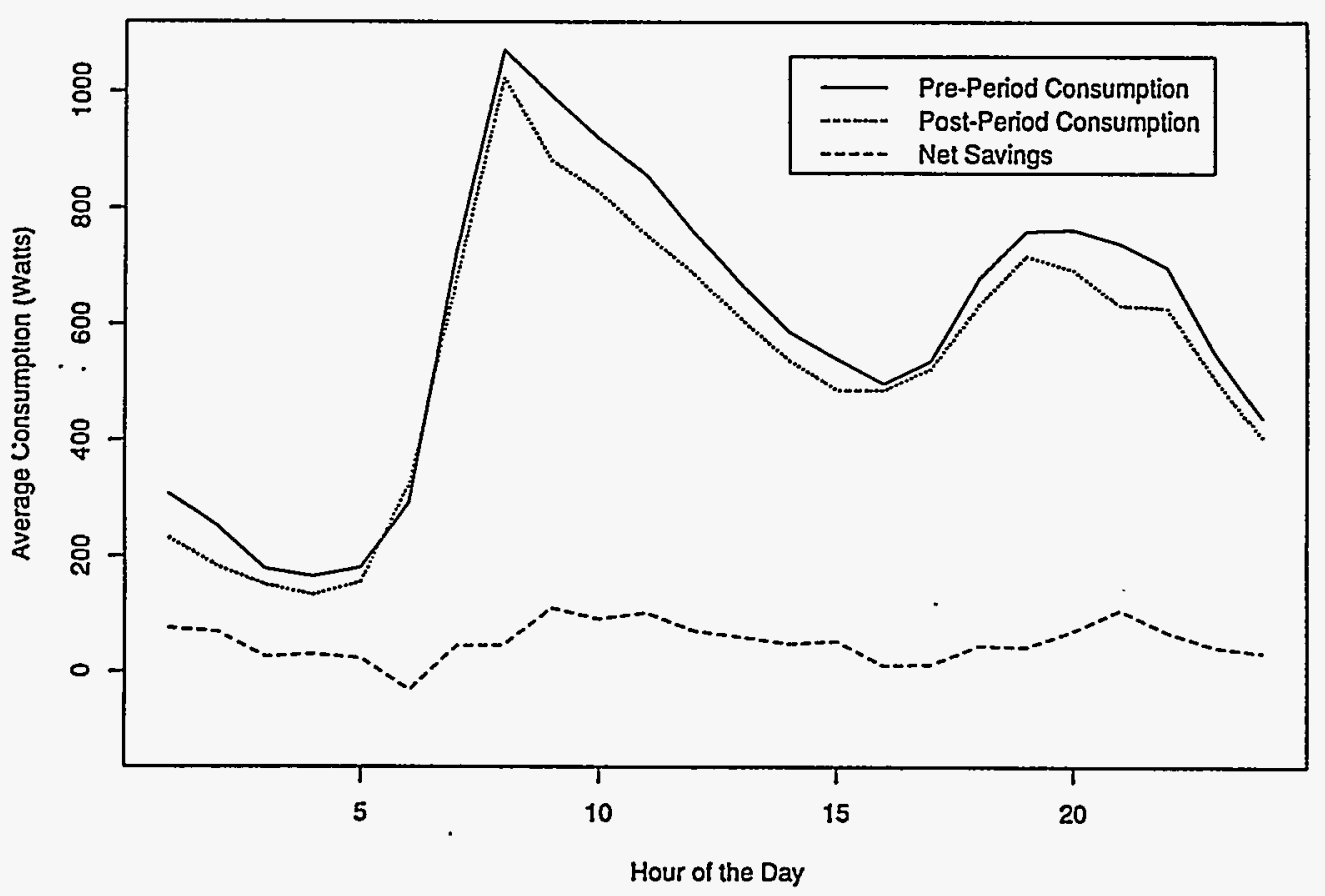

Figure I.9 April Hot-Water Profiles: Control Sites, All Days 


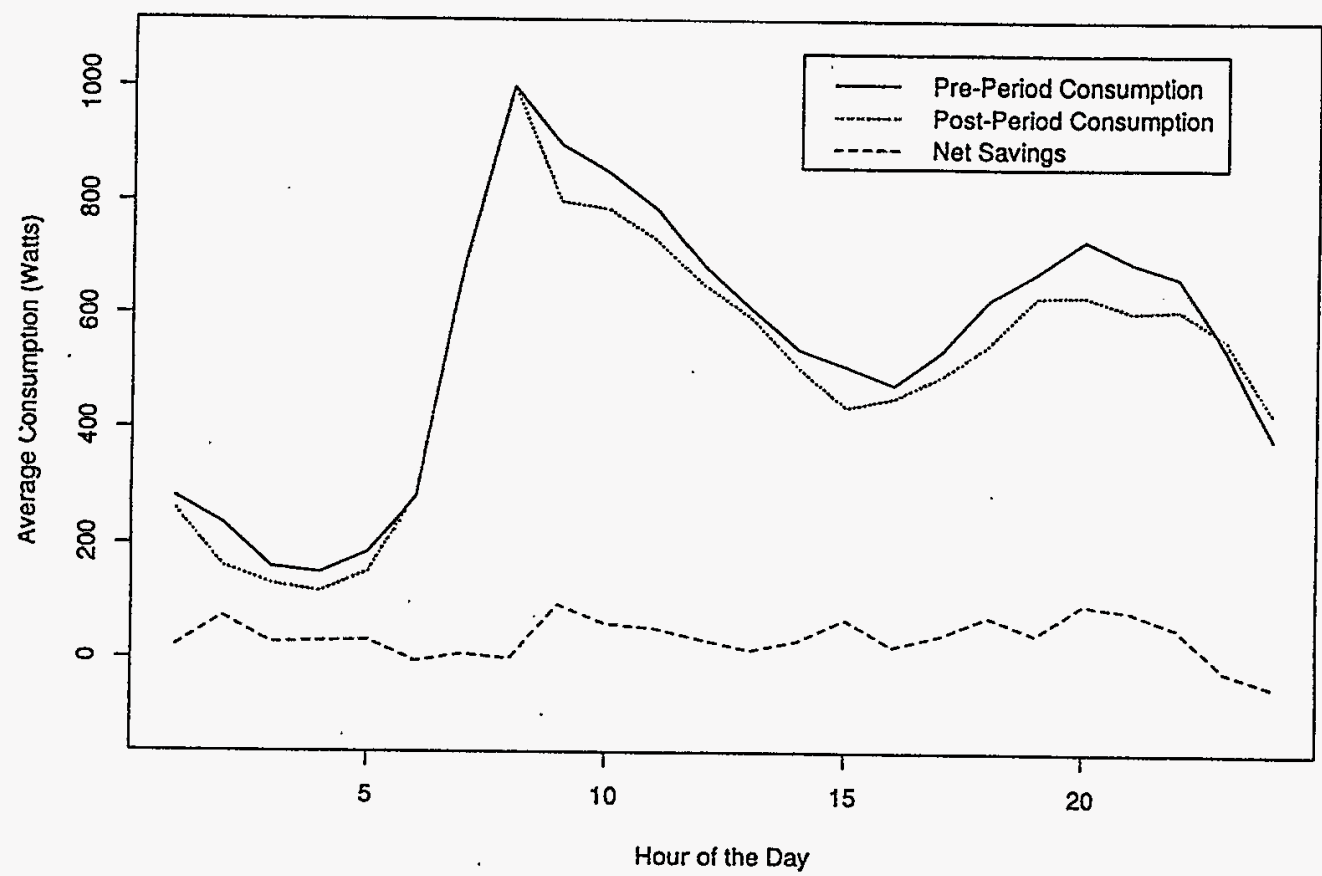

Figure I.10 May Hot-Water Profiles: Control Sites, All Days

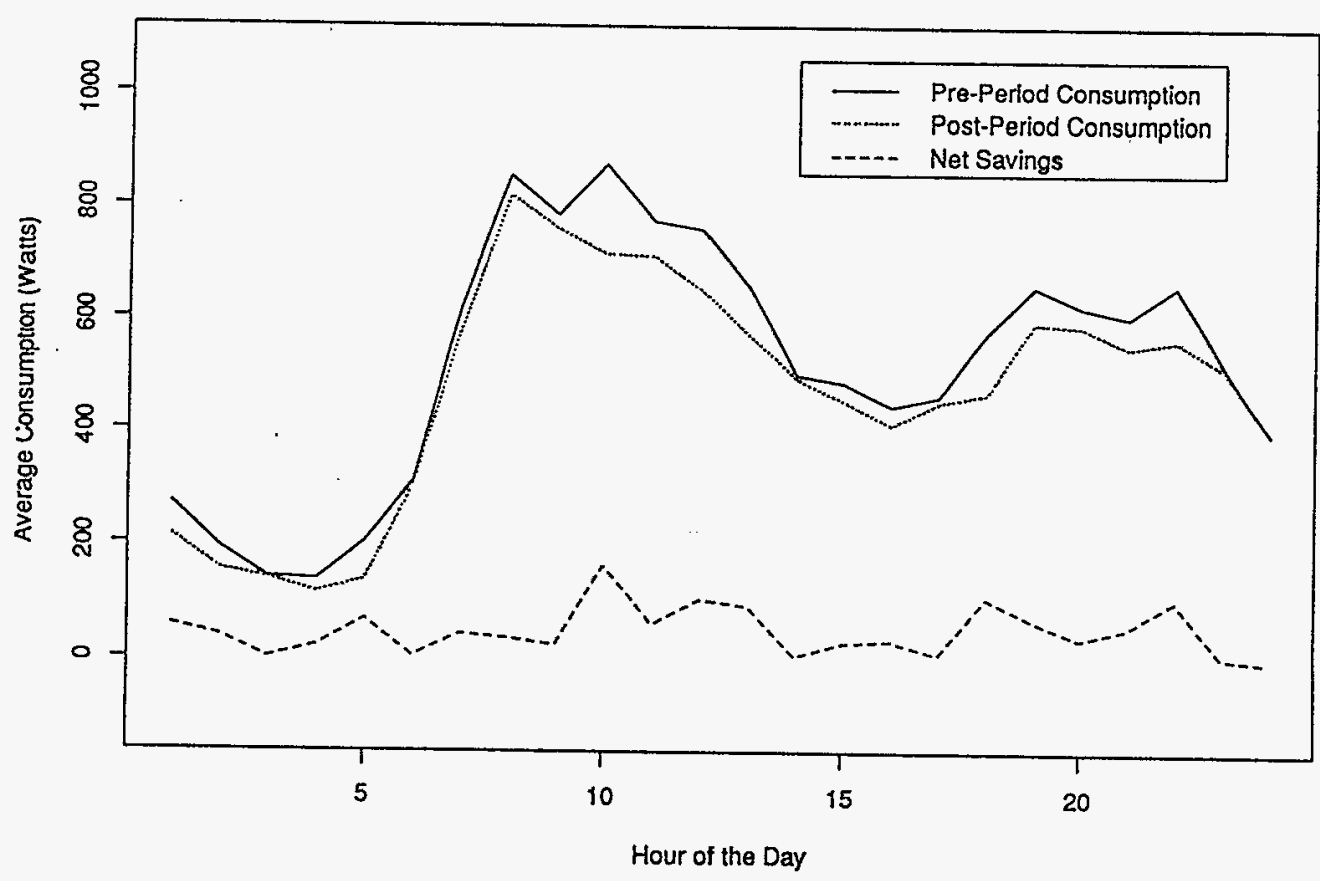

Figure I.11 June Hot-Water Profiles: Control Sites, All Days 


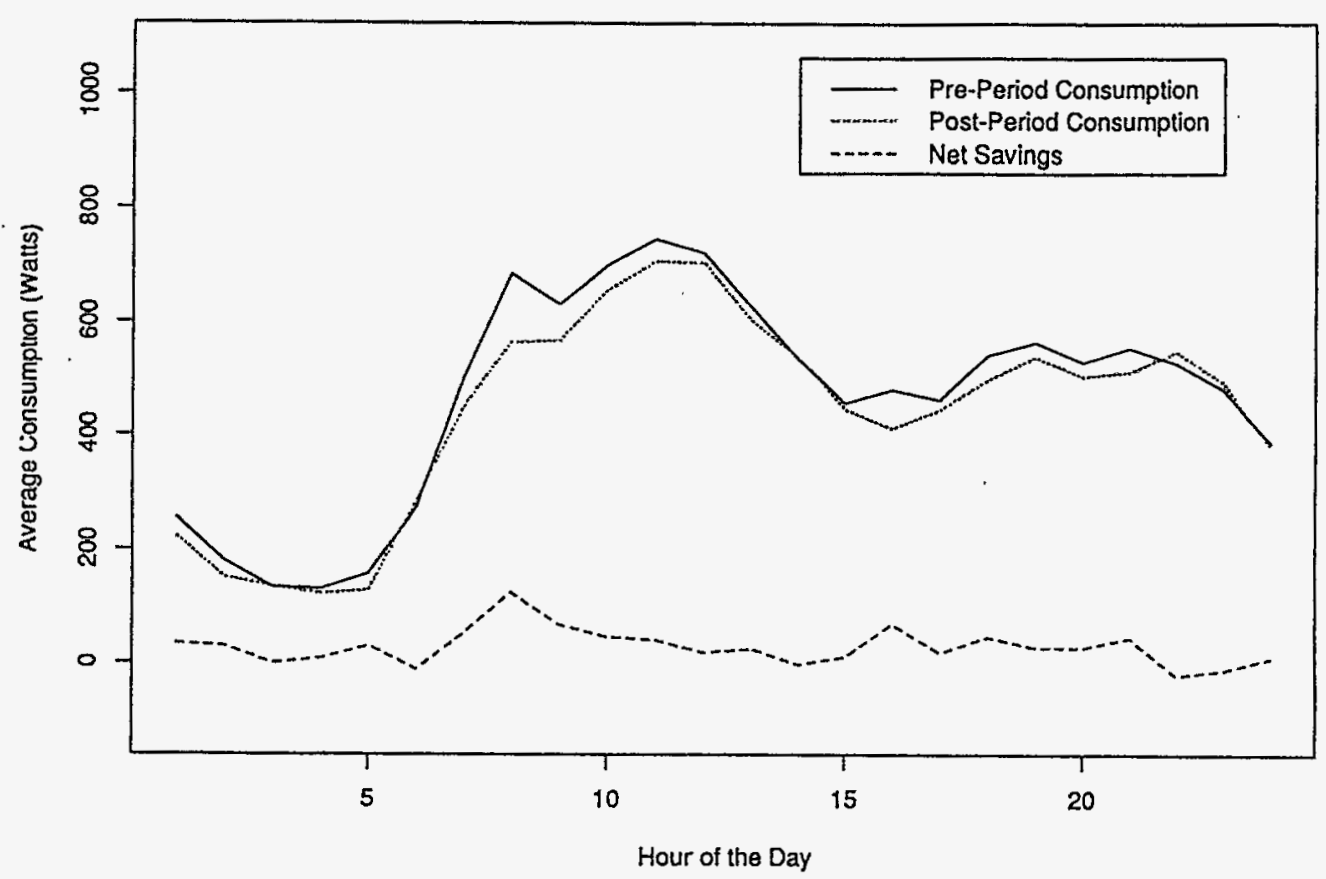

Figure I.12 July Hot-Water Profiles: Control Sites, All Days

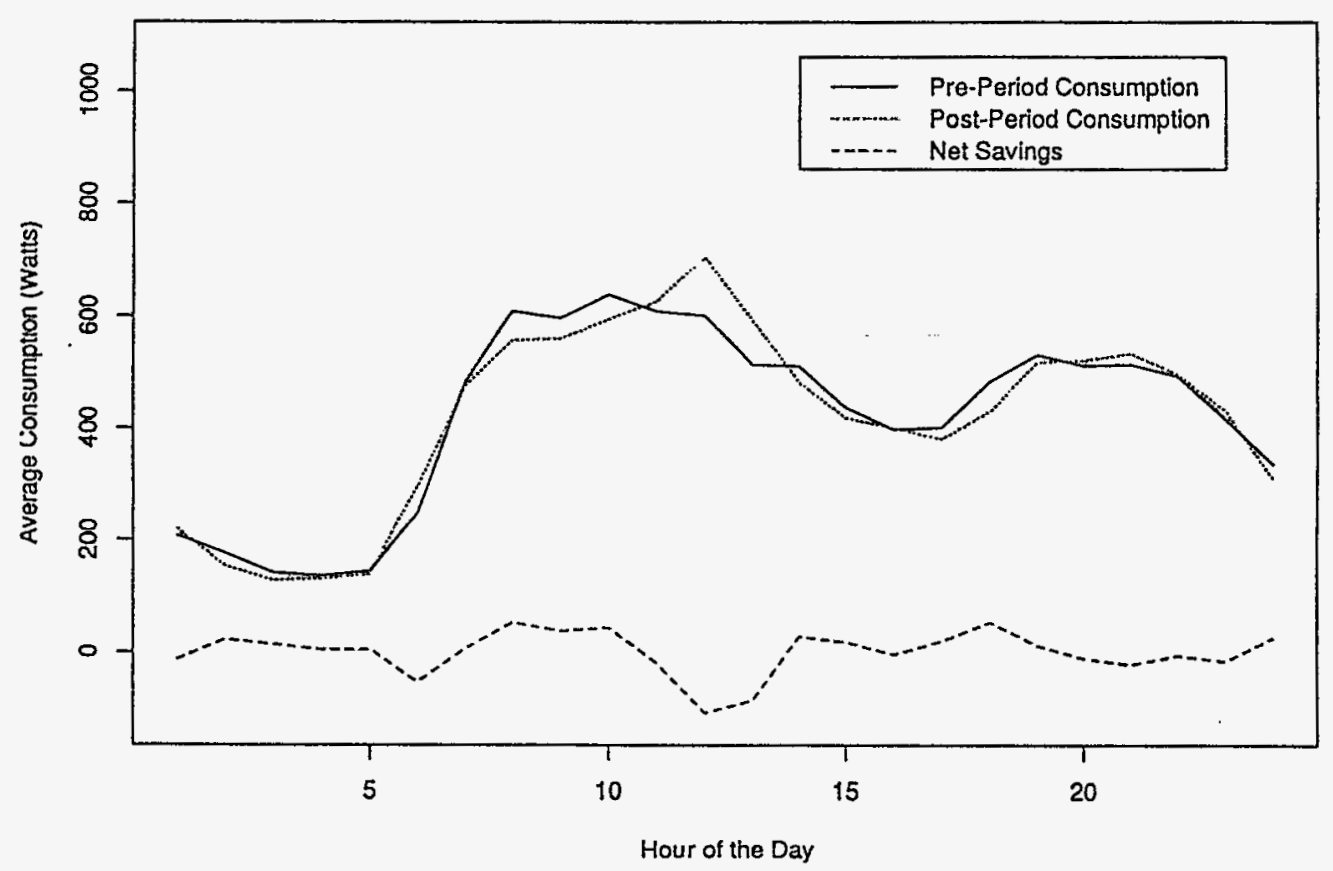

Figure I.13 August Hot-Water Profiles: Control Sites, All Days 


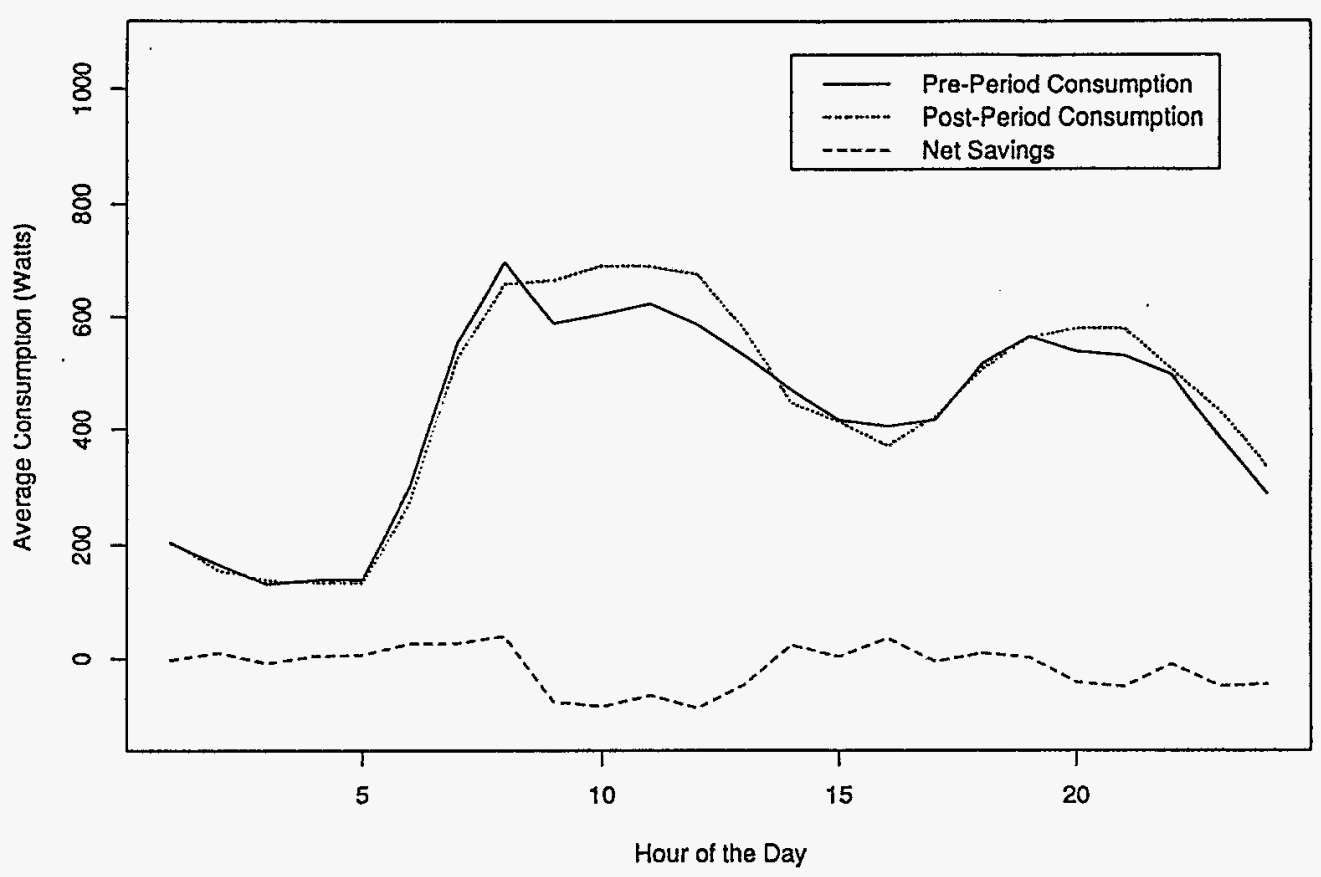

Figure I.14 September Hot-Water Profiles: Control Sites, All Days

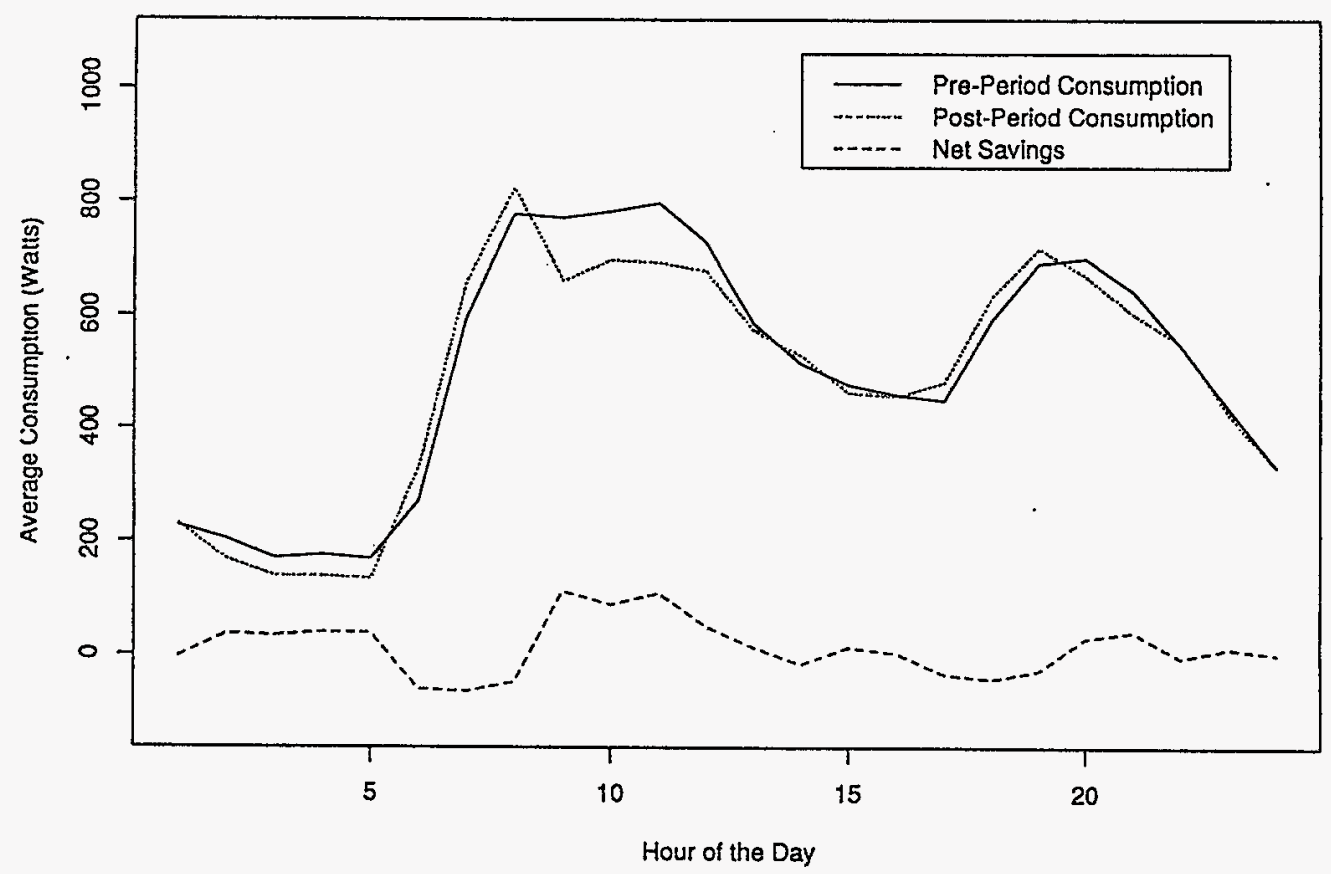

Figure I.15 October Hot-Water Profiles: Control Sites, All Days 


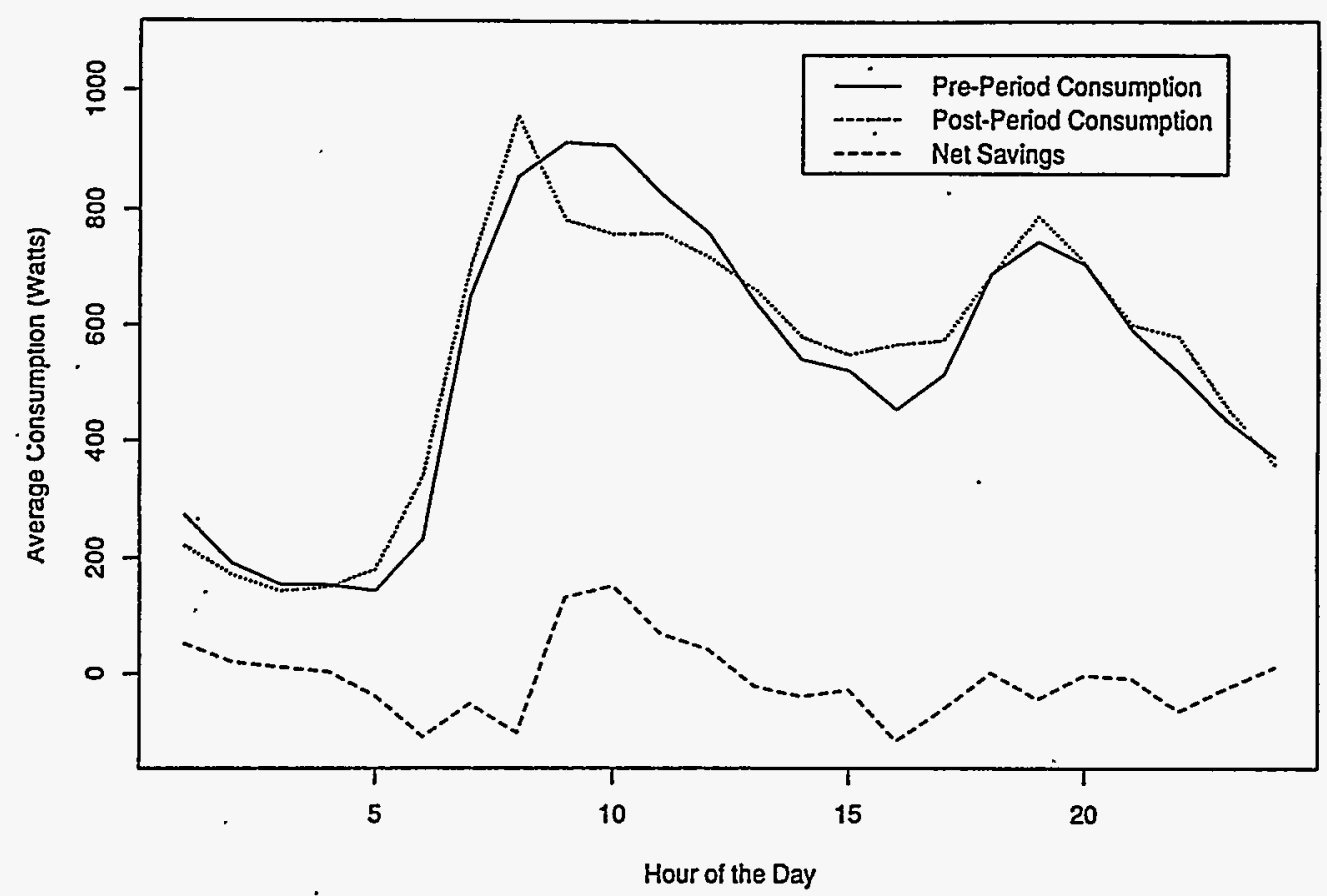

Figure I.16 November Hot-Water Profiles: Control Sites, All Days

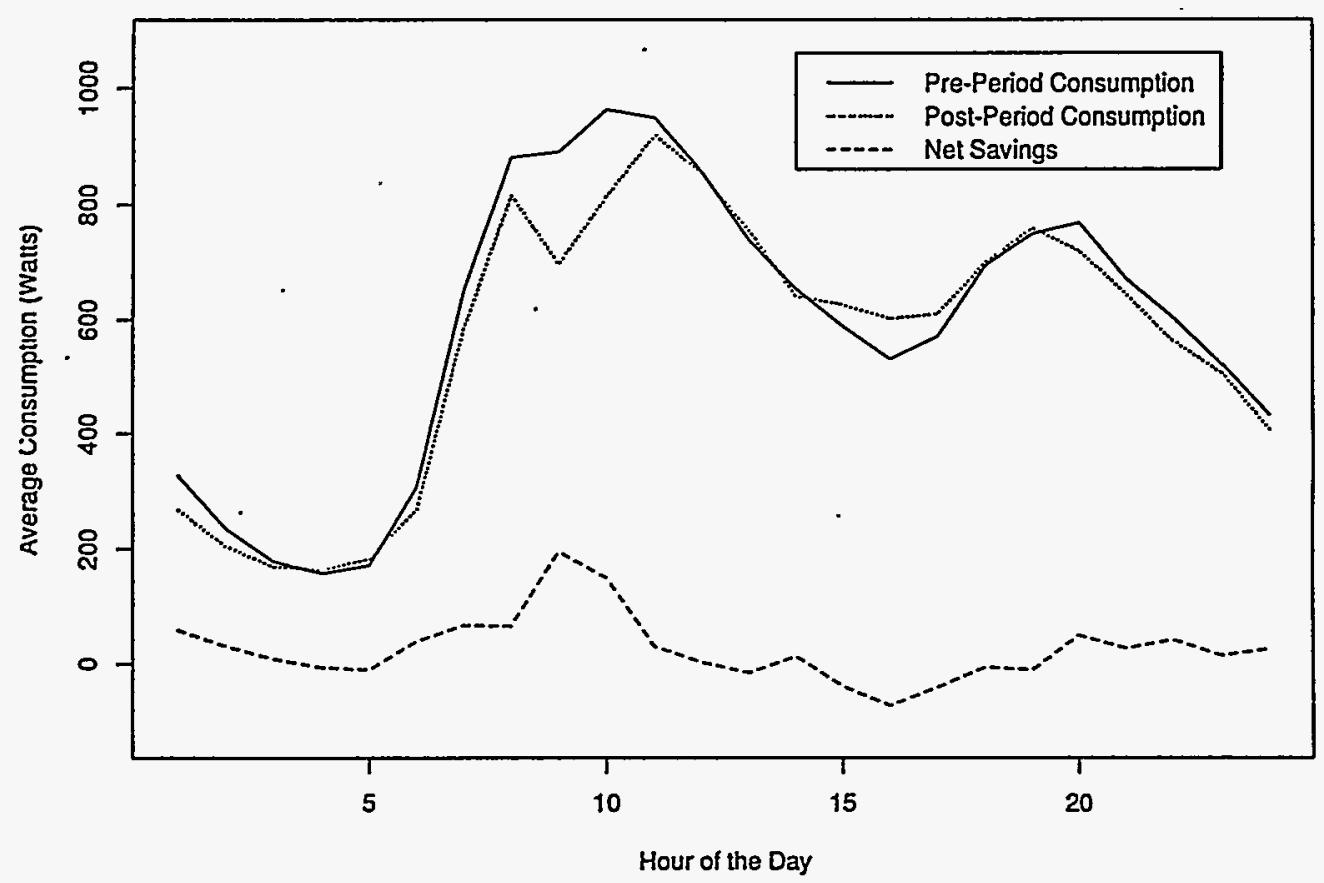

Figure I.17 December Hot-Water Profiles: Control Sites, All Days 


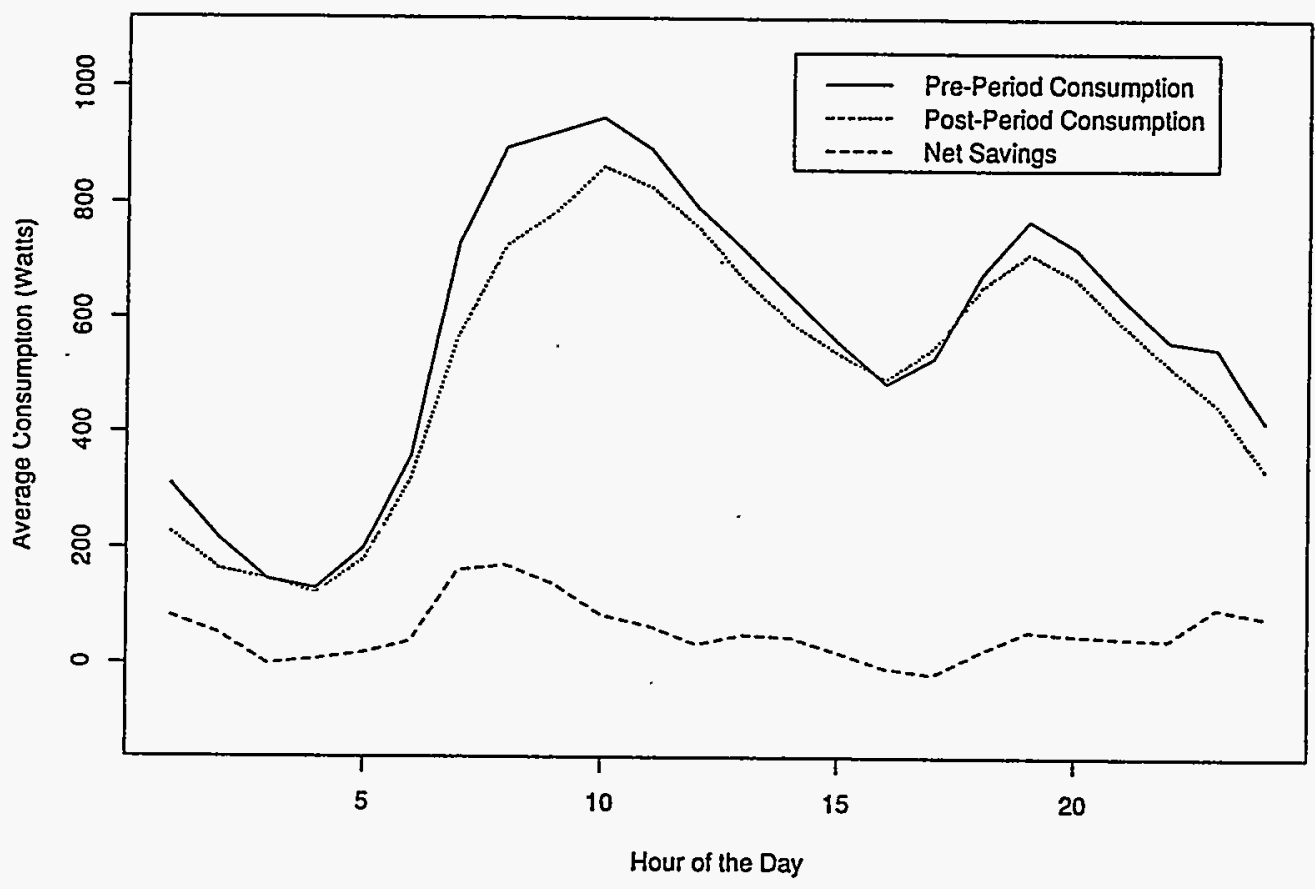

Figure I.18 January Hot-Water Profiles: Test Sites, All Days

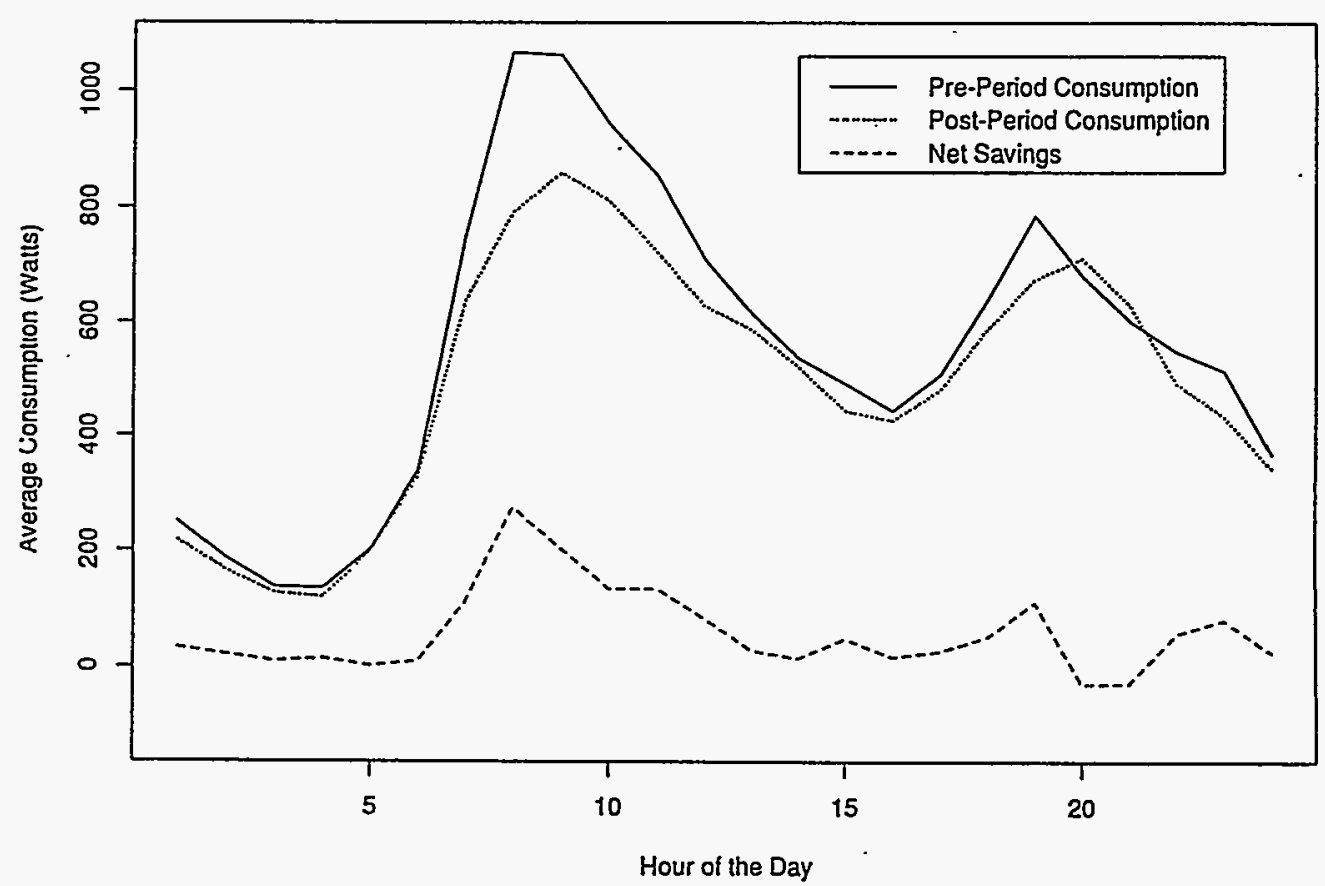

Figure I.19 February Hot-Water Profiles: Test Sites, All Days 


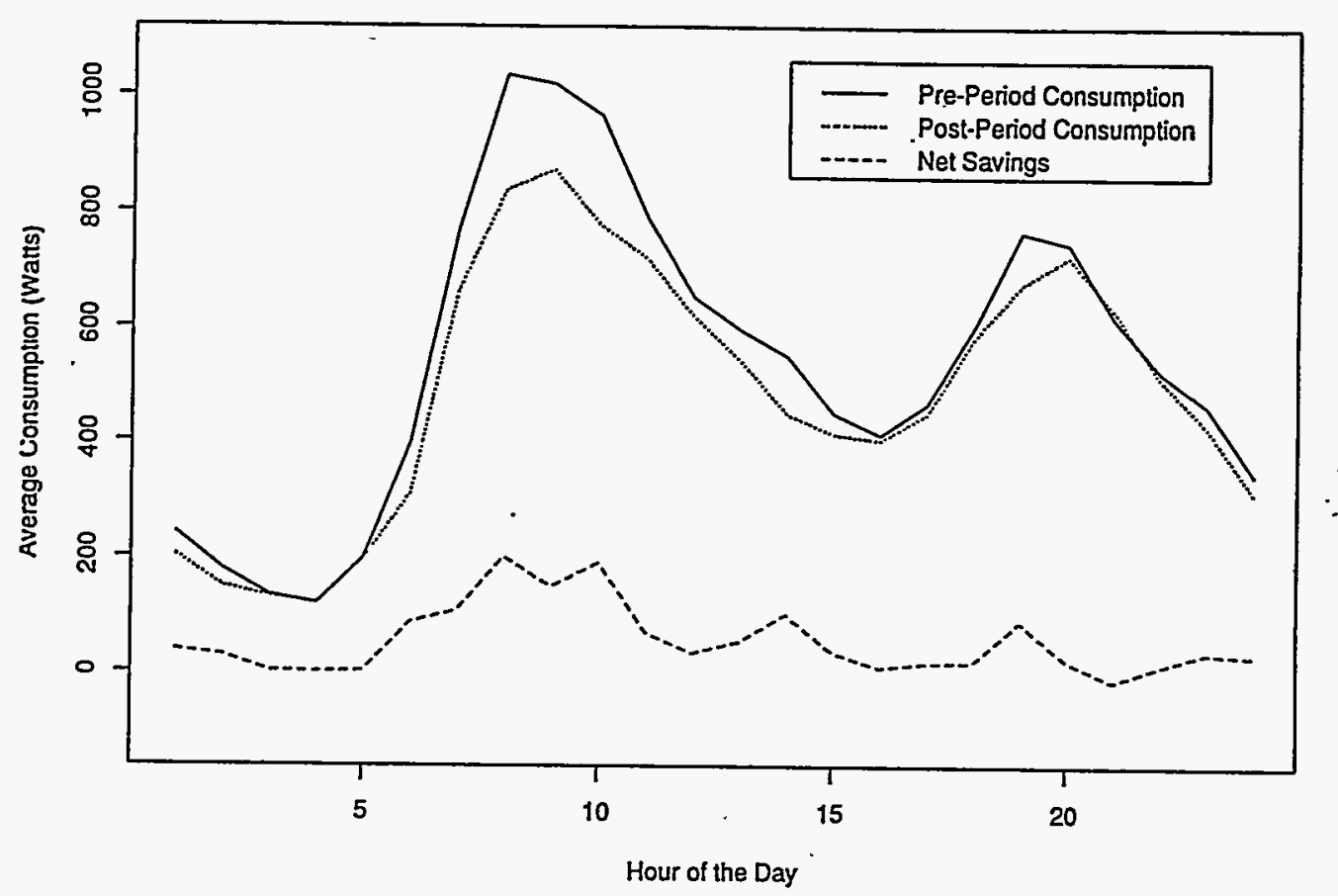

Figure I.20 March Hot-Water Profiles: Test Sites, All Days

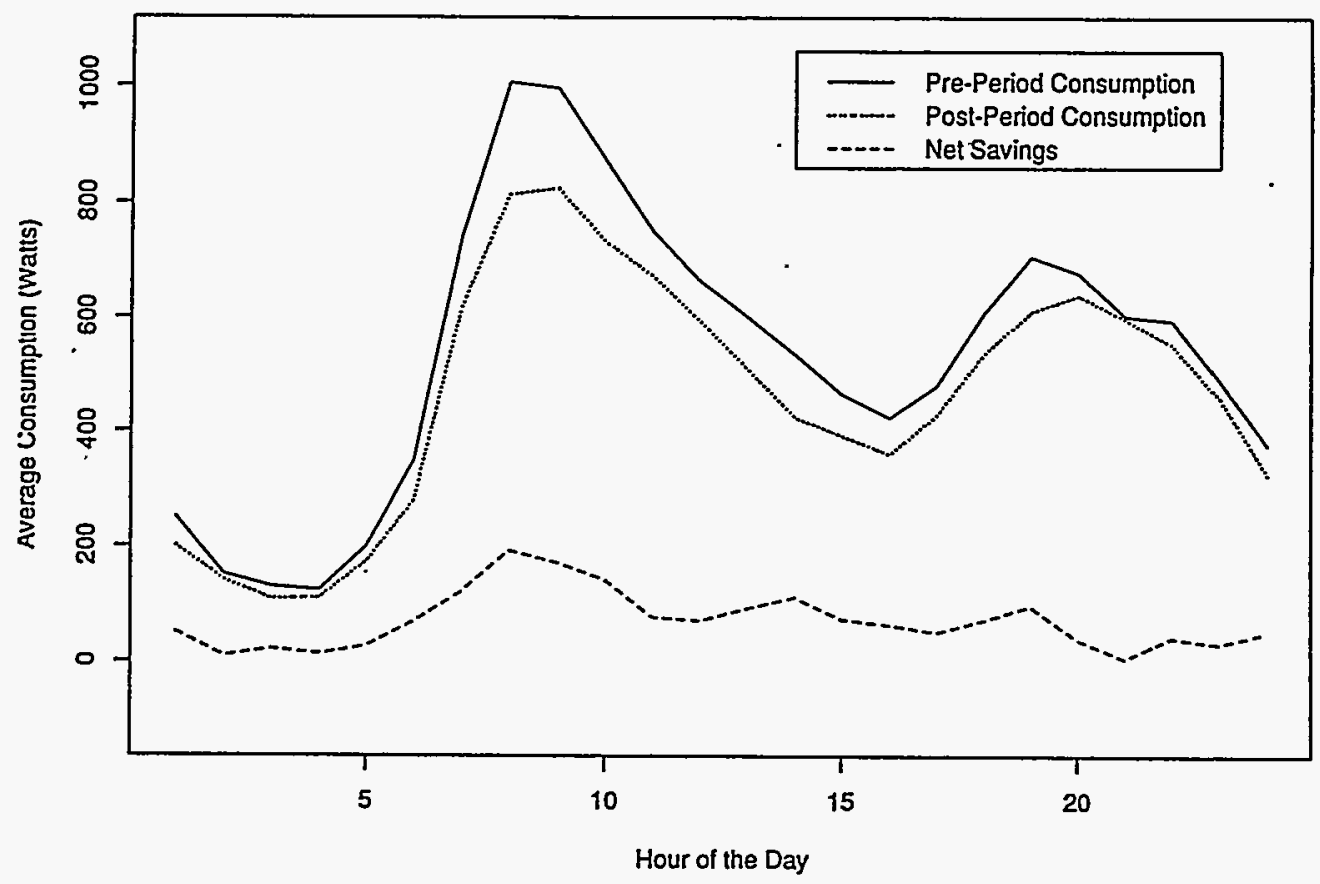

Figure I.21 April Hot-Water Profiles: Test Sites, All Days 


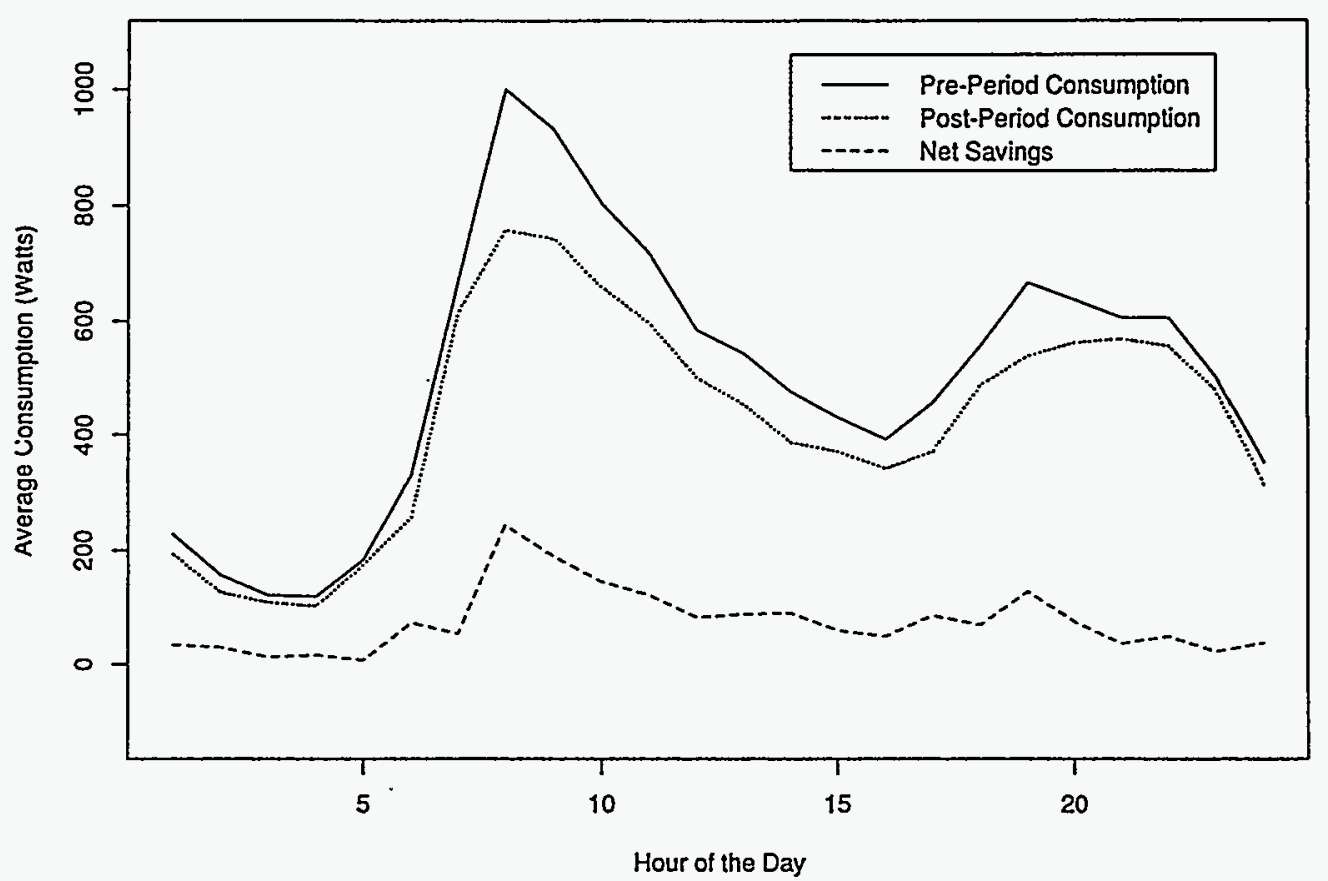

Figure I.22 May Hot-Water Profiles: Test Sites, All Days

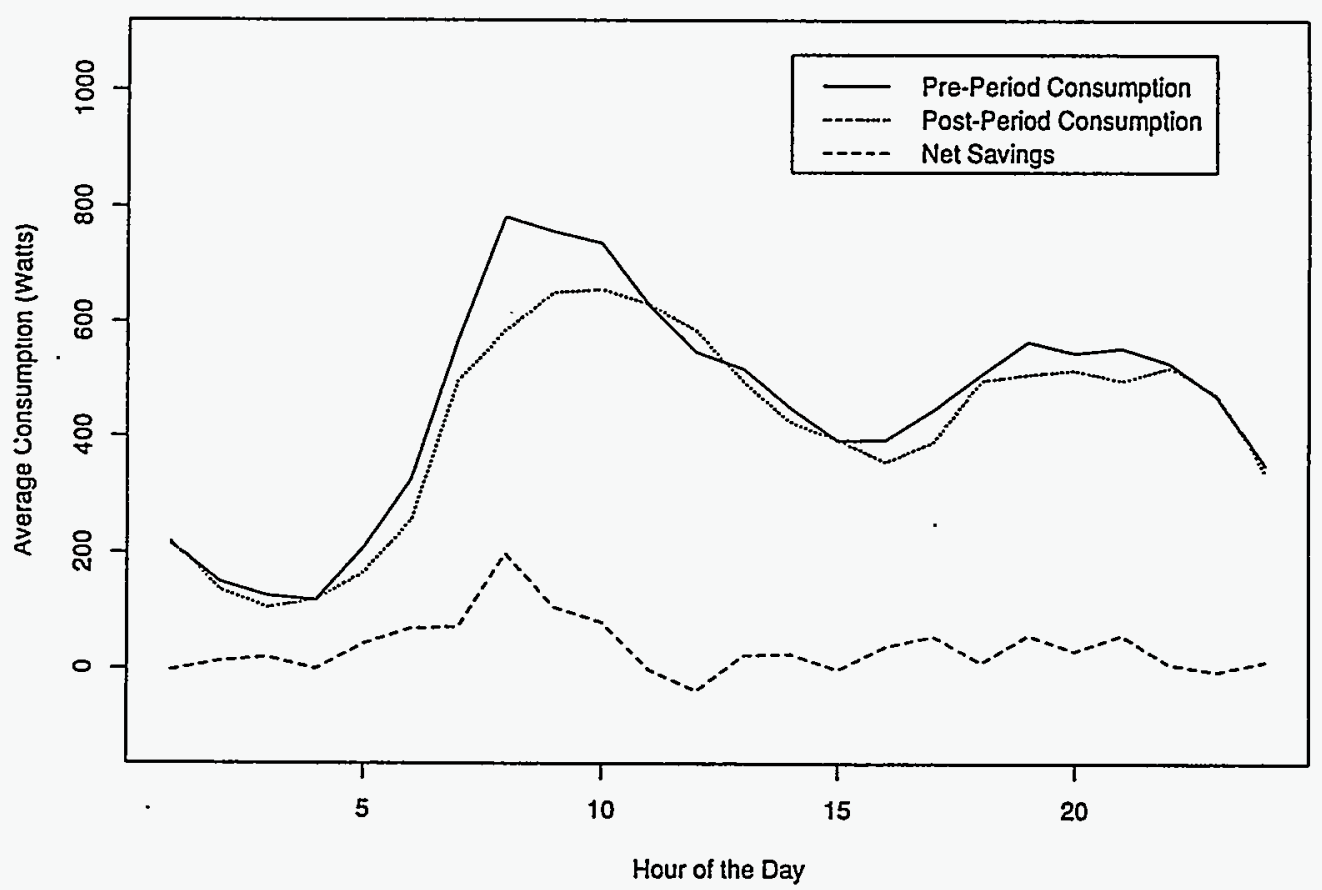

Figure I.23 June Hot-Water Profiles: Test Sites, All Days 


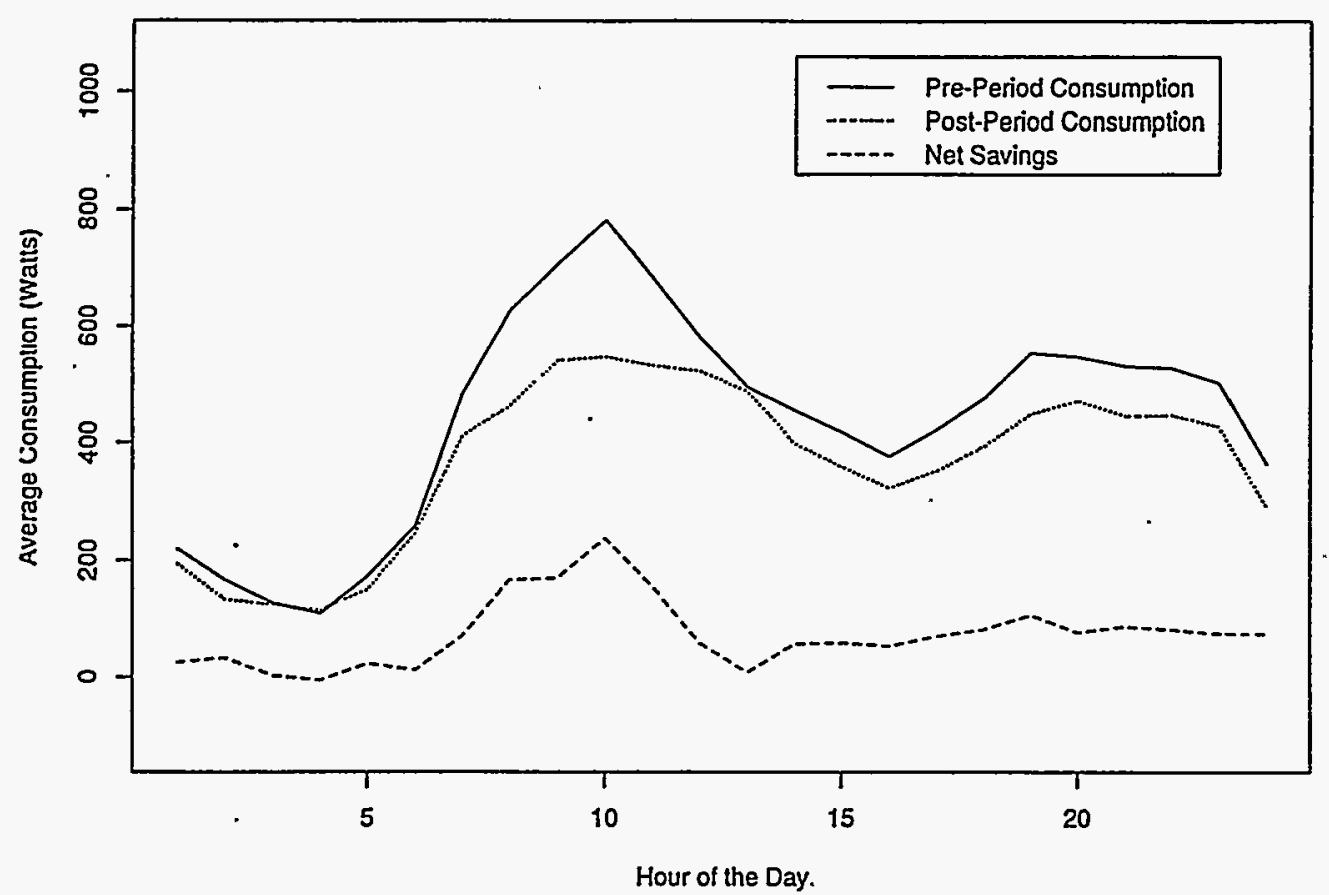

Figure I.24 July Hot-Water Profiles: Test Sites, All Days

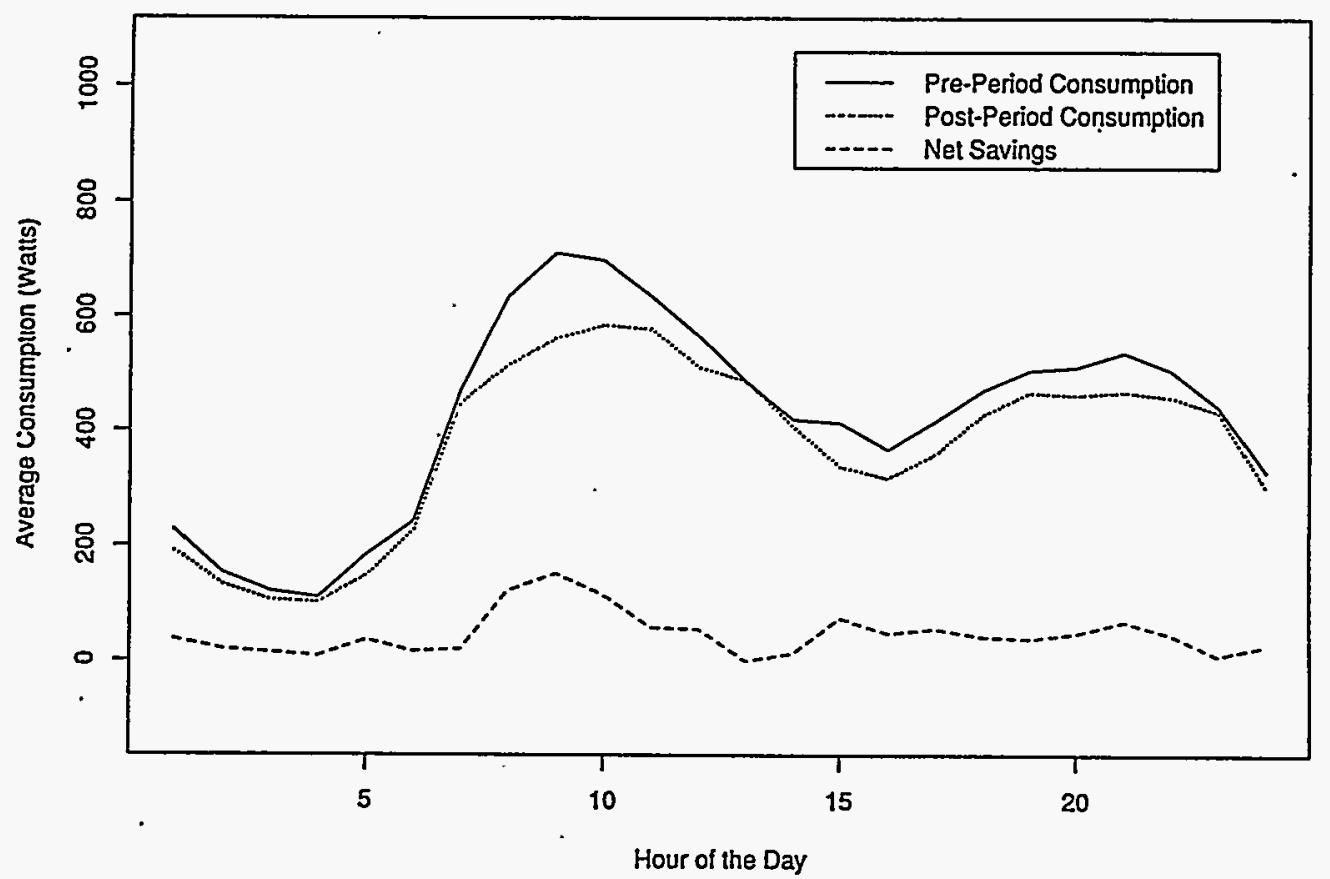

Figure 1.25 August Hot-Water Profiles: Test Sites, All Days 


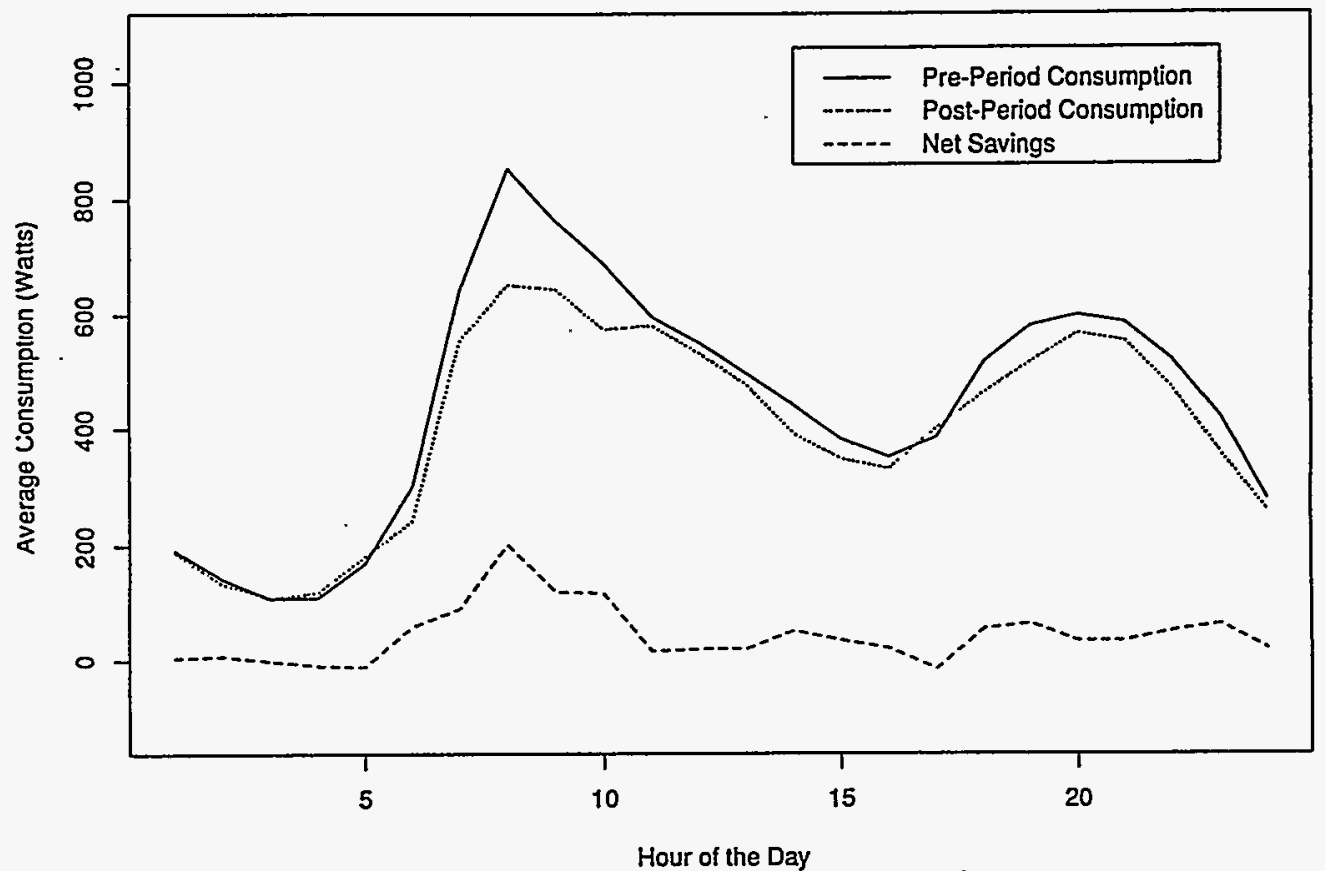

Figure I.26 September Hot-Water Profiles: Test Sites, All Days

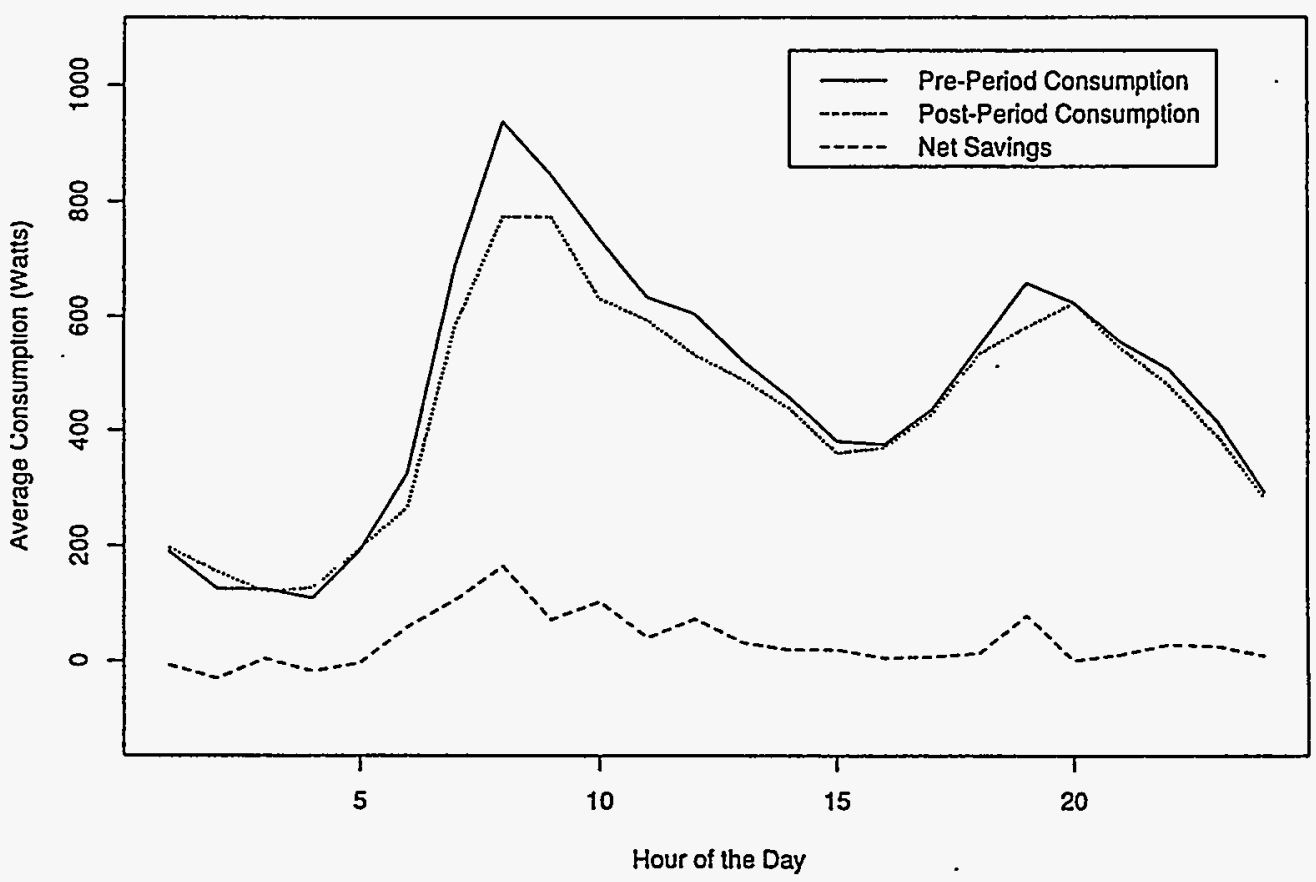

Figure 1.27 October Hot-Water Profiles: Test Sites, All Days 


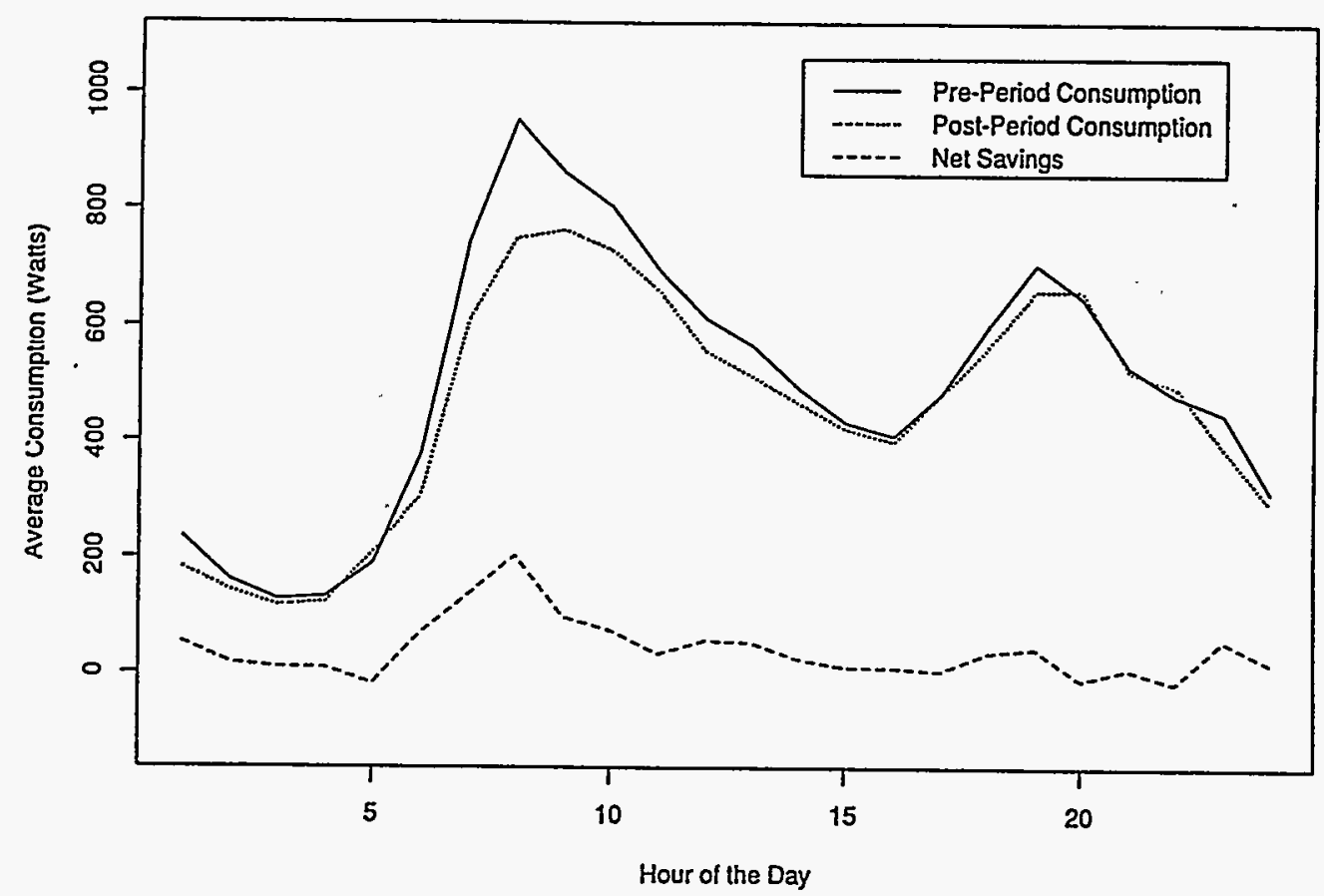

Figure I.28 November Hot-Water Profiles: Test Sites, All Days

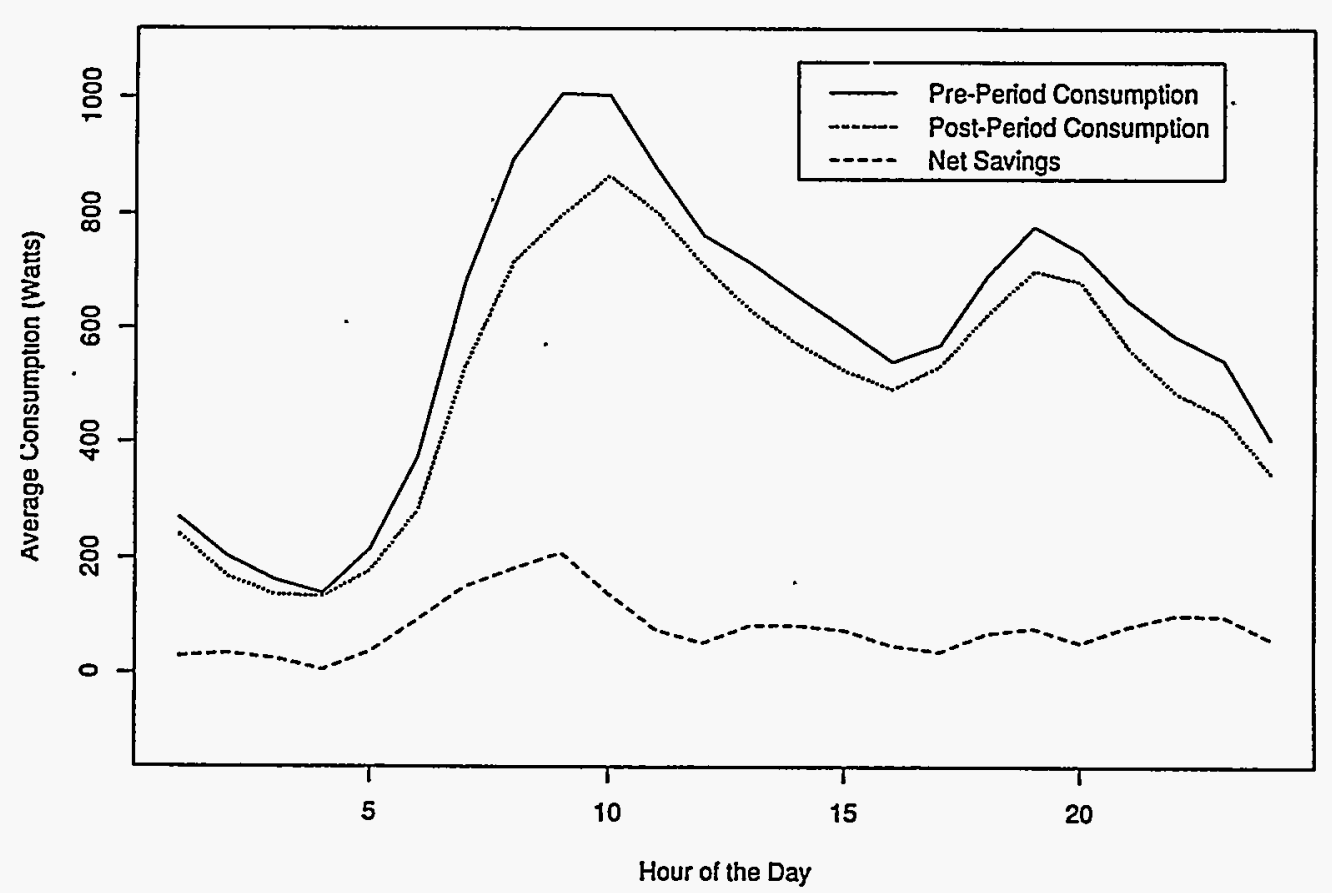

Figure 1.29 December Hot-Water Profiles: Test Sites, All Days 


\section{I.3 References}

Pratt, R. G., and B. A. Ross. 1991. Measured Electric Hot Water Standby and Demand Loads from Pacific Northwest Homes. PNL-7889, Pacific Northwest Laboratory, Richland, Washington.

Warwick, W. M., and S. A. Bailey. 1993. Results from an Energy-Efficient Showerhead Field Study. PNL-8715, prepared for the Bonneville Power Administration under a Related Services Agreement with the U.S. Department of Energy by Pacific Northwest Laboratory, Richland, Washington. 


\section{DISTRIBUTION}

No. of

Copies

OFPSITE

2 DOE/Office of Scientific and

Technical Information

\section{QNSITE}

DOE Richland Operatons Office

D. D. Green

Pacific Northwest Laboratory

S. A. Bailey

D. W. Purser

W. M. Warwick (15)

Publishing Coordination

Technical Report Files (5)

Distr.1 